\title{
EFEITOS DE MODOS DE APLICAÇÃO E INCORPORAÇÃO DE CALCÁRIO E GESSO EM POMARES DE CITROS
}

\author{
PEDRO HENRIQUE DE CERQUEIRA LUZ \\ Engenheiro Agrônomo
}

Orientador: Prof. Dr. GODOFREDO CESAT WTII

Tese apresentada à Escola Superior de Agricustura "Luiz de Queiroz", da Universidade de Sso Paulo, para obtencilo do titulo de Dourtor em Agronomia, Área de Concentraçăo Sotos e Nutrictro de Plantas.

PIRACICABA

Eatado de S6 Panlo - Drasil

Fevereiro - 1995 
Ficha catalografica oreparada pela Secào de Livros da Divisăo de Eitblioteca e Documentacăo - FClo/usF

L979e Lua Fedro Henrique de Cerqueira calcario e oesso em oomares de citros. Firacicata. 1995.

1590. i145.

jese - ESALE

Eitsliografia.

1. Cajagem 2. Corretivo agricola - Aolicacão J. Fru ta citrica - Lajagem 4. Solo - Quimica - Alteracao Escoia Guberior de Aoricultura Luiz de Gueiroz. Firaci -catia

CDE $\quad 554.5$ 


\section{EFEITOS DE MODOS DE APLICAÇÃO E INCORPORAÇÃO DE CALCÁRIO E GESSO EM POMARES DE CITROS}

PEDRO HENRIQUE DE CERQUEIRA LUZ

Aprovada em 10.05.1995

Comissð̃o Julgadora:

Prof. Dr. Godofredo Cesar Vitti ESALQ/USP

Prof. Dr. Jairo Antonio Mazza ESALQ/USP

Prof. Dr. Antonio Enedi Boaretto CENA/USP

Prof. Dr. Rubismar Stolf CCAUFScar

Dr. Joaquim Téffilo Sobrinho CCSM/AC

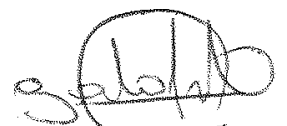

Prof. Dr. GODOFREDOCESAR VTTTI

Orientador 
Aos meus pais

Paulo (in memoriam) e Maria Ruth

OFERECO

Ao

meu filho Henrique, que por ora ainda năo sabe bem do que se trata;

e

a Lúcia, minha esposa, por comprender o que se passa, meu reconhecimento pelo carinho, apoio e incentivo;

DEDICO 


\section{AGRADECIMENTOS}

Ao Prof. Dr. Godofredo César VTTTI, do Departamento de Ciência do Solo da ESALQ/ USP, pela valiosa orientaçăo, efetiva colaboração e sobretudo pela amizade.

A Faculdade de Zootecnia e Engenharia de Alimentos/USP, através do Depto de Zootecnia, pela possibilidade da especialização.

Ao grupo Rodas (Montecitnus), em especial ao $\mathrm{Eng}^{\circ} \mathrm{Agr}^{9}$ Marcelo Carminati de Almeida, por tornar possivel a condução da parte expenimental deste trabalho, e ao Sr. Edson Trevisan, responsavel pela Faz. Santa Helena, pela ajuda nas atividades de campo.

Ao Depto de Ciência do Solo da ESALQ/USP, pelas facilidades concedidas no decorrer da execução deste trabalho.

A FAPESP. Fundação de Amparo à Pesquisa do Estado de São Paulo, pela concessão de auxdlio à pesquisa, usado na realização das análises de solo e folha.

A CAPES-Coordenação de Aperfeiçoamento de Pessoal de Nivel Superior pela bolsa de de estudos do programa PICD- Programa de Incentivo e Capacitação de Docentes. 
Ȧ EECB-Estação Experimental de Citricultura de Bebedouro, pela realização das analises tecnológicas (1 $1^{\mathrm{a}}$ e $2^{\mathrm{a}}$ safras).

Ao Centro de Citricultura "Sylvio Moreira", do IAC, pelo apoio nas análises tecnológicas ( $3^{\mathrm{a}}$ safra).

Ao Prof. César Gonçalves de Lima, do Depto de Ciências Básicas da FZEANUSP, pelo apoio nas análises estatisticas e sugestōes apresentadas.

Ao Prof. Valdo Radrigues Herling, do Depto de Zootecnia da FZEA USP, pelo incentivo, amizade e prestativa colaboração.

Ao $\mathrm{Eng}^{\circ} \mathrm{Agr}^{\circ}$ José Carlos Casagrande, CCAUfSCar por colocar à disposição o laboratório de análise de solos, plantas e fentilizantes, e ao técnico Antonio Campagna, pela realização das análises granulométricas do calcário;

A Bibliotecária Ana Maria Zaia Gheller, CCA UFSCar, pelo apoio no levantamento bibliografico 


\section{SUMARIO}

\section{Página}

LISTA DE FIGURAS

viii

LISTA DE TABELAS

$\mathrm{x}$

LISTA DE QUADROS...................................................................

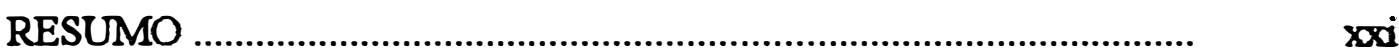

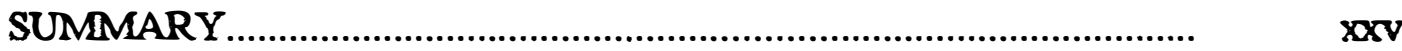

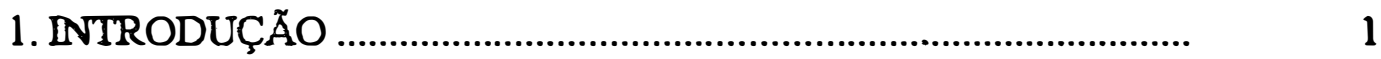

2. REVISÅO DE LITERATURA …......................................................

2.1. Tecnologia e modos de aplicação e incorporação de corretivos....

2.2. Calagem, gessagem e iocorporação e seus reflexos sobre os atributos quilmicos do solo.

2.3. Comportamento dos citros quanto a calagem, gessagem e incorporação dos condicionadores de solo

3. MATERIAL E MÉTODOS

3.1. Caracterização do meio fisico

3.1.1. Area e localização do experimento

3.1.2. Solo

3.1.3. Dados climáticos

3.2. Caracternsticas do pomar...

3.3. Caracteristicas dos corretivos

3.4. Variáveis avaliadas 
3.4.2. Atributos de planta ...........................................................

3.4.3. Atributos da aplicação de calcário....................................... $\quad 36$

3.5. Delineamento experimental das parcelas..................................... 38

3.5.1. Fatores ............................................................................

3.5.1.1. Modos de aplicação do calcário..................................... 39

3.5.1.2. Gessagem ................................................................

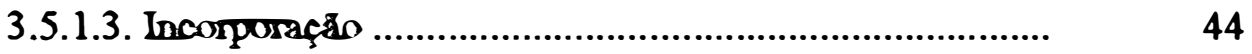

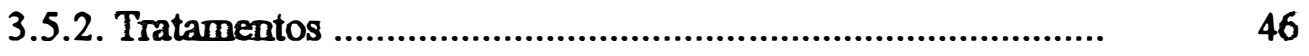

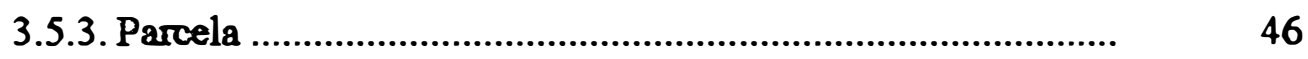

3.5.4. Esquema de campo …........................................................ 46

3.5.5. Analise estatistica............................................................. 50

3.6. Instalação e condução do experimento ........................................

4. RESULTADOSE DISCUSSÅO ……………………………….... 55

4.1. Perfil transversal dos modos de aplicaçăo do calcário................... 55

4.2. Efeitos sobre as variaveis de planta ............................................ $\quad 70$

4.2.1. Produção ...........................................................................

4.2.2. Qualidade tecnológica dos frutos ......................................

4.3. Efeitos sobre os atributos quimicos do solo .................................

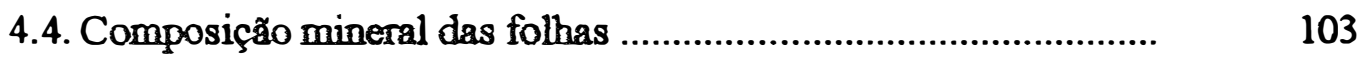

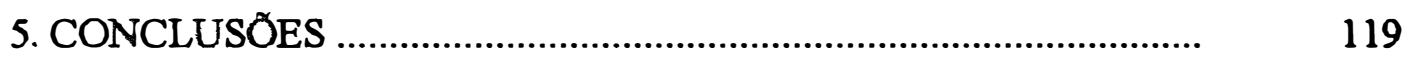

REFERENCIAS BIBLIOGRAFICAS ............................................. 121

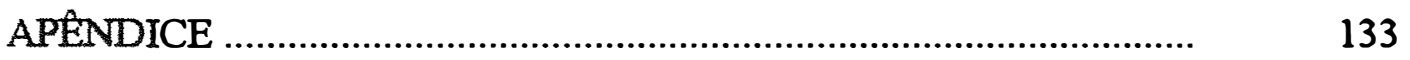




\section{LISTA DE FIGURAS}

pagina

FIGURA 1. Extrato do balanço hídrico decendial para os anos de 1991 a 1994 para a regiăo de Bebedouro - Armazenamento maximo = $125 \mathrm{~mm}$.

FIGURA 2. Esquema da disposicão dos coletores para a coleta do perfil transversal de aplicação de calcánio em pomares de citros instalados

FIGURA 3. Esquema dos modos de aplicação de calcário a lanço e em faixa em pomares de citros instalados.

FIGURA 4. Ilustraçåo do aplicador de corretivo com mecanismo distribuidor tipo pendular.

FIGURA 5. Ilustração do aplicador de corretivo com mecanismo distribuidor tipo centrifingo com dois discos.

FIGURA 6. Croqui da parcela experimental. .48

FIGURA 7. Croqui das parcelas experimentais. .49

FIGURA 8. Perfil transversal de aplicação de calcário para o modo a lanço. ....59

FIGURA 9. Perfil transversal de aplicação de calcário para o modo em faixa. ..60 
FTGURA 10. Distribuição em percentagem das frações granulometricas no perfil transversal para o modo de aplicação a lanço.

FIGURA 11. Distribuição em porcentagem das frações granulometricas no perfil transversal para o modo em faixa.

FIGURA 12. Curva do PRNT para os perfis transversias de aplicação de calcário dos modos a lanço e em faixa.

FIGURA 13. Efeito das safras sobre o comprimento dos frutos da laranjeira Pera do Rio (Citrus sinensis L. Osbeck).

FIGURA 14. Efeito das safras sobre o peso/ fruto da laranjeira Pera do Rio (Citru sinensis L. Osbeck).

FIGURA 15. Efeito das safras sobre a porcentagem de suco extraido (\%) da laranjeira Pera do Rio (Citrus sinensis L. Osbeck)

FIGURA 16. Efeito das safras sobre o diAmetro do fruto (mm) da laranjeira Pera do Rio (Citrus sinensis L. Osbeck). 


\section{LISTA DE TABELAS}

página

TABELA 1. Dados de Reatividade Relativa -\% das particulas de corretivos em fưção da granulometria.

TABELA 2. Distribuição média de radicelas de Pera Rio em porcentagem nas direçð̌es horizontais e verticais.

TABELA 3. Atributos quimicos e fisicos para caracterizaçăo do solo da área do expenimento. Local: Faz. Santa Helena, Monte Azul Pta. Talhăo $=14$

TABELA 4. Dados médios de precipitação $(\mathrm{mm})$ e temperatura $\left.{ }^{\circ} \mathrm{C}\right)$ da Estação Experimental de Citricultura de Bebedouro - SP (1978-1993).

TABELA 5. Caractenisticas quimicas e fisicas do calcário e gesso utilizados no experimento. Local: Faz. Santa Helena - Monte Azul Pta.

TABELA 6. Combinaçåo dos fatores Aplicaçăo, Gessagem e Incorporação para obtenção dos tratamentos.

TABELA 7. Cronograma das atividades realizadas no experimento de"Efeitos de modos de aplicação e incorporação de calcário e gesso em pomares de citros. Local: Faz. Santa Helena - Monte Azul Paulista. 54

TABELA 8. Perfil transversal de aplicação de calcário para o método a lanço. 56 
TABELA 9. Perfil transversal de aplicação de calcário para o método em faixa 57

TABELA 10. Distribuição em porcentagem das frações granulométricas no perfil transversal do modo de aplicação de calcário a lanço. 62

TABELA 11. Distribuição em porcentagem das frações granulométricas no perfil transversal do modo de aplicação de calcário em faixa. 63

TABELA 12. Reatividade Relativa e PRNT no perfil transversal do modo de aplicação de calcário a lanço.

TABELA 13. Reatividade Relativa e PRNT no perfil transversal do modo de aplicação de calcário em faixa.

TABELA 14. Valores médios da Produção de frutos (tha) para a laranjeira Pera do Rio (Citrus sinensis L. Osbeck) submetida a modos de aplicação de calcário, gesso e incorporação

TABELA 15. Valores médios do peso/fruto (g) para a laranjeira Pera do Rio (Citrus sinensis L. Osbeck) submetida a modos de aplicação de calcário, gesso e incorporação. 73

TABELA 16. Valores médios de suco extraído (\%) para a laranjeira Pera do Rio (Citrus sinensis L. Osbeck) submetida a modos de aplicação de calcário, gesso e incorporação.

TABELA 17. Valores médios do comprimento do fruto (mm) para a laranjeira Pera do Rio (Citrus sinensis L. Osbeck) submetida a modos de aplicação de calcánio, gesso e incorporação. 
TABELA 18. Valores médios do diâmetro de fruto $(\mathrm{mm})$ para a laranjeira Pera do Rio (Citrus sinensis L. Osbeck) submetida a modos de aplicação de calcário, gesso e incorporação.

TABELA 19. Valores médios de Brix (\%) para a laranjeira Pera do Rio (Citrus sinensis L. Osbeck) submetida a modos de aplicação de calcário, gesso e incorporação 77

TABELA 20. Valores médios de acidez (\%) para a laranjeira Pera do Rio (Citrus sinensis L. Osbeck) submetida a modos de aplicação de calcário, gesso e incorporação.

TABELA 21.Valores médios da relação Brix/acidez (Ratio) para a laranjeira Pera do Rio (Citrus sinensis L. Osbeck) submetida a modos de aplicação de calcário, gesso e incorporação. 79

TABELA 22. Correlação simples entre as variáveis de proctução e de qualidade tecnológica dos frutos da laranjeira Pera do Rio (Citrus sinensis L. Osbeck). 86

TABELA 23. Teores médios de cálcio $\left(\mathrm{Ca}-\mathrm{meq} . / 100 \mathrm{~cm}^{3}\right)$ do solo sob experimento com Pera do Rio (Citrus sinensis L. Osbeck).

TABELA 24. Teores médios de magnésio (Mg - meq./100 $\mathrm{cm}^{3}$ ) do solo sob experimento com Pera do Rio (Citrus sinensis L. Osbeck) 90

TABELA 25. Valores médios de $\mathrm{pH} \mathrm{CaCl}_{2}$ do solo sob experimento com Pera do Rio (Citrus sinensis L. Osbeck). 
TABELA 26.Valores médios da relação cálcio/magnésio (Ca/Mg) do solo sob expenimento com Pera do Rio (Citrus sinensis L. Osbeck).

TABELA 27. Valores módios de saturaçăo por bases (V\%) do solo sob experimento com Pera do Rio (Citrus sinensis L. Osbeck).

TABELA 28. Teores médios de aluminio trocável $\left(\mathrm{Al} \mathrm{meq} / 100 \mathrm{~cm}^{3}\right)$ do solo sob experimento com Pera do Rio (Citrus sinensis L. Osbeck). 97

TABELA 29. Valores médios da saturação por Alumbio -m (\%) do solo sob experimento com Pera do Rio (Citrus sinensis L. Osbeck). 99

TABELA 30. Valores médios da Capacidade de Troca Catiônica (CTC $\mathrm{meq} / 100 \mathrm{~cm}^{3}$ ) do solo sob experimento com Pera do Rio (Citrus sinensis L. Osbeck). 100

TABELA 31. Teores médios de sulfato $\left(\mathrm{S}_{-} \mathrm{SO}_{4}-\mu \mathrm{g} / \mathrm{cm} \mathrm{cm}^{3}\right)$ do solo sob experimento com Pera do Rio (Citrus sinensis L. Osbeck). 101

TABELA 32. Teores médios de potássio $\left(\mathrm{K}-\right.$ meq./100 $\left.\mathrm{cm}^{3}\right)$ do solo sob experimento com Pera do Rio (Citrus sinensis L. Osbeck). 102

TABELA 33.Valores médios da relação cálcio/potássio (Ca/K) do solo sob expenimento com Pera do Rio (Citrus sinensis L. Osbeck). 104

TABELA 34.Valores médios da relação magnèsio/potássio (Mg/K) do solo sob expenimento com Pera do Rio (Citrus sinensis L. Osbeck). 105 
TABELA 35. Valores médios da relação cálcio tmagnésio/potássio $(\mathrm{Ca}+\mathrm{Mg} / \mathrm{K})$ do solo sob expenimento com Pera do Rio (Citrus sinensis L. Osbeck)

TABELA 36.Teores médios de cálcio (Ca-\%) em folhas de Pera do Rio (Citrus sinensis L. Osbeck) submetida a gessagem, modos de aplicação de calcário e incorporaçāo

TABELA 37.Teores medios de magnesio (Mg-\%) em folhas de Pera do Rio (Citrus sinensis L. Osbeck) submetida a gessagem, modos de aplicação de calcário e incorporaf̧ăo. 108

TABELA 38.Teores medios da relação calcio/magnésio (Ca/Mg) em folhas de Pera do Rio (Citrus sinensis L. Osbeck) submetida a gessagem, modos de aplicação de calcário e incurporaçăo. 109

TABELA 39.Teores médios da relação cálcio/potássio $(\mathrm{Ca} / \mathrm{K}) \mathrm{em}$ folhas de Pera do Rio (Citrus sinensis L. Osbeck) submetida a gessagem, modos de aplicação de calcário e incorparação.

TABELA 40.Teores médios da relação cálciotmagnésio/potássio $(\mathrm{Ca}+\mathrm{Mg} / \mathrm{K})$ em folhas de Pera do Rio (Citrus sinensis L. Osbeck) submetida a gessagem, modos de aplicação de calcário e incorparação. 112

TABELA 41.Teores médios de potássio (K-\%) em folhas de Pera do Rio (Citrus sinensis L. Osbeck) submetida a gessagem, modos de aplicação de calcário e incorporação. 
TABELA 42.Teores médios de nitrogênio (N-\%) em folhas de Pera do Rio (Citrus sinensis L. Osbeck) submetida a gessagem, modos de aplicação de calcário e incorporação.

TABELA 43.Teores médios de fósforo (P-\%) em folhas de Pera do Rio (Citrus sinensis L. Osbeck) submetida a gessagem, modos de aplicaçăo de calcário e incorporação

TABELA 44.Teores médios de enxofre (S-\%) em folhas de Pera do Rio (Citrus sinensis L. Osbeck) submetida a gessagem, modos de aplicação de calcário e incorporação

TABELA 45. Teores médios da relaçăo magnésio/potassio ( $\mathrm{Mg} / \mathrm{K})$ em folhas de Pera do Rio (Citrus sinensis L. Osbeck) submetida a gessagem, modos de aplicação de calcário e incorponạăo. 


\section{LISTA DE QUADROS}

página

QUADRO 1. Caracteristicas dos modos de aplicação de calcário.

42

QUADRO 2. Esquema da análise de variância para as variáveis das análises foliares. 50

QUADRO 3. Esquema da analise de variancia para as variáveis de produção e das análises tecnológicas dos frutos

QUADRO 4. Esquema da análise de variâncis para os atributos químicos do solo. 52

QUADRO 5. Análise da variancia dos efeitos de modos de aplicação de calcário, gesso e incorporação sobre a produção de frutos $(\mathrm{kg} / \mathrm{ha})$ da laranjeira Pera do Rio (Citrus sinensis L. Osbeck).

QUADRO 6. Análise da variancia dos efeitos de modos de aplicação de calcário, gesso e incorporação sobre o peso/fruto (g) da laranjeira Pera do Rio (Citrus sinensis L. Osbeck).

QUADRO 7. Análise da variância dos efeitos de modos de aplicação de calcário, gesso e incorporação sobre a porcentagem de suco extratdo da laranjeira Pera do Rio (Citrus sinensis L. Osbeck).

QUADRO 8. Análise da variância dos efeitos de modos de aplicação de calcário, gesso e incorporação sobre o comprimento do fruto (mm) da laranjeira Pera do Rio (Citrus sinensis L. Osbeck). 
QUADRO 9. Analise da variância dos efeitos de modos de aplicação de calcário, gesso e incorparaçło sobre o diâmetro do fruto $(\mathrm{mm})$ da laranjeira Pera do Rio (Citrus sinensis L. Osbeck).

QUADRO 10. Análise da variância dos efeitos de modos de aplicação de calcário, gesso e incorparação sobre o Brix (\%) da laranjeira Pera do Rio (Citrus sinensis L. Osbeck).

QUADRO 11. Análise da variância dos efeitos de modos de aplicação de calcário, gesso e incorporaçăo sobre a acidez da laranjeira Pera do Rio (Citrus sinensis L. Osbeck). 140

QUADRO 12. Análise da variancia dos efeitos de modos de aplicaçăo de calcário, gesso e incorporaçåo sobre a ratio (Brix/acidez) da laranjeira Pera do Rio (Citrus sinensis L. Osbeck).

QUADRO 13. Análise da variância dos efeitos de modos de aplicação de calcário, gesso e incorporação sobre os teores de cálcio (Ca) no solo em pomar de Pera do Rio (Citrus sinensis L. Osbeck).

QUADRO 14. Análise da variância dos efeitos de modos de aplicação de calcário, gesso e incorporação sobre os teares de magnésio (Mg) no solo em pomar de Pera do Rio (Citrus sinensis L. Osbeck). 143

QUADRO 15. Análise da variância dos efeitos de modos de aplicaçăo de calcário, gesso e incorporaça sobre o valor do $\mathrm{pH}\left(\mathrm{CaCl}_{2}\right)$ no solo em pomar de Pera do Rio (Citrus sinensis L. Osbeck). 
QUADRO 16. Análise da variância dos efeitos de modos de aplicaçăo de calcário, gesso e incorparaçăo sobre a relação CaMMg no solo em pomar de Pera do Rio (Citrus sinensis L. Osbeck).

QUADRO 17. Análise da vañancia dos efeitos de modos de aplicação de calcário, gesso e incosporaçă sobre o indice de saturaçăo por bases (V\%) no solo em pomar de Pera do Rio (Citrus sinensis L. Osbeck).

QUADRO 18. Análise da variancia dos efeitos de modos de aplicação de calcário, gesso e incarporafăo sobre os teores de aluminio ( Al ) no solo em pomar de Pera do Rio (Citrus sinensis L. Osbeck).

QUADRO 19. Analise da vanância dos efeitos de modos de aplicaf̧ão de calcário, gesso e incurporaçăo sobre o indice de saturaçăo por aluminio ( $m$ ) no solo em pomar de Pera do Rio (Citrus sinensis L. Osbeck)...

QUADRO 20. Análise da variancia dos efeitos de modos de aplicação de calcário, gesso e incorporaçăo sobre os valores da capacidade de troca catiônica ( CTC ) no solo em pomar de Pera do Rio (Citrus sinensis L. Osbeck).

QUADRO 21. Análise da variancia dos efeitos de modos de aplicação de calcário, gesso e incorporação sobre os teores de sulfato $\left(\mathrm{S}^{-\mathrm{SO}_{4}}\right)$ no solo em pomar de Pera do Rio (Citrus sinensis L. Osbeck). 150

QUADRO 22. Análise da variancia dos efeitos de modos de aplicação de calcário, gesso e incorporação sobre os teores de potássio $(\mathrm{K})$ no solo em pomar de Pera do Rio (Citrus sinensis L. Osbeck). 
QUADRO 23. Análise da variancia dos efeitos de modos de aplicação de calcário, gesso e incorparação sobre a relação $\mathrm{Ca} / \mathrm{K}$ no solo em pomar de Pera do Rio (Citrus sinensis L. Osbeck).

QUADRO 24. Análise da variância dos efeitos de modos de aplicação de calcário, gesso e incorporação sobre a relação $\mathrm{Mg} / \mathrm{K}$ no solo em pomar de Pera do Rio (Citrus sinensis L. Osbeck).

QUADRO 25. Análise da variancia dos efeitos de modos de aplicação de calcário, gesso e incorporaçăo sobre a relação $\mathrm{Ca}+\mathrm{Mg} / \mathrm{K}$ no solo em pomar de Pera do Rio (Citrus sinensis L. Osbeck)

QUADRO 26. Análise da variância dos efeitos de modos de aplicaçăo de calcário, gesso e incorparação sobre os teores foliares de cálcio (Ca) em pomar de Pera do Rio (Citris sinensis L. Osbeck)

QUADRO 27. Análise da variancia dos efeitos de modos de aplicaçăo de calcário, gesso e incorporação sobre os teores foliares de magnesio (Mg) em pomar de Pera do Rio (Citrus sinensis L. Osbeck).

QUADRO 28. Análise da variancia dos efeitos de modos de aplicação de calcário, gesso e incorporação sobre a relação calcio/magnésio (CaMg) em folhas de Pera do Rio (Citrus sinensis L. Osbeck)

QUADRO 29. Análise da variância dos efeitos de modos de aplicação de calcário, gesso e incorporação sobre a relação calcidpotássio (Ca/K) em folhas de Pera do Rio (Citrus sinensis L. Osbeck) 
QUADRO 30. Análise da variância dos efeitos de modos de aplicação de calcário, gesso e incorporação sobre a relação cálciotmagnésio/potássio $(\mathrm{Ca}+\mathrm{Mg} / \mathrm{K})$ em folhas de Pera do Rio (Citrus sinensis L. Osbeck).

QUADRO 31. Analise da variância dos efeitos de modos de aplicação de calcário, gesso e incorporaçăo sobre os teores foliares de potássio (K) em pormar de Pera do Rio (Citrus sinensis L. Osbeck).

QUADRO 32. Análise da variância dos efeitos de modos de aplicação de calcário, gesso e incorparaçăo sobre os teores foliares de nitrogênio (N) em pomar de Pera do Rio (Citrus sinensis L. Osbeck).

QUADRO 33. Análise da variância dos efeitos de modos de aplicação de calcário, gesso e incorparação sobre os teones foliares de fósforo (P) em pomar de Pera do Rio (Citrus sinensis L. Osbeck). 158

QUADRO 34. Análise da variância dos efeitos de modos de aplicação de calcário, gesso e incorporação sobre os teores foliares de enxofre (S) em pomar de Pera do Rio (Citrus sinensis L. Osbeck).

QUADRO 35. Análise da variancia dos efeitos de modos de aplicação de calcário, gesso e incorporação sobre a relação magnésio/potássio $(\mathrm{Mg} / \mathrm{K})$ em folhas de Pera do Rio (Citrus sinensis L. Osbeck). 159 


\title{
EFEITOS DE MODOS DE APLICAÇÃO E INCORPORAÇ̃̃O DE CALCÁRIO E GESSO EM POMARES DE CITROS
}

\author{
Autor: PEDRO HENRIQUE DE CERQUEIRA LUZ \\ Orientador: Prof. Dr. GODOFREDO CÉSAR VITTI
}

RESUMO

A calagem em pomares de citros está se tomando uma prática necessária, uma vez que a acidez dos solos, sobre os quais se encontram é um problema marcante. Desta forma, a presente pesquisa foi conduzida em um Podzólico vermelho amarelo distrofico, em Monte Azul Paulista SP, com a laranjeira Pera do Rio (Citrus sinnensis L. Osbeck) sobre limoeiro Cravo (Citrus limonia L. Osbeck), com o objetivo de avaliar os efeitos de modos de aplicação e incorporação de calcário e gesso, sobre os atributos quimicos do solo, de planta bem como da aplicação.

O delineamento experimental empregado foi o de blocos ao acaso, com 4 repetiçðes, sendo os tratamentos em esquema fatorial $3 \times 2 \times 2$, testando-se os modos de aplicação de calcário a lanço e em faixa, com e sem incorporação e com e sem gesso. A parcela experimental constou de 3 linhas de 6 plantas, sendo considerada como úteis as 4 plantas da linha central, guardando-se uma planta no indcio e outra no final como 
bordadura, sendo o espaçamento dos citros $8,0 \mathrm{~m}$ entrelinhas e 4,0m entre plantas na linha. O tamanho da parcela foi consequência do fato da aplicação e incorporação dos corretivos serem mecanizadas. A aplicaçăo dos tratamentos ocorreu em setembro de 1991, estando o pomar com 4 anos, sendo colhidas as 3 safras seguintes $(1992,1993$ e 1994), tanto para época normal bem como para a temporă, além de serem feitas amostragens de solo em dois locais e três profundidades, e coletas de folha em março de 1992 e abril de 1993.

Os modos de aplicação testados interferiram no perfil transversal de aplicação, tanto no aspecto quantitativo, através das doses aplicadas, bem como nos qualitativos, afetando a simetria de aplicação e implicando na segregação. O modo em faixa, atingiu a dosagem esperada na faixa, não deixando de distribuir o calcário no centro da entrelinha, parem em doses menores, por outro lado, o a lanço, concentrou o calcário na entrelinha, ficando a faixa da projeçăo da copa com taxa de aplicaçăo abaixo da desejada. A segregaçăo foi maior para a aplicação a lanço, refietindo-se no valor do Poder Relativo de Neutralizaçăo Total - PRNT, conđuzindo a potenciais diferenciados de reaçăo do calcário no solo, na largura trabalho adotada.

Os modos de aplicaf̧ăo provocaram efeitos significativos sobre os atributos quimicos do solo, para as variaveis relacionadas à calagem Os teores de Ca diferiram entre locais, na aplicação em faixa, sendo superior na copa em comparação à entrelinhas, o que não foi observado para o modo a lanço. A gessagem promoveu aumentos nos teores médios de $\mathrm{Ca}$, nas duas épocas, promovendo a movimentação deste em profundidade na segunda época. O Mg apresentou comportamento semelhante ao do Ca. De uma maneira geral, ocorreu reduçăo nos valores de $\mathrm{Ca}$ e $\mathrm{Mg}$, entre as épocas, principalmente $\mathrm{na}$ 
posição da copa, evidenciando a acidificação que ocorre devido à adubaçăo, o que foi confirmado pelos dados do $\mathrm{pH}_{\mathrm{CaC}}$. Essas alterações refletiram na saturação por bases V(\%), sendo portanto afetada pelos modos de aplicação, atingindo para a camada de 0$20 \mathrm{~cm}$ na primeira época valor de cerca de $60 \%$, tendo os valores recturidos na segunda amostragem. Notou-se efeito favorável da calagem sobre a retençăo de $\mathrm{K}$ no solo. A CTC teve seu valor aumentado, nas duas épocas, devido a calagem, e entre locais, foi maior na copa que na entrelinha.

A gessagem elevou significativamente os teores de $\mathrm{SO}_{4}$, bem como promoveu um gradiente crescente com a profundidade, enquanto que a incorporação levou a redução do mesmo. Para o Al a gessagem não manifestou efeito na primeira época, porem concuziu a rectução nos seus teores na segumda, ao contrário da incorporaçåo cujo efeito significativo, no sentido de diminuir os teores foi na primeira época. Para local, na primeira época năo houve distinçăo entre copa e entrelinha, no entanto, na segunda os teores foram superiores na copa, posição mais sujeita d acidificação devido às adubaçóes. O modo de aplicação a lanço levou a maior redução do Al na entrelinha, enquanto que o em faixa o fez na copa. A saturaçăo por Al teve o mesmo comportamento do Al.

O estado nutricional da laranjeira Pera do Rio foi afetado pelos fatores testados, de forma tal que a gessagem promoveu acréscimos nos teores foliares de Ca e redução para o Mg, na primeira época, refletindo na relação $\mathrm{Ca} / \mathrm{Mg}$ elevando-a nas duas épocas, bern como na $\mathrm{Ca} / \mathrm{K}$ somente na última. Para o $\mathrm{S}$ observou-se tendências de acréscimos na segunda época. A incorporação refletiu na relação $\mathrm{Ca} / \mathrm{K}$ no sentido de elevà-la.

Embora os tratamentos tivessem provocado efeitos sobre os atributos quimicos de solo, com reflexos no estado nutricional da planta, não se detectaram efeitos destes 
sobre a produçåo. Por outro lado, a incorporaçảo proporcionou alterações nos aspectos fisicos dos frutos, através da recução do diâmetro e conprimento, que levaram ao menor peso por fruto, sem no entanto afetar a produtividade, alem disso provocou uma queda na relação Brix/acidez (ratio), fato ocomido somente na primeira safra. Tal comportamento sugere que se deva evitar o uso de tal pratica. 


\title{
EFFECTS OF METHODS OF APPLICATION AND INCOR- PORATION OF LIME AND PHOSPHOGYPSUM TO CITRUS ORCHARDS
}

\author{
Author: PEDRO HENRIQUE DE CERQUEIRA LUZ \\ Adviser: PROF. DR. GODOFREDO CESAR VTTTI
}

\section{SUMMARY}

Liming at citrus orchards has become a necessary practice, taking into account that soil acidity at those sites is a considerable problem. This way, this research was performed in a red yellow Podzol localized at Monte Azul Paulista, in Sao Paulo State, planted with Pera of Rio orange (Citrus simmensis L. Osbeck) rootstock on Rangpur lime (Citrus limonia L. Osbeck) aiming at to evaluate the effects of methods of application and incorporation as well as the application itself of lime and phosphogypsum on the chemical attributes of the soil and the plant.

The experimental design was randomized blocks with four replications, and the treatments set in a $3 \times 2 \times 2$ factorial. Two methods of application (broadcast and strips), two methods of incorporation (with and without incorporation) and two kinds of soil correctives (lime and phosphogypsum) were tested against a control which did not receive any product. The experimental plot consisted of 3 rows of 6 plants each, with four plants of the central row being considered as the effective plot. (One plant at each end of the central row was considered as border.) Row spacing was $8.0 \mathrm{~m}$. and $4.0 \mathrm{~m}$ between 
plants in the row. Plot size resulted from the mechanized distribution and inconporation of the correctives. Application was done in September, 1991, when the archard was 4 years old. Harvesting was accomplished in the three following years $(1992,1993$, and 1994) at the normal season as well as out of season. Soil samplings at two sites and three soil depths besides leaves sampling in March 1992 and April 1993 were also done.

The methods of application tested interfered in the transversal profile of application as concerned to the quantitative aspect, through the doses applied, as well as to the qualitative aspects, thus affecting the symmetry of application and incurning segregation.

The method of application in strips allowed the expected dose to reach the strip, this way distributing lime also in the center of the interrow, although in smaller doses. On the other hand, broadcast application allowed lime to be concentrated at the interrow causing the soil area shaded by the tree to effectively receive a smaller dose. Segregation was higher for broadcast application, thus reflecting in the value of the Total Neutralization Relative Power, and causing differential potential of soil response to lime to occur at the width of the working area.

The methods of application caused significant effects on the soil chemical attributes, conceming the variable related to liming. Calcium contents differed between sites when application was done in strips and it was shown to be more concentrated in the leaves as compared to the interrow. This fact did not occur in the other method of application. Application of phosphogypsum led to increases in the average contents of $\mathrm{Ca}$ at the two sampling times causing movement in depth at the second sampling time. In a broad sense, reduction of the values of $\mathrm{Ca}$ and $\mathrm{Mg}$, at different times of sampling, mainly concerning localization in the leaves, evidencing the acidification caused by fertilization. This fact was confirmed by $\mathrm{pH} \mathrm{CaCl}$.data These alterations reflected on the $\mathrm{V} \%$, which 
was in turn affected by the methods of application, reaching $60 \%$ in the $0-20 \mathrm{~cm}$ layer at the first time of sampling. The values were refuced by the time the second sampling was done. A favorable effect of liming on $\mathrm{K}$ retention in the soil was observed. Cation exchange capacity increased at the two sampling times, due to liming. Increasing was higher at the soil area shaded by tree than in the interrow.

Application of phosphogypsm raised $\mathrm{SO} 4$ contents and promoted increasing gradient in depth, while incorporation caused reduction of those elements content. Phosphogypsum did not have any effect on $\mathrm{Al}$ at the first sampling time, but it did lead to a reduction in the content of that element at the second samplingtime as opposed to incorporation which significantly reduced Al contents at the first sampling time. No differences were observed concerning site of application at the first sampling time. At the second sampling time, however, contents were higher in the soil under the tree shade, where accidity is usually higher due to fertilizing. Broadcast application conduced to higher $\mathrm{Al}$ reduction at the interrow, while application in strips lead to similar reduction in the soil area shaded by the tree. Aluminum saturation had the same effect as Al.

The nutritional status of Pera of Rio orange was affected by the treatments. Phosphogypsum application increased the foliar contents of $\mathrm{Ca}$ and decreased the foliar content of $\mathrm{Mg}$, as indicated at the first sampling time. These alterations reflected on the $\mathrm{Ca} \mathrm{Mg}$ ratio which was shown to be increased at the two sampling times. The ratio $\mathrm{Ca} K \mathrm{~K}$ was shown to be increased onty at the second sampling time. Concerning to $\mathrm{S}$, onty a trend to increase was observed at the second sampling time. Incorporation increased the $\mathrm{Ca} / \mathrm{K}$ ratio.

Although the treatments generated effects on the soil chemical attributes, and consequently reflecting on the plant nutritional status, no effects on the yield were observed. On the other hand, incoporation affected physical aspects of the fruit. 
xxviii

Diameter and heigth were reduced leading to a decrease in fruit weigh although productivity was not affected. A decrease in the ratio Brix/acidity was also obtained at the first harvest. These results indicate liming in citrus orchards should not be prescribed. 


\section{INTRODUÇÃO}

A utilizaçăo da pratica da calagem em pomares de citros, é necessária e reconhecida pelo meio técnico cientifico e mais recentemente pelos produtores, uma vez que a acidez dos solos no Brasil é considerada como um dos principais fatores que impede a plena manifestação do potencial produtivo. No caso de citros muitos pomares estão implantados e sendo conduzidos sob tais condições.

Pare que a calagem tenha êxito, vários aspectos devem ser levados em consideração, tais como o modo de aplicaçăo e a incorporaçă do calcánio. No entanto pouca atenção tem sido dada às técnicas de aplicação, pois narmalmente se encontra apenas um tipo de recomendaç constatação possivelmente seja reflexo do nưmero incipiente de trabalhos de pesquisa que têm sido desenvolvidos no pais nesses últimos tempos.

A recomendação usual para o modo de aplicação de calcário em citros já implantados, é a distribuição do produto a lanço em area total no pomar. Todavia, a posição das plantas sobre a área define a linha, ou seja projeção da copa, e a entrelinha tambem conhecida como rua, as quais no decorres do manejo do pomar acabam recebendo tratamentos difererciados, principalmente sob os aspecto da adubação e do controle de plantas daninhas e pragas. Tal situação é pertinente nessa discussão, pois as adubações, via de regra aplicadas localizadamente na projeção da copa, conduzem à 
acidificaçăo do solo, bem como o uso do enxofre no controle dos ácaros. Desta forma o processo de acidificação do solo ocorrera com intensidades diferenciadas para posições distintas dentro dos pomares, principalmente no caso das adubaçðes nitrogenadas. Nesse contexto, uma interessante alternativa é a aplicaçăo do corretivo em faixa, por direcionar a distribuiçăo do calcário numa regiåo onde o potencial de reaçåo é maior, além de favorecer o aproveitamento pelas raizes.

Os distribuidores de corretivos, de uma maneira geral são voltados para a aplicação a lanço, consequéncia da recomendaçăo para o modo de aplicação. De acordo com testes de aplicação, com exceção do tipo "cocho", os equipamentos apresentam um perfil transversal de distribuição que normalmente comcentra a quantidade do corretivo aplicado na posição mais central da largura de aplicação, o que requer o emprego da sobreposição entre as consecutivas passadas da máquina no campo. Todavia, para as condiçðes dos pomares de citros, cujo espaçamento entrelinhas dificilmente supera os 8 ou $10 \mathrm{~m}$, a queståo da sobreposição fica prejudicada, o que conduz a colocação de maiores doses na porçåo central da entrelinha. No entanto, atualmente os fabricantes oferecem como assessório dispositivos para direcionar a aplicação do corretivo em faixa, para serem colocados nos distribuidores convencionais.

Para incorporação do corretivo de solo, a indicação que se encontra é que seja feita na etapa de preparo do solo, antes da araçåo ou da gradeação, com vistas a posicionar através da mobilização mecánica do solo, o produto em profundidade permitindo a correçăo da acidez nessas camadas. Contudo, para pomares já implantados, a mobilização mecânica do solo em profundidade fica comprometida devido aos riscos da danificação das raizes, o que leva a incorporaçăo somente no meio da entrelinha, usando- 
se uma grade leve. Para contomar essa situação, uma alternativa seria o uso do gesso como um melhorador do ambiente radicular nas camadas mais profundas do solo.

Considerando-se os aspectos acima citados relacionados à calagem, o presente trabalho tem por objetivo, verificar a validade da seguinte hipótese: a utilização de diferentes modos de aplicação e incorporação do calcário, bem como o uso do gesso em pomares de citros instalados, implica:
a) na obtenção de perfis transversais de aplicação distintos;
b) em alteraçðes na produtividade e qualidade tecnológica dos frutos;
c) no estado nutricional das plantas; $e$
d) em alteraçð̃es dos atributos químicos do perfil do solo. 


\section{REVISÃO DE LITERATURA}

\subsection{Tecnologia e modos de aplicação e incorporação de corretivos}

Calcário e gesso agricola podem ser distribuidos na superficie do solo, ou aplicados em sub-superficie, cuja técnica encontra-se ainda em fase experimental. Desta forma, o principal enfoque sera dado a aplicação superficial, a qual pode ser feita de diversas maneiras. A maioria dos pesquisadores envolvidos nessa área, sugere que a distribuiçăo do calcário deva ser feita a lanço em área total, tais como: MALAVOLTA et al. (1974); MALAVOLTA (1979); ANGHINONI (1983); QUAGGIO (1985); RAIJ (1991).

No que diz respeito a unifurmidade de aplicação, BUCKMAN \& BRADY (1976) já davam destaque a esse aspecto ao afirmar que "a uniformidade de distribuição, que não deverá ser negligenciada, é tão importante como o tipo e a quantidade do calcário empregado". Posteriormente outros autores tambem enfatizaram a importância da homogeneidade de aplicação, como CANDELON (1971); GARCIA FERNANDEZ (1976), CERQUEIRA LUZ et al. (1984); QUAGGIO (1985); DALLMEYER (1986)

Com a mecanização da aplicação dos corretivos, surgiram vários tipos de distribuidores, que podem ser classificados, de acordo com MIALHE (1986), quanto aos mecanismos distribuidores e dosadores. Sendo assim, pode-se distinguir, quanto ao 
dosador, dois tipos: volumétrico e gravitacional; e para o distribuidor três: a) queda livre; b) inércia ou pentular (Figura 4) e c) centrifugos (Figura 5 )

Os distribuidores do tipo inércia ou pendular, segundo ZMMMERMAN (1969) e PORTELLA et al. (1993), proporcionam vantagens para o produtor, pois não são indicados apenas para a aplicação de corretivos, mas tambèn para o uso com fertilizantes e sementes, o que confere grande versatilidade para o equipamento.

Devido a diversidade de mecanismos distribuidores, e da expectativa da adequada execução da operação de aplicação dos corretivos, CERQUEIRA LUZ \& TOURINO (1986), discutiam a necessidade da obtençăo de dados que contribuissem para a tomada de decisão em relação a correta utilização dos equipamentos, bem como do seu aperfeiçoamento e desenvolvimento. Para tanto, os referidos autores sugerem a execução de ensaios dos distribuidores de corretivos. Nesse sentido, POPP \& ULLRICH (1985), indicam as variáveis que interferem na qualidade de aplicação, e que estão relacionadas com o perfis longitudinal e transversal, que são: taxa de aplicação, simetria e segregação. DALLMEYER (1986) tambem cita essas variáveis e complementa afirmando que os distribuidores devem ser avaliados não somente pela quantidade de trabalho que proporcionam mas principalmente pelo seu desempenho qualitativo.

Nesse sentido, não basta apenas analisar a variação da dosagem no perfil transversal, mas também verificar a interferência do lançamento mecânico sobre o prođuto aplicado, o que é feito atraves da observação da segregação, que segundo KEPNER et al. (1972), está relacionada com o tamanho, densidade e forma das particulas dos produtos. As maiores e de maior densidade, para uma mesma condição de lançamento, atingem maiores distâncias. As particulas com tamanho inferior a 1,0mm, 
são mais suscetiveis a influência da densidade, e ficam mais sujeitas à açåo do vento, fato conhecido como deriva.

Os perfis transversais de aplicaçåo, para os diferentes tipos de mecanismos distribuidores a lanço, comportam-se de maneira distints, de forma tal que as normas ISO/DIN 5690 e ASAE 534l, sugerem tomar 50\% do valor máximo da taxa de aplicação no perfil transversal, como critério para se proceder a sobreposição. COELHO et al. (1992) apresentam de maneira geral, os procerlimentos para avaliaçăo do desempenho de distribuidores de corretivos, e nas suas considerações finais, ressaltam que as metodologias empregadas podem perfeitamente ser adaptadas às condições de campo, para servirem como uma fermmenta awailiar ao produtor, porem alertam que podera implicar em algum prejuizo na precisăo.

Usando a metodologia da norma ISO/DNN 5690, PORTELLA et al. (1993) realizaram testes com um distribuidor tipo pendular, com vistas a avaliar a precisão de 4 pênculos (2 tipo concha e 2 com defletor terminal), aplicando 4 tipos de produtos, sendo 2 fertilizantes (NPK- 5.25.25 e uréia) e 2 sementes (aveia e arroz), submetidos a 3 vazỏes e 3 velocidades de deslocamento. Os resultados indicaram que os pêndulos tipo comcha foram mais precisos, apresentando coeficiente de variaçăo para a taxa de aplicaçăo, no perfil transversal, em média igual a $15 \%$ para a uréia, enquanto que o pêndulo com defletor alcançou 16,8\%. Com relação à velocidade de deslocamento, os autores concluíram que não implicou em diferenças no desempenho dos pêndulos, principalmente na aplicação dos fertilizantes. Com o mesmo procedimento, FONTANA \& DALLMEYER (1985) tinham obtido em media um CV = 13,9\% para o perfil transversal para um distribuidor pencular. 
Um dos fatores ligados a resposta das culturas à calagem é a qualidade dos corretivos, que pode ser avaliada através de um indice, confurme ALCARDE (1985), denominado de Poder Relativo de Neutralização Total - PRNT, que leva em consideração aspectos químicos do carretivo, por meio do poder de neutralizaçåo ( $\mathrm{E}_{\mathrm{CaCO}} \%$ ) e flsicos levando-se em conia a granulometria, através da Eficiência Relativa Granulométrica (Ergr \%) ou Reatividade Relativa (RR\%). Desta forma, de acordo com a legislação contida em BRASIL (1986) a Tabela 1 contém os valores da reatividade das partlculas, que devem ser consideradas no calculo do PRNT. Cabe lembrar que tais valores foram considerados usando-se as taxas de eficiência adotadas no Estado de Ohio (USA). Assim sendo, a segregação que pode ocorrer devido ao uso dos distribuidores de corretivos, principalmente nos que fazem aplicação a lanço, torna-se importante pois afetará a correçåo do solo, uma vez que interferina no PRNT.

TABELA 1. Dados de Reatividade Relativa -\% das particulas de corretivos em função da granulometria.

\begin{tabular}{cccc}
\hline Material & Peneira - ABNT & Diâmetro (mm) & Reatividade Relativa - (\%) \\
\hline Retido & 10 & 2,000 & 2ero \\
Retido & 20 & 0,840 & 20 \\
Retido & 30 & 0,297 & 60 \\
Passa & 30 & 0,297 & 100 \\
\hline
\end{tabular}

Fonte: BRASIL (1986) 
Além da adequada uniformidade de aplicação do corretivo sobre a superficie do solo, há necessidade de incorporá-los, pois as operações de preparo do solo para as culturas, via de regra năo conseguem proporcionar uma adequada mistura do calcário com o solo, tanto nas direções horizontais como verticais, e para se obter uma boa ação neutralizante do mesmo, ANGHINONI (1983) e QUAGGIO (1985) comentam da importância de proporcionar o contato intimo das particulas do corretivo com o solo, uma vez que estes apresentam baixa solubilidade. Desta forma atribuem a uma má incorparaçđo, a obtençæo de resultados de correção inferiores aos esperados, alegando que a recomendação é baseada em métodos calibrados em laboratório, no qual se consegue uma perfeita mistura com o solo.

Quanto a capacidade de incorporaçăo dos corretivos ao solo, os implementos agricolas se comportan de maneira distinta, segundo ANGHINONI (1983). Normalmente, os implementos usados nessa tarefa, são aqueles empregados na fase de preparo do solo, que coincide com a melhor época para a aplicação do calcário, para a implantaçåo das culturas. Sendo assim, o arado tende a depositar o material no fundo do sulco, enquanto que as grades, promovem mistura apenas na camada superficial. A recomendação de se aplicar metade da dose antes da aração e a outra depois, porím antes da gradagem, leva a uma baa distribuição vertical, todavia a horizontal fica comprometida, conforme os comentánios do citado autor, o que talvez não seja bem aceito pelos técnicos envolvidos nessa área. Além desses implementos, DALMEYER (1986) numa boa revisåo sobre o tema, lembra que existem outras opções para incorporaçăo, tal como a enxada rotativa, cultivadores e escarificadores, observando que sob o ponto de vista de incorporaçăo, a enxada rotativa tem bom desempenho, porem sob o enfoque 
conservacionista é condenável. Lembra que no Brasil a incurporaça é feita predominantemente pelas grades, que deixa a desejar quanto a incorporação, mas nåo compromete a conservaçăo.

Esses comentánios são pertinentes para as culturas a serem implantadas, principalmente para os cereais anuais, no entanto, para as perenes e semi perenes, a preocupação com a correçåo do solo não deve se restringir apenas na implantaçăo, mas tambem após o estabelecimento. Cabe comentar que no Brasil são escassos os programas de pesquisa que avaliam métodos de aplicaçåo de calcário ou corretivos em culturas pertenes.

No contexto de citros, SILVEIRA (1990) discutindo os problemas da mecanizaçăo na citricultura, destacou as caractenisticas das grades usadas, via de regra para o controle de plantas daninhas, mas que tambem promovem a incorporação de corretivos, lembrando que devem possuir protetor lateral, com a finalidade de recobrir os discos, no lado que o implemento trabalha sob a copa, evitando assim, danos aos ramos inferiores.

ANGHINONI (1983) alertava para o fato que muitos produtores de frutiferas ainda faziam a calagem somente na cova, afirmando ser indesejável pela pequena fração do solo corrigida, sendo preferivel fazê-la em área total e incarporá-la o máximo possivel $(40-50 \mathrm{~cm})$ por se tratar de sistemas radiculares profundos. O mesmo autor discorria acerca da utilização indiscriminada da prática da subsolagem por prodưtores de maçå dos estados do sul do pais, que achavam que tal operação incorporaria o calcário a grandes profundidades, todavia avaliaçðes de perfis do solo de pomares estabelecidos ( 2 a 5 anos) demonstravam a baixa eticiência dessa prática. Essa posiçåo é compartilhada por STOLF 
et al. (1988) que desenvolveram uma metodologia de incorporaf̧̄o profunda de corretivos para cana-de-açúcar, utilizando-se do sulcador (duplo) por atingir profundidades semelhantes a do subsolador que é o equipamento de manejo de solo, que realmente atinge as maiores profundidades, porém de ação limitada como elemento incorporador, conforme já comentado.

Uma interessante alternativa é apresentada por ANGHINONI (1983), baseada na cultura da maçă, mas que pode ser adaptada para outras frutiferas, é a aplicação de calcário em faixas de 2 a 3m de largura, no sentido da linha, por ocasião do plantio, em doses proporcionais à mesma. Dentro desse contexto, SUZUKI (1989) realizou uma pesquisa com maçã testando modos de aplicação, a lanço em área total e em faixa, que correspondia a $3 / 5$ do espaçamento entrelinhas $(5,0 \mathrm{~m})$, ou seja com uma largura de $3,0 \mathrm{~m}$. Avaliou ainda nesse estudo, duas categorias de incorporação, sendo uma a $20 \mathrm{~cm}$ e a outra até $40 \mathrm{~cm}$ de profundidade, pesquisa condurida durante 57 meses apos plantio.

Em citros são poucos os trabalhos nessa área, destacando-se o de CARVALHO (1987), que conduziu um experimento em Lavras - MG, para verificar o comportamento do limoeiro Cravo em sementeira, para dois modos de aplicação de superfosfato simples e de calcário dolomitico, sendo um totalmente incorporado (misturado ao substrato) e o outro aplicação localizada no sulco de plantio das sementes. SOUTO (1993) também avaliou métodos de aplicação em limoeiro Cravo, porem em viveiro, testando 8 modos de aplicação, frutos da combinação a lanço e no sulco, em superficie e incorporado, nas laterais ou no fundo do sulco.

Ao se considerar pomar de citros implantados, a questão modos de aplicação versus incorporação do calcário torna-se complexa, pois deve-se levar em conta a 
presença das radicelas que são as principais responsáveis pela nutrição da planta, de acordo com MOREIRA (1988), que complementava dizendo do desconhecimento do produtor acerca do comportamento do sistema radicular dos citros, admitindo com isso o uso de práticas inadequadas para o manejo do solo, tais como gradagens freqnentes ( 3 ou mais vezes/ano) nos pomares.

O autor tinha fortes argumentos para as suas afimmações, pois alguns anos antes estudara com detalhes o sistema radicular da laranjeira Pera sobre limoeiro Cravo,plantada em 1.975, no espaçamento 4,5 x 9,0m encontrando em 1981(6 anos após) uma distribuição de radicelas como pode ser visto na Tabela 2, pseparada a partir de dados de MOREIRA (1983). Analisando-a, percebe-se que as radicelas concentram-se nas camadas superficiais, periazendo cerca de $46,0 \%$ nos primeiros $15 \mathrm{~cm}$ do solo, e acumulando aproximadamente $60,0 \%$ nos $30 \mathrm{~cm}$ de profundidade, camadas que tem possibilidade de serem atingidas por equipamentos de mobilização mecânica do solo. A distribuição horizontal a partir do tronco, revelou um comportamento linear da porcentagem de radicelas em função da distância do tronco, o que implica em cuidados no manejo da entrelinha, tanto da correção e adubação como do controle de plantas daninhas. Desta forma, percebe-se que a passagem de grade, que geralmente atua na faixa de 10 a $15 \mathrm{~cm}$ de profundidade, certamente cortará as radicelas presentes na projeção de sua passagem. Portanto, a incorporação dos corretivos em citros implantados fica comprometida, pois se por um lado facilita a ação neutralizante do calcário, por outro danifica as radicelas da faixa incorporada.

SALVO FILHO (1991) ao discutir métodos utilizados para controle das ervas daninhas nos pomares citricos, condena o uso da gradeação alegando aspectos já 
comentados, e levantando outros problemas provocados pelo uso de tal prática, como o de pragas e doenças, propagação de plantas daninhas e compactação do solo pelo efeito do "pé-de-grade".

TABELA 2. Distribuição média de radicelas de Pera Rio em parcentagem nas direçб̃es horizontais e verticais.

\begin{tabular}{ccc|ccc}
\hline \multicolumn{3}{c|}{ Distribuição Vertical } & \multicolumn{3}{c}{ Distribuiçăo Horizontal a partir de tronco } \\
\hline Profundidade & Radicelas (\%) & Distáncia & \multicolumn{2}{c}{ Radicelas (\%) } \\
(cm) & Individual & Acumulada & $(\mathrm{m})$ & Individual & Acumulada \\
\hline $00-15$ & 45,96 & 45,96 & $00-0,7$ & 18,36 & 18,36 \\
$15-30$ & 13,40 & 59,36 & $0,7-1,4$ & 16,14 & 34,50 \\
$30-60$ & 13,76 & 73,12 & $1,4-2,1$ & 18,43 & 52,93 \\
$60-90$ & 11,49 & 84,61 & $2,1-2,8$ & 16,66 & 69,59 \\
$90-120$ & 7,22 & 91,83 & $2,8-3,5$ & 15,15 & 84,74 \\
$120-180$ & 7,87 & 99,70 & $3,5-4,2$ & 15,04 & 99,78 \\
\hline
\end{tabular}

Fonte: MOREIRA (1983)

DE NEGRI (1988) também concorda com a posição de se evitar o uso indiscriminado das gradagens em pomares adultos, e fornece uma sugestão que concilia grade, roçadeira e herbicida como técnica de manejo, considerando-se aspectos de clima e solo, indicando o uso de 3 a 4 passagens de roçadeira no verão para controlar as plantas 
daninhas e uma gradagem no fim do periodo chuvoso, com vistas a incorporar adubos fosfatados e calcário, além do uso de herbicidas para o complemento do controle do mato.

\subsection{Calagem, gessagem e incorporaçăo e seus reflexos sobre os atributos} químicos do solo

A citricultura paulista tem-se expandido nesses últimos anos, e segundo um levantamento feito por DEMATTE \& VITTI (1992), atraves de análises quimicas dos solos dessas áreas, revelou que $25 \%$ delas apresentam baixa saturação por bases nas camadas superficiais e subsuperficiais, sendo que $70 \%$ dos solos avaliados podem apresentar bloqueamento quimico ao desenvolvimento sadicular, levando-se em consideraçăo os efeitos depreciativos do $\mathrm{Al}$ ou da falta de $\mathrm{Ca}$ em profundidade.

A prática da calagem provoca diversos efeitos sobre os atributos quimicos do solo, que de acordo com MALAVOLTA (1985) podem ser: fornecimento de cálcio e magnésio; neutralizaçăo do aluminio; aumento na disponibilidade e aproveitamento de outros elementos importantes para a nutrição de plantas ( $P, \mathrm{~K}, \mathrm{~S}$ e Mo). No entanto, para a manifestação de tais efeitos, QUAGGIO (1985) menciona os fatores ligados ao solo que estão implicados nas respostas à calagem, que são dependentes da natureza do complexo coloidal; do grau de acidez e da capacidade de reter água e fornecer os demais nutrientes para as plantas. Além de afetar os atributos quimicos, a calagem segundo o autor, altera as caracteristicas fisicas e biológicas do solo, de forma tal que geralmente é muito dificil explicar qual ou quais os fatores que são responsáveis pelos aumentos de prođução observados com essa prática. 
Por outro lado, a acidez dos solos não se restringe somente d̀ camada arável, ocorrendo em subsuperflcie, o que dificulta a correçåo atraves dos calcários, que segundo VITTI \& DONADIO (1988) não desce com facilidade no perfil do solo, particularmente nos mais pesados (argilosos). A movimentação de Ca devido à calagem, é bastante lenta sendo mais evidente quando se emprega altas doses e/ou sob regime de alta pluviosidade, confunme RTCHEY et al. (1983).

Sendo assim, SOUZA \& RTCHEY (1986) sugerem como uma das alternativas a incorporação do calcário alèm dos tradicionais $10-20 \mathrm{~cm}$. Apresentaram evidências favoráveis a incorporação do calcário a $30 \mathrm{~cm}$ de profundidade, reduzindo a saturação por aluminio. Outros trabalhos apontam nesse sentido como GONZALEZERICO et al. (1979); LOPES (1983); CHAVES et al. (1988)

No estudo de SUZUKJ (1989) a incorparação profunda $(20-40 \mathrm{~cm})$ de calcário proporcionou aumentos nos teores de $\mathrm{Ca}$ e $\mathrm{Mg}$ para a camada de $30-40 \mathrm{~cm}$ de profundidade, e até mesmo na de $40-50 \mathrm{~cm}$. Os modos de aplicação também afetaram os aributos quimicos do solo, elevando-os a lanço e reduzindo-os em faixa ( $3 / 5$ do espaçamento da macieira que era de $5,0 \mathrm{~m}$ ) devido ao efeito "diluição" durante as operaçð̃es de preparo do solo.

No entanto, como afirma RAIJ (1988), atraves da calagem é possivel corrigirse a acidez dos solos, ficando os efeitos restritos à camada aravel, pouco excedendo 15 a $20 \mathrm{~cm}$, pois as incorporaçð̃es profundas e bem feitas são por demais dispendiosas. Desta forma, uma alternativa que tem sido utilizada para proporcionar melhores condiçð̄es no ambiente radicular em profundidade de solos ácidos, é o emprego do gesso agricola, que devido a sua maior solubilidade, pode enriquecer as camadas mais profundas em 
consequência da movimentaça de $\mathrm{Ca}$ e também de $\mathrm{Mg}$, além de recuzair a atividade do Al e fornecer enxofre, predispondo as plantas ao maior aproveitamento de água no perfil do solo. Esse último efeito foi justamente o que despertou o interesse pelo uso do gesso no estudo pioneiro de RTCHEY et al. (1980), com milho no cerrado, usando super fosfato simples e triplo. A utilizaçăo do gesso como melhorador do ambiente radicular é compartilhada por outros autores tais como: VITTI \& MALAVOLTA (1985); MORELLI et al. (1987) E DEMATTE \& VITTI (1992).

Sendo assim, MAZZA (1993) conduziu 04 experimentos em 04 unidades de solo (LEa, PV, LVp e LR), dos quais 2 foram em cana planta e 02 em soqueiras, com o intuito de avaliar os efeitos do gesso e combinaçōes deste com o calcário, sobre os atributos quimicos do solo bem como na produtividade da cana-de-açúcar. Os resultados evidenciaram os efeitos significativos do calcário sobre os teores de $\mathrm{Ca}, \mathrm{Mg}$, saturaçăo por bases $\mathrm{V} \%$, pH e CTC, principalmente na camada superficial do solo, enquanto que o gesso funcionou como fornecedor de $\mathrm{Ca}$, além de proporcionar a redistribuição de $\mathrm{Ca}, \mathrm{Mg}$ e sulfato no perfil do solo (em profundidade) sendo eficiente na reduçăo da saturaçăo por Al.. As tendências observadas para os referidos parâmetros, refletiram diretamente na V\%, sendo que o calcário (do tipo convencional dolomitico) foi eficiente para elevá-la aos patamares esperados, porém apenas no primeiro ano, pois 18 meses apos a aplicação os valores estavam abaixo do pretendido, e que no meio do ciclo da cultura, mesmo nas maiores dosagens, o valor da V\% já era semelhante ao original do solo. Tal efeito tambem ocorreu nos experimentos com cana soca, de maneira que apos 2 cortes no solo PV e 3 no LEa já havia necessidade de reaplicação dos insumos. Cabe comentar que o uso do gesso foi mais efetivo nos Latossolos que nos Podzolicos. 
A combinação do calcário com o gesso parece ser interessante, uma vez que o calcário devido a mais baixa solubilidade terá maior ação na superficie, enquanto que o gesso mais solưvel, terá ação em subsuperficie, de acordo com comentáios de DEMATTE \& VTTTI (1992).

Quanto ao uso dos condicionadores de solo, BORKET et al. (1987) sugerem que o gesso deva ser aplicado antes do calcário, alegando para tanto, a menor percolação do sulfato (que fica mais adsorvido) e consequentemente menor movimentação de Ca e Mg.

No contexto de citros, ANDERSON (1987), conduriu um experimento de longa duração, em Valência sobre limão rugoso, plantado nưm solo arenoso ácido da regiåo central da Flórida, testando 2 tratamentos de correçåo contra um cantrole. Os tratamentos foram: a) calcário dolomitico aplicado para manter o $\mathrm{pH}=7,0$ durante o estudo (15 anos) e b) calcário calcitico mais gesso, fornecendo uma outra fonte de Mg. Amostras de solo foram coletadas $(0-15 \mathrm{~cm})$ depois de 14 anos de condução do ensaio, revelando que os corretivos mantiveram o $\mathrm{pH}$ em torno de 7,0 , enquanto no controle era de 4,8. Os corretivos elevaram os teores de Ca e Mg, havendo superioridade do calcário dolomitico quanto ao fornecimento de Mg.

Com o intuito de verificar o comportamento da Pera Rio sobre o limão cravo, em relação aos macronutrientes $\mathrm{P}, \mathrm{K}$, e Ca, SOUZA (1976) instalou e condurziu um experimento durante os 3 primeiros anos após plantio, em Latossolo vermelho escuro, fase cerrado, em Alfenas - MG. O delineamento foi um fatorial $4^{3}$ com confundimento sem repetições, testando 4 niveis para os fatores estudados. As fontes usadas foram: superfosfato simples; cloreto de potássio e calcário calcitico. Os resultados evidenciaram 
que o $\mathrm{P}$ foi o nutriente mais atuante em todas as variáveis estudadas. $\mathrm{O} C \mathrm{Ca}$ apresentou-se com teores distintos no solo entre os tratamentos testados.

Num estudo de medio prazo acerca dos efeitos da calagem sobre o solo e citros, QUAGGIO (1991) testou em esquema fatorial 4 x 4, calcário calcitico e dolomítico em 4 doses (0, 3, 6 e 9 tha) num Latossolo vermelho escuro, da Estação Experimental "Silvio Moreira" do Instituto Agronómico de Campinas, em Cordeirópolis SP. O pomar de Valência sobre limão Cravo foi implantado em janeiro de 1983, usando-se os dados de análise do solo e folha durante 4 safras até o ano de 1989. As amostras de solo foram coletadas em 2 locais, na projeção da copa e na entrelinha, em 3 profundidades (0-20, 2040 e $40-60 \mathrm{~cm}$ ). Uma das alteraçơes quimicas mais relevantes foi a acentuada acidificação do solo no transcorrer do experimento, principalmente na posição da copa, tomando-se os teores de Ca mais Mg. Outro aspecto observado foi a correção do subsolo na camada de $20-40 \mathrm{~cm}$ principalmente na posição da copa. Notou-se também uma maior retenção de $\mathrm{K}$ devido à calagem, o que foi atribuido a liberação de cargas dependentes de $\mathrm{pH}$ e de concentrações maiores de outros contra-ions como Ca e Mg, os quais acompanham os cofons no processo de lixiviação, citando o autor que tal efeito aumentaria em muito a eficiência dos fertilizantes potássicos usados na citricultura.

CASARIN (1994) estudou o comportamento de vários materiais corretivos sobre os atributos quimicos de um Latossolo vermelho escuro da região de Pirassununga SP. Os tratamentos testaram calcários calcítico, magnesiano e dolomítico, gesso, e magnesita e a mistura desta com calcário calcitico e gesso. A capacidade de troca catiônica era elevada, o que implicou em doses consideráveis dos corretivos, uma vez que adotou-se o método de necessidade de calagem baseado na saturaçăo por bases - V\%, 
com vistas a elevá-la a $70 \%$. Desta forma os tratamentos, 10 meses após a aplicação, proporcionaram aumentos significativos nos teores de $\mathrm{Ca}$, bem como detectou-se efeito de caminhamento deste no perfil do solo devido ao uso do gesso, que tamberm arrastou o $\mathrm{K} \mathrm{e}$ o Mg para as camadas mais profundas do solo $(40-60 \mathrm{~cm})$, além de gerar um gradiente crescente com a profundidade para o $\mathrm{S}_{-} \mathrm{SO}_{4}$. Obteve tambem rełução no $\mathrm{Al}$ devido ao uso dos corretivos e reflexos na CTC, de forma que o gesso propiciou a rectução da saturação por Al somente na $2^{\mathrm{a}}$ época.

CIPOLLI (1986) iniciou um estudo na Estação Experimental de Citricultura de Bebedouro SP, na implantação de um pomar de laranjeira Pera do Rio sobre limão Cravo, em dezembro de 1984, com a finalidade de estudar os efeitos da utilização de calcário calcinado e gesso, quando aplicados isolados e misturados em duas proporçøes (70:30 e 50:50) sobre a fertilidade do solo e caracteristicas da planta. Os dados das análises do solo (0-20 e 20-40 cm) indicaram aumentos nos teores de Ca para todos os corretivos, e elevação no pH e V\% principalmente para os tratamentos que levaram calcário calcinado, fato esse que ficou marcante para o Mg. Tais alteraçð̃es ocorreram com maior intensidade na camada superficial. Para o $\mathrm{SO}_{4}$ verificou-se maiores valores para a camada de 20 a $40 \mathrm{~cm}$, sendo atribuido à lixiviação. Com relação ao $\mathrm{K}$, o autor não notou efeitos dos tratamentos sobre este, alegando que os teores encontrados estavam muito elevados. De todos os corretivos empregados, o calcário calcinado na maior dose foi o que promoveu as maiores alteraçð̃es nos atributos químicos do solo, seguido de perto pela mistura calcário mais gesso (70:30).

No mesmo local do estudo conduzido por CIPOLLI (1986), foi reinstalado o experimento por AMARAL (1989), usando os mesmos tratamentos e delineamento, 
adotando o critério de calagem a elevação da V\% para $70 \%$, sendo aplicados em novembro de 1987, portanto no $3^{\circ}$ ano do pomar. Em março de 1988 e de 1989, respectivamente 4 e 16 meses após calagem, foram feitas amostragens do solo (0-20 e 20$40 \mathrm{~cm}$ em 1988, acrescentando a camada de $40-60 \mathrm{~cm}$ em 1989), cujos resultados apontaram para a elevação do pH para os tratamentos com calcário, não obtendo diferenças significativas para o parametro entre a testemunha e aqueles com gesso exclusivo, não havendo diferenças entre as épocas de amostragem. Com relação ao $\mathrm{Mg}$, $\mathrm{o}$ uso dos calcários e as misturas elevaram seus teores a patamares satisfatórios $(0-20 \mathrm{~cm})$, enquanto que o gesso não diferiu da testemunha, por outro lado a mistura de calcário mais gesso (70:30), proporcionou a melhor condição, pois nas duas camadas analisadas os valores aumentaram, na primeira amostragem Todavia, na segunda época notou-se reduçăo geral dos teores, porén mais acentuada para essa mistura, sendo tal fato atribuido ao efeito de lixiviação do gesso. Percebe-se também nessa época, que nos tratamentos com gesso isolado, os maiores teores de $\mathrm{Mg}$, embora baixos, estão na camada de $40-60 \mathrm{~cm}$, reforçando o comentánio do autor. Os teores de Ca sofreram aumentos significativos para todos os tratamentos em relação à testemunha, principalmente na camada de $0-20 \mathrm{~cm}$, mantendo-se entre as epocas. Para as camadas inferiores os tratamentos com gesso apresentaram maiores valores, embora houvesse redução entre épocas, evidenciando a maior movimentação de bases devido ao $\mathrm{SO}_{4}$. Os aumentos desses teores fizeram-se sentir na $\mathrm{V} \%$, que aumentou, de uma maneira geral, da $1^{a}$ para a $2^{\mathrm{a}}$ epoca, tendo os maiores valores, cerca de $70 \%$ para o calcário calcinado em maior dose e $63 \%$ para a mistura $70: 30$, dentro da camada de $0-20 \mathrm{~cm}$, com pequenos reflexos nas camadas inferiores. A adubação potássica não foi testada como fator, no entanto na $2^{a}$ 
época, o teor encontrado para a testemunha foi muito baixo evidenciando uma maior retenção devida a calagem. O gesso exclusivo em maior dose, tambem propiciou os menores valores para o $\mathrm{K}$, corroborando o fato da lixiviação que o mesmo provoca. Quanto ao $\mathrm{SO}_{4}$ o uso do gesso quer isolado ou na mistura com calcário fez subir os teores, notando ainda para o gesso isolado, significativos aumentos em profiundidade.

Dando continuidade ao experimento, PARO (1991) reaplicou os mesmos tratamentos em maio de 1990, fazendo as amostragens do solo em março de 1990 (efeito residual do trabalho de AMARAL 1989) e um ano depois, portanto durante $06^{\circ}$ e $7^{\circ}$ anos do pormar. As tendéncias observadas nos anos anteriores para os efeitos dos tratamentos sobre os atributos quimicos do solo continuaram, mas no entanto, em março de 1990 (1 la $^{\mathrm{a}}$ época de amostragem) notou-se decrescimos acentuados nos teores de $\mathrm{Ca}$ e $\mathrm{Mg}$, bem como na V\%, o que motivou a reaplicação dos corretivos. Um ano depois, os resultados evidenciaram aumentos efetivos para o $\mathrm{Ca}, \mathrm{Mg}$ e $\mathrm{V} \%$, assim como decréscimo no $\mathrm{Al}$, para os tratamentos com mistura calcário mais gesso (70:30) e para o calcário calcinado em maior dose, revelando-se os melhores tratamentos ao longo dos 5 últimos anos do experimento.

Em condição de pomar de citros, porem com laranja 'Hamlin' enxertada sobre limoeiro Cravo, com 8 anos de idade, em Bebedouro - SP, VECCHI (1993) implantou um experimento num Latossolo vermelho escuro álico, textura média, com a finalidade de verificar os efeitos da utilização de calcário calcítico e magnesiano quando aplicados isolados, e das misturas de magnesita com gesso e com calcário calcitico, sobre as caracteristicas quimicas do solo, bem como na qualidade e quantidade da produção. As doses dos corretivos foram calculadas para elevar a V\% para $70 \%$, sendo os produtos 
aplicados em 1990 e reaplicados em 1992. As amostragens de solo foram realizadas em março de 1991 e 1992, em 3 profundidades $(0-20,20-40$ e 40-60 cm). Os dados alcançados mostraram reflexos dos corretivos sobre o pH elevando-o, sendo o maior valor para o tratamento magnesita mais gesso. O Ca aumentou significativamente em relação a testemunha, para todos os tratamentos, sendo que com o uso do gesso seu teor cresceu em profundidade. Os valores do Mg para a testemunha e quando se usou calcário calcitico exclusivo, apresentaram-se menores, porem a mistura do gesso e do calcário calctico com magnesita proporcionaram teores adequados. Para o Al notou-se efeitos dos corretivos no sentido de reduzirem-no, com maior efetividade na camada de 0-20cm, e da associação da magnesita com gesso, houve também redução na camada de $20-40 \mathrm{~cm}$ O uso do gesso elevou os teores de $\mathrm{S}_{-} \mathrm{SO}_{4}$ do solo nas duas épocas de amostragem, tendo um efeito marcante em profundidade. A V\% sofreu aumentos significativos em relação a testemunha $(13,8 \%$ para $0-20 \mathrm{~cm})$ alcançando o maior valor $(49,4 \%)$ para a mistura magnesita/gesso, porém não atingindo o esperado, fato esse que o autor atribui a baixa fertilidade inicial do solo, não sendo portanto suficientes as quantidades dos corretivos aplicados.

Este estudo teve sequência com VIEIRA (1994) que observou efeitos semelhantes aos anteriores (VECCHI 1993), porém constatou redução nos teores de Ca e Mg (com exceção dos tratamentos com magnesita) refletindo-se na V\% que também diminuiu em função do tempo. Outro efeito observado foi a maior retenção de $\mathrm{K}$ devido ao emprego dos corretivos. A CTC mostrou-se superior nos tratamentos com calcário magnesiano e calcitico. Considerando-se que a ordem de grandeza dos teores de Ca e Mg, bem como da V\% já estavam baixos nas épocas amostradas por VECCHI (1993), os 
resultados obtidos por VIEIRA (1994) apontam para a reaplicação dos corretivos, o que foi sugerido pelo autor.

Os estudos que tem por objetivo verificar os efeitos da calagem, incorporada ou nfo, bem como da gessagem sobre os atributos químicos do solo, via de regra detectaram alteraçōes significativas para os fatores testados, indicando a efetividade de tais práticas em atingir os propósitos as quais se destinam

\subsection{Comportamento dos citros quanto a calagem, gessagem e incorporação dos condicionadores do solo}

Nesses últimos anos tem surgido alguns trabalhos de respostas a calagem com citros em nossas condições, sendo uma interessante constatação, visto ser uma cultura que demanda experimentos grandes, de relativa duraçăo e onerosos. Dentre esses, destacam-se os já comentados trabalhos de CIPOLLI (1986); AMARAL (1989); QUAGGIO (1991); VECCHI (1993); CASARIN (1994); PARO (1994) e VIEIRA (1994).

Antes de abordar tais estudos, não poderia deixar de comentar acerca do expenimento de longa duraçăo de ANDERSON (1987), com Valência sobre limão rugoso, espaçadas de 7,6 por $7,6 \mathrm{~m}$, no qual obteve efeitos significativos e positivos dos corretivos sobre a produção de frutos, praticamente dobrando-a, até o $17^{\circ}$ ano, exceção feita ao $10^{\circ}$ ano. Entre os corretivos não se detectou diferenças, evidenciando a eficiência da fonte de Mg empregada.

O estudo de SOUZA (1976) não detectou efeito do $\mathrm{Ca}$, via calagem, no desenvolvimento vegetativo, na produção e nem nas caracteristicas dos frutos, embora 
tenha se encontrado teores significativamente diferentes no solo, o que foi atribuido a fonte de $\mathrm{P}$, que foi o superfosfato simples, sendo mais eficiente como formecedor de Ca. Com relação à nutrição, o P aplicado aumentou a concentraçåo de $\mathrm{N}$ e de $\mathrm{K}$ na folha, enquanto que a fonte de $\mathrm{K}$ aumentou sua própria concentração e recturiu a de $\mathrm{Ca}$, devido ao antagonismo. O calcário calcitico, elevou os teores de $\mathrm{P}$ e provocou a redução de $\mathrm{K}$. Interessante notar nesse estudo com Pera Rio, a alta variabilidade para os dados de protuçăo, com coeficiente de variaçăo de $43,6 \%$, na fase de crescimento e desenvolvimento da variedade, o que pode estar associado a aspectos varietais, implicando na dificuldade da manifestação de resposta às variáveis testadas.

Quanto aos modos de aplicação, o estudo de CARVALHO (1987) revelou que incorporando-se os proautos, possibilitou-se maiores respostas das plantas ds doses avaliadas, principalmente para o $\mathrm{P}$, do que quando distribuiu-se em linha no fundo do sulco, em condição de sementeira. Por outro lado, SOUTO (1993), nåo encontrou efeitos significativos para modos de aplicação de $\mathrm{P}$, em viveiro, para as variáveis de planta (incremento e diâmetro do caule e altura de planta). Tal comportamento foi explicado pelo elevado teor inicial no solo dos nutrientes testados ( $\mathrm{P}, \mathrm{S}$ e Ca), além da alta variabilidade destes no solo.

Na pesquisa de SUZUKI (1989) com maçã, a produção e circunferência do tronco foram afetadas de maneira positiva para a incorporação do calcário, enquanto que os modos de aplicação nåo promoveram efeitos sobre tais variáveis.

O experimento iniciado por CIPOLLI (1986), um ano após aplicação dos tratamentos com corretivos, no $1^{\circ}$ ano depois do plantio da laranja Pera sobre limão 
cravo, constatou efeitos benéficos do calcário nos teores foliares de $\mathrm{Ca}$ e $\mathrm{Mg}$ e seus reflexos no crescimento das plantas.

Dando sequência ao estudo, AMARAL (1989) colheu as safras referentes ao $3^{\circ}, 4^{\circ}$ e $5^{\circ}$ anos do pomar, constatando respostas na produção para os tratamentos com os corretivos em relaçăo à testemunha, sendo os tratamentos com calcário calcinado, nas 2 doses e a mistura calcário mais gesso (70:30) aqueles que proporcionaram as melhores produçōes durante as 3 safras, gerando diferença de 0,25 caixa/planta por safra.

PARO (1994) colheu as safras relativas aos $6^{\circ}$ e $7^{\circ}$ anos do citado experimento, obtendo dados semelhantes aos anteriores, portanto confinmando a efetividade dos tratamentos com calcário calcinado e da mistura deste com gesso, sobre a prođução de futos. Todavia, não encontrou diferenças entre os tratamentos com gesso isolado e a testemunha, sugerindo não se adotar o uso exclusivo do gesso. Com relação aos aspectos tecnológicos dos frutos, praticamente não se encontrou diferenças significativas em função dos tratamentos testados. Analisando-se as 5 safras colbidas, percebe-se que o tratamento com a mistura de calcário mais gesso na proporf̧ăo 70:30 foi o que proporcionou os melhores resultados, fato esse que deve ser devido a condiçð̃es do melhor equilibrio dos atributos químicos do solo.

A experimentação de doses de calcário calcitico e dolomitico, realizada por QUAGGIO (1991) produziram respostas acentuadas na laranjeira Valência, obtendo-se máxima proturtividade e lucratividade quando a acidez foi corrigida para atingir $60 \%$ de saturação por bases. Os ganhos de produção foram devidos ao aumento do número de frutos por planta, independente do crescimento da arvore. Notou efeitos significativos sobre a qualidade dos frutos, de maneira que a calagem elevou os teores dos sólidos 
solưveis, e acidez no suco, devido ao maior suppimento de $\mathrm{Mg}$ às plantas. Com o passar das safras, os frutos ficaram menores porem o nimero por planta aumentou, fato conhecido na citricultura, estando de acordo com as discussões feitas sobre esse aspecto em DI GIORGI et al. (1993). Observou-se forte antagonismo entre Ca e $\mathrm{K}$, de tal maneira que a relação $\mathrm{Ca} / \mathrm{K}$ no solo foi mais impurtante, pois relacionuo-se de forma mais efetiva com o suprimento de $\mathrm{Ca}$ e alta produtividade, do que a relação $\mathrm{Ca} / \mathrm{Mg}$, inclusive devido a menor variabilidade e persistência da primeira. Este comportamento antagónico entre Ca e K e Ca e Mg, já tinha sido comentado por KAMPFER (1963).

Testando materiais corretivos em Pera Rio, no estádio de desenvolvimento, CASARIN (1994), não encontrou respostas sobre a produção um ano após a aplicação dos corretivos, no entanto, na safra seguinte obteve efeitos positivos e significativos na produtividade quando comparados com a testemumha. Entre os corretivos, a combinação de magnesita mais gesso proporcionou a maior prołuçåo. Quanto às caractensticas de qualidade dos frutos, na $1^{\text {a }}$ safra não se observou efeitos, por outro lado, tal como na produçă, os tratamentos afetaram aspectos qualitativos dos frutos na $2^{a}$, de maneira que houveram ganhos positivos para o Brix, sendo a associação de magnesita mais calcário calcitico a que gerou o maior valor, enquanto que a combinação desta com gesso, embora elevasse o Mg no solo, apresentou os menores valores para o Brix, o que não foi comentado, talvez pela dificuldade de explicar tal comportamento, pois de acordo com QUAGGIO (1991), o Mg tem importante papel sobre o valor do Brix.

VECCHI (1993) não observou respostas para os corretivos testados em laranjeira 'Hamlin' na primeira safra apos aplicação dos tratamentos, no entanto na seguinte, o tratamento contendo a mistura magnesita mais gesso gerou proctuç̃es 
significativamente superiores à testemunha, devido ao maior supnimento de Ca em profundidade proporcionado pelo gesso, além da redução na saturação de aluminio. Com relação às caracteristicas dos frutos, a semelhança da prołução, não se notou efeitos dos tratamentos na $l^{\text {a }}$ safra, todavia na posterior, o tratamento magnesita/gesso conduziu a futos maiores e mais pesados, o que deve ter refletido na produrtividade. Para os aspectos tecnológicos dos frutos os tratamentos afetaram a acidez, ratio e porcentagem de suco extraldo, na $2^{\mathrm{a}}$ safra, de maneira que a combinação magnesita / calcário calcitico levou a menores valores de acidez que implicaram na obtenção da maior ratio, ao redor de 12 , estando dentro da faixa considerada como ideal para a industrialização, que de acordo com VIEGGAS (1991) pode variar entre 11 e 16. O tratamento com calcário magnesiano forneceu a maior \% de suco extraido. Tem-se a impressão que o $\mathrm{Mg}$ favorece a qualidade tecnológica, embora não se observasse reflexos no Brix como era esperado.

Em continuidade ao experimento, VIEIRA (1994) detectou respostas positivas para a produção na $3^{\text {a }}$ safra após implantação, para os tratamentos que usaram magnesita, quer com gesso ou calcário calcitico. Para a $4^{a}$ safra o tratamento que proporcionou a maior produção foi o que utilizou o calcário magnesiano, que na safra anterior tinha alcanfado a menor produtividade, fato esse que o autor tenta explicar embasado na relação $\mathrm{Ca} M g$ que tivera sido maior nesse tratamento no ano anterior, predispondo melhores condições ao sistema radicular. No entanto, quando se analisa as 4 safras juntas, percebe-se que há alternância para produtividade entre os tratamentos, comportamento esse que foi detectado pelo efeito significativo da interação tratamentos versus anos, indicando que os tratamentos manifestaram-se de maneira diferenciada em função dos anos, embora verificou-se tendência de melhores resultados para os 
tratamentos com magnesita. O estado nutricional da 'Hamlin' foi afetado pelos corretivos, no sentido de elevar os teores de Mg quando se utilizou magnesita e maiores valores para o S devido ao gesso. Para as caracteristicas fisicas e tecnológicas dos frutos não se captou efeito dos tratamentos, embora tenha se obtido teores superiores de Mg no solo, que poderia ter afetado a Brix e acidez.

Observando-se tais trabalhos, nota-se que as respostas para produção dos citros à aplicação dos corretivos, bem como para a incorporafăo dos mesmos, nem sempre acarrem, embora os atributos quimicos do solo de uma maneira geral mostrem reflexos. Os ganhos em produção são mais evidentes nos estudos que avaliaram doses dos corretivos, principalmente naqueles que testaram elevadas doses. 


\section{MATERIAL E MÉTODOS}

\subsection{Caracterização do meio fisico}

\subsection{1. Área e localizaçãa do experimento}

O experimento foi instalado em uma área de produçăo comercial de citros, de propriedade de Fábio Zucchi Rodas, em local denominado Fazenda Santa Helena, no talhăo número 4 (quatro) que conta com 4,179 ha. Essa propriedade está situada a 8,0 lom do municipio de Monte Azul Paulista, Estado de São Paulo, tendo por coordenadas terrestre $21^{\circ} 54^{\prime}$ latitude sul , 48 $39^{\prime}$ longitude oeste e $640 \mathrm{~m}$ de altitude.

\subsubsection{Solo}

O solo foi identificado a nivel de grande grupo como Podzblico Vermelho Amarelo distrofico, textura areia-media/média, relevo suavemente ondulado.

A caracterização quimica e fisica da camada arável do solo, foi feita através de análises, de amostras coletadas a 3 (três) protundidades ou seja: 0 - 20, 20 - 40 e $40-60$ cm, efetuadas pelo laboratório de análises de solos do Departamento de Ciência do Solo da Escola Superior de Agricultura "Luiz de Queiroz" da Universidade de São Paulo em Piracicaba - SP, cujos resultados constam da Tabela 3. 


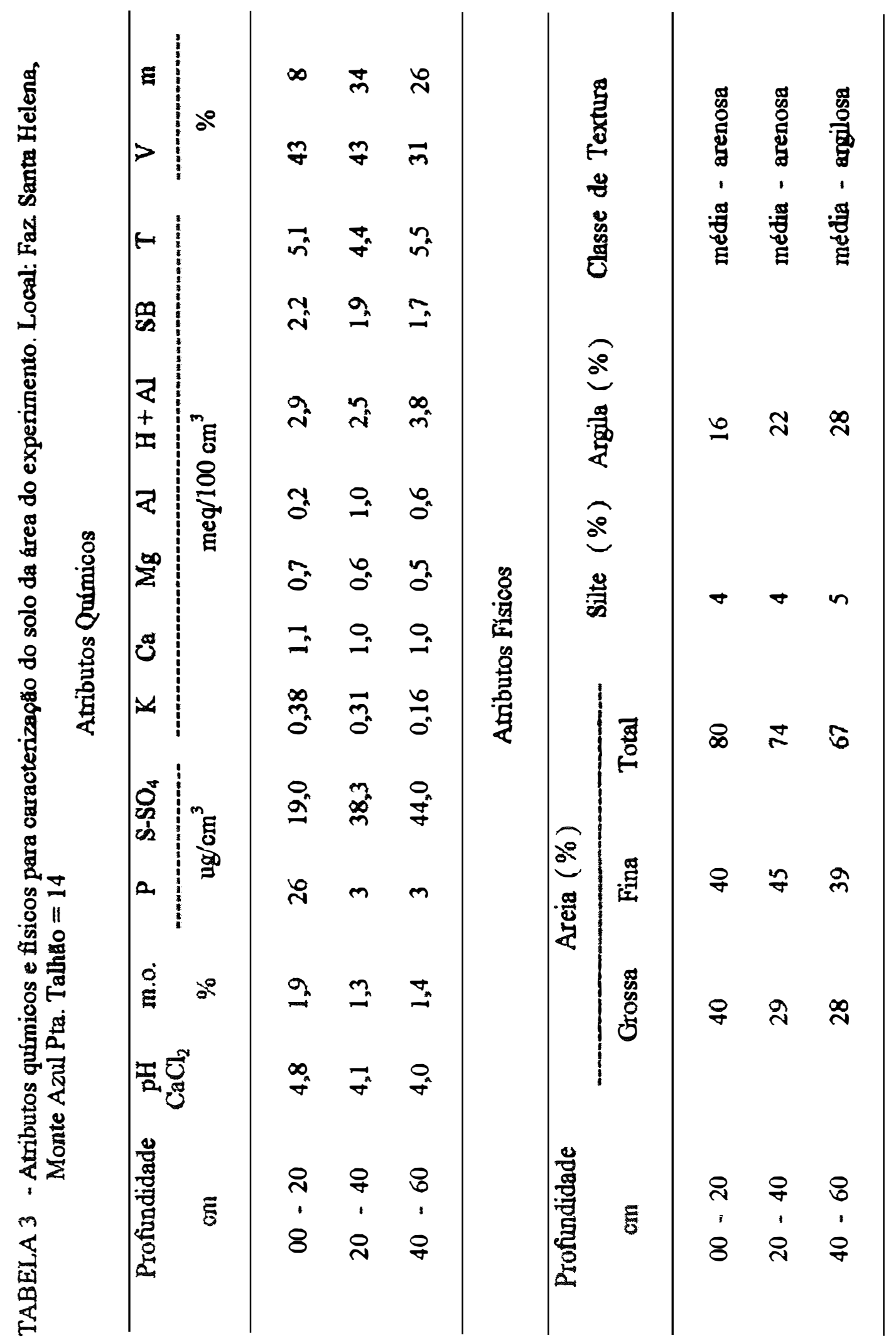


A partir dos dados da análise para fins de fertilidade do solo, determinou-se a dose de calcário a ser aplicada, adotando-se o método da saturação por bases para a recomendação de calagem conforme RAIJ (1983). Utilizou-se o valor de $70 \%$ para a saturação por bases a ser atingida, de acordo com a sugestão contida em GRUPO PAULISTA DE ADUBAÇÃO E CALAGEM PARA CIIROS (1988), desta forma, obteve-se a dosagem de 2,10t/ha. Para o gesso considerou-se o critério de LOPES (1986), que indica a adição de $25 \%$ a mais de $\mathrm{CaO}$ através do gesso, com base no $\mathrm{CaO}$ do calcário, que no presente estudo levou a uma dose de $800,0 \mathrm{~kg} / \mathrm{ha}$.

\subsubsection{Dados climáticos}

A região, segundo classificação de KOEPPEN, é do tipo Cwa, ou seja, mesotérmico de inverno seco e verảo quente e chuvoso, sendo que a temperatura média do mês mais quente ultrapassa $22^{\circ} \mathrm{C}$.

A partir de dados climáticos obtidos junto a Estação Experimental de Citricuitura de Bebedouro- EECB, no pentodo de 1978 a 1993 para a regiăo estudada, conforme Tabela 4, nota-se que o mês mais frio é junho com $19,3^{\circ} \mathrm{C}$, enquanto que o mais quente é fevereiro, com $27,5^{\circ} \mathrm{C}$. A temperatura média anual é de $23,4^{\circ} \mathrm{C}$. A distribuição pluviométrica indica que o mês mais chuvoso é janeiro, com precipitação média de $303,1 \mathrm{~mm}$, enquanto que julho apresenta a menor média, ou seja 23,2 mm.

Com base nos dados climáticos fornecidos pela EECB, determinou-se o balanço hidrico segundo o método de THORNTHWAITE \& MATHER (1955), em base decendial (10 dias), para os anos de 1991 a 1994, com vistas a verificar o comportamento climático 
TABELA 4. Dados médios de precipitação (mm) e temperatura( ${ }^{\circ}$ C) da Estação Experimental de Citricultura de Bebedouro - SP. (1.978-1.993)

\begin{tabular}{ccc}
\hline MES & PRECIPTAÇÃO (mm) & TEMPERATURA $\left.{ }^{\circ} \mathrm{C}\right)$ \\
\hline Janeiro & 303,1 & 25,1 \\
\hline Fevereiro & 181,0 & 27,5 \\
\hline Março & 212,6 & 24,3 \\
\hline Abril & 80,6 & 21,6 \\
\hline Maio & 69,4 & 19,3 \\
\hline Junho & 25,7 & 19,5 \\
\hline Julho & 23,2 & 21,5 \\
\hline Agosto & 34,6 & 22,7 \\
\hline Setembro & 55,6 & 24,6 \\
\hline Outubro & 117,2 & 25,1 \\
\hline Novembro & 183,1 & Média $=23,4$ \\
\hline & 266,9 & \\
\hline Dezembro & $1,553,0$ & \\
\hline
\end{tabular}


do local, para os anos nos quais o experimento foi condurido. A Figura 1 contém os graficos referentes aos citados balanços hidricos.

\subsection{Características do pomar}

O experimento foi instalado em pomar de laranja 'Pêra do Rio' (Citrus sinensis L. Osbeck) enxertada sobre limoeiro 'Cravo' ( Citrus limonia L. Osbeck), implantado em janeiro de 1988, estando portanto com 3,5 anos, plantado no espaçamento de 8 (oito) metros entrelinhas e 4 (quatro) entre plantas na linha.

\subsection{Caracteristicas dos corretivos}

O calcário empregado no experimento foi caracterizado quanto aos aspectos fisicos e qưmicos com vistas a atender as exigências da legislação em vigor contidas em BRASIl (1986), sendo classificado como dolomitico, bem como o gesso, cujos dados estão na Tabela 5.

\subsection{Variaveis avaliadas}

\subsubsection{Atributos químicos do solo}

As avaliações dos atributos químicos do solo foram feitas através de análises quimicas segundo metodologia de RAIJ \& QUAGGIO (1983), para os seguintes parámetros: $\mathrm{Ca}^{2+}, \mathrm{Mg}^{2+}, \mathrm{K}^{+}, \mathrm{H}^{+}, \mathrm{P}, \mathrm{pH} \mathrm{Cacl}_{2}, \mathrm{Al}$ rocável de acordo com RAIJ \& ZULLO (1977) e $\mathrm{S}^{-\mathrm{SO}_{4}}$ conforme VTTI (1989). 


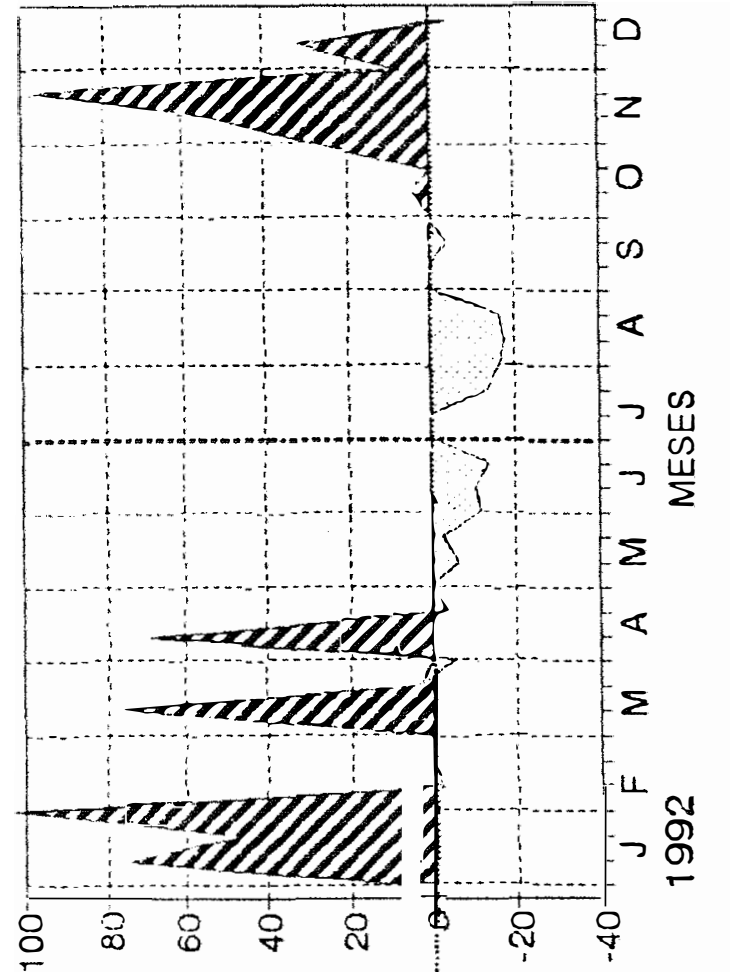

(uu) $\exists \perp N \exists 0 \exists 0 \times \exists: 01 \exists \exists 0$

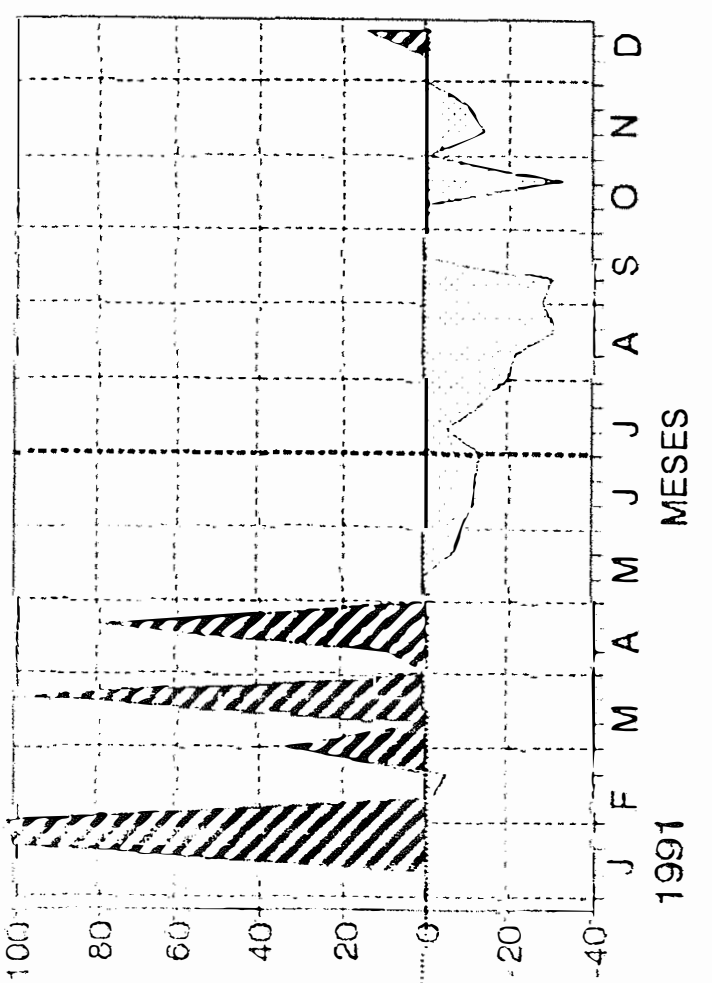

(uru) $\Xi L N \exists C \exists O X \exists$ O

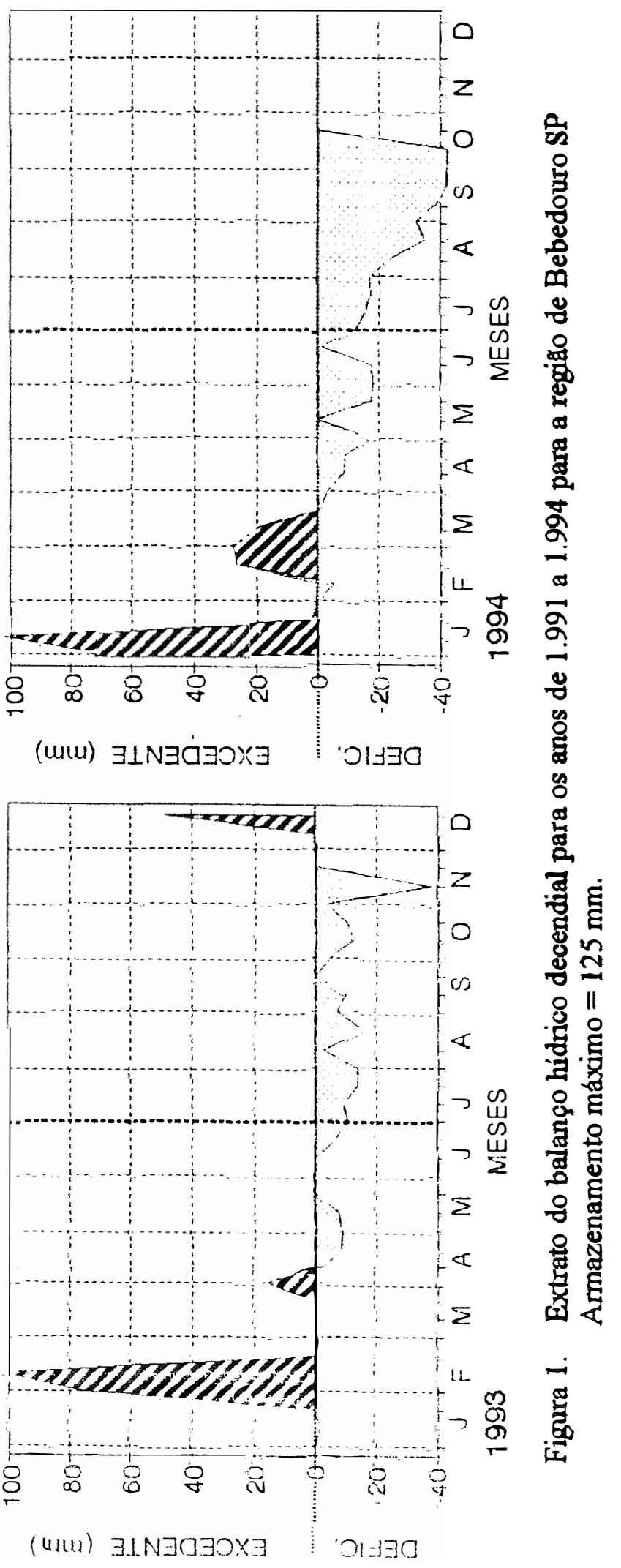



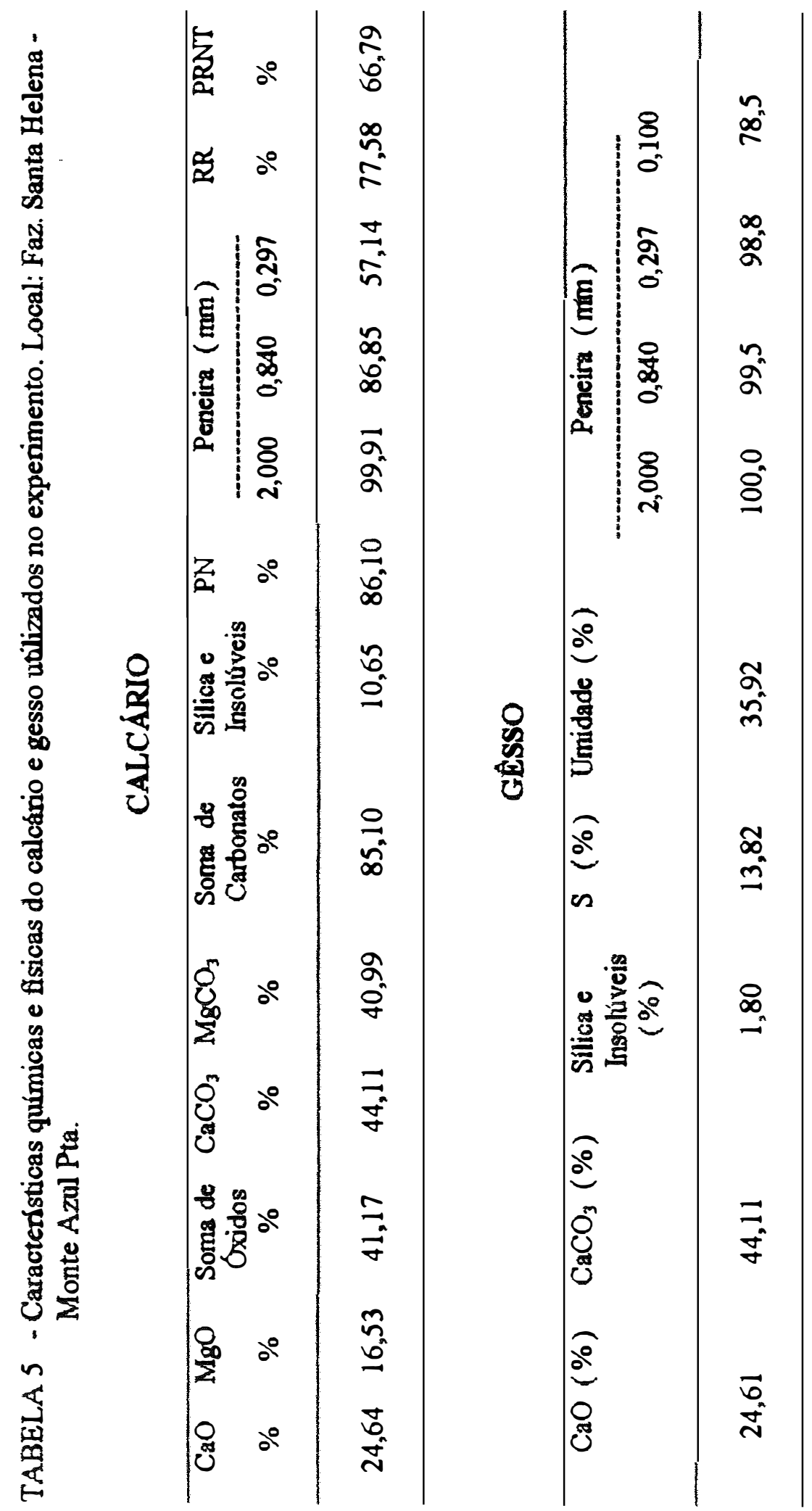
A partir da determinação desses atributos do solo, calcularam -se as relações $\mathrm{Ca} / \mathrm{Mg}, \mathrm{Ca} / \mathrm{K}, \mathrm{Ca}+\mathrm{Mg} / \mathrm{K}$ e os valores da saturação por bases - V\%.

As amostras de solo a serem analisadas, foram retiradas em dois locais nas parcelas, ou seja na projeção da copa e no centro das entrelinhas. Para cada local a amostragem foi conduzida considerando-se trés camadas em profundidades: 0 a 20; 20 a 40 e 40 a $60 \mathrm{~cm}$. Foram realizadas duas épocas de amostragem do solo, sendo a primeira cerca de 6 meses após a aplicação do calcário (maŗo/92), e a segunda um ano após a primeira (abril/93), ou seja 18 meses após a aplicação.

\subsubsection{Atributos de planta}

Como atributos de planta, foram avaliados os seguintes parâmetros:

- produçăo de frutos; obtido para cada parcela, a partir da massa colhida pela sua respectiva área em $\mathrm{kg} / \mathrm{ha}$. Foram realizadas duas colheitas por safra, sendo a primeira em agosto, que vem a ser a principal, e a outra em março/abril que é tida como "temporă", considerando-se tratar da variedade Pera Rio. Os valores obtidos nas duas épocas por safra foram somados afim de se obter a produção anual, que foi utilizada para a realização das análises estatísticas. As safras colhidas foram as de 92/93, 93/94 e 94/95, respectivamente os anos de 1992, 1993 e 1994, sendo portanto aos 4,5 e 6 anos de idade do pomar,

- andilises tecnológicas; foram realizadas para avaliar as caracteristicas quimicas e fisicas dos frutos a saber: massa e tamanho, percentagem de suco, Brix ( \%), acidez ( \%) e Ratio. Para a realização das análises tecnológicas, colheu-se uma amostra de 10 (dez) frutos por parcela, sendo determinada a massa e as dimensões do diâmetro e altura (ou 
comprimento). Após tal procodimento, fez-se a extração do suco, com vista a obter a porcentagem de suco extraído - \%suco, o que foi feito através de espremedor elétrico nas duas primeiras safras e por meio de extratora na última. De posse do suco, determinou-se o Brix por meio de refratômetro e a acidez por titulação segundo MENDES (1976). Quanto às épocas de análise, seguiu-se as da colheita principal da Pera Rio (agosto), sendo feita nas três safras collhidas;

- anslise foliar; feita segundo as recomendações de BATAGLIA et al.. (1983), para N, P, $\mathrm{K}, \mathrm{Ca}, \mathrm{Mg}$ e S, sendo a amostragem executada em ramos com frutos de diâmetro de 2 a $4 \mathrm{~cm}$, na altura mediana da planta, coletando $03^{\text {o }}$ e $4^{\underline{0}}$ pares de folhas, nos quatro quadrantes da planta em conformidade com as recomendações do GRUPO PAULISTA DE ADUBAÇÃO E CALAGEM PARA CITROS (1990).A amostragem para a analise foliar foi feita em duas épocas, seguindo as mesmas adotadas para a determinação dos atributos quifmicos do solo.

\subsubsection{Atributos da aplicaçæo de calćário}

Para avaliar os parametros da aplicação de calcário utilizou-se da metodologia sugerida por CERQUEIRA LUZ \& TOURNO (1986) para coleta e análise do perfil transversal da aplicaçăo à campo, sendo verificados: taxa de aplicaçăo, coeficiente de variação e simetria, sendo esse último calculado segundo a Eq. (1). Essa metodologia consta da colocação de caixas coletoras $(0,3 \times 0,5 \mathrm{~m})$ dispostas transversalmente (perpendicularmente) ao eixo de aplicação do trator mais aplicador, como pode ser observado na FIGURA 2. Cabe comentar que o esquema de sobreposição entre as 

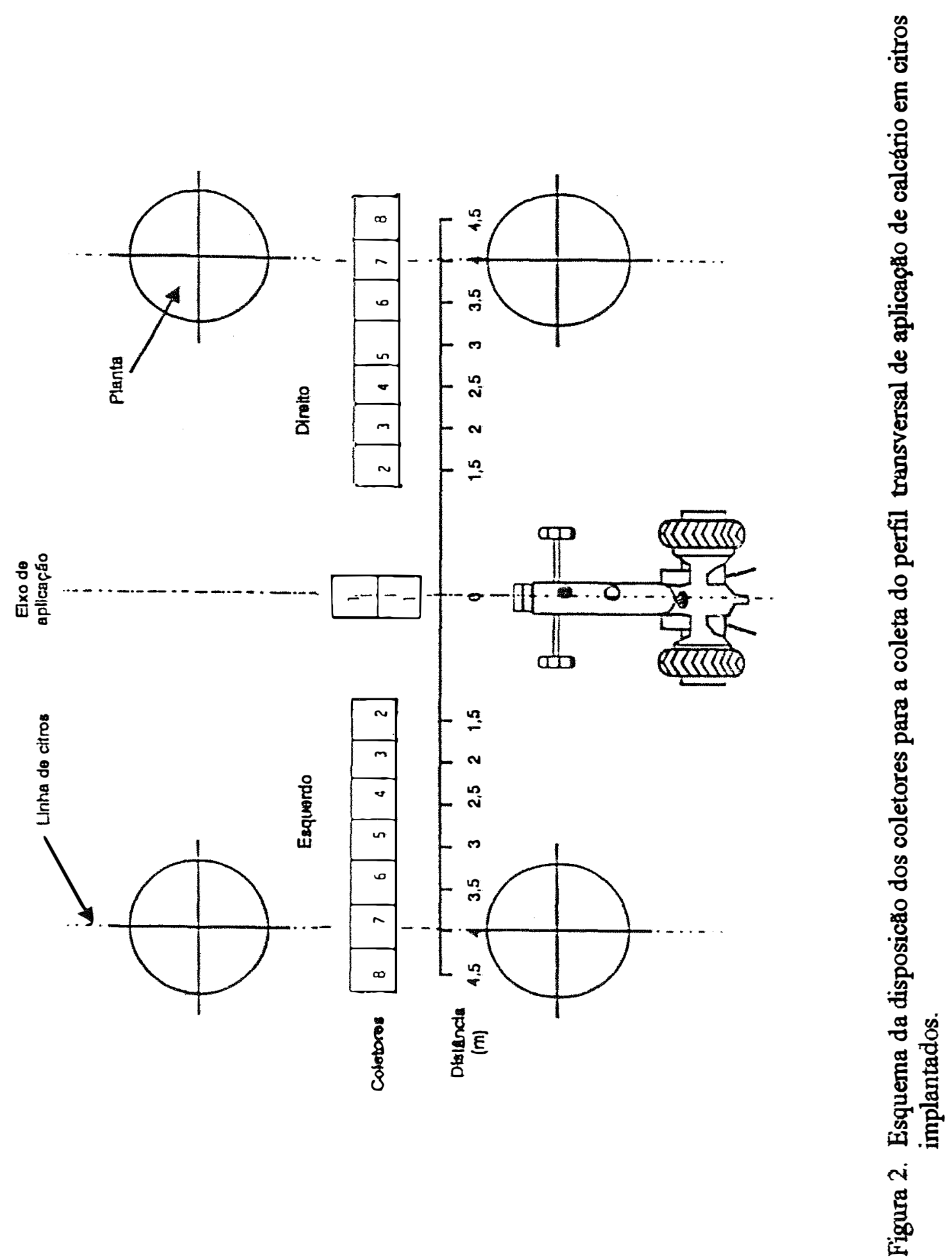
passadas do conjunto mecanizado, no caso de citros, fica condicionado a um esquema fixo, que é decorrente do espaçamento entrelinhas.

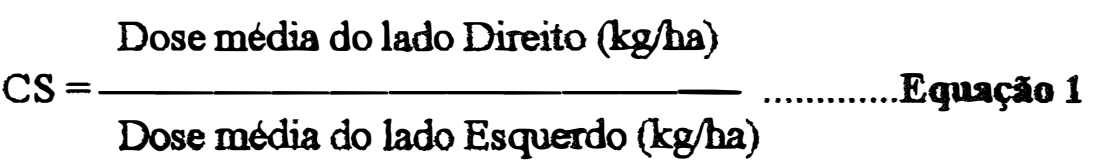

Além desses aspectos, foi também avaliada a segregação, uma vez que o calcário empregado apresenta variaç̃̃es granulométricas. Desta forma foram feitas análises granulométricas para as amostras coletadas no perfil transversal de aplicação, seguindo o mesmo procedimento metodológico já citado. A análise granulométrica foi conduzida segundo as exigências da legislação em vigor ( BRASIL 1986).A partir dos resultados de gramulometria, foram calculadas a Reatividade Relativa, e posteriormente o PRNT, de acordo com os procedimentos que constam na citada legislação.

\subsection{Delineamento experimental das parcelas}

O delineamento experimental adotado foi o de blocos ao acaso, com os tratamentos dispostos no esquema fatorial $3 \times 2 \times 2$, com 4 (quatro) repetições. Os fatores estudados com os respectivos niveis foram:

a) Modo de aplicação - " $A$ " (3 niveis):

A.1 - Aplicação a lanço;

A.2 - Aplicação em faixa;

A.3 - Sem calcário (testemunha) 
b) Gessagem - "G”(2 niveis):

G.1 - Com gesso;

G.2 - Sem gesso;

c) Incorparzção - "T"(2 níveis):

I.1 - Com grade de disco;

I.2 - Sem incorporação

\subsubsection{Fatores}

\subsubsection{Modos de aplicação do calcário}

O modo de aplicação a lanço visa a distribuição do produto sobre toda a área do pomar, enquanto que o em faixa proporciona a aplicação em apenas uma parte da área, que corresponde a uma fração do espaçamento entrelinhas, o que pode ser determinado,

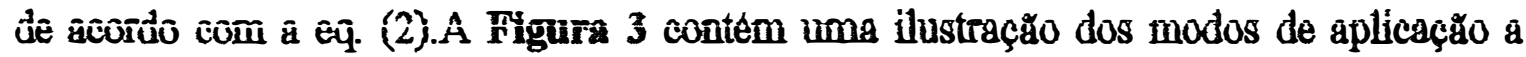
lanço e em faixas que podem ser usados em citros.

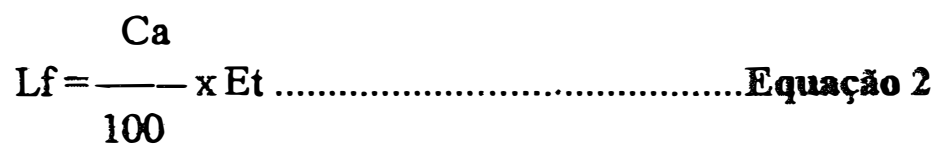

onde;

$$
\begin{aligned}
& \mathrm{Lf}=\text { largura da faixa }(\mathrm{m}) \\
& \mathrm{Ca}=\text { Coeficiente de Aplicação }(\%) \\
& \mathrm{Et}=\text { Espaçamento entrelinhas }(\mathrm{m})
\end{aligned}
$$

No expenimento em questão, considerando-se a idade do pomar e o espaçamento entrelinhas, adotou-se um coeficiente de aplicação de $50 \%$, ou seja uma largura da faixa de aplicação de 4,0 (quatro) metros por linha de plantas, ou seja 2,0 (dois) metros de distância do tronco. Como consequência da escolha do coeficiente de aplicação, se obteve 
A) A lanso.

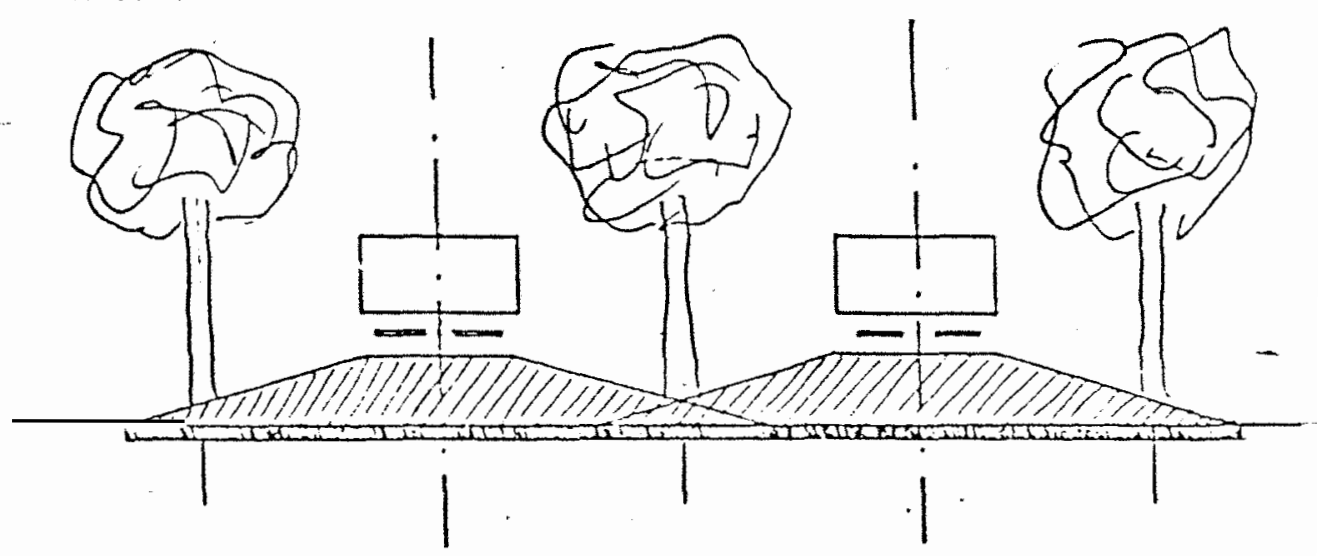

(1) Em.faixa.

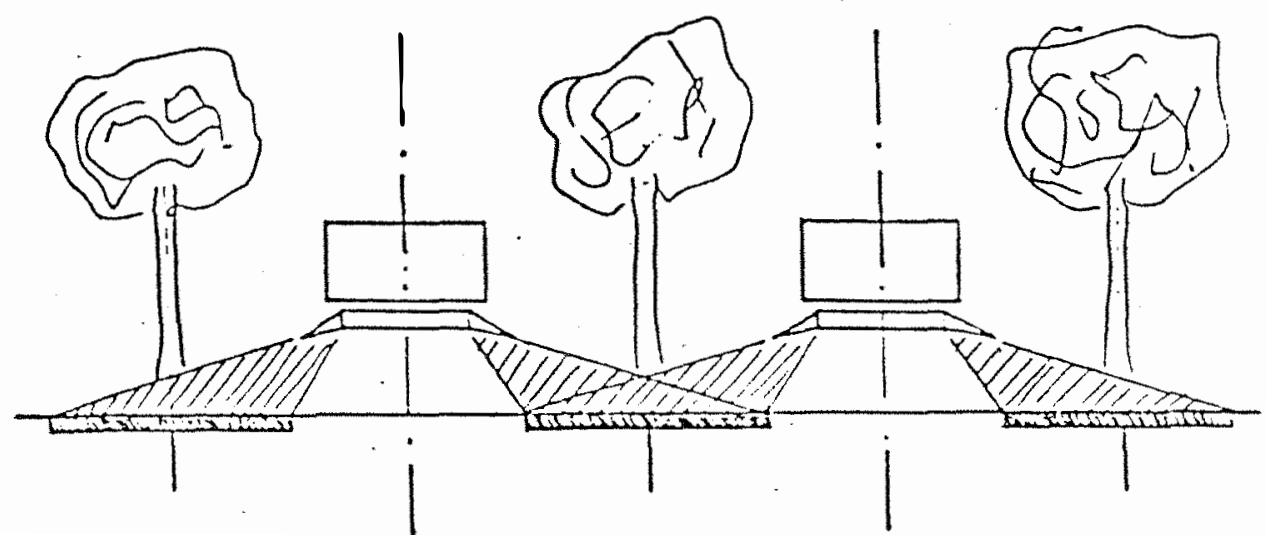

FIGURA 3. Esquema dos modos de aplicação de calcário a lanço e em faixa em citros. 
a área de aplicação, que vem a ser aquela que efetivamente recebeu o produto, de acordo com a eq. (3)

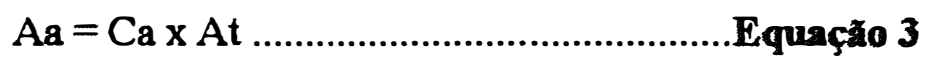

onde;

$$
\begin{aligned}
& \mathrm{Aa}=\text { Area de aplicação (ha); } \\
& \mathrm{Ca}=\text { Coeficiente de aplicação; } \\
& \mathrm{At}=\text { Área total (ha) }
\end{aligned}
$$

No presente experimento a área de aplicação foi de $0,5 \mathrm{ha}$, o que representa a distribuição do corretivo em apenas metade da área (50\%). Como a dose é obtida da razão entre a quantidade aplicada ( em massa ou volume) pela área de aplicação, conforme eq. (4), nesse caso para se alcançar na faixa de aplicaçăo $(4,0 \mathrm{~m})$ a dose recomendada $(2,10 t / h a)$, que é normalmente feita para unidades de área total ( ha ou alq), a quantidade a ser distribuida deveria ser de $1,05 \mathrm{t}$, que corresponde à metade daquela que se empregaria na aplicação a lanço, conforme Quadro 1. Todavia, de acordo com CERQUEIRA LUZ et al. (1993), a redução da quantidade a ser aplicada por área na aplicação em faixa não é diretamente proporcional a área, pois o aplicador de corretivo do tipo a lanço, mesmo com dispositivo para direcionar a distribuição em faixa, não aplica unicamente na faixa selecionada, o que requer a adequação da quantidade a ser colocada por área, que segundo testes dos referidos autores, para condiçð̃es semelhantes a do experimento, é de $2 / 3$ da dosagem recomendada para a área total. Desta forma, para o modo de aplicação em faixa, deveria ser aplicada uma quantidade de 1,40t/ha, para equivaler a dose recomendada para a área total que foi de 2,10tha. 


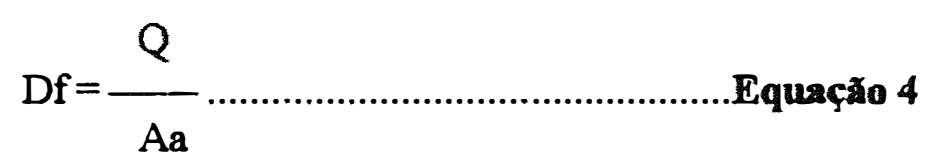

onde;

$$
\begin{aligned}
& \mathrm{Df}=\text { dose na faixa (tha); } \\
& \mathrm{Q}=\text { quantidade }(\mathrm{t}) ; \\
& \mathrm{Aa}=\text { área de aplicação (ha) }
\end{aligned}
$$

Para a aplicação a lanço do calcário utilizou-se de um aplicador de corretivo com mecanismo distribuidor do tipo pendular, com pêndulo convencional com defletor terminal e dosador gravitacional, de acordo com a classificação contida em MILLHE (1986), cuja ilustração consta da Figura 4, tracionado por um trator com $61 \mathrm{cv}$ de

\begin{tabular}{|c|c|c|c|c|c|}
\hline $\begin{array}{l}\text { Modo de } \\
\text { aplicação }\end{array}$ & $\begin{array}{c}\text { Largura da } \\
\text { faixa }\end{array}$ & $\begin{array}{l}\text { Coeficiente } \\
\text { de aplicação }\end{array}$ & $\begin{array}{c}\text { Area } \\
\text { aplicada }\end{array}$ & $\begin{array}{c}\text { Quantidade } \\
\text { total }\end{array}$ & $\begin{array}{l}\text { Recomendação } \\
\text { de calagem }\end{array}$ \\
\hline & (m) & & (ba) & $(\mathrm{t})$ & (t/ha) \\
\hline a lanço & 8,0 & 1,0 & 1,0 & 2,1 & 2,1 \\
\hline em faixa & 4,0 & 0,5 & 0,5 & 1,05 & 2,1 \\
\hline
\end{tabular}
potencia no motor, passando-se uma vez por entrelinha.

QUADRO 1. Caracteristicas dos modos de aplicação de calcário.

A aplicação em faixa foi feita com o mesmo aplicador, porem utilizando-se um pêndulo curto seccionado, indicado para esse tipo de aplicação, para direcionar o produto 


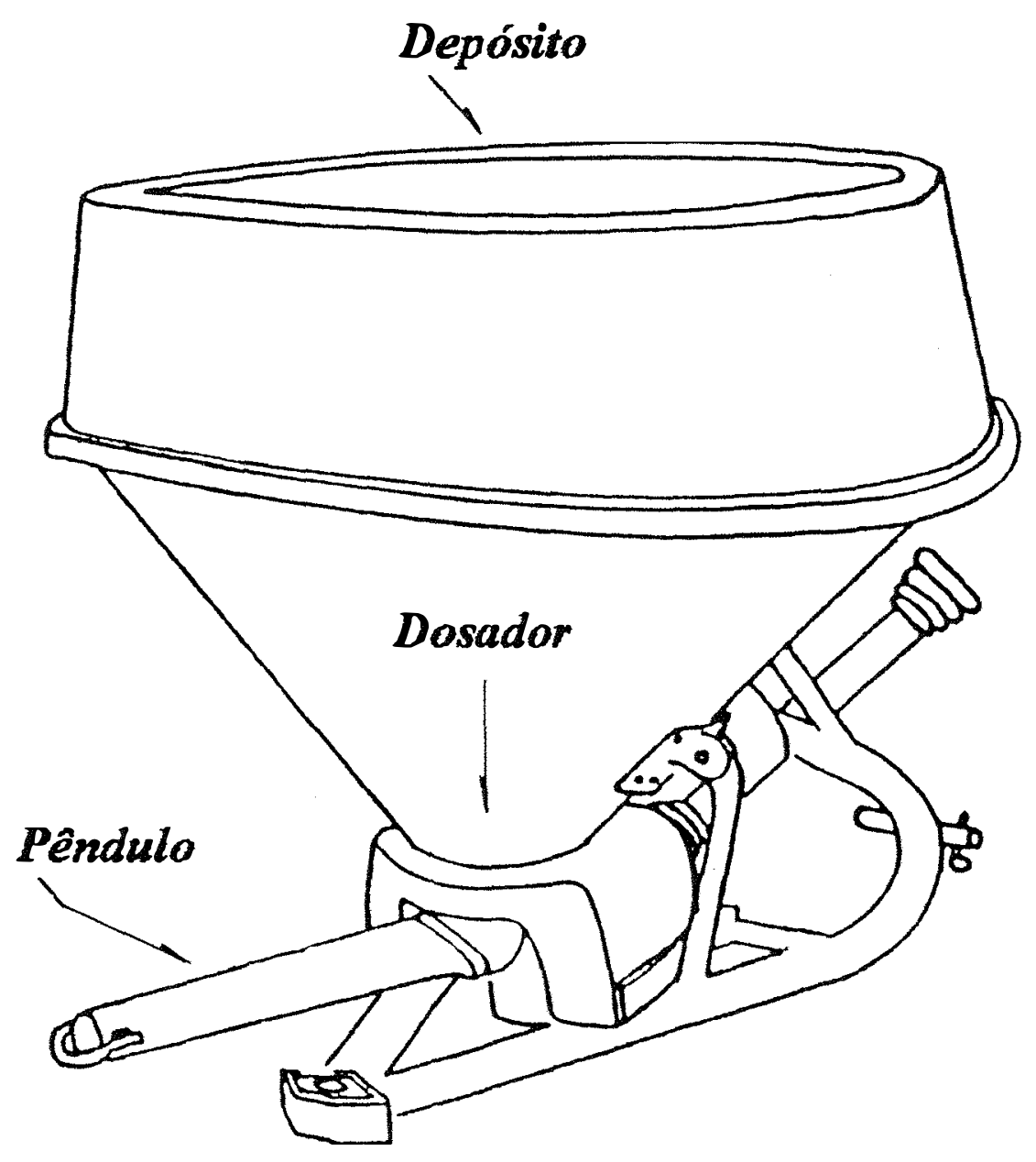

Fonte: CERQUEIRA LUZ (1989)

FIGURA 4. Ilustração do aplicador de corretivo com mecanismo ditribuidor tipo pendular usado na aplicação de calcário. 
na faixa de aplicação selecionada, sendo tracionado pelo mesmo trator do tratamento a lanço, porém passando-se duas vezes por entrelinha, pelo fato do pêndulo direcionar o produto apenas para um dos lados.

\subsubsection{Gessagem}

A gessagem foi feita com um aplicador de corretivo, segundo MIILHE (1986), com distribuidor tipo centrifugo com dois discos e dosador vohmétrico tipo esteira, fazendo-se a aplicação a lanço em área total. A fonte de potência usada foi a mesma dos tratamentos de distribuição do calcário. $\mathrm{Na}$ Figura 5 pode-se observar um esquema desse aplicador. A aplicação do gesso foi levada a efeito antes da distribuição do calcário bern como da incorparação.

\subsubsection{Incorporaçẫo}

Para possibilitar a incorporação dos corretivos usou-se uma grade de discos com 2 seções, com protetor lateral do lado direito, compostas de 10 discos de $16^{\prime \prime}$ cada, espaçados a $185 \mathrm{~mm}$, com uma massa total de $390 \mathrm{~kg}$, sendo portanto $19,5 \mathrm{~kg} / \mathrm{disco}$, com uma largura de corte de $1,7 \mathrm{~m}$, implicando na necessidade de se passar duas vezes por entrelinha, estando de acordo com as caractensticas citadas por SILVEIRA (1990) para esse tipo de equipamento. A incorporação que esse equipamento proporcionou foi superficial, atuando por cerca de 8 a $10 \mathrm{~cm}$ de profundidade, promovendo a mistura do corretivo com o solo, bem como o nivelamento da superticie. A incorporação dos produtos foi realizada imediatamente após a aplicação de ambos. 


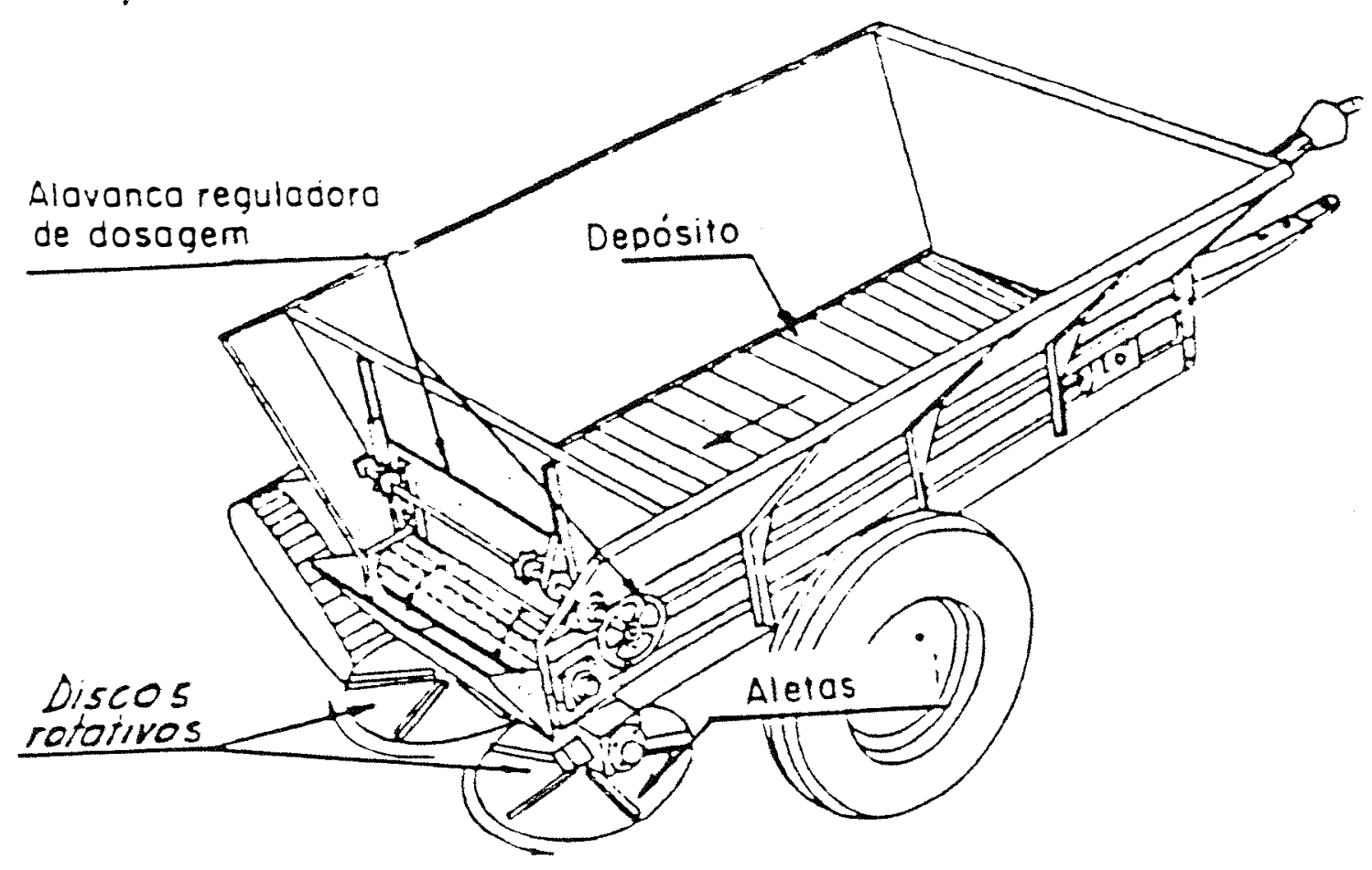

Fonte: MLALHE (1986)

FIGURA 5. Tlustraçăo do aplicador de corretivo com mecanismo distribuidor tipo centrifugo com dois discos usado na aplicaçăo do gesso. 


\subsubsection{Tratamentos}

Considerando-se a combinação dos fatores Aplicação, Gessagem e Incorporação, obteve-se os tratamentos colocados na Tabela 6, os quais para serem distribuidos dentro dos blocos, foram sorteados.

\subsubsection{Parcela}

A Figura 6 contém um esquema da parcela experimental, a qual constou de 3 linhas com 6 plantas cada, totalizando 18 plantas, das quais as 4 plantas da linha central foram consideradas como úteis, adotando uma planta no início e outra no final como bordachra. A área correspondente a cada uma delas foi de $576 \mathrm{~m}^{2}$, totalizando-se uma área total para o experimento de $27.648 \mathrm{~m}^{2}$. As dimensões da parcela são decarrentes do fato das operações de aplicação de calcário e gesso, bem como da incorporação serem realizadas mecanicamente, necessitando portanto de grande espaço para que nåo houvesse interferências de um tratamento sobre outro.

\subsubsection{Esquema de campo}

O esquema de campo é ilustrado na Figura 7, onde pode-se verificar a distribuição dos tratamentos nos blocos após sorteio. 
TABELA 6. Combinação dos fatores Aplicação, Gessagem e Incorpuraçăo para obtenção dos tratamentos.

\begin{tabular}{|c|c|c|c|}
\hline $\begin{array}{l}\text { MODOOS DE } \\
\text { APLICAÇÁO } \\
\text { DE CALCÁRIO }\end{array}$ & FATORES & NCORPORAÇÃO & TRATAMENTO \\
\hline A Lanço & Com & Com & 1 \\
\hline A Lanço & Com & Sem & 2 \\
\hline A Lanço & Sem & Com & 3 \\
\hline A Lanço & Sem & Sem & 4 \\
\hline Em Faixa & Com & Com & 5 \\
\hline Em Faixa & Com & Sem & 6 \\
\hline Em Faixa & Sem & Com & 7 \\
\hline Em Faixa & Sem & Sem & 8 \\
\hline Sem Calcario & Com & Com & 9 \\
\hline Sem Calcário & Com & Sem & 10 \\
\hline Sem Calcário & Sem & Com & 11 \\
\hline Sem Calcário & Sem & Sem & 12 \\
\hline
\end{tabular}




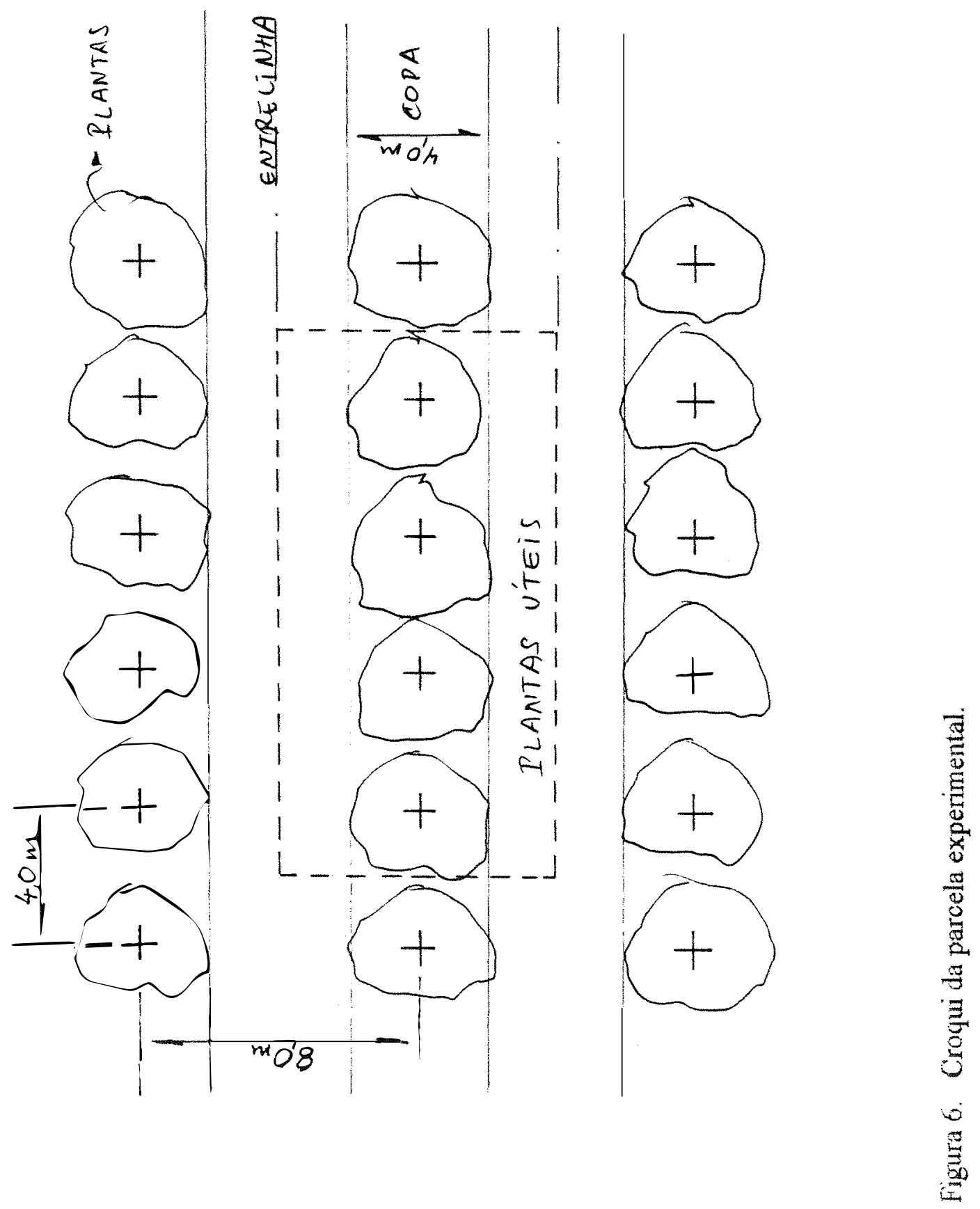




\begin{tabular}{|c|c|c|c|}
\hline a & $n$ & $m$ & $n$ \\
\hline $\mathrm{N}$ & $\sim$ & 0 & $\nabla$ \\
\hline 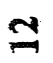 & $r$ & $=$ & 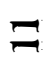 \\
\hline- & -1 & n & 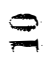 \\
\hline$\vec{\nabla}$ & $\infty$ & $\Xi$ & $a$ \\
\hline$\stackrel{\ominus}{ }$ & $n$ & $\nabla$ & $m$ \\
\hline$n$ & $\Xi$ & r & $\Rightarrow$ \\
\hline$\Xi$ & 기 & 二 & $\infty$ \\
\hline$\infty$ & $\infty$ & $a$ & $r$ \\
\hline m & a & 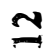 & $\leadsto$ \\
\hline 0 & $T$ & $\infty$ & $\infty$ \\
\hline in & $\equiv$ & N & $\stackrel{2}{7}$ \\
\hline$=$ & $\Xi$ & $=$ & - \\
\hline
\end{tabular}

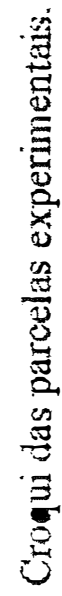

$\frac{0}{6}$

焉 


\subsubsection{Anślise estatística}

Os dados relativos às analises foliares foram estudados seguindo-se 0 delineamento proposto conforme esquema apresentado no Quadro 2.

QUADRO 2. Esquema da análise de variância para as variáveis das análises foliares

\begin{tabular}{|c|c|}
\hline Causa de variação & G.L. \\
\hline 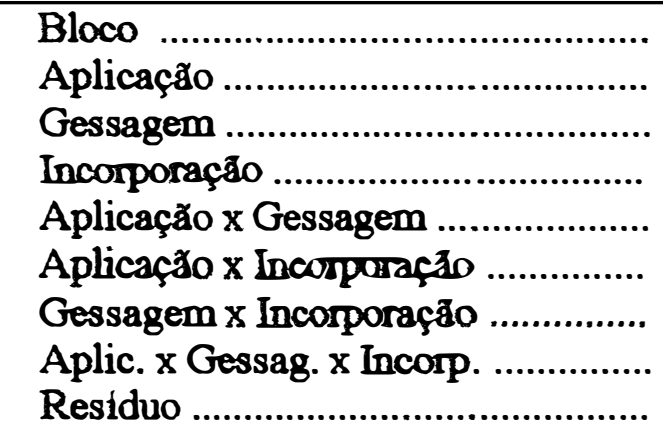 & $\begin{array}{c}3 \\
2 \\
1 \\
1 \\
2 \\
2 \\
1 \\
2 \\
33\end{array}$ \\
\hline 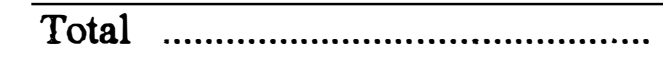 & 47 \\
\hline
\end{tabular}

Por outro lado, os dados relativos à produção e às variáveis tecnológicas dos frutos foram analisados seguindo o esquema em parcelas subdivididas no tempo, de acordo com o Quadro 3.

Para os dados referentes aos atributos químicos do solo foi adotado o esquema de análise em parcelas sub-sub-divididas, considerando-se o fator local designado às subparcelas e o fator profundidade às sub-sub-parcelas, como pode ser visualizado no Quadro 4. 
QUADRO 3. Esquema da análise de variância para as variáveis de prođuçăo e análises tecnológicas dos frutos.

\begin{tabular}{|c|c|}
\hline Causa de variação & G.L. \\
\hline Bloco ............................................... & 3 \\
\hline 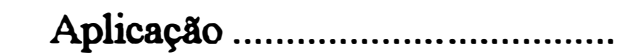 & 2 \\
\hline 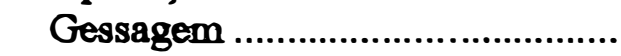 & 1 \\
\hline 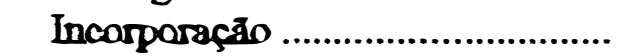 & 1 \\
\hline Aplicaçåo x Gessagem .................. & 2 \\
\hline Aplicação x Incorporação ............ & 2 \\
\hline Gessagem x Incorporação ............ & 1 \\
\hline Aplic. x Gessag. x Incorp. ........... & 2 \\
\hline 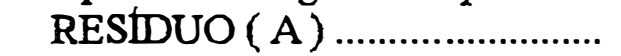 & 33 \\
\hline Safra & 2 \\
\hline Safra x Aplicação ........................ & 4 \\
\hline Safra x Gessagem ........................ & 2 \\
\hline Safra x Incorporação ................... & 2 \\
\hline Safra x Aplic. x Gessag. ............ & 4 \\
\hline Safra x Aplic. x Incorp. ............. & 4 \\
\hline Safra x Gessag. x Incorp. .......... & 2 \\
\hline Safra x Aplica x Gessag x Incorp & 4 \\
\hline 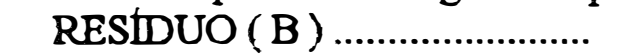 & 72 \\
\hline TOTAL $\ldots \ldots \ldots \ldots \ldots \ldots \ldots \ldots \ldots \ldots \ldots \ldots$ & 143 \\
\hline
\end{tabular}


QUADRO 4. Esquema de análise de variância para os atributos quimicos do solo.

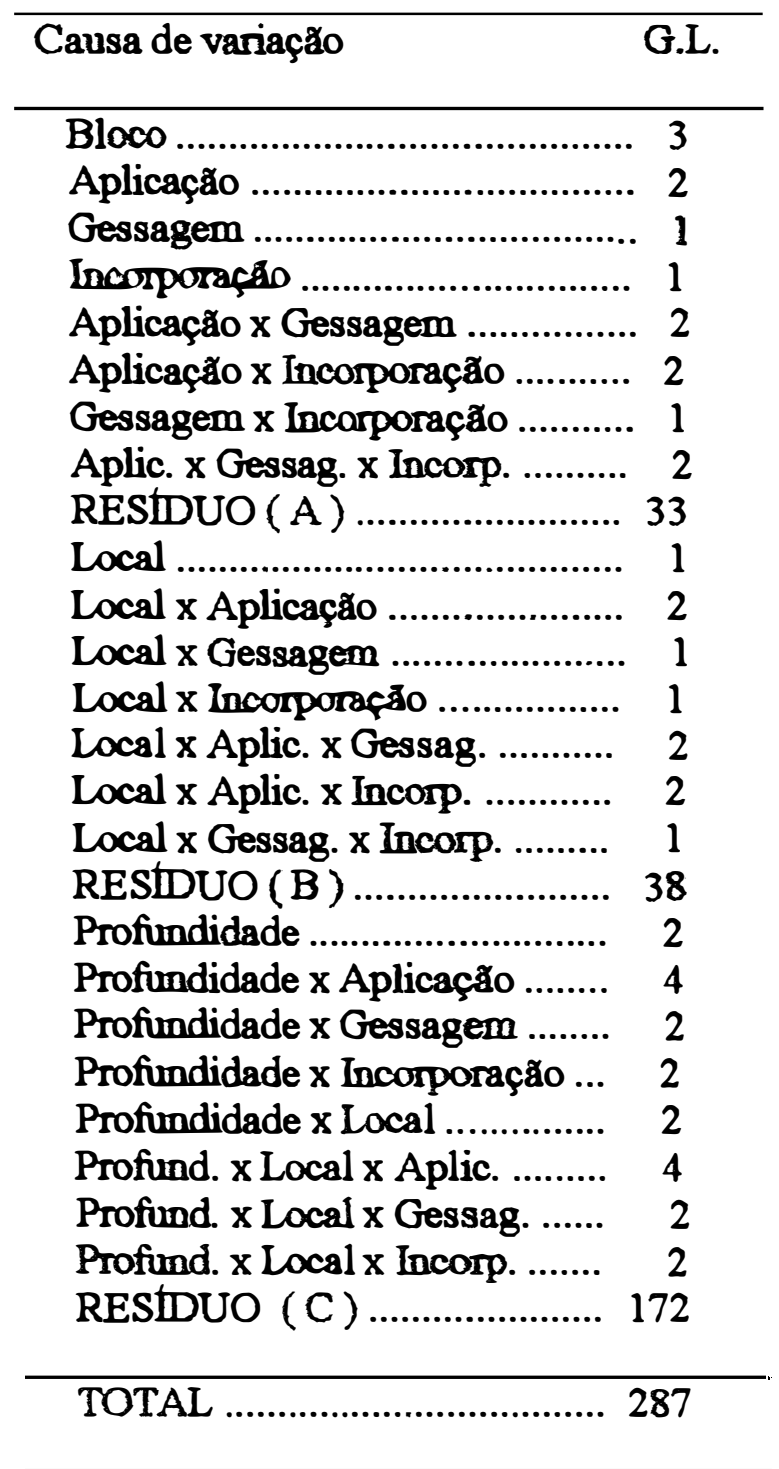

\subsection{Instalação e condução do experimento}

O experimento foi instalado em setembro de 1991 e conduzido até agosto de 1994, sendo que as atividades nele realizadas constam do cronograma colocado na Tabela 7. 
A condução do pomar no local do ensaio, no tocante a plantas daninhas, foi feita mediante o controle quimico através do uso de herticidas ou por meio de roçadora. Quanto ao controle fitossanitário, seguiu-se as recomendaçðes utilizadas normalmente sem interferências. A adubaçăo dos citros levou em conta as necessidades do pomar, bem como as caracteristicas do solo, preocupando-se com as épocas de aplicação. 
TABELA 7. Cronograma das atividades realizadas no experimento de "Efeitos de modos de aplicação e incorporação de calcário e gesso em pomares de citros". Local: Faz. Santa Helena - Monte Azul Paulista - SP.

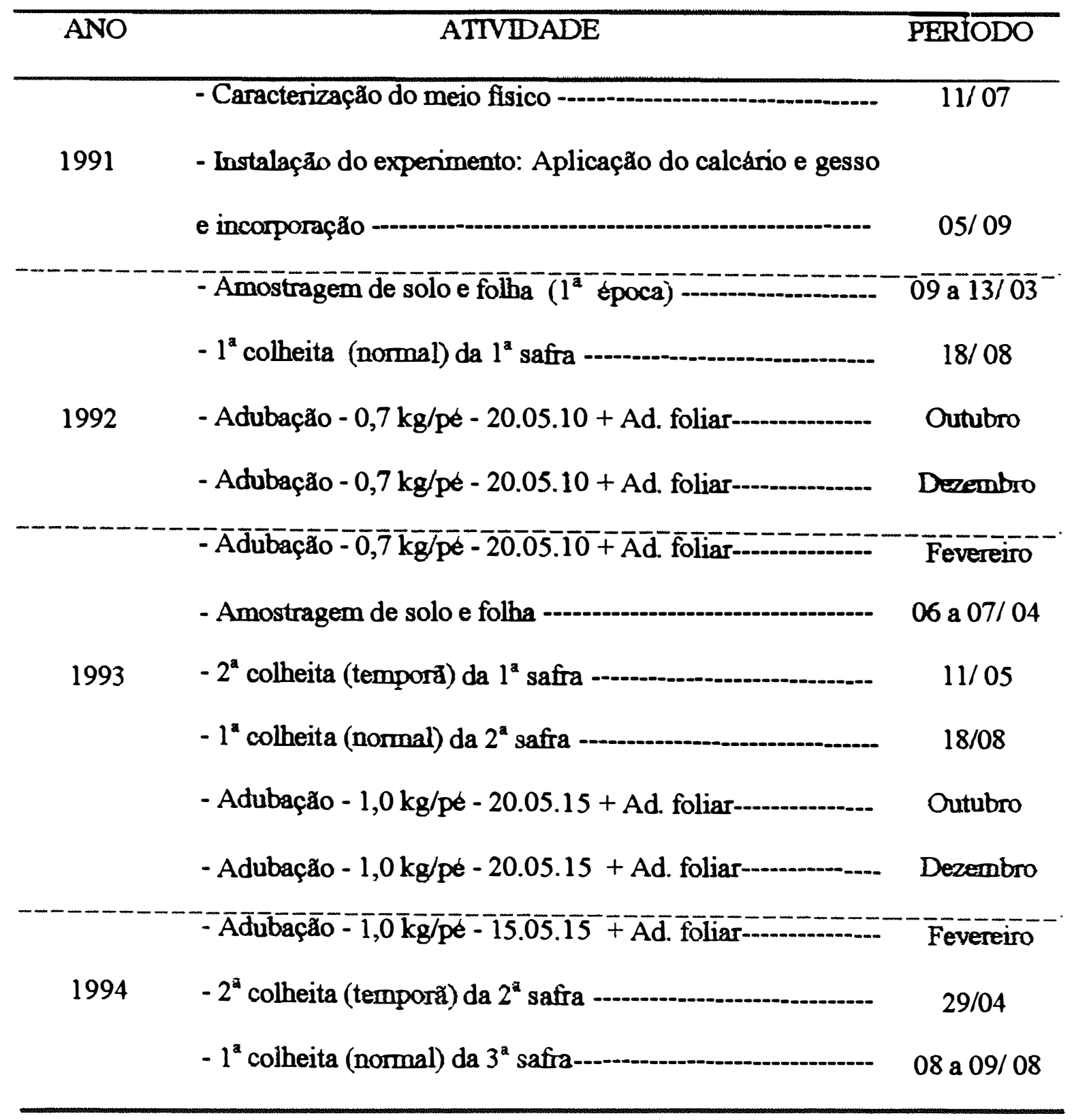




\section{RESULTADOS E DISCUSSÃO}

\subsection{Perfil transversal dos modos de aplicação do calcário}

Os valores obtidos para os perfis transversais de aplicação para os dois modos testados estão nas Tabelas 8 e 9, respectivamente para o a lanço e o em faixa. Observando-as, nota-se para o modo a lanço uma media geral de 1,85 tha para a dose do calcário e de 1,68 tha para o em faixa, estando respectivamente $12,0 \%$ e $20,0 \%$ abaixo da dose recomendada que era de 2,10 tha.

Considerando-se a posição da aplicação do calcário, ou seja a faixa (distando 2,0 $\mathrm{m}$ do tronco de cada lado) e o centro (sendo os 4,0 m centrais da entrelinha), percebese que para o modo em faixa, a dose na faixa (Coeficiente de Aplicação de 50\%), que é a zona de interesse, foi de 2,09 tha, atingindo a dose recomendada, enquanto que no centro foi de 1,18 tha, posição na qual o objetivo era minimizar a dosagem. Por outro lado, na aplicação a lanço, em termos gerais, a dose alcançada na faixa foi de 1,21 tha e no centro de 2,49 tha estando respectivamente $42,3 \%$ abaixo e $18,6 \%$ acima da dose recomendada, comportando-se de maneira oposta à aplicação em faixa ou seja, 
TABELA 8. Pertil transversal de aplicação de calcario para o método a lanço.

\begin{tabular}{|c|c|c|c|c|c|c|c|}
\hline LADO & COLETOR & $\begin{array}{l}\text { Disthmcia } \\
\text { (m) }\end{array}$ & $\begin{array}{l}\text { Dados Básicos } \\
\text { (Mr) }\end{array}$ & $\begin{array}{l}\text { Sobreposi } \\
\text { EAE I }\end{array}$ & $\begin{array}{l}\text { Siçădo } \\
\text { D/D }\end{array}$ & $\begin{array}{l}\text { Perfil Trans } \\
\text { versal (tha) }\end{array}$ & $\begin{array}{l}\text { Médias } \\
\text { (Uha) }\end{array}$ \\
\hline & & 8,0 & & 2,65 & & 2,65 & \\
\hline & & 6,5 & & 2,95 & & 2,95 & \\
\hline E & & 6,0 & & 2,36 & & 2,36 & \\
\hline $\bar{s}$ & $\overline{8} \bar{E}$ & 5,5 & 0,01 & 2,97 & & 2,98 & \multirow{7}{*}{ Faixa $=1,53$} \\
\hline $\mathrm{Q}$ & & 5,0 & & 1,27 & & 1,27 & \\
\hline U & $7 \mathrm{E}$ & 4,5 & 0,03 & 0,31 & & 0,34 & \\
\hline $\mathbf{E}$ & & 4,0 & & & & & \\
\hline $\mathbf{R}$ & $6 \mathrm{E}$ & 3,5 & 0,31 & 0,03 & & 0,34 & \\
\hline D & $5 E$ & 3,0 & 1,27 & & & 1,27 & \\
\hline O & $4 \mathrm{E}$ & 2,5 & 2,97 & 0,01 & & 2,98 & \\
\hline & $3 \bar{E}$ & 2,0 & 2,36 & & & 2,36 & \multirow{3}{*}{ centro $=2,65$} \\
\hline & $2 \mathrm{E}$ & 1,5 & 2,95 & & & 2,95 & \\
\hline & $1 \mathrm{E}$ & 0,0 & 2,65 & & & 2,65 & \\
\hline & 1D & 0,0 & 2,65 & & & 2,65 & \multirow{3}{*}{ centro $=2,33$} \\
\hline & 2D & 1,5 & 2,21 & & & 2,21 & \\
\hline & 3D & 2,0 & 2,13 & & & 2,13 & \\
\hline $\mathrm{D}$ & $4 \bar{D}$ & 2,5 & 1,74 & & 0,01 & 1,75 & \multirow{7}{*}{ Faira $=0,88$} \\
\hline I & $5 \mathrm{D}$ & 3,0 & 0,64 & & & 0,64 & \\
\hline $\mathbf{R}$ & 6D & 3,5 & 0,22 & & 0,02 & 0,24 & \\
\hline $\mathrm{E}$ & & 4,0 & & & & & \\
\hline I & $7 \mathrm{D}$ & 4,5 & 0,02 & & 0,22 & 0,24 & \\
\hline$T$ & & 5,0 & & & 0,64 & 0,64 & \\
\hline \multirow[t]{4}{*}{$\mathrm{O}$} & $8 \mathrm{D}$ & 5,5 & 0,01 & & 1,74 & 1,75 & \\
\hline & & 6,0 & & & 2,13 & 2,13 & \\
\hline & & 6,5 & & & 2,21 & 2,21 & \\
\hline & & 8,0 & & & 2,65 & 2,65 & \\
\hline $\begin{array}{l}\text { Media } G \\
\text { Metia } G \\
\text { Media } G\end{array}$ & 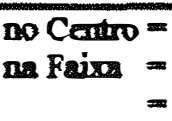 & & & & & $\begin{array}{l}C V=52,8 \% \\
C S=0,77\end{array}$ & \\
\hline
\end{tabular}


TABELA 9. Perfil transversal de aplicacåo para o método em fáxa

\begin{tabular}{|c|c|c|c|c|c|c|c|c|}
\hline Lado & Coletor & $\begin{array}{l}\text { Distincia } \\
\text { (m) }\end{array}$ & $\begin{array}{c}\text { Dados } \\
\text { Basicos } \\
\text { (tha) }\end{array}$ & ED & $\begin{array}{l}\text { Sotrepprigho } \\
\text { D/E }\end{array}$ & D/D & $\begin{array}{c}\text { Perfil } \\
\text { Tansveral } \\
\text { (tha) }\end{array}$ & $\begin{array}{l}\text { Medias } \\
\text { (tha) }\end{array}$ \\
\hline & & 8,0 & & & 0.35 & 0.25 & 0.60 & \\
\hline & & 6,5 & & & 0.13 & 0.65 & 0.78 & \\
\hline E & & 6,0 & & & 0.04 & 2.13 & 2.17 & \\
\hline$s$ & $8 \bar{E}$ & 5.5 & 0.00 & 0.01 & $\overline{0.01}$ & 2.78 & 2.80 & \\
\hline $\mathrm{Q}$ & & 5.0 & & 0.03 & & 2.31 & 2.34 & \\
\hline $\mathrm{U}$ & $7 E$ & 4.5 & $0.00^{\circ}$ & 0.04 & & 1.90 & 1.94 & Faixa $=$ \\
\hline E & & 4.0 & & 0.27 & & 0.27 & 0.54 & 2,09 \\
\hline $\mathbf{R}$ & $6 \mathrm{E}$ & 3.5 & 0.00 & 1.90 & & 0.04 & 1.94 & \\
\hline D & $5 E$ & 3.0 & 0.00 & 2.31 & & 0.03 & 2.34 & \\
\hline \multirow{7}{*}{ O } & 4E & 2.5 & 0.01 & 2.78 & & 0.01 & 2.80 & \\
\hline & $\overline{3} \bar{E}$ & 2.0 & 0.04 & 2.13 & & & 2.17 & \\
\hline & $2 \mathrm{E}$ & 1.5 & 0.13 & 0.65 & & & 0.78 & Centro= \\
\hline & $1 \mathrm{E}$ & 0.0 & 0.35 & 0.25 & & & 0.60 & 1,18 \\
\hline & 1D & 0.0 & 0.25 & 0.35 & & & 0.60 & \\
\hline & $2 \mathrm{D}$ & 1.5 & 0.65 & 0.13 & & & 0.78 & Centro= \\
\hline & $3 \mathrm{D}$ & 2.0 & 2.13 & $\underline{0.04}$ & & & 2.17 & 1,18 \\
\hline D & $\overline{4} \bar{D}$ & 2.5 & 2.78 & 0.01 & 0.01 & & 2.80 & \\
\hline I & 5D & 3.0 & 2.31 & & 0.03 & & 2.34 & \\
\hline $\mathrm{R}$ & $6 \mathrm{D}$ & 3.5 & 1.90 & & 0.04 & & 1.94 & Faixa $=$ \\
\hline E & 7D & 4.0 & 0.27 & & 0.27 & & 0.54 & 2,09 \\
\hline I & 8D & 4.5 & 0.04 & & 1.90 & & 1.94 & \\
\hline $\mathrm{T}$ & 9D & 5.0 & 0.03 & & 2.31 & & 2.34 & \\
\hline \multirow[t]{4}{*}{$\mathrm{O}$} & 10D & 5.5 & 0.01 & & 2.78 & 0.01 & 2.80 & \\
\hline & & 6,0 & & & 2.13 & 0.04 & 2.17 & \\
\hline & & 6,5 & & & 0.65 & 0.13 & 0.78 & \\
\hline & & 8,0 & & & 0.25 & 0.35 & 0.60 & \\
\hline & $\begin{array}{l}\text { Geral in } \\
\text { Geral n } \\
\text { a Geral }\end{array}$ & $\begin{aligned} & =1, \\
& =2,\end{aligned}$ & & & & & $\begin{array}{l}C V=51,39 \\
C S=1,0\end{array}$ & \\
\hline
\end{tabular}


concentrando o calcário aplicado no centro da entrelinha e reduzindo a quantidade na posição da faixa, o que pode ser melhor visualizado nas Figuras 8 e 9, feitas com base nos dados das referidas tabelas. O fato da aplicação em faixa distribuir tambem o produto na entrelinha é importante, visto que as radicelas não se restringem à posição da copa, que detém cerca de 53\% delas, conforme MOREIRA (1983). Esses comentários acerca do cumportamento da aplicação entre os modos em faixa e a lanço, estão de acordo com os resultados obtidos por CERQUEIRA LUZ et al. (1993).

Com relação a quantidade média aplicada, esperava-se 2,10 tha para o modo a lanço e 1,40 tha para o em faixa (2/3 da dosagem recomendada), obtendo-se respectivamente 1,85 tha que ef $11,9 \%$ abaixo e 1,68 tha que e $13,5 \%$ acima da expectativa. Desta forma, o modo em faixa permitiu uma redução de $20 \%$ na quantidade de calcário a ser usado por área, ou seja podendo-se distribuir $80 \%$ ou $4 / 5$ do esperado, sem deixar de aplicar no meio da entrelinha, usando-se um distribuidor pendular, dandose duas passadas por entrelinha. No entanto, os dados de CERQUEIRA LUZ et al. (1993), para um distribuidor centrfugo com dois discos, com uma passada por entrelinha, encontrou $66,6 \%$ ou $2 / 3$ da dose esperada

A dispersão dos valores da dose no perfil transversal de ambos modos foi semelhante, com um Coeficiente de Variação -CV de 52,8 \% para o a lanço e de $51,3 \%$ para o em faixa, ambos altos, quando compara-se com aqueles obtidos por FONTANA \& DALLMEYER (1985), e também por PORTELLA et al. (1993), principalmente para o a lanço, pois para o em faixa, já esperava-se maior valor pelo fato de direcionar o produto em zonas pré estabelecidas. No entanto, é pertinente comentar que nos ensaios desses aplicadores utilizou-se o critério para o ponto de sobreposicão, 50\% do máximo valor 


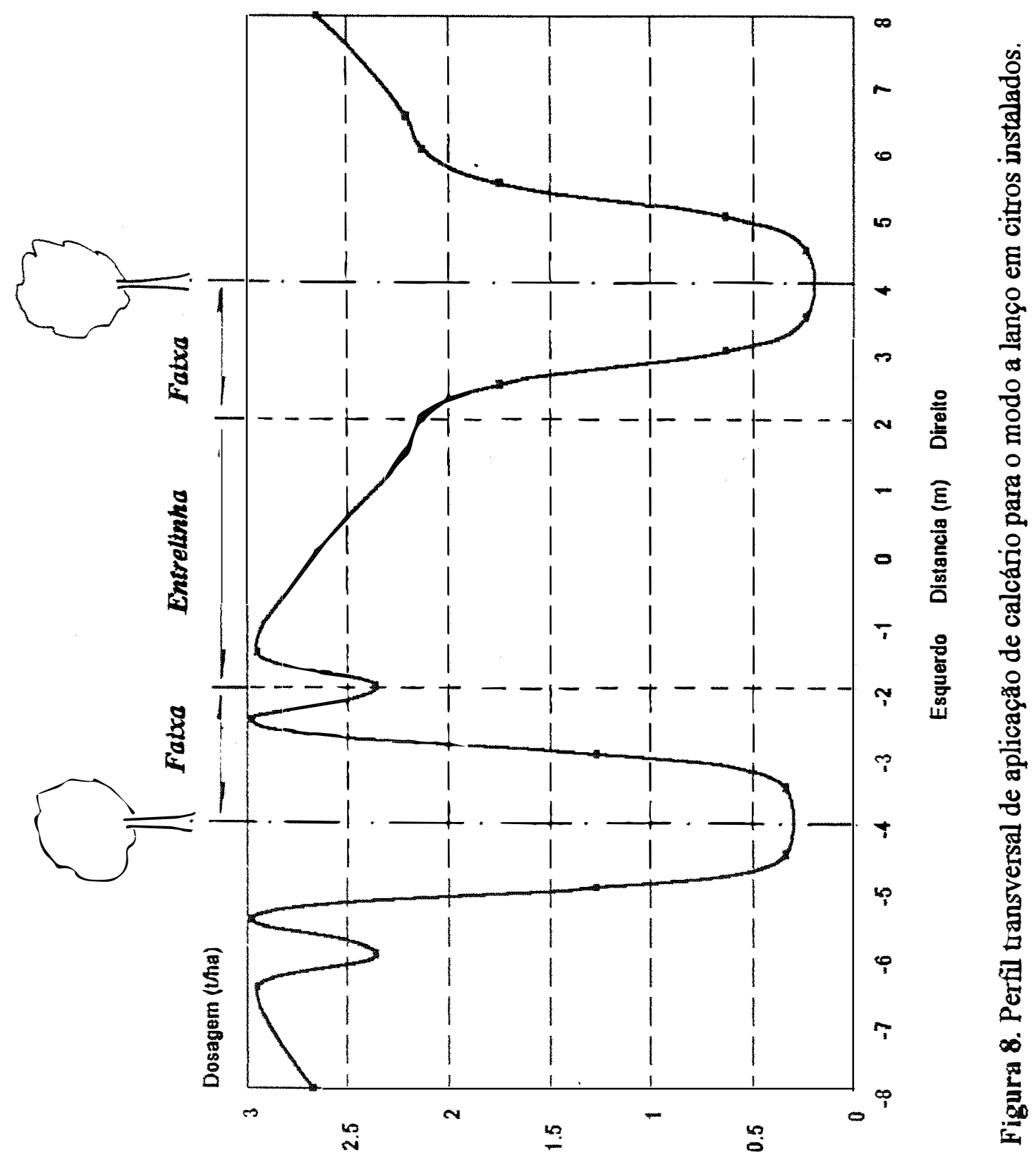




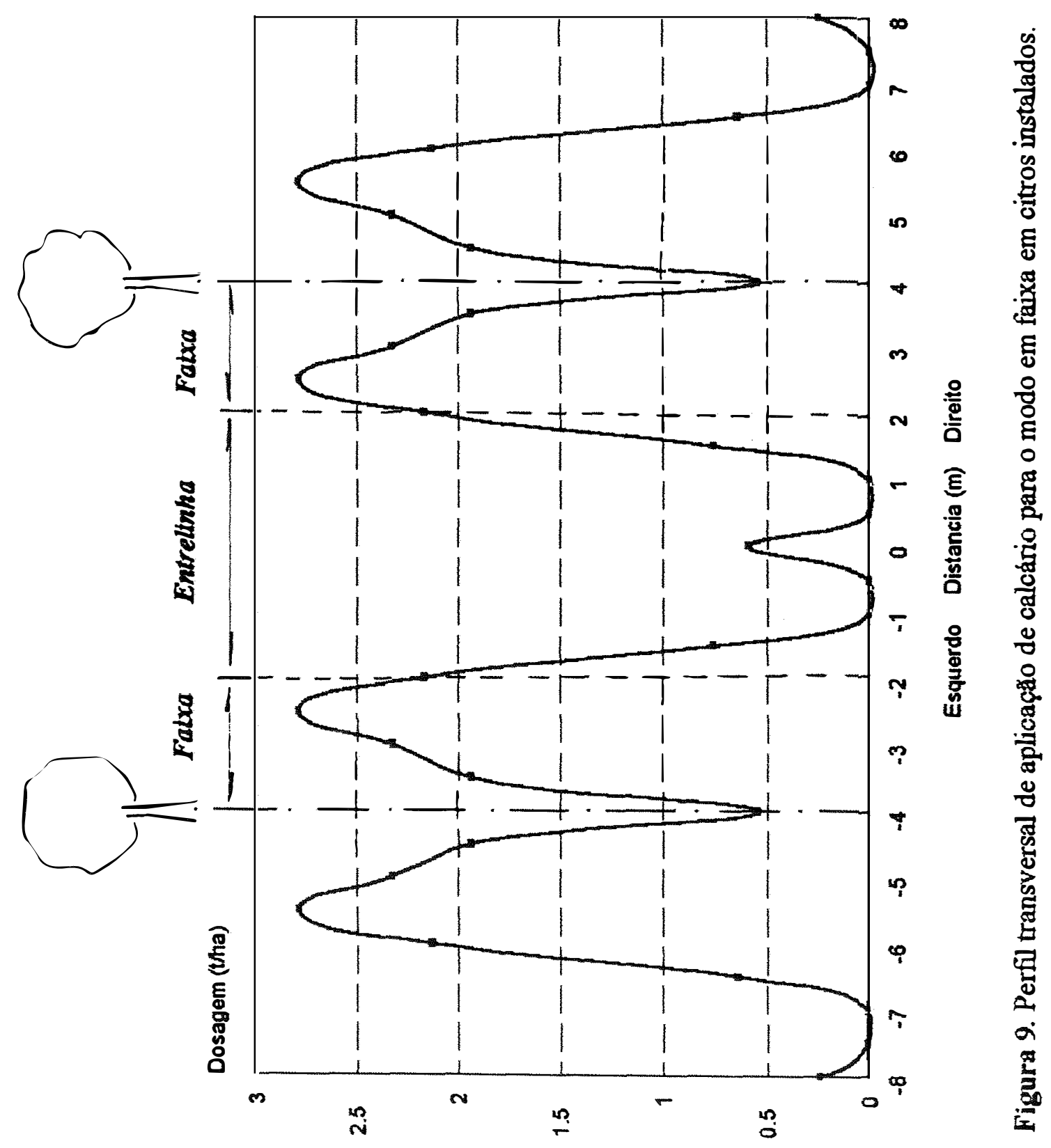


obtido no perfil transversal, o que definirá o espacamento entre as passadas largura de trabalho). No caso do presente experimento, o esquema de sobreposição fica vinculado ao espaçamento do pomar, que era de 8,0m entrelinhas. Desta forma o valor elevado para o CV na aplicação a lanço tem razåo de ser, pois é relativo a uma largura de trabalho de $8,0 \mathrm{~m}$, pois o aplicador deu apenas uma passada por entrelinba. Para o modo em faica, houve a necessidade de se passar duas vezes por entrelinha, sendo portanto o esquema de sobreposição resultante, relativo a langura de trabalho de $4,0 \mathrm{~m}$

Quanto a simetria da aplicação, ou seja a expectativa que se tem para que o produto seja igualmente distribuido nos dois lados do eixo de aplicação, para o modo a lanço, encontrou-se um coeficiente de simetria de 0,77 , indicando que o aplicador direcionou maiores quantidades de produto para o lado esquerdo, uma vez que o direito ficou com $77 \%$ do que caiu no esquerdo. Na aplicação em faixa, como o aplicador passou duas vezes por entrelinha, resultou na perfeita simetria, distribuindo o calcário igualmente em relação ao eixo de aplicação do conjunto trator mais aplicador de corretivo.

No que diz respeito à segregação, com base nos resultados das análises granulométricas das amostras do perfil transversal dos dois modos de aplicação, elaborou-se as Tabelas 10 e 11, que contèm a distribuição percentual dessas frações, a partir das quais confeccionou-se as curvas que constam das Figuras 10 e 11, onde observa-se de uma maneira geral, que houve uma maior segregação para a aplicação a lanço, cujo comportamento foi concentrar a participação das menores fraçốes no centro da aplicação, e aumentar as das particulas grosseiras nas extremidades da largura de aplicação, estando de acordo com os comentários de POPP \& ULRICH (1985). A partir dos $2,5 \mathrm{~m}$ do centro da aplicação, as alterações granulométricas são mais evidentes, 
TABELA 10. Distribuição em \% das frações granuiométricas no perfil transversal do modo de aplicação de calcário a lanço.

\begin{tabular}{cccccc}
\hline Amostra & Distancia & \multicolumn{4}{c}{ Distribuicăo \% da Granulometria - $\phi$ (mm) } \\
& (m) & $>2,0$ & $0,84-2,0$ & $0,3-0,84$ & $<0,3$ \\
\hline 8E & 5,5 & - & - & - & - \\
7E & 4,5 & 8,1 & 41,3 & 17,2 & 33,4 \\
6E & 3,5 & 4,3 & 30,2 & 25,7 & 39,8 \\
5E & 3,0 & 1,3 & 18,8 & 38,1 & 41,8 \\
4E & 2,5 & 0,4 & 8,6 & 41,6 & 49,3 \\
3E & 2,0 & 0,5 & 6,6 & 32,6 & 60,2 \\
2E & 1,5 & 0,7 & 9,7 & 30,4 & 59,2 \\
IE & 0,0 & 0,6 & 9,9 & 32,0 & 57,4 \\
\hline 1D & 0,0 & 0,9 & 9,1 & 31,5 & 58,5 \\
2D & 1,5 & 0,6 & 8,5 & 35,1 & 55,8 \\
3D & 2,0 & 0,3 & 8,7 & 37,1 & 53,9 \\
4D & 2,5 & 0,4 & 12,3 & 41,6 & 45,8 \\
5D & 3,0 & 1,5 & 25,7 & 33,2 & 39,6 \\
6D & 3,5 & 3,7 & 40,6 & 19,5 & 36,2 \\
TD & 4,5 & 7,8 & 48,4 & 14,6 & 29,2 \\
8D & 5,5 & - & - & - & - \\
\hline
\end{tabular}


TABELA 11. Distribuição em \% das fraçỏes granulométricas do perfil transversal do modo de aplicação de calcário em faixa.

\begin{tabular}{cccccc}
\hline Amostra & Distância & \multicolumn{5}{c}{ Granulometria - $\phi$ em mm } \\
& (m) & $>2,0$ & $2,0-0,84$ & $0,84-0,3$ & $<0,3$ \\
\hline 4E & 2,5 & - & - & - & - \\
3E & 2,0 & 0,0 & 0,0 & 28,6 & 71,4 \\
2E & 1,5 & 0,0 & 2,7 & 23,4 & 73,9 \\
1E & 0,0 & 0,0 & 5,4 & 23,6 & 71,0 \\
\hline ID & 0,0 & 1,4 & 7,6 & 26,4 & 64,6 \\
2D & 1,5 & 0,0 & 5,9 & 33,7 & 60,4 \\
3D & 2,0 & 0,6 & 9,8 & 30,8 & 58,8 \\
4D & 2,5 & 0,7 & 9,9 & 29,6 & 59,8 \\
5D & 3,0 & 0,4 & 9,4 & 28,1 & 62,1 \\
6D & 3,5 & 1,1 & 10,4 & 27,6 & 60,9 \\
7D & 4,0 & 0,0 & 6,6 & 22,9 & 70,5 \\
8D & 4,5 & 0,0 & 1,3 & 39,2 & 59,5 \\
9D & 5,0 & - & - & - & - \\
10D & 5,5 & - & - & - & - \\
\hline
\end{tabular}




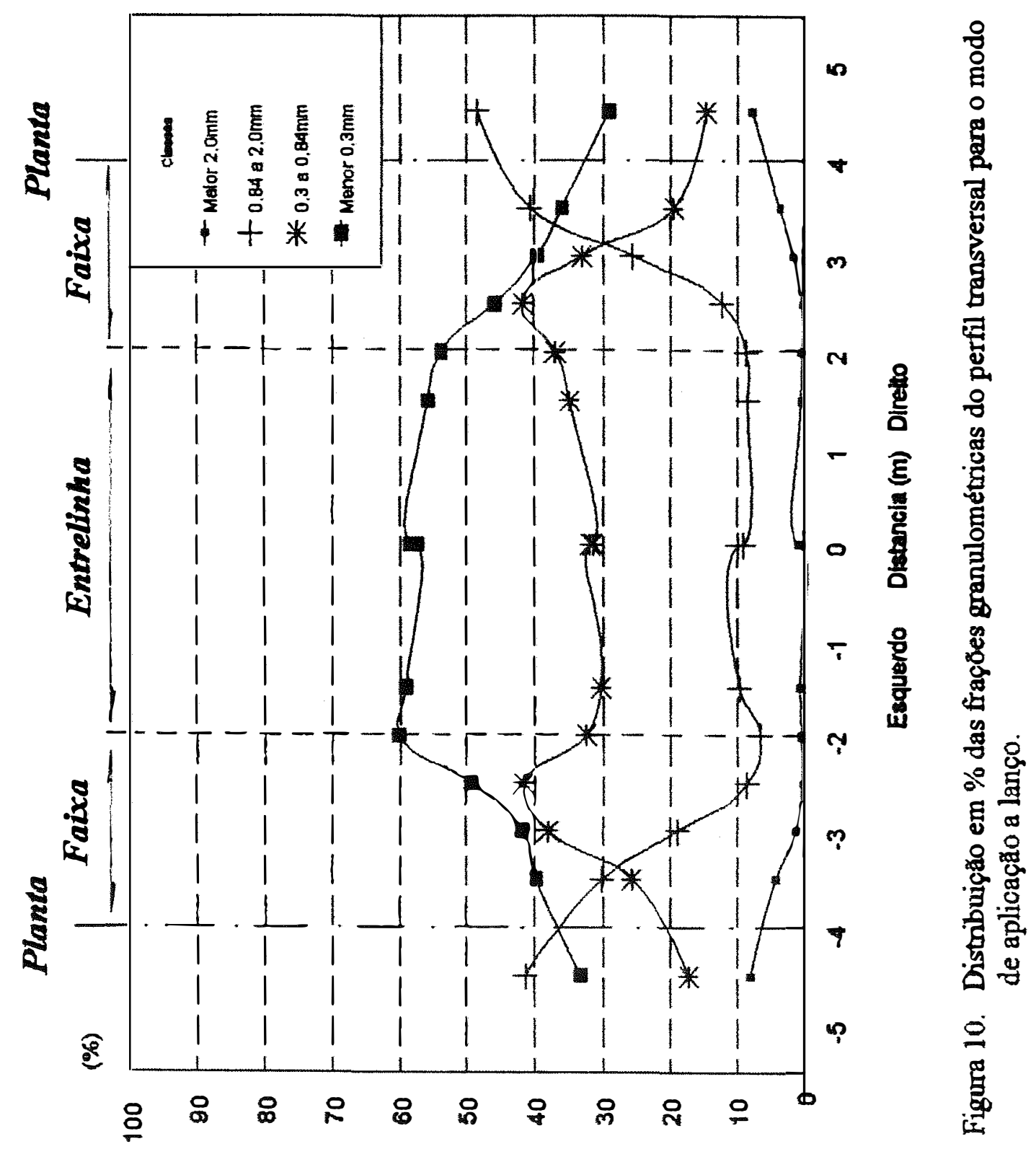




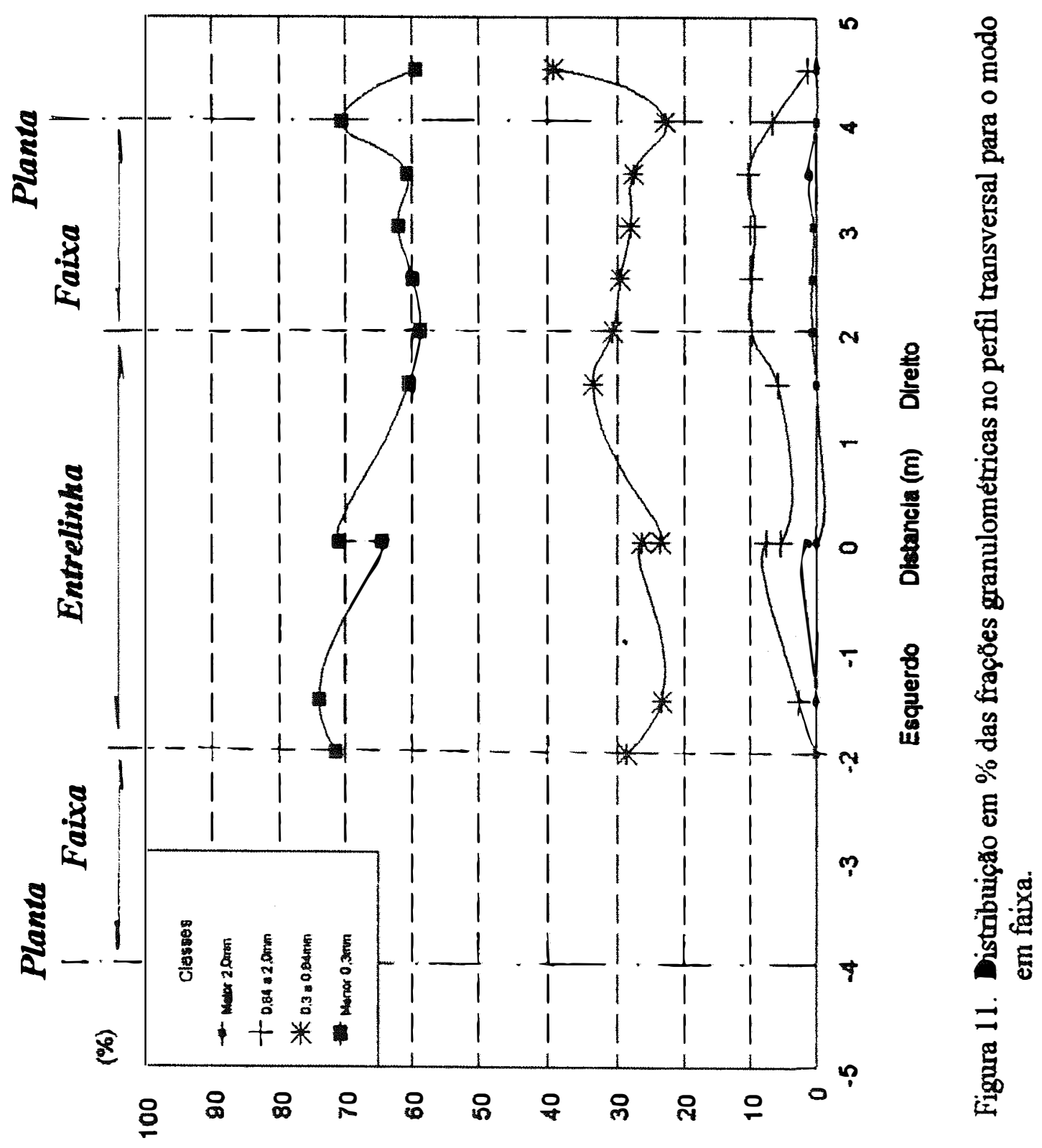


reduzindo-se acentuadamente a participação das classes de diâmetro inferior a $0,3 \mathrm{~mm}$ e a compreendida entre 0,3 e $0,84 \mathrm{~mm}$, bem como aumentando significativamente as classes de particulas entre 0,84 e 2,0 $\mathrm{mm}$ e as maiores que $2,0 \mathrm{~mm}$, o que é devido ao fato das particulas de maiores tamanhos alcançarem maiores distância de lançamentos, conforme KEPNER et al. (1972). Por outro lado, no modo de aplicação em faixa nota-se pequenas variaçð̃es na composição granulométrica do perfil transversal.

Tal comportamento refletiu de maneira marcante na reatividade relativa, uma vez que esta é fundamentada no tamanho das particulas, de acordo com ALCARDE (1985), como pode ser notado na Tabela 12 , onde se verifica maiores reatividades relativa, na ordem de 77,0 a $81,0 \%$ na porção central da aplicação ( 0 a 2,0 m) caindo para cerca de $76,0 \%$ a $47,0 \%$ nas extremidades da largura de aplicação ( 2,5 a 4,5 m), para o modo a lanço, enquanto que para o em faixa, de acordo com a Tabela 13 , a reatividade relativa pouco variou.

Para o produtor, essas variações, na qualidade da aplicação em função da segregafăa, poderão ser notadas através do PRNT, que segundo ALCARDE (1985) é um Indicador do potencial de reatividade do corretivo. Nas referidas tabelas, percebe-se que para o modo a lanço, a média para o PRNT foi de $59,89 \%$ com um coeficiente de variação de $16,32 \%$, o que implica em uma amplitude de $28,79 \%$ ou seja o menor valor do PRNT no perfil transversal foi $41,02 \%$ e o maior $69,81 \%$, enquanto que para a aplicação em faixa o PRNT médio foi de 71,62 \% com um coeficiente de variação de apenas $4,23 \%$, sendo o menor valor do perfil $68,48 \%$ e o maior $76,26 \%$ o que resulta numa amplitude de 7,78\%. A Figura 12 contem as curvas do PRNT em função da 
TABELA 12. Reatividade Relativa e PRNT no perfil transversal do modo de aplicação de calcário a lanço.

\begin{tabular}{|c|c|c|c|c|c|c|}
\hline \multirow[t]{2}{*}{ Amostra } & \multirow{2}{*}{$\begin{array}{c}\text { Distância } \\
\text { (m) }\end{array}$} & \multicolumn{3}{|c|}{ Reatividade das Fraçoes (\%) } & \multirow{2}{*}{$\begin{array}{l}\text { Reatividade } \\
\text { Relativa \% }\end{array}$} & \multirow{2}{*}{$\begin{array}{c}\text { PRNT } \\
\%\end{array}$} \\
\hline & & $0,84<\phi<2,0$ & $0,30<\phi<0,84$ & $\phi<0,30$ & & \\
\hline $8 \mathrm{E}$ & 5,5 & - & - & $=$ & - & - \\
\hline $7 \mathrm{E}$ & 4,5 & 8,26 & 10,32 & 33,40 & 51,98 & 44,75 \\
\hline $6 \mathrm{E}$ & 3,5 & 6,04 & 15,42 & 39,80 & 61,26 & 52,74 \\
\hline $5 \mathrm{E}$ & 3,0 & 3,76 & 22,86 & 41,80 & 68,42 & 58,91 \\
\hline $4 \mathrm{E}$ & 2,5 & 1,72 & 24,96 & 49,30 & 75,98 & 65,42 \\
\hline $3 \mathrm{E}$ & 2,0 & 1,32 & 19,56 & 60,20 & 81,08 & 69,81 \\
\hline $2 \mathrm{E}$ & 1,5 & 1,94 & 18,24 & 59,20 & 79,38 & 68,35 \\
\hline $1 \mathrm{E}$ & 0,0 & 1,98 & 19,20 & 57,40 & 78,58 & 67,66 \\
\hline ID & 0,0 & 1,82 & 18,90 & 58,50 & 79,22 & 68,21 \\
\hline $2 \mathrm{D}$ & 1,5 & 1,70 & 21,06 & 55,80 & 78,56 & 67,64 \\
\hline $3 \mathrm{D}$ & 2,0 & 1,74 & 22,26 & 53,90 & 77,90 & 67,07 \\
\hline $4 \mathrm{D}$ & 2,5 & 2,46 & 24,96 & 45,80 & 73,22 & 63,04 \\
\hline 5D & 3,0 & 5,14 & 19,92 & 39,60 & 64,66 & 55,67 \\
\hline $6 \mathrm{D}$ & 3,5 & 8,12 & 11,70 & 36,20 & 56,02 & 48,23 \\
\hline $7 \mathrm{D}$ & 4,5 & 9,68 & 8,76 & 29,20 & 47,64 & 41,02 \\
\hline 8D & 5,5 & - & - & - & - & - \\
\hline
\end{tabular}


TABELA 13. Reatividade Relativa e PRNT no perfil transversal do modo de aplicaçăo de calcário em faixa.

\begin{tabular}{|c|c|c|c|c|c|c|}
\hline \multirow[t]{2}{*}{ Amostro } & \multirow{2}{*}{$\begin{array}{c}\text { Distância } \\
\text { (m) }\end{array}$} & \multicolumn{3}{|c|}{ Reatividado das fraçöes } & \multirow{2}{*}{$\begin{array}{l}\text { Reatividado } \\
\text { Relativa \% }\end{array}$} & \multirow{2}{*}{$\begin{array}{c}\text { PRNT } \\
\%\end{array}$} \\
\hline & & $0,84<\phi<2,0$ & $0,30<\phi<0,84$ & $\phi<0,3$ & & \\
\hline $4 \mathrm{E}$ & 2,5 & - & - & - & - & - \\
\hline $3 \mathbf{E}$ & 2,0 & 0,00 & 17,14 & 71,43 & 88,57 & 76,26 \\
\hline $2 \mathrm{E}$ & 1,5 & 0,54 & 14,02 & 73,95 & 88,51 & 76,21 \\
\hline $1 \mathrm{E}$ & 0,0 & 1,08 & 14,17 & 70,98 & 86,23 & 74,24 \\
\hline ID & 0,0 & 1,52 & 15,84 & 64,56 & 81,92 & 70,53 \\
\hline $2 \mathrm{D}$ & 1,5 & 1,18 & 20,20 & 60,44 & 81,82 & 70,45 \\
\hline 3D & 2,0 & 1,97 & 18,45 & 58,75 & 79,17 & 68,17 \\
\hline 4D & 2,5 & 1,97 & 17,75 & 59,87 & 79,59 & 68,53 \\
\hline 5D & 3,0 & 1,88 & 16,86 & 62,08 & 80,82 & 69,59 \\
\hline 6D & 3,5 & 2,08 & 16,58 & 60,87 & 79,53 & 68,48 \\
\hline $7 \mathrm{D}$ & 4,0 & 1,32 & 13,71 & 70,53 & 85,56 & 73,67 \\
\hline 8D & 4,5 & 0,25 & 23,54 & 59,49 & 83,28 & 71,70 \\
\hline 9D & 5,0 & - & - & - & - & \\
\hline 10D & 5,5 & - & - & - & - & \\
\hline & & & & & & $\begin{array}{r}71,62 \% \\
4,23 \%\end{array}$ \\
\hline
\end{tabular}




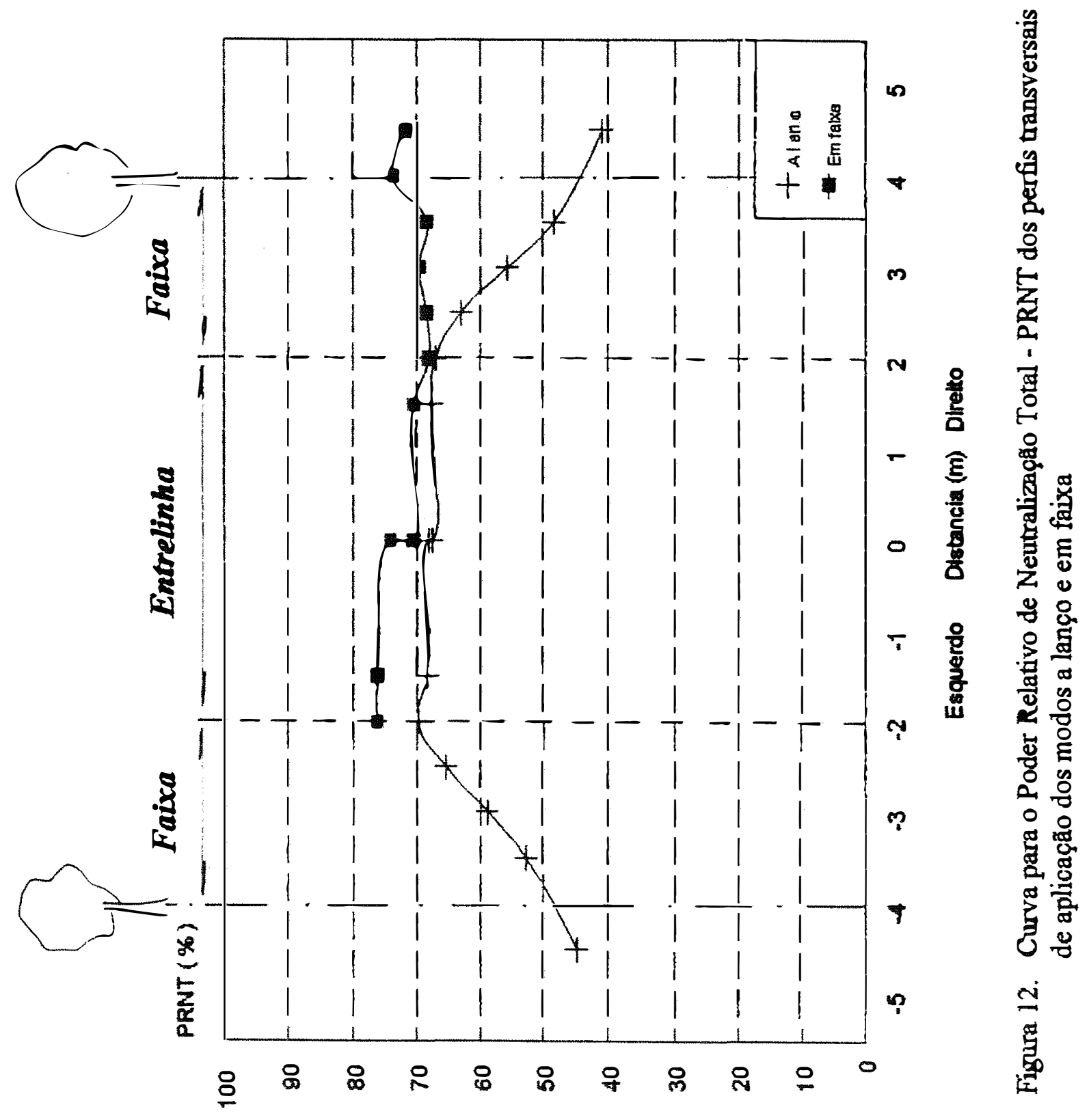


distância, na qual pode-se visualizar o comportamento do mesmo para os dois modos de aplicação.

Desta forma, os modos de aplicação testados interferiram tanto no aspecto quantitativo do perfil transversal de aplicação, ou seja na dose aplicada, quanto no qualitativo, através do PRNT, o que conduz a potenciais diferenciados de reaçåo do calcário no solo, quer seja entre modos de aplicação, bem como para o mesmo modo em função da posição, principalmente para o a lanço.

\subsection{Efeitos sobre as variáveis de planta}

\subsubsection{Produçăo}

A produçăo de citros por área é apresentada na Tabela 14, cuja análise estatistica do Quadro 5, colocado no apêndice, não revela diferenças significativas para os tratamentos testados durante as três safras, bem como para a média de todas as safras. Na safra 92/93, percebe-se que a magnitude da produção é semelhante a de 91/92, o que possivelmente esteja associado ao fato de ter-se colhido duas vezes por safra, sendo que nesse ano agricola (92/93) devido às condições climáticas da safra anterior, como pode ser visto nos gráficos do balanço hidrico da Figura 1, gerou-se prołuçåo de frutos fora das épocas de colheita previstas no experimento. Outro aspecto a ser considerado é a elevada variabilidade para os dados de produçåo, que implica na dificuldade de se obter respostas para os fatores testados, embora tenha se obtido ate 8,0 tha de diferença entre as medias da $3^{a}$ safra, entre a testemunha absoluta e o tratamento com calagem em faixa, com gesso e sem incorporação. Estudo conduzido por SOUZA (1976), também obteve coeficiente de variação elevado para os dados de prođução, numa laranjeira Pera Rio (na 


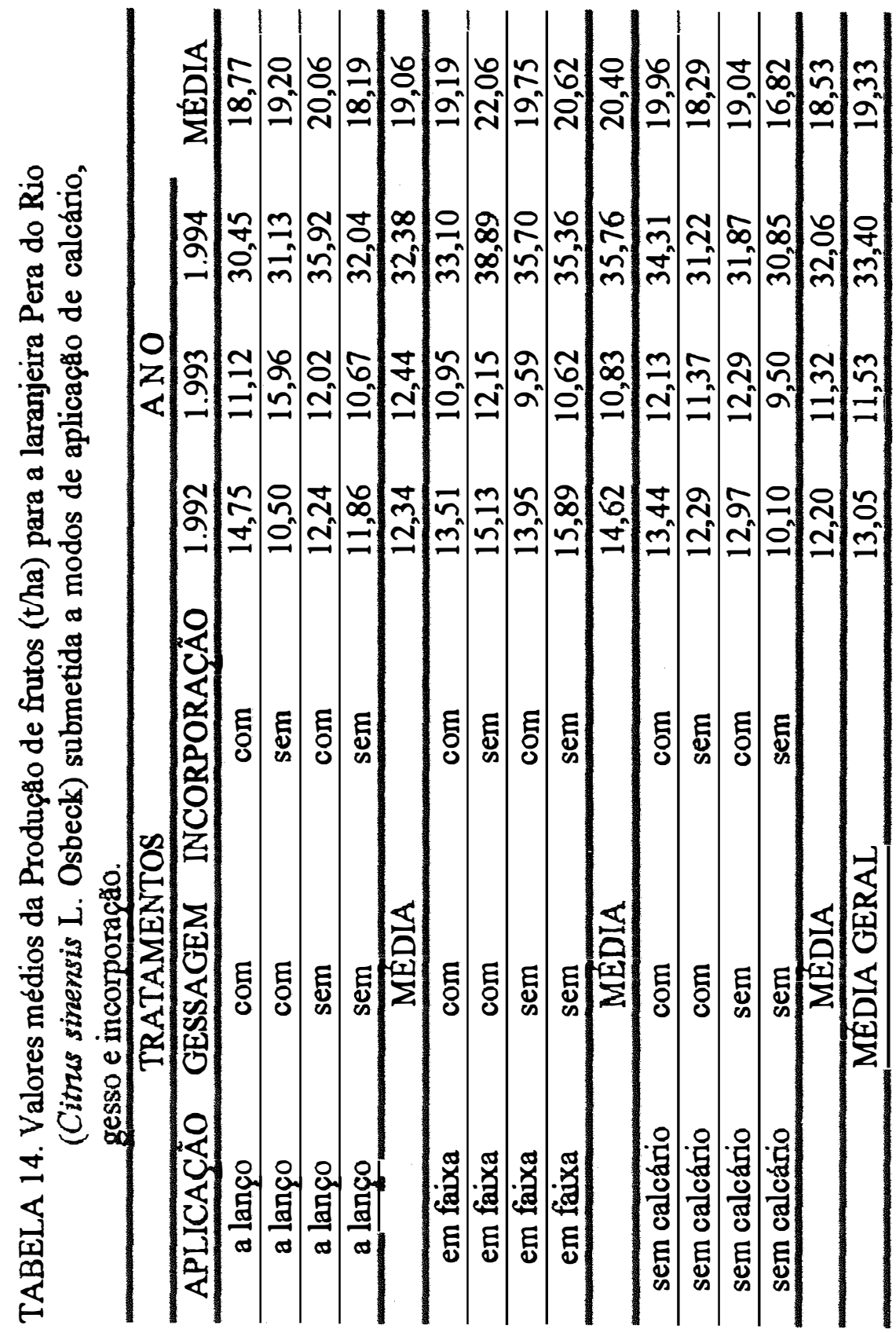


mesma fase de crescimento), não encontrando respostas para o uso da calagem. Outro fato a ser considerado é a alternância de produção que pode ocorrer com os citros, conforme comentário de VIEIRA (1994), que hora obteve efeito para um tratamento, ora para outro, numa avaliação de 4 safras seguidas para laranja 'Hamlin'. Quanto aos modos de aplicação, embora nåo tenha sido estudo com calagem, SOUTO (1993) nåo detectou efeitos no limoeiro cravo, na fase de viveiro, para 8 métodos testados, enquanto que CARVALHO (1987), conseguiu respostas para limão cravo em sementeira, para o uso de superfosfato simples incorporado. A não obtençăo de efeitos para a incarporaçăo, vem ao encontro das sugestões feitas por algums autores, no sentido de evitar sua utilização, alegando que tal prática acarretará mais danos que beneflicios, conforme MOREIRA (1983); MOREIRA (1988); DE NEGRI (1988); SALVO FILHO (1991).

Outra questão a ser considerada é o número de safras colhidas para verificar respostas para calagem em citros, pois nesses casos talvez fosse interessante trabalhar com ensaios de longa duração, como os de ANDERSON (1987). No entanto cabe comentar que a resposta à calagem ficou vinculada a apenas uma única dose de calcário, de 2,10 t/ha, seguindo-se a recomendação de VIOLANTE NETTO et al. (1988), muito embora tenha se encontrado diferenças de $5,3 \mathrm{t} / \mathrm{ha}$ para as médias de todas as safras, entre a testemunha absoluta e o tratamento com calagem em faixa, com gesso e sem incorporação.

\subsubsection{Qualidade tecnologica dos frutos}

Os resultados das variáveis relacionadas à qualidade tecnológica estão nas Tabelas 15 a 21, cuja análise estatistica (Quadros 6 a 12) detectou efeito apenas para o 


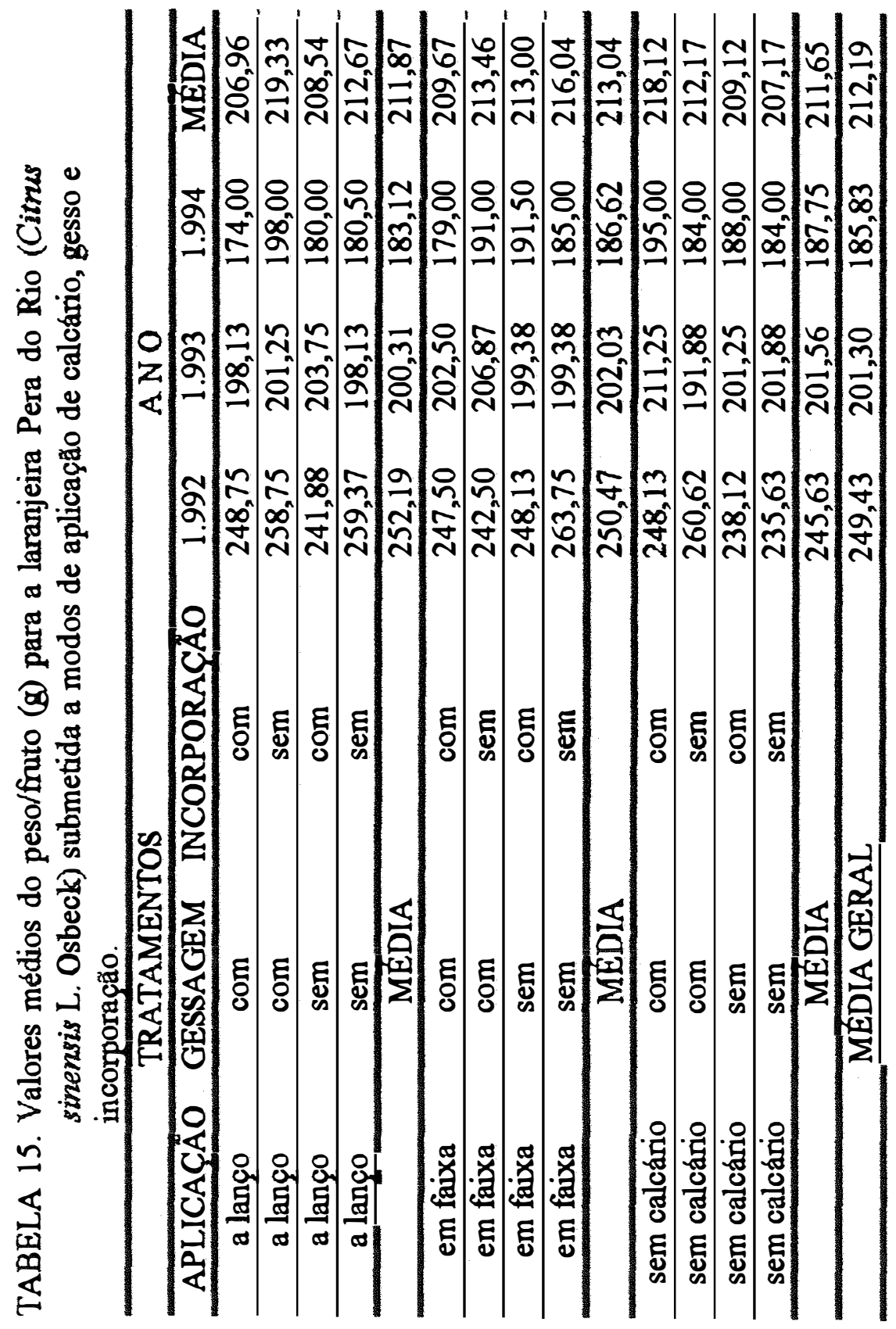




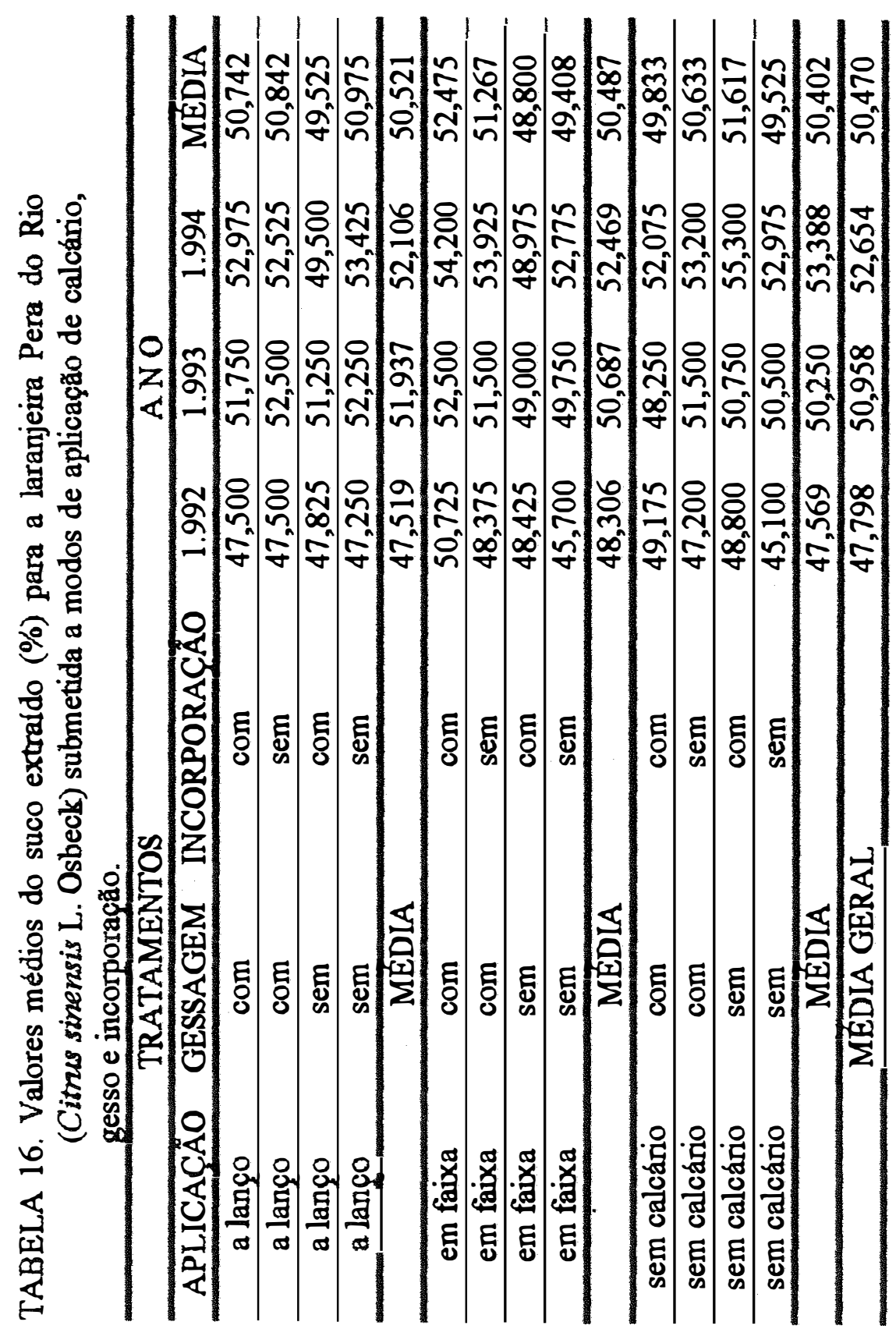




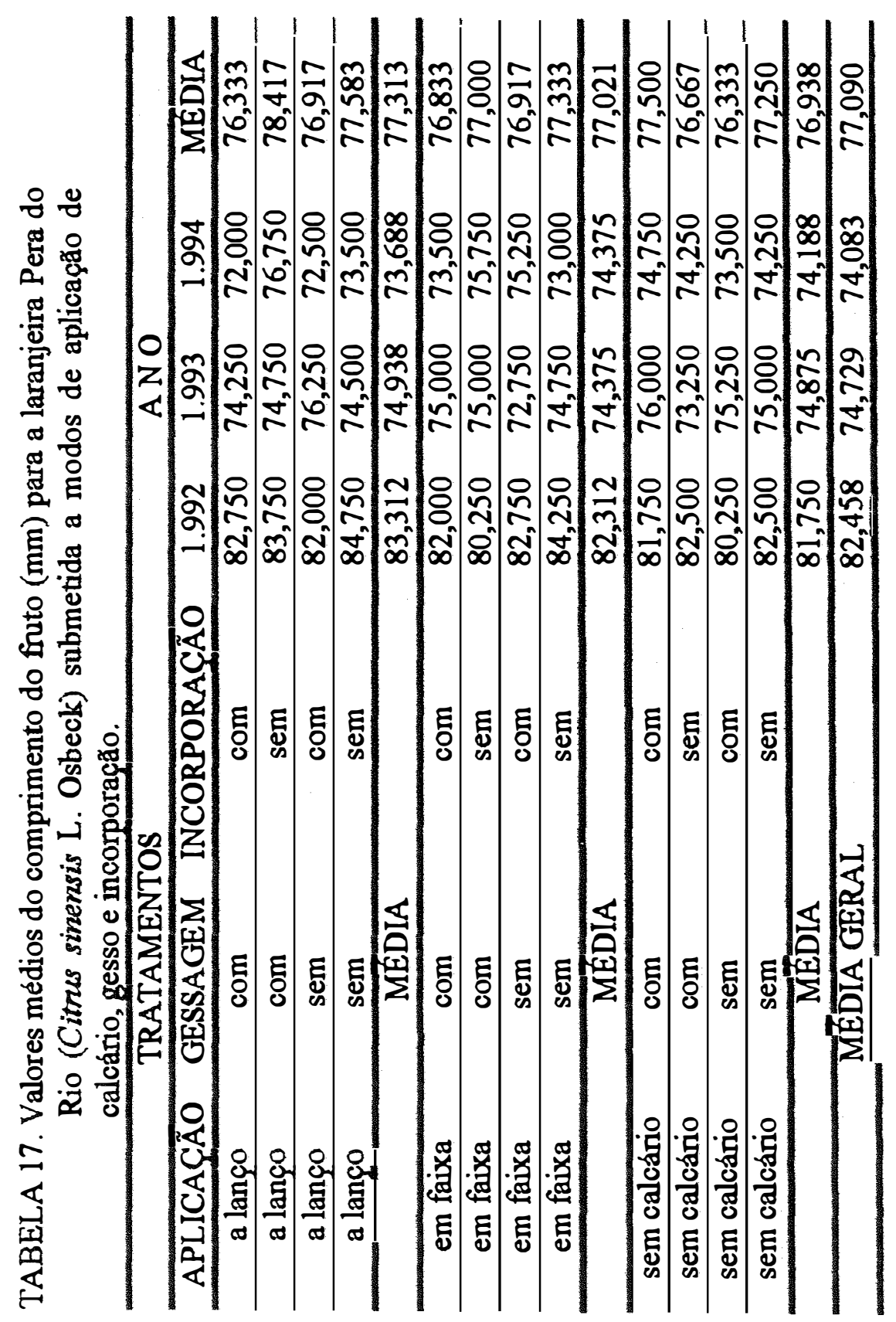




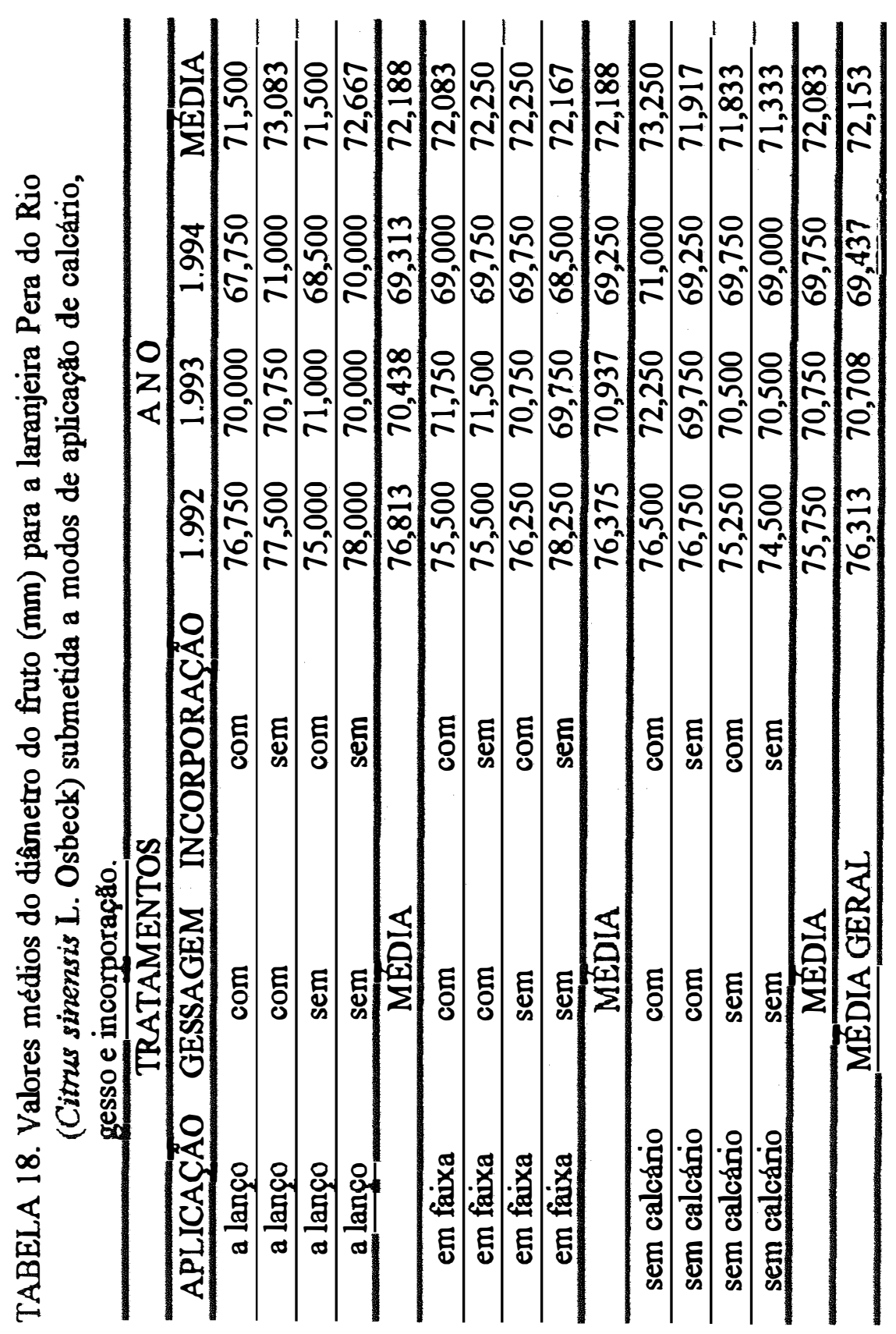




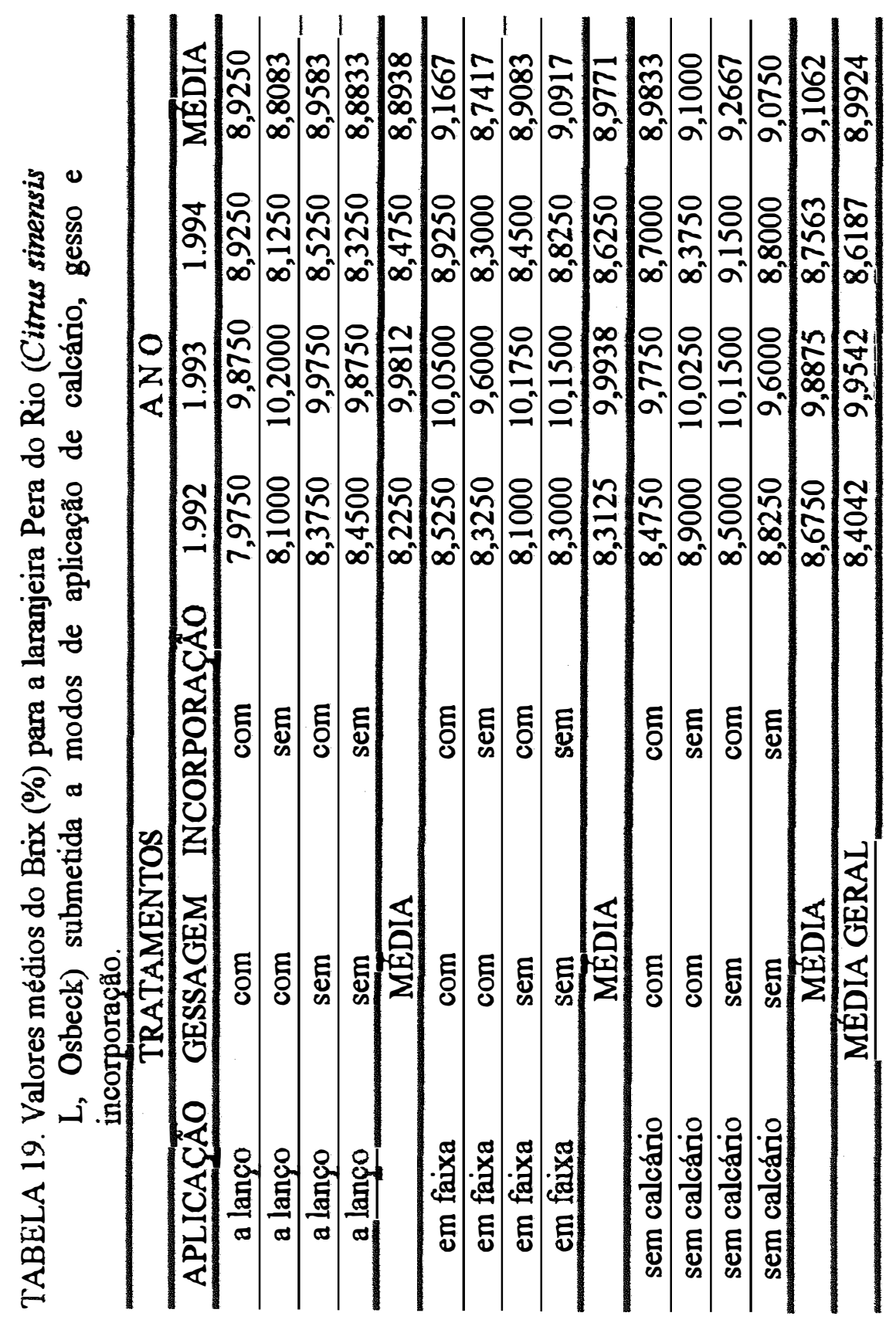




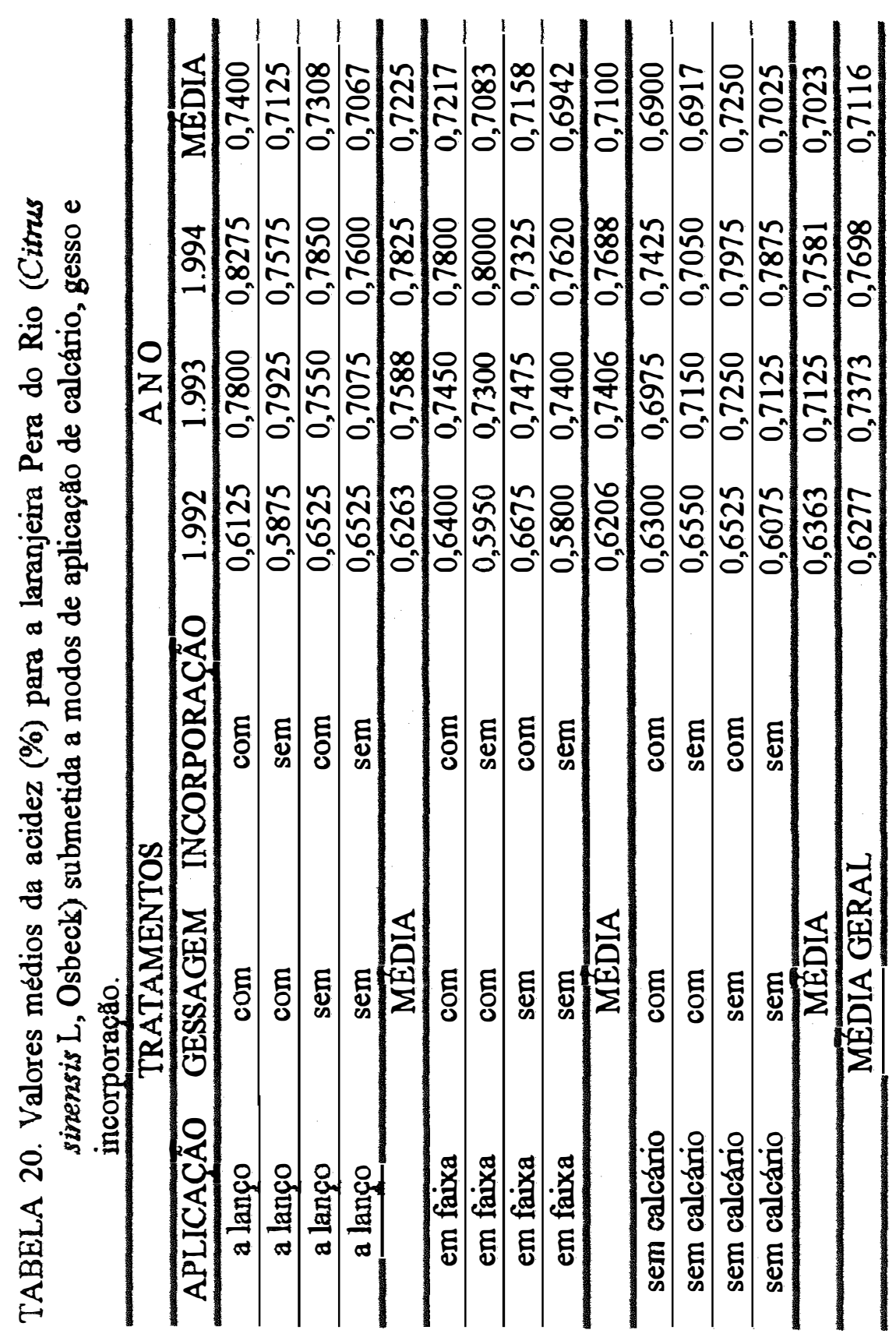




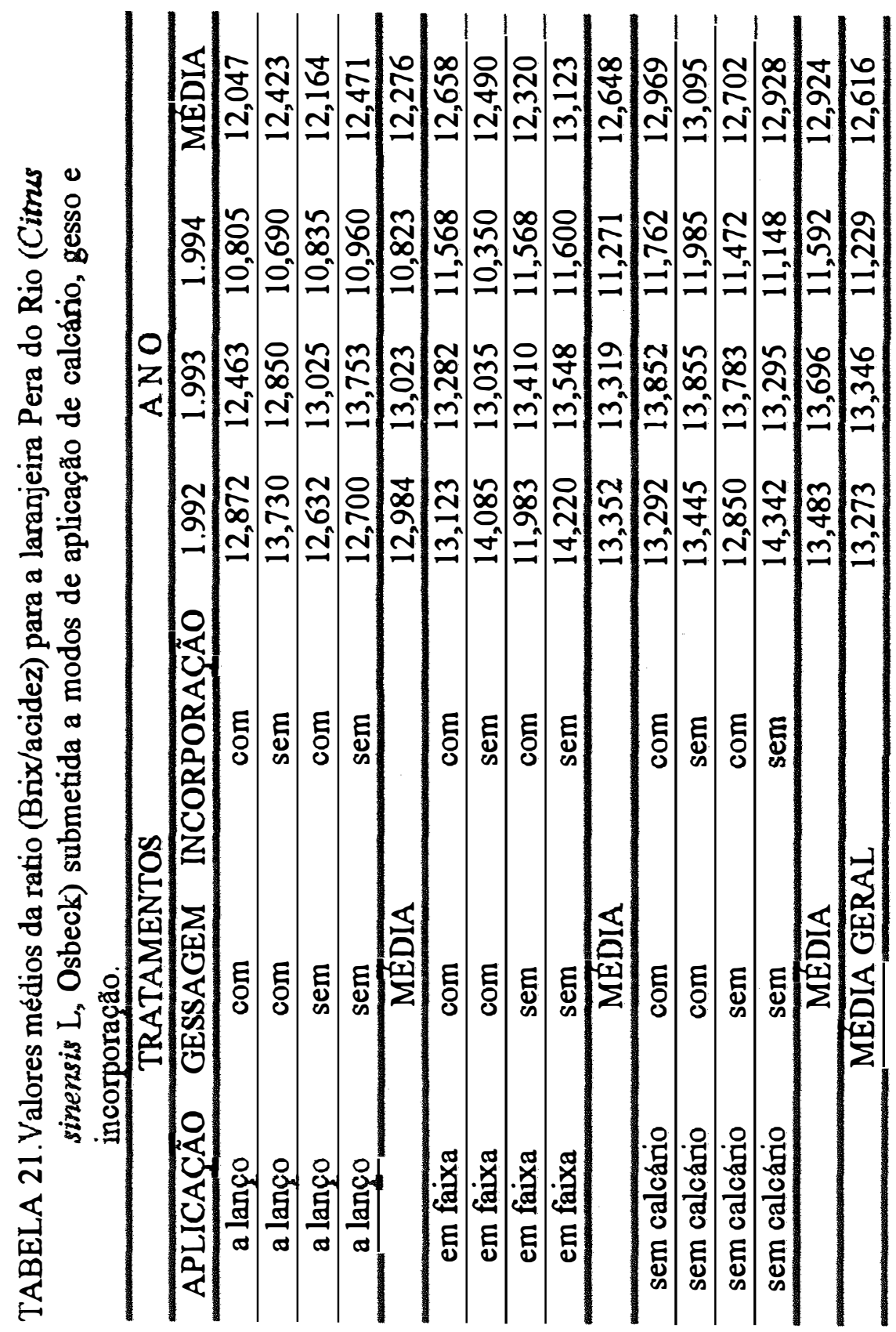


fator incorporafăo, que alterou os aspectos fisicos e quimicos dos frutos, somente na primeira safra, atraves da redução do diâmetro e altura do fruto, que levaram ao menor peso por fruto, commortamento que não refletiu de maneira significativa na procução, conforme já visto, Além disso, a incorparação levou a obtenção de menores valores na relaçåo brix/acidez, rechuzindo a Ratio, o que nos leva a sugerir a supressão dessa prática dentro desse contexto, o que vem corroborar os comentários feitos para a produção, estando mais uma vez de acordo com as orientações de MOREIRA (1988); DE NEGRI (1988); SALVO FILHO (1991).

A não observância de efeitos significativos do uso de conretivos sobre os aspectos de qualidade de frutos, também foram obtidos por PARO (1994) e VIEIRA (1994).

Quanto a ordem de grandeza das caractensticas quimicas dos frutos, nota-se que a Ratio esteve ao redor de 13 nas duas primeiras safras, diminuindo para 11,2 na última, o que se deve aos acréscimos na acidez e redução no Brix, estando cormpreendidos dentro da faixa considerada como ideal, ou seja de 11 a 16 , quanto ao estágio de maturação segundo VIERGAS (1991).

A análise de regressão polinomial do efeito do tempo (safra) sobre as caracteristicas fisicas do fruto, comprimento, diametro, peso e extração de suco (\%), constatou redução nas 3 primeiras variaveis, e aumento na última, com o tempo, como pode ser visto nas Figuras 13 a 16, fato esse que é reconhecido na citricultura, uma vez que plantas mais jovens produzem frutos maiores e mais pesados, estando de acordo com as dados de QUAGGIO (1991) e com os comentários de DI GIORGI et al. (1993). 


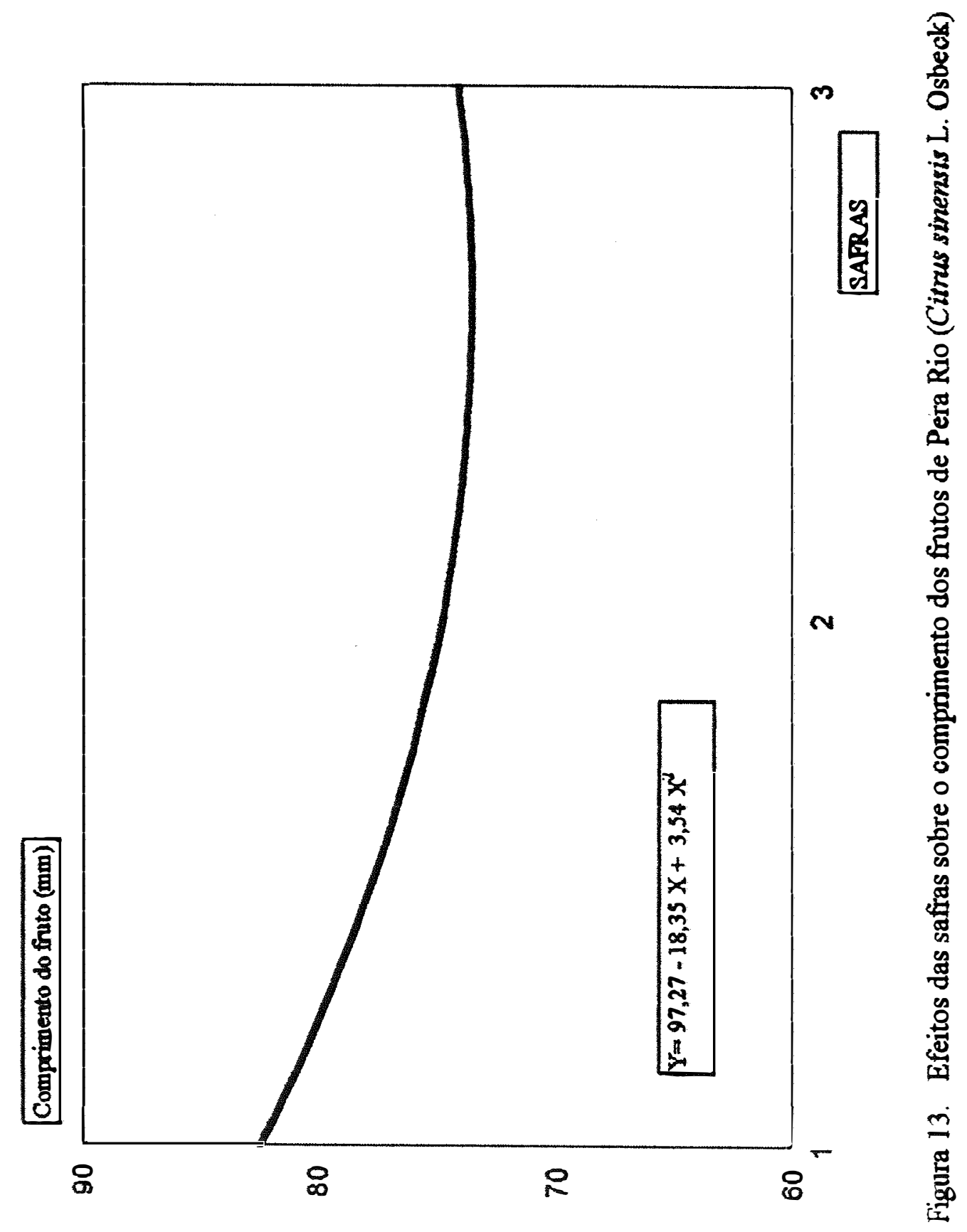




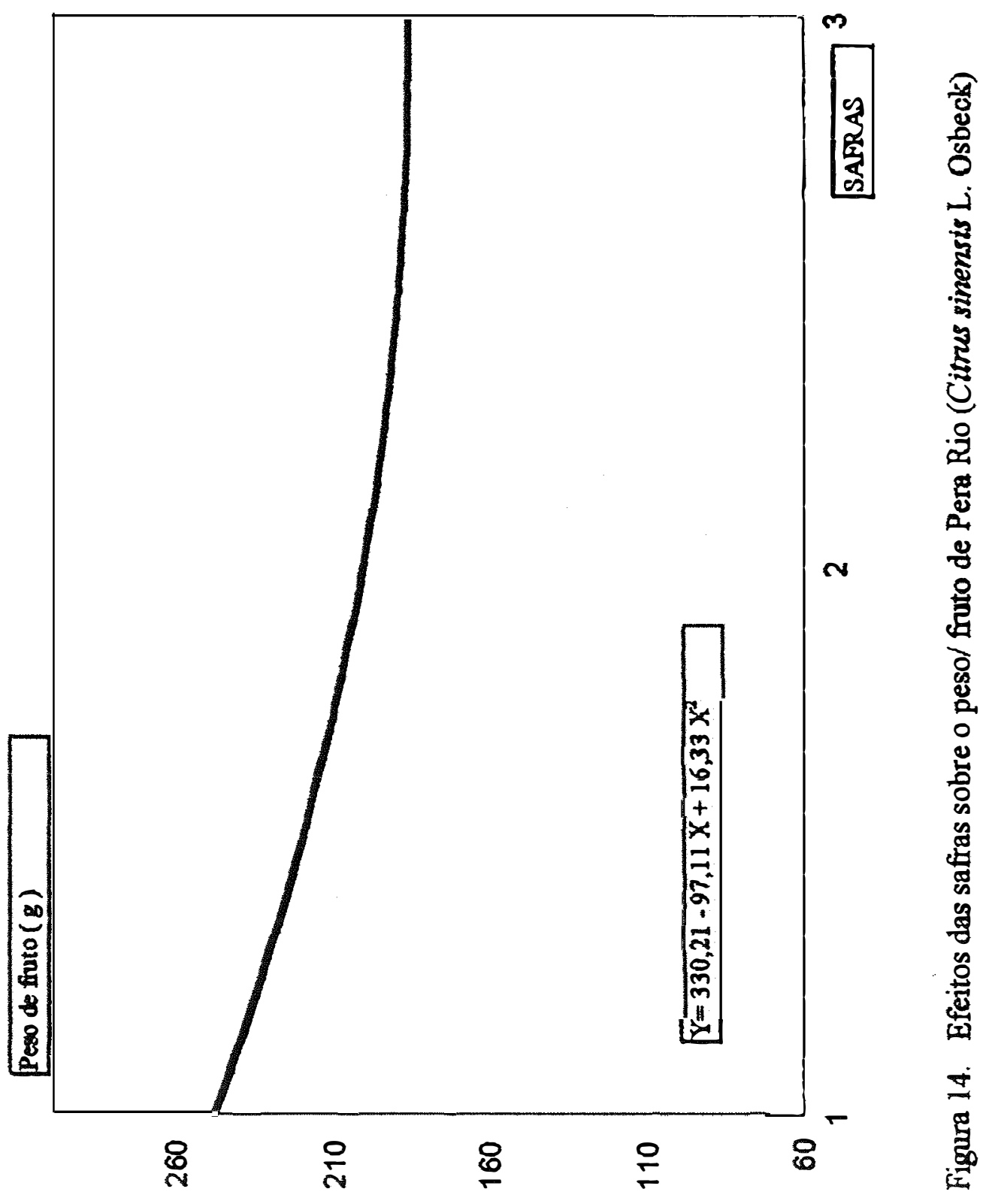




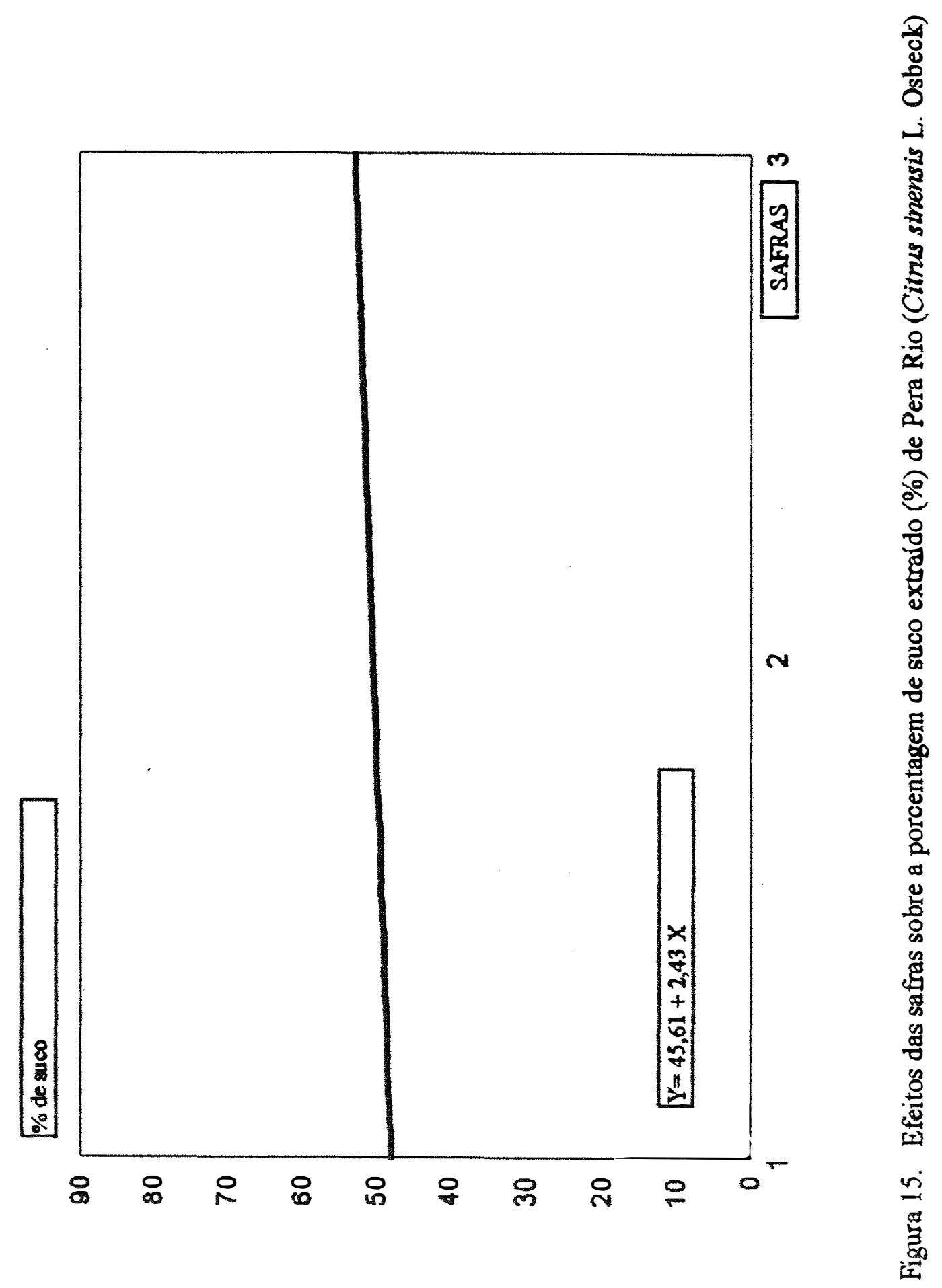




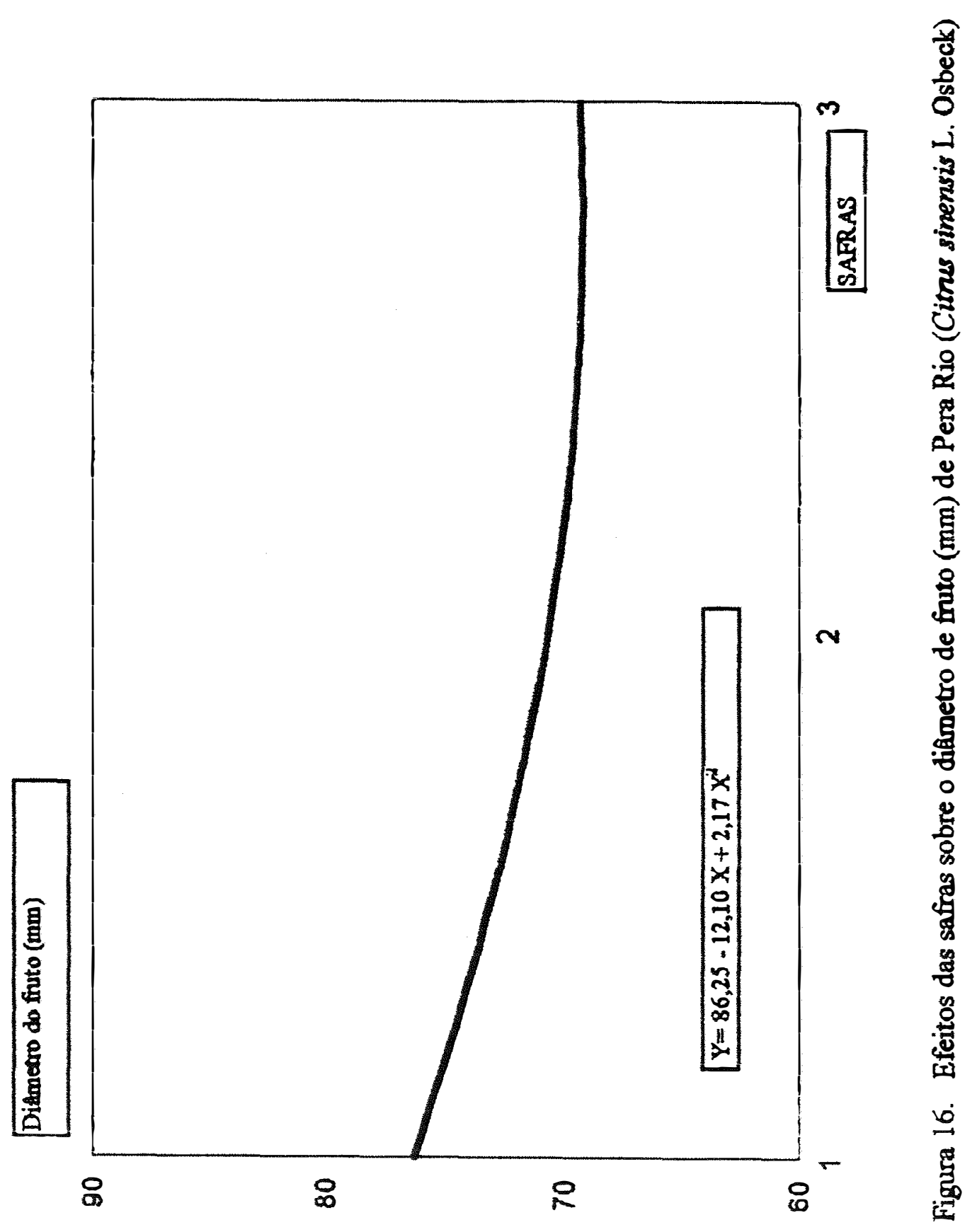


A partir dos dados de produção e das caracteristicas quantitativas e qualitativas dos frutos, fez-se uma análise de correlação simples, cujo resultado se encontra na Tabela 22, onde detectou-se alta correlação positiva entre as variáveis fisicas dos frutos (peso, diAmetro e comprimento). Por outro lado, encontrou-se correlaçб̃es medianas negativas entre produção e as caracteristicas fisicas dos frutos, fato esse que tambem é considerado pelos citricultores, de acordo com DI GIORGI et al. (1993), pois a medida que aumenta a prođução ha uma redução nas dimensơes dos frutos, o que é compensado pelo maior número deles por planta.

\subsection{Efeitos sobre os atributos quifmicos do solo}

Para verificação dos efeitos dos tratamentos sobre os atributos quimicos do solo, foram coletadas amostras de solo em dois locais (copa e centro da entrelinha) em três profundidades $(0-20,20-40$ e $40-60 \mathrm{~cm})$ em duas épocas, o que gerou um número muito grande de dados, por esta razåo serão comentados a seguir os resultados mais relevantes, no que diz respeito as alterações quimicas do perfil do solo. Desta forma, os resultados serão discutidos por variável e posteriormente a relação enire elas.

Sendo assim, nota-se para o Ca conforme Tabela 23, que os tratamentos de modos de aplicação do calcário provocaram efeitos significativos sobre os teores (Quadro 13), bem como para a interaçă local x aplicação, de forma que para o modo em faixa, houve distinção para as médias de Ca entre a copa e a entrelinha, com maiores valores na primeira do que na segunda, nas duas épocas de amostragem evidenciando a persistência da localização do calcário quando aplicado em faixa. Por outro lado, as médias de Ca 


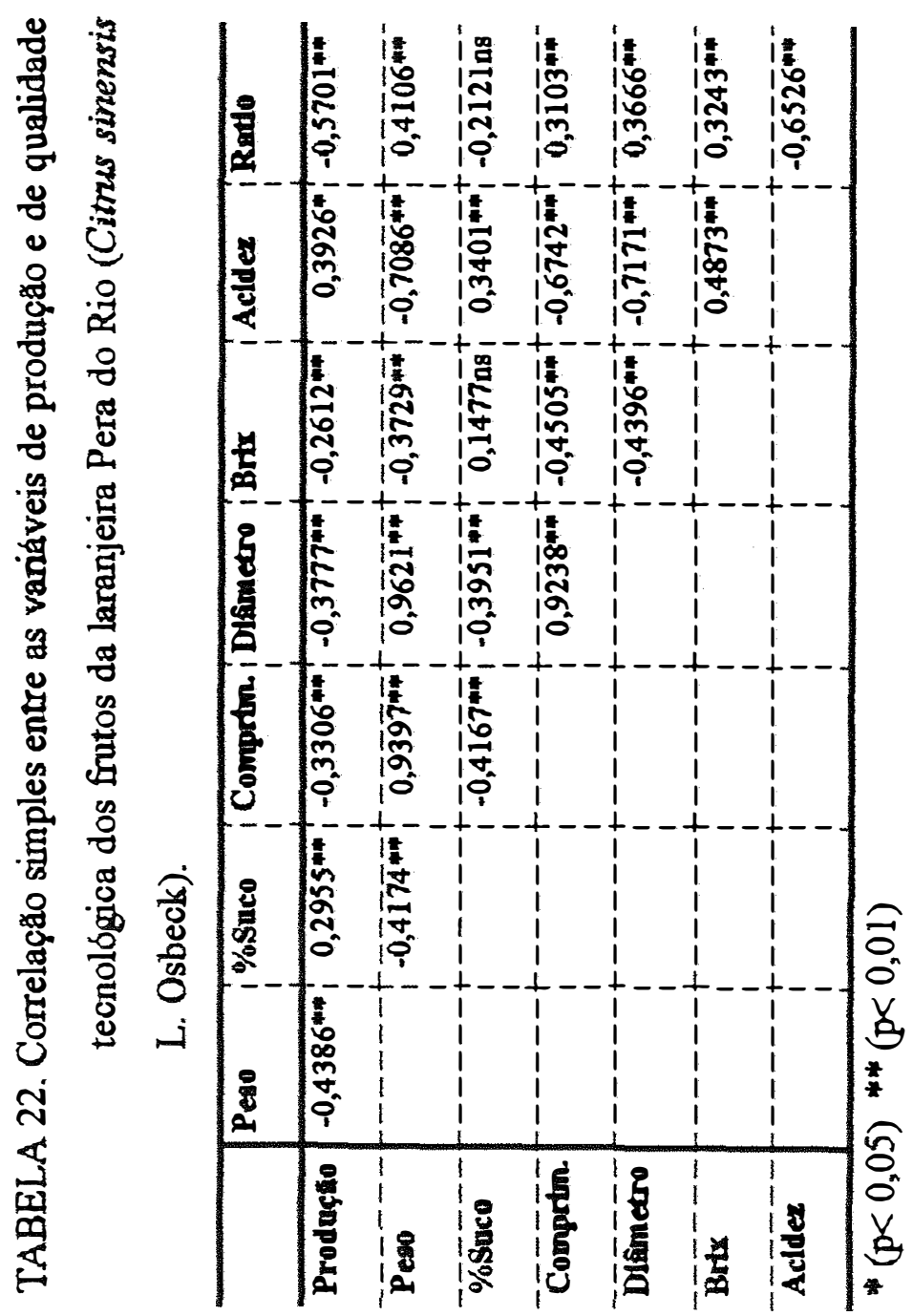




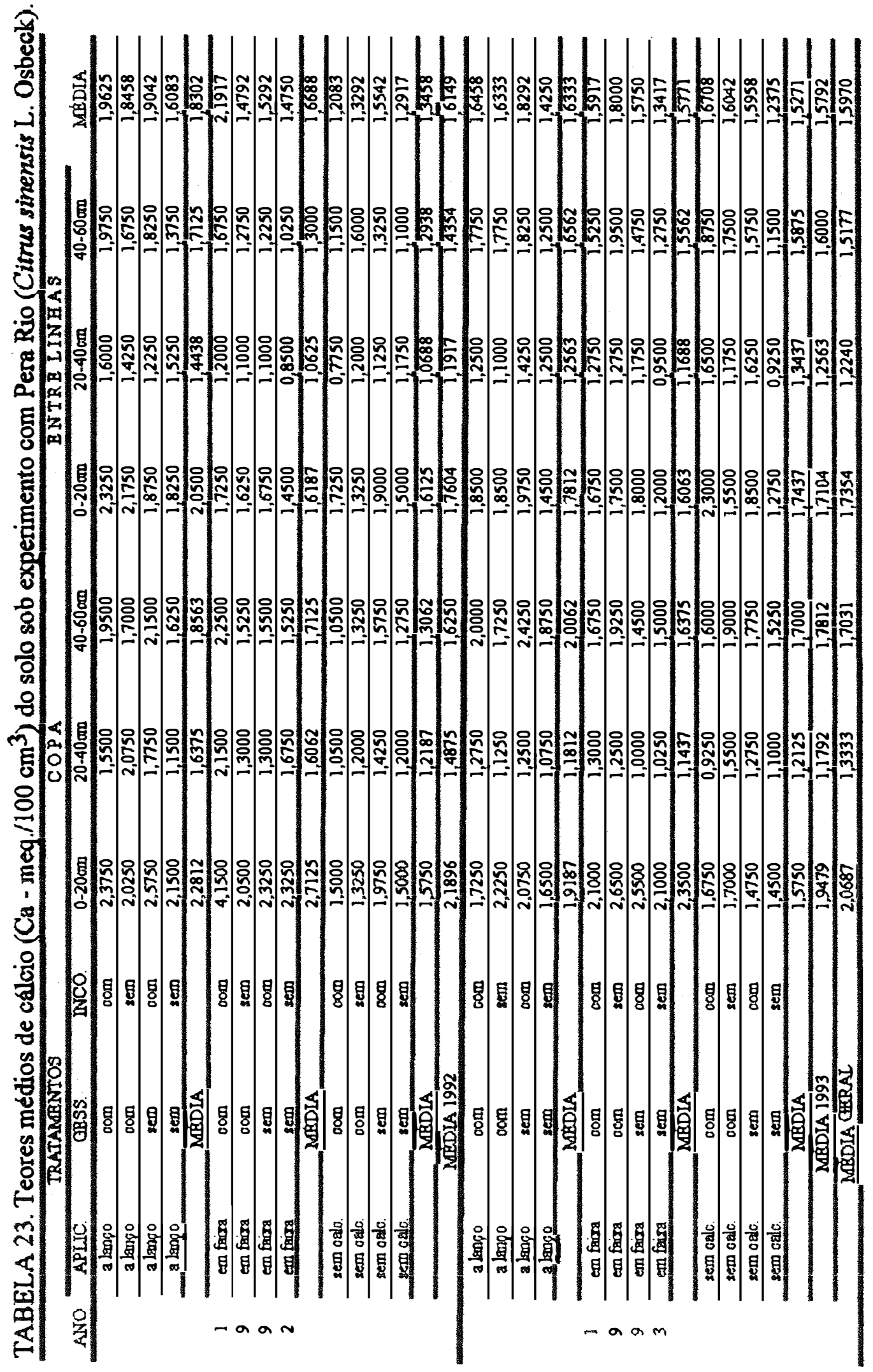


não diferiram entre locais de amostragem para os tratamentos a lanço e sem calcário, como era de se esperar, concordando com os resultados alcançados por SUZUKI (1989) e CARVALHO (1987)

No tocante ao fator gessagem, a análise estatística indicou que as médias gerais para o $\mathrm{Ca}$, com e sem gesso diferiram entre si, apresentando maiores teores naquele que usou o insumo, na primeira época, com tendência na segunda, estando de acordo com os trabalhos de VITII \& MALAVOLTA (1985); MORELLI et al.. (1987); DEMATTE \& VITTI (1992); MAZZA(1993). Para incorporação, os dados foram diferentes entre si na primeira época de amostragem, porém nāo diferiram na segunda, e nas camadas do perfil do solo, os teores apresentaram magnitudes diferenciadas apenas na camada de 0-20 cm na primeira época, com maiores valores de Ca nas áreas submetidas à incorporação, indicando que esta foi efetiva apenas na camada de 0-20cm na primeira época, estando em conformidade com os comentários de RAIJ (1988) relativos a dificuldade de se incorporar o corretivo.

No que diz respeito à grandeza dos valores de $\mathrm{Ca}$, na primeira época as médias gerais dos tratamentos com calcário elevaram os teores para 2,3 e 2,8 meq/100 $\mathrm{cm}^{3}$ respectivamente para a aplicação a lanço e em faixa, na projeção da copa na camada de 0$20 \mathrm{~cm}$, enquanto aquele sem calcário apresentou valor de $1,6 \mathrm{me} / 100 \mathrm{~cm}^{3}$, constatando-se a efetividade do calcário em aumentar os teores de Ca, uma vez que DECHEN (1983) cita de uma maneira geral como nivel critico para o Ca teores de 1,0 a 1,5 meq/100 $\mathrm{cm}^{3}$ de terra. 
Um aspecto interessante que foi observado, é que os teores de Ca decresceram sensivelmente de um ano para o outro, a ponto de redurir as diferenças entre as médias dos tratamentos com e sem calcário, e no que diz respeito a profundidade, percebe-se que há uma tendência de redução nos teores na camada de $0-20 \mathrm{~cm}$, enquanto que ocorre aumento nos mesmos para as camadas mais profundas principalmente na de 40-60 cm. Tal compartamento deve-se a lixiviação do Ca que ocorre no perfil do solo, conforme os comentários feitos por RAIJ (1988), numa relevante e abrangente revisão bibliogrática sobre esse aspecto. Os dados obtidos por MAZZA (1993), tambem evidenciaram tal comportamento, levando a necessidade de reaplicação dos corretivos cerca de 2 a 3 anos após aplicação em cana-de-açúcar.

Para o Mg, de acordo com a Tabela 24, os tratamentos provocaram efeitos (Quadro 14) semelhantes aos do $\mathrm{Ca}$, ou seja, elevando os teores para os tratamentos com calcário, sobretudo na camada de 0-20cm, na primeira época. Com relação aos modos de aplicação, na posição copa, os teores foram maiores para o método em faixa, provocando diferenças significativas para posição, enquanto que para os outros modos os teores não diferiram entre copa e entrelinha.

A incorporação refletiu apenas na camada de 0-20cm, na pnimeira época para os tratamentos que receberam calagem, concondando com os dados obtidos para o Ca. No tocante ao gesso, as médias gerais para os tratamentos de aplicação não mostram efeito, pois estas não diferiram entre si. Quanto a ordem de grandeza dos teores de $\mathrm{Mg}$, na primeira época, independente da profundidade, os tratamentos com calcário apresentaram respectivamente para o modo a lanço e em faixa valores de 1,07 e 1,26 


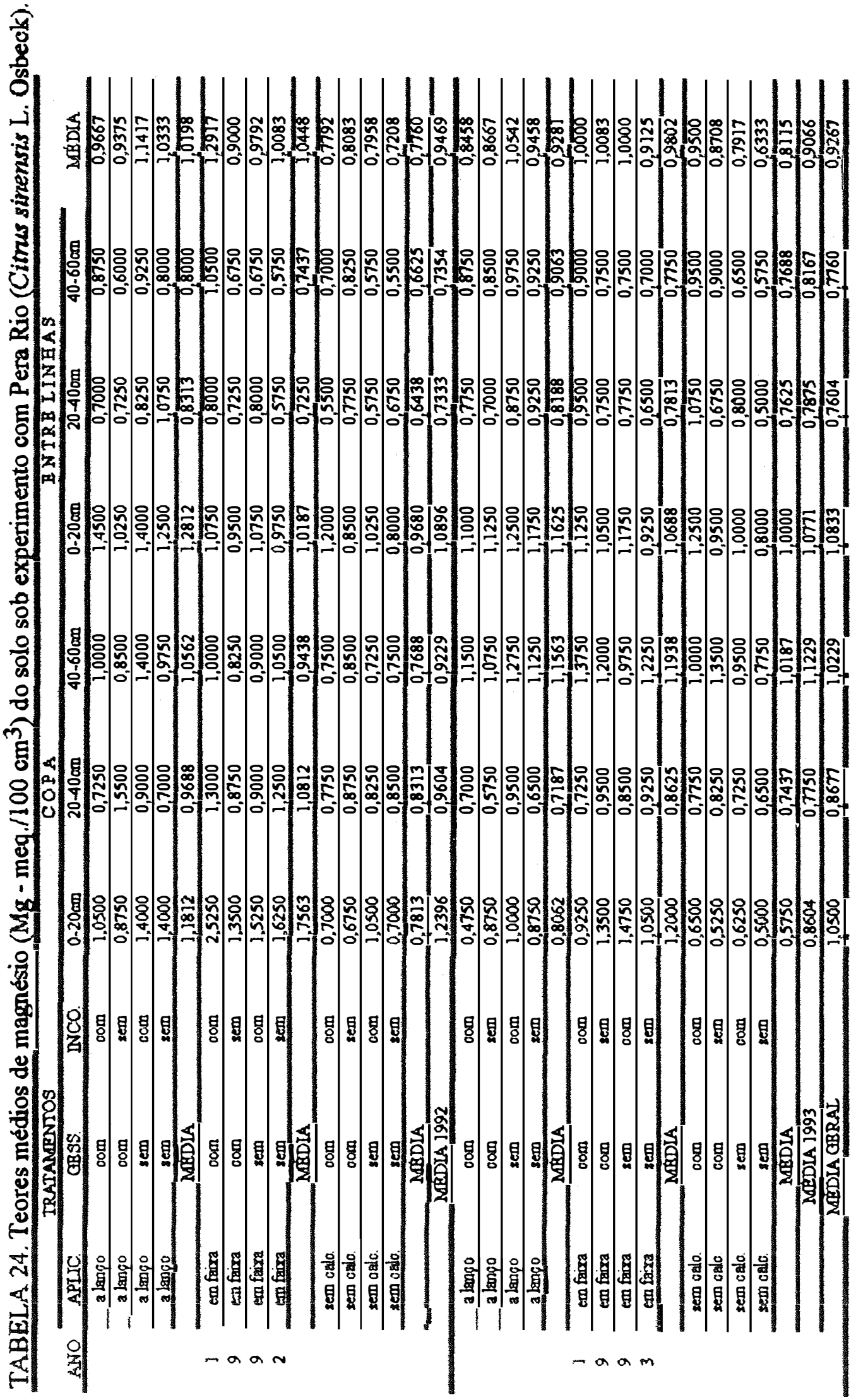


meq $/ 100 \mathrm{~cm}^{3}$, enquanto que a testemunha ficou com $0,79 \mathrm{meq} / 100 \mathrm{~cm}^{3}$ para a posição copa e na entrelinha os dados obtidos foram: 0,$97 ; 0,83$ e $0,76 \mathrm{meq} / 100 \mathrm{~cm}^{3}$ para a mesma ordenação dos tratamentos citados acima, revelando as respostas para o emprego do calcário bem como dos modos de aplicação, estando os teores acima de $0,8 \mathrm{meq} / 100 \mathrm{~cm}^{3}$ considerado como critico para a nutrição dos citros, de acordo com QUAGGIO (1991).

Da mesma maneira que para o $\mathrm{Ca}$, os valores de $\mathrm{Mg}$ reduxiram da primeira para a segunda época, principalmente na posição copa, ocorrendo também lixiviação, uma vez que houve aumento do mesmo em camadas profundas ( $40-60 \mathrm{~cm}$ ). Esses aspectos corroboram os dados conseguidos por QUAGGIO (1991), que alega ser o uso da adubação a causa da recução dos teores de $\mathrm{Ca}+\mathrm{Mg}$, na camada aravel do solo, marcadamente na projeção da copa, local sobre o qual são feitas as adubaçð̌es, e partanto são colocadas quantidades consideráveis de ânions. O emprego de fertilizantes nitrogenados, principalmente os que contém o nitrogênio nas formas amoniacal e amtdica, colaboram nesse sentido, sendo talvez as principais causas da acidificação do solo. Os resultados para o $\mathrm{pH}_{\mathrm{CaCl}}$ colocados na Tabela 25, evidenciam tais comentários, pois a recução nos valores do mesmo foram maiores na posição copa, havendo compontamentos distintos com relação aos modos de aplicação, ocorrendo diferenças estatisticas (Quadro 15) para os modos em faixa e sem corretivo, na primeira época para as médias de copa versus entrelinha, sendo maior na copa para o tratamento em faixa, indicando o posicionamento do calcário, e menor quando não se utilizou o calcário, evidenciando os aspectos de acidificação já comentados. 


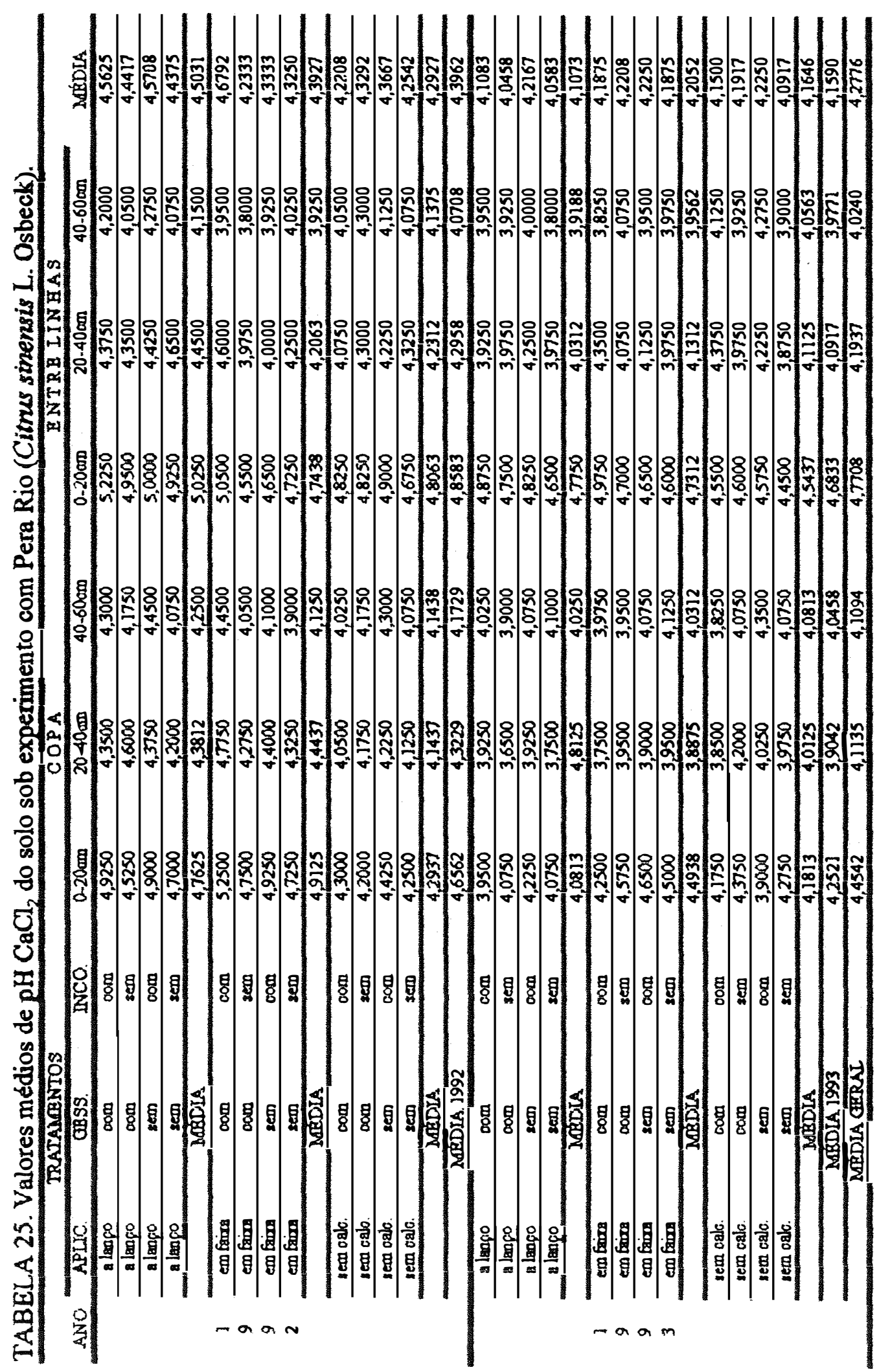


A relação Ca Mg (Tabela 26) foi afetada pela gessagem, uma vez que esta aumentou os teores de $\mathrm{Ca}$, conforme comentado anteriormente, sem no entanto alterar os de $\mathrm{Mg}$, fazendo com que a relação CaMg elevasse significativamente (Quadro 16).

Como os elementos $\mathrm{Ca}$ e $\mathrm{Mg}$ são predominantes no complexo de troca de cátions do solo, o comportamento de ambos refletiu na porcentagem de saturação de bases V\% como pode ser observado na Tabela 27, onde na primeira época obteve-se efeito significativo (Quadro 17) dos modos de aplicação sobre a variável em questăo, com maiores valores de saturação na posição copa para o tratamento em faixa do que na entrelinha, enquanto que para os outros modos não há distinção entre as médias de saturação para posição. Na primeira época as médias dos tratamentos que receberam calcário na posição copa, foram superiores a da testemunha, por outro lado na posição da entrelinha, a saturação por bases foi maior para a aplicação a lanço, não havendo diferenças entre as médias dos tratamentos em faixa e o sem calcário. Acréscimos na V\% devido ao emprego de corretivos, também foram alcançados por AMARAL (1989); QUAGGIO (1991); VECCHI (1993); PARO (1994 ); VIEIRA (1994). Com relação aos valores da saturação por bases, na primeira época e na posição da copa, para a camada de 0-20cm, foram de $58,1 \%$ e $63,1 \%$ respectivamente para os modos a lanço e em faixa, enquanto que para o que não recebeu calcário o valor foi de $47,0 \%$. Por outro lado, na mesma época e camada, porém na posição da entrelinha os dados obtidos foram: $61,9 \%$ para o modo a lanço; $55,6 \%$ para o em faixa e $56,6 \%$ para o sem calcário. A incorporação refletiu somente na primeira época, elevando a V\%, estando em concordância com os dados de $\mathrm{Ca}$ e Mg. Nas camadas inferiores, os dados de saturação 


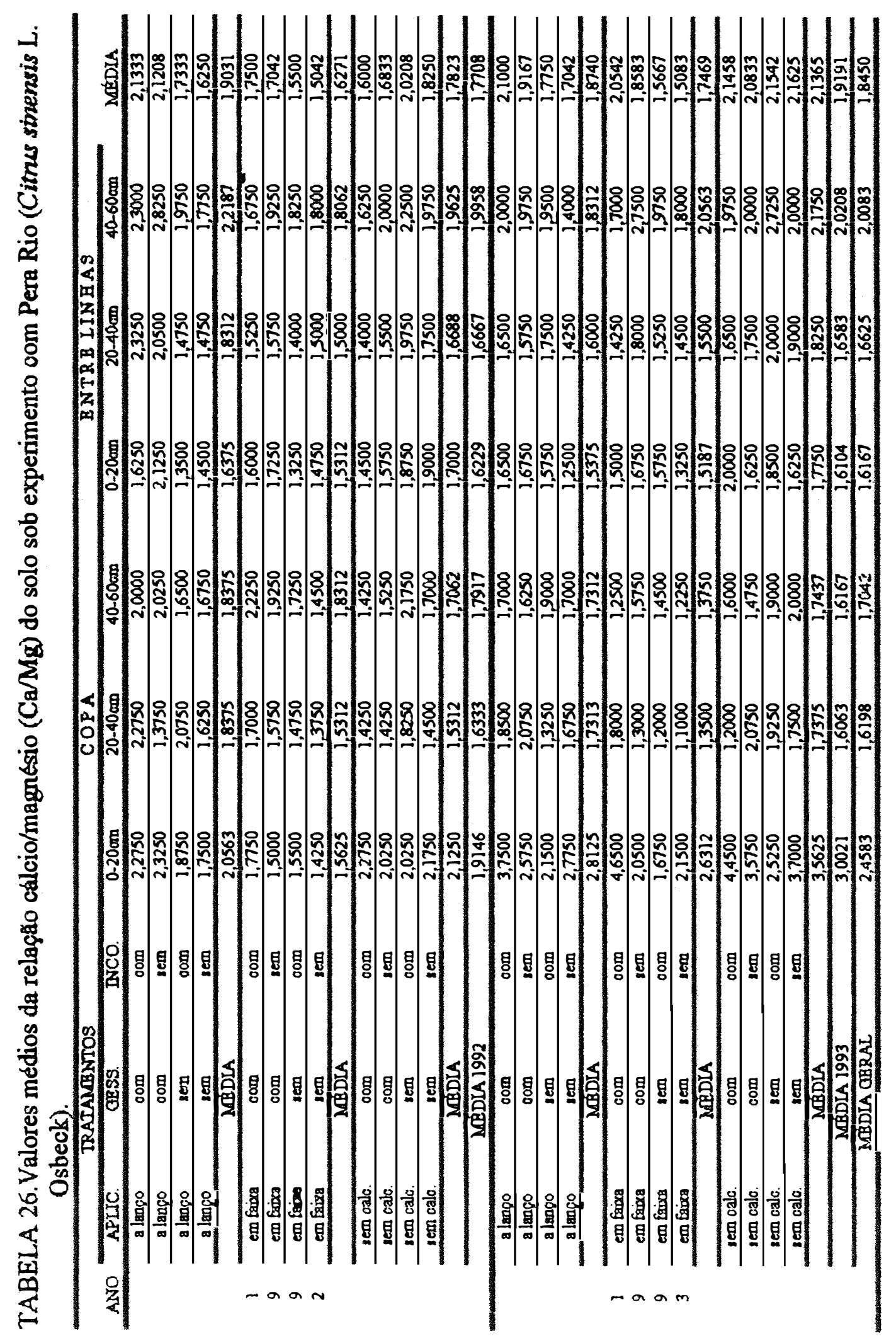




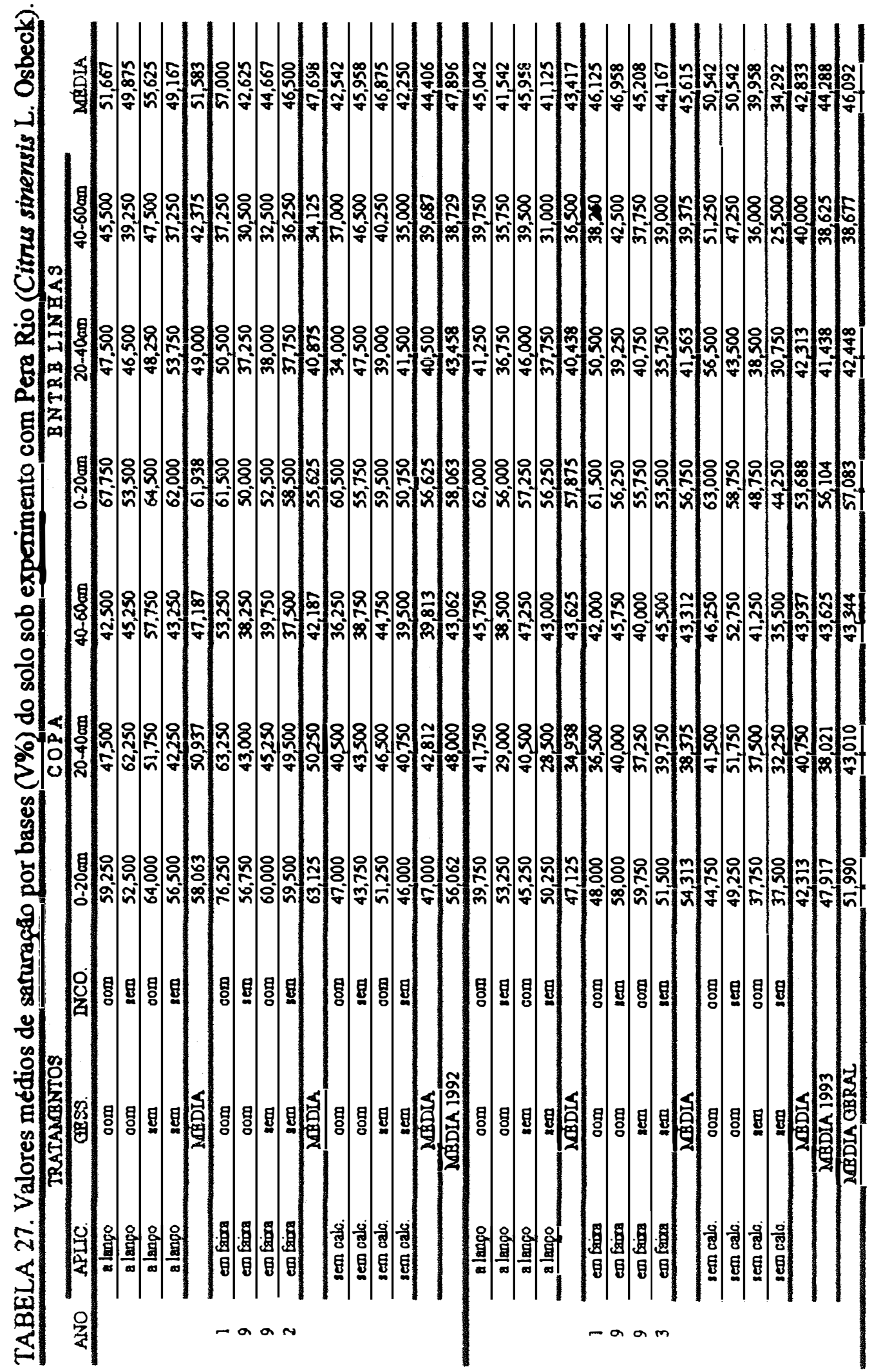


foram inferiores, não atingindo a recomendação esperada que era de $70 \%$, conforme GRUPO PAULISTA DE ADUBAÇÃO E CALAGEM PARA CITROS (1988). Como houve reduçăo nos teores de Ca e Mg da $1^{\underline{a}}$ para a $2^{\underline{a}}$ epoca, devido ao processo de acidificação do solo, os dados de saturação por bases diminutram acentuadamente, na posição copa, a ponto de não mais se obter diferenças entre as médias para posição, bem como entre tratamentos de aplicação, corroborando os dados de MAZZA (1993).

Para o Al, de acordo com a Tabela 28 não encontrou-se efeito significativo (Quadro 18) para os modos de aplicação, devido aos baixos valores obtidos para o tratamento sem calcário, principalmente na entrelinha, o que não era esperado. Por outro lado, o fator gessagem que na primeira época nđ̃o manifestou efeitos sobre os teores do $\mathrm{Al}$, na segunda proporcionou redução significativa, estando de acordo com os resultados obtidos por CASARIN (1994). Quanto a incorporação, tal como para o Ca e Mg, os efeitos ocorreram somente na primeira época, de forma a diminuir os teores de $\mathrm{Al}$, principalmente na camada de $0-20 \mathrm{~cm}$. Para local, em termos de média geral, não houve distinção entre copa e entrelinha na primeira época, no entanto, na segunda o Al foi superior na copa, evidenciando os aspectos de acidificação já comentados anteriormente para o Ca e Mg nessa posição. Embora para a média geral de Al não hourvesse diferenças entre locais, a interação local $x$ aplicação apresentou-se significativa, de maneira que a aplicação a lanço recuziu mais o Al na entrelinha do que na copa, o que concorda com a maior dose aplicada por esse modo nessa posição, enquanto que o em faixa condưiu a maiores reduções no Al na copa do que na entrelinha, corroborando também os dados de aplicação ( item 4.1). 


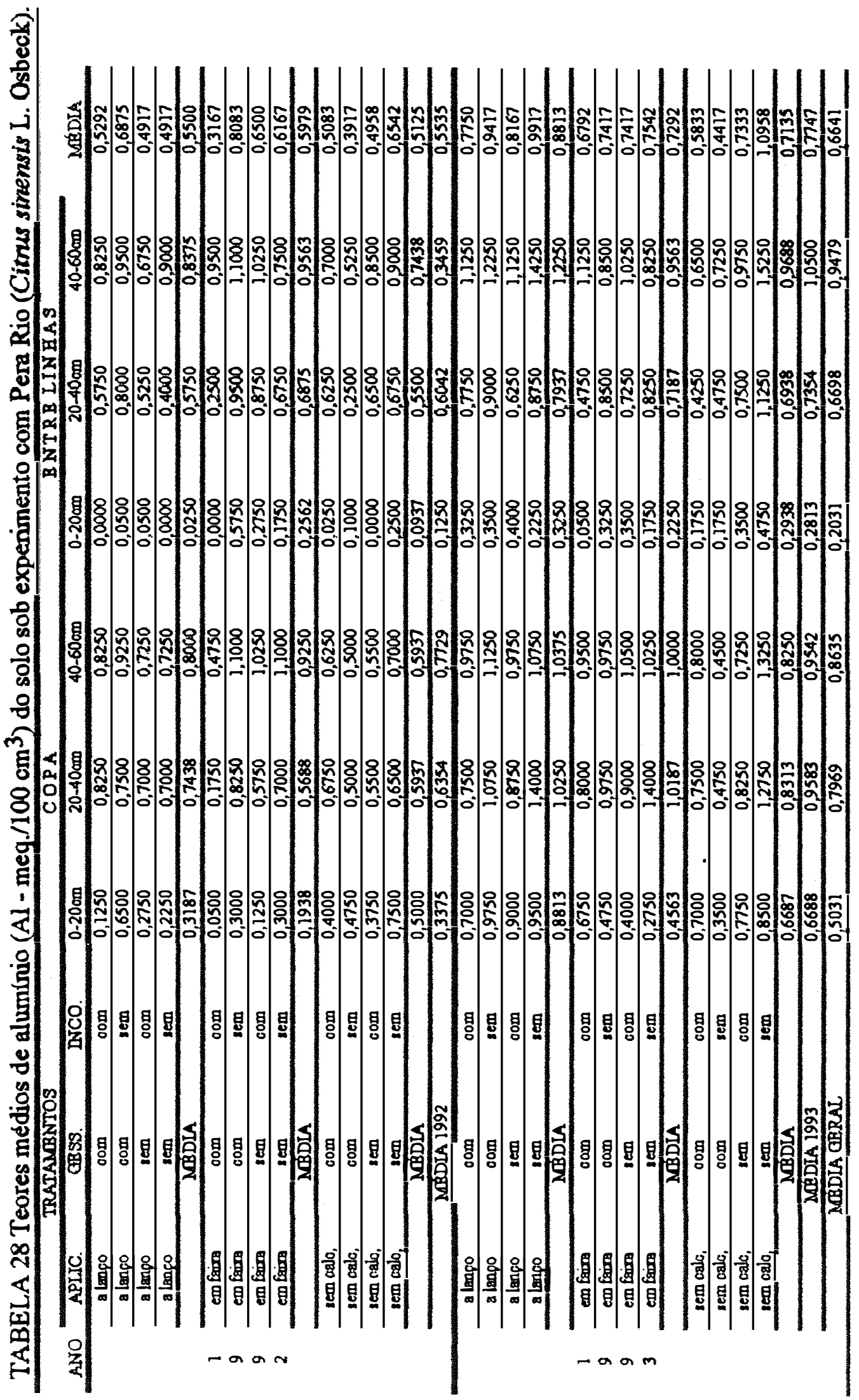


O comportamento do Al refletiu sobre os valores da saturação por aluminio m, (Tabela 29) com os mesmos efeitos significativos (Quadro 19), como o da gessagem, que segundo MAZZA (1993) é uma eficiente maneira de se rechuzir o valor de m, quer pela redução do Al, bem como pelo acréscimo no Ca, concardando com VECCHI (1993).

Os modos de aplicação interferiram sobre o valor da CTC, como pode ser visto na Tabela 30 e Quadro 20 nas duas épocas, no sentido de elevá-la, assim como para local e protundidade. Maiores valores foram encontrados na posição da copa nas duas épocas, sendo os maiores incrementos na camada de $0-20 \mathrm{~cm}$. Como se trata da CTC calculada, os aumentos devido à calagem devem-se provavelmente aos acréscimos nos teores de $\mathrm{Ca}$ e $\mathrm{Mg}$, bem como ao $\mathrm{K}$, na copa devido às adubaçðes. Tais efeitos também foram encontrados por CASARIN (1994) e MAZZA (1993).

O comportamento dos atributos químicos do solo aliado ao das técnicas de aplicação, nos leva a sugerir a altemancia dos modos de aplicação de calcário em pomares de citros instalados, de acordo com a necessidade de calagem.

A gessagem elevou significativamente (Quadro 21) os teores de $\mathrm{SO}_{4}$, que estão colocados na Tabela 31, bem como promoveu um gradiente crescente com a profundidade, o que também foi conseguido por AMARAL (1989); PARO (1991); VIEIRA (1994); CASARIN (1994). A incorporação levou a redução do $\mathrm{SO}_{4}$, o que talvez possa ser explicado pela maior predisposição do mesmo à movimentação no perfil, uma vez que mecanicamente já é colocado a cerca de $10-15 \mathrm{~cm}$ de profundidade.

Embora não se tenha feito distinção para a adubação, è interessante verificar a maneira como se compartou os teores de K no solo (Tabela 32), sendo a posição copa a que merece destaque, pois via de regra é a que recebe adubaçåo potássica, tanto é 


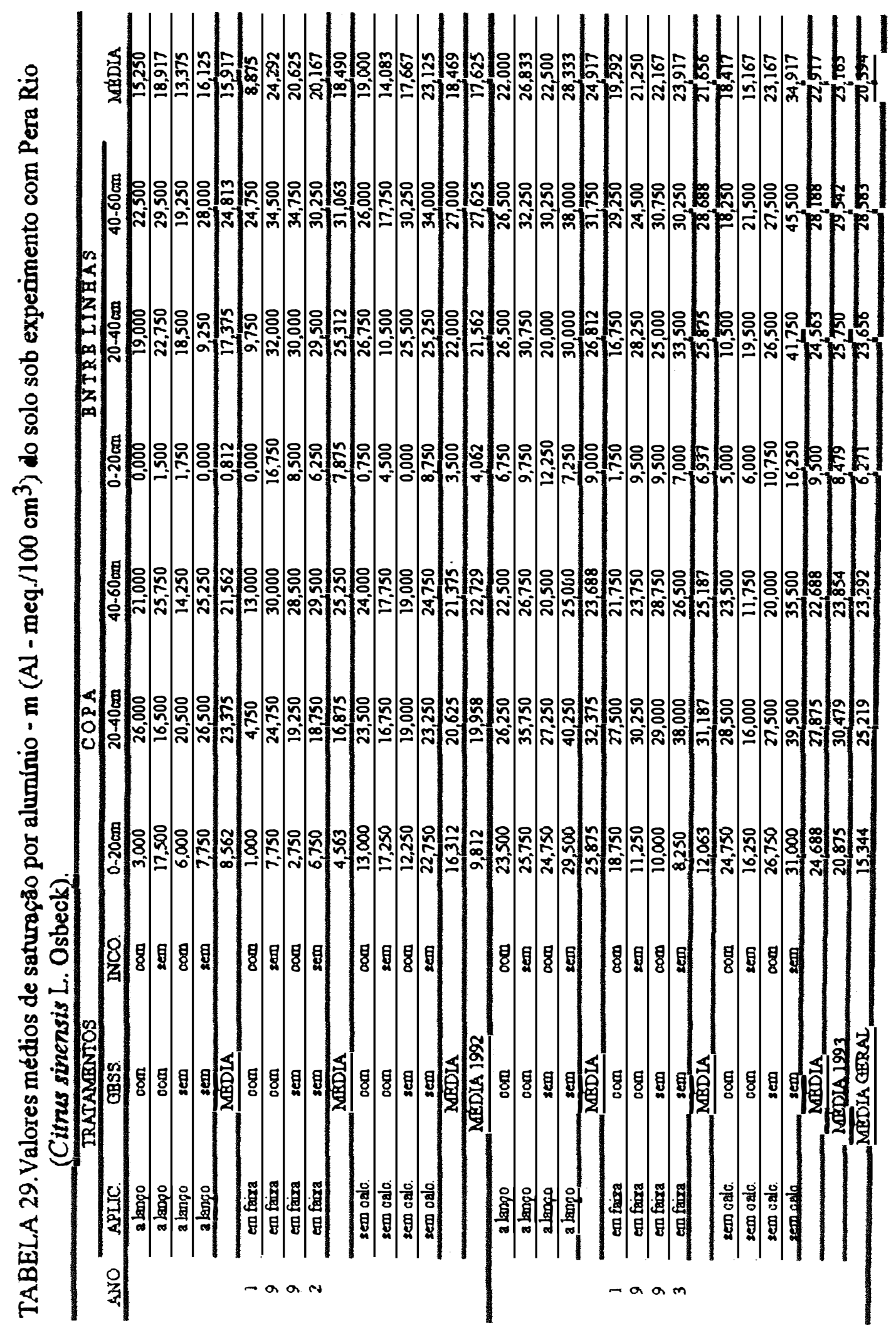




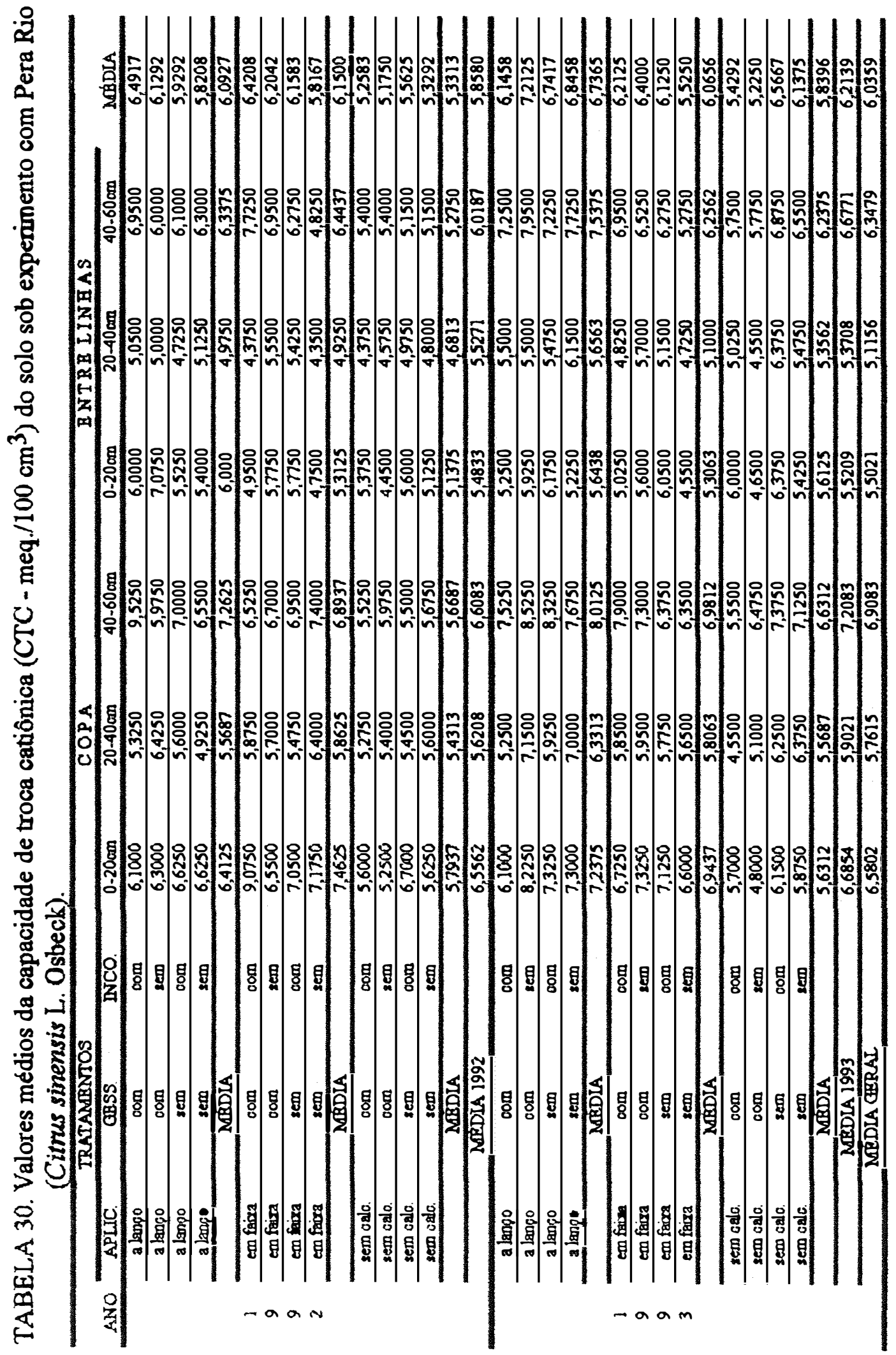




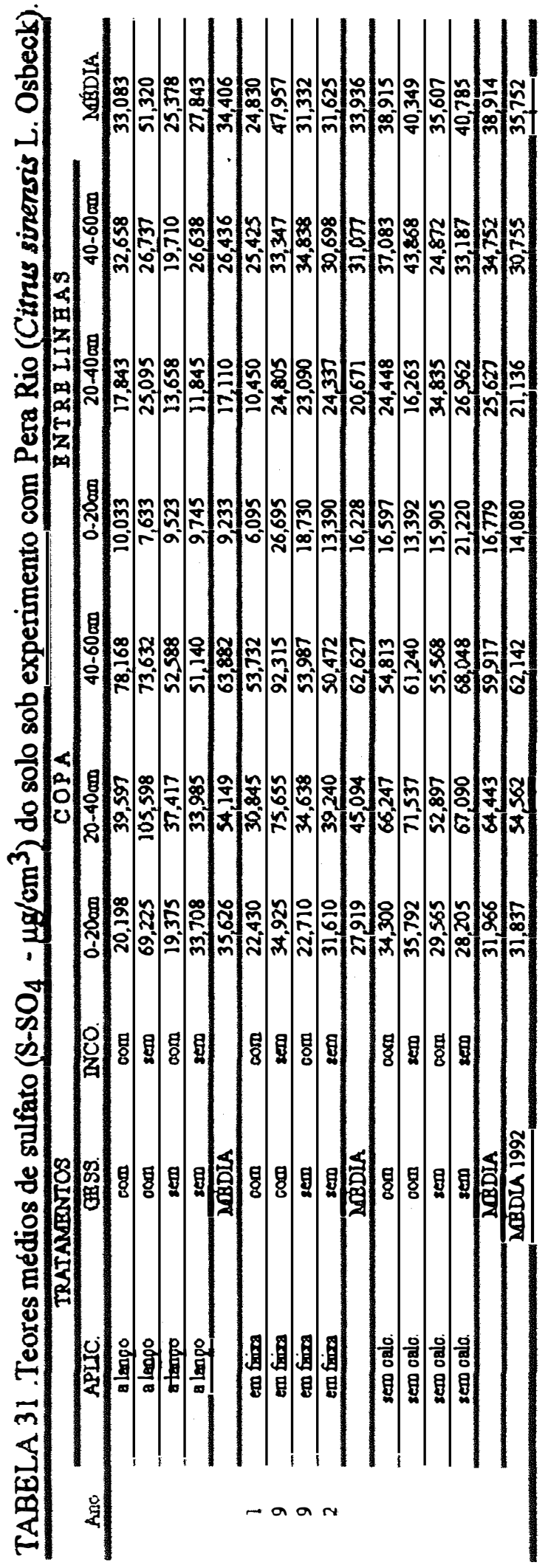




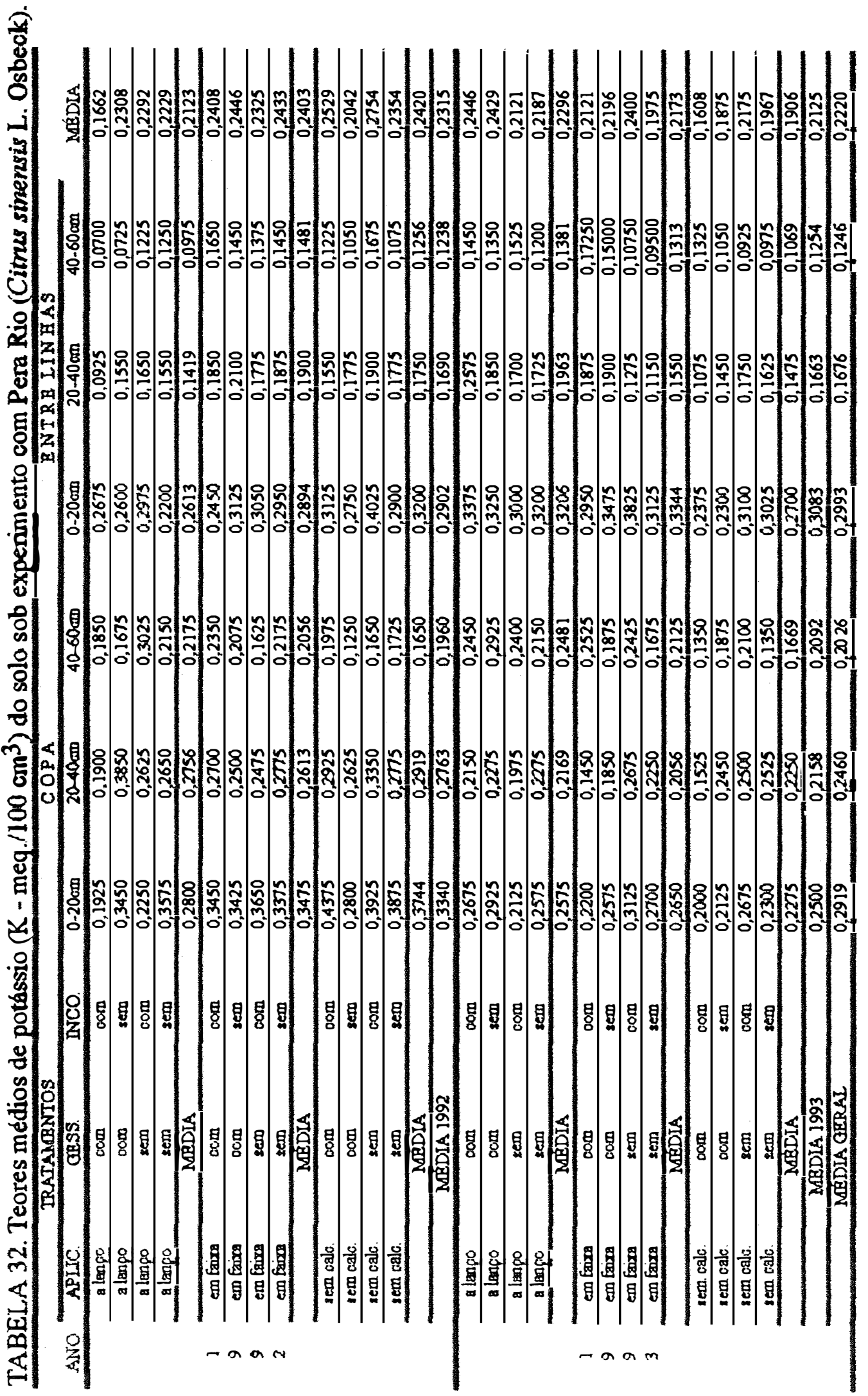


assim, que os teores médios de K são maiores estatisticamente (Quadro 22) na posição da copa. Fixando a posição ( copa ), e observando-se as épocas de amostragem do solo, nota-se que os teores cairam sensivelmente da primeira para a segunda época, e que a redução foi maior para o tratamento sem calcário. Isto se deve provavelmente, a maior liberaçåo de cargas negativas dependentes de $\mathrm{pH}$ proporcionadas pela calagem, efeito também observado por QUAGGIO (1991); VIEIRA (1994). Tal fato se confinma na observância da relação CaK (Tabela 33), pois como o $\mathrm{K}$ foi o mesmo para todos os tratamentos, percebe--se que essa relação foi menor na primeira época para o tratamento sem calcário, e maior na segunda, o que talvez esteja relacionado a maior redução nos teores de K, devido a não calagem, uma vez que os teores de Ca nessa condição não se diferenciam. A relação $\mathrm{Mg} / \mathrm{K}$ apresentou -se de maneira semelhante à $\mathrm{Ca} / \mathrm{K}$, de acordo com a Tabela 34, inclusive obtendo-se as mesmas significancias estałsticas (Quadros 23 e 24) para as diferenças entre médias, para posiçăo de amostragem versus tratamentos de aplicação. O mesmo comportamento foi observado na relação $\mathrm{Ca}+\mathrm{Mg} / \mathrm{K}$ (Tabela 35 e Quadro 25)

\subsection{Composição mineral das folhas}

O estado nutricional da Pera Rio foi afetado pelos fatores testados, com exceção dos modos de aplicação, de maneira que a gessagem promoveu acrescimos significativos (Quadros 26, 27 e 28) no teor de Ca e redução para o $\mathrm{Mg}$, na $1^{\text {a }}$ época, refletindo na relação Ca Mg nas duas épocas, no sentido de elevá-la, conforme Tabelas 36, 37 e 38, respectivamente. A relação Ca/K contida na Tabela 39, também sofreu influência significativa da gessagem (Quadro 29), de maneira crescente na $1^{\text {a }}$ epoca, devido 


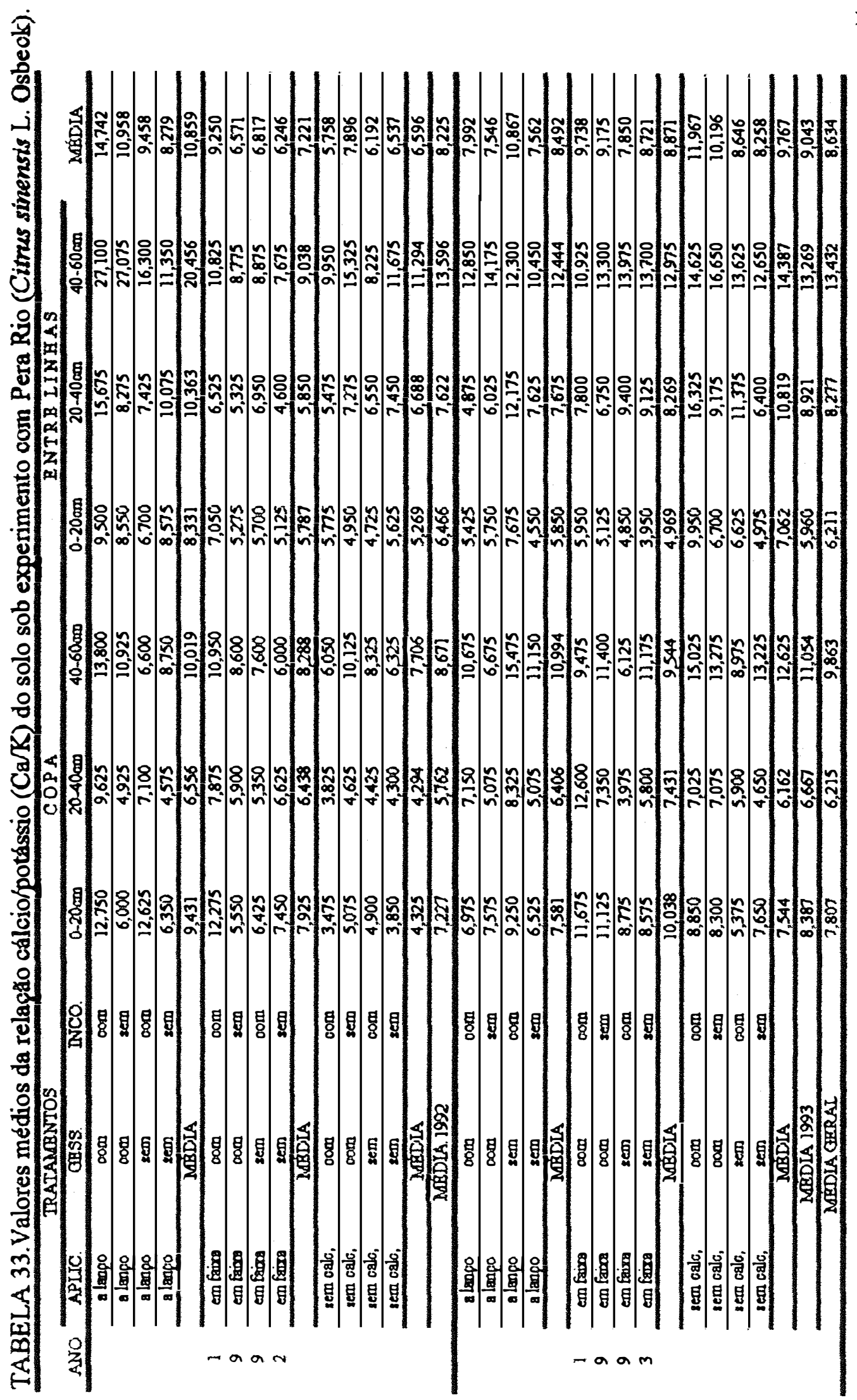




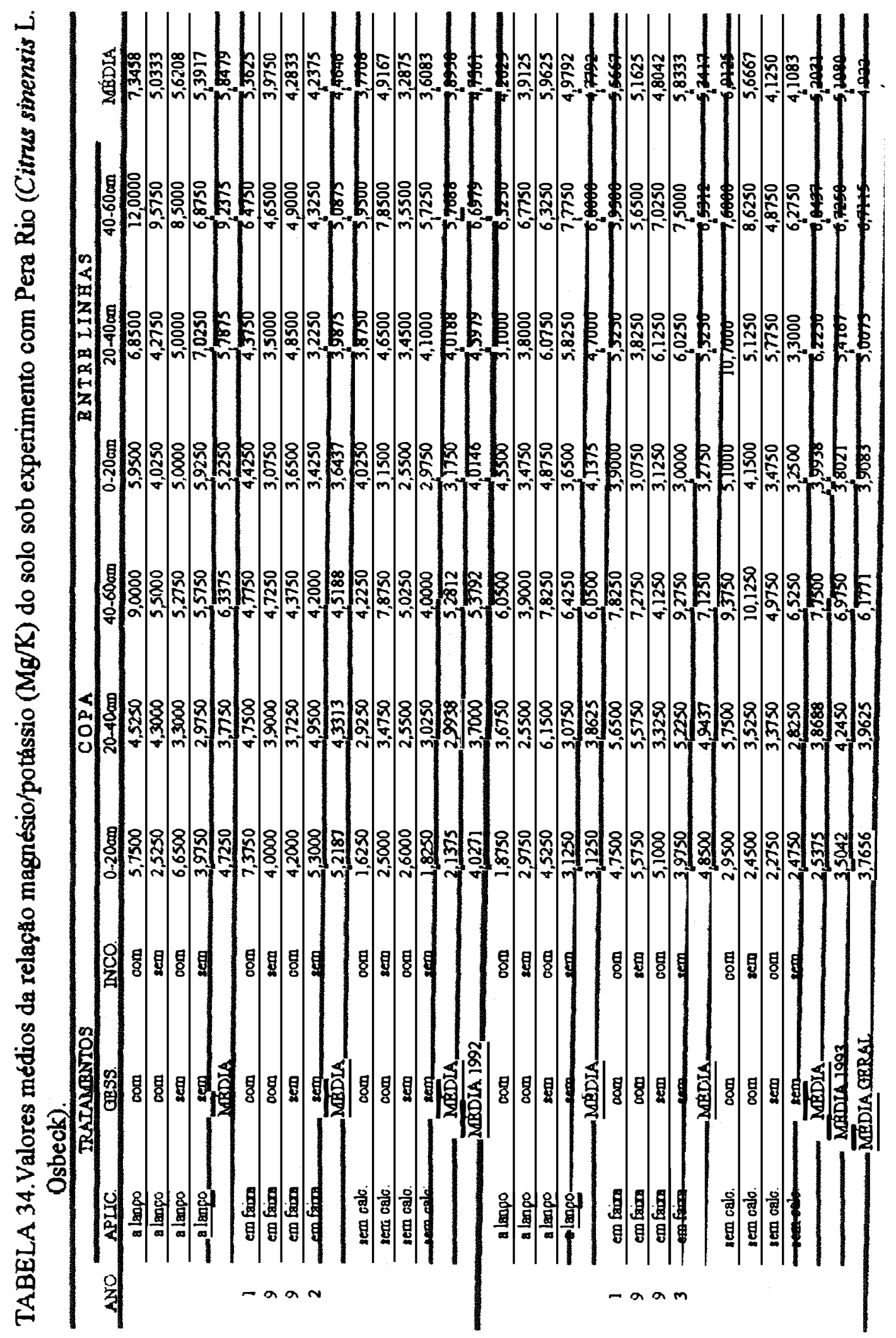




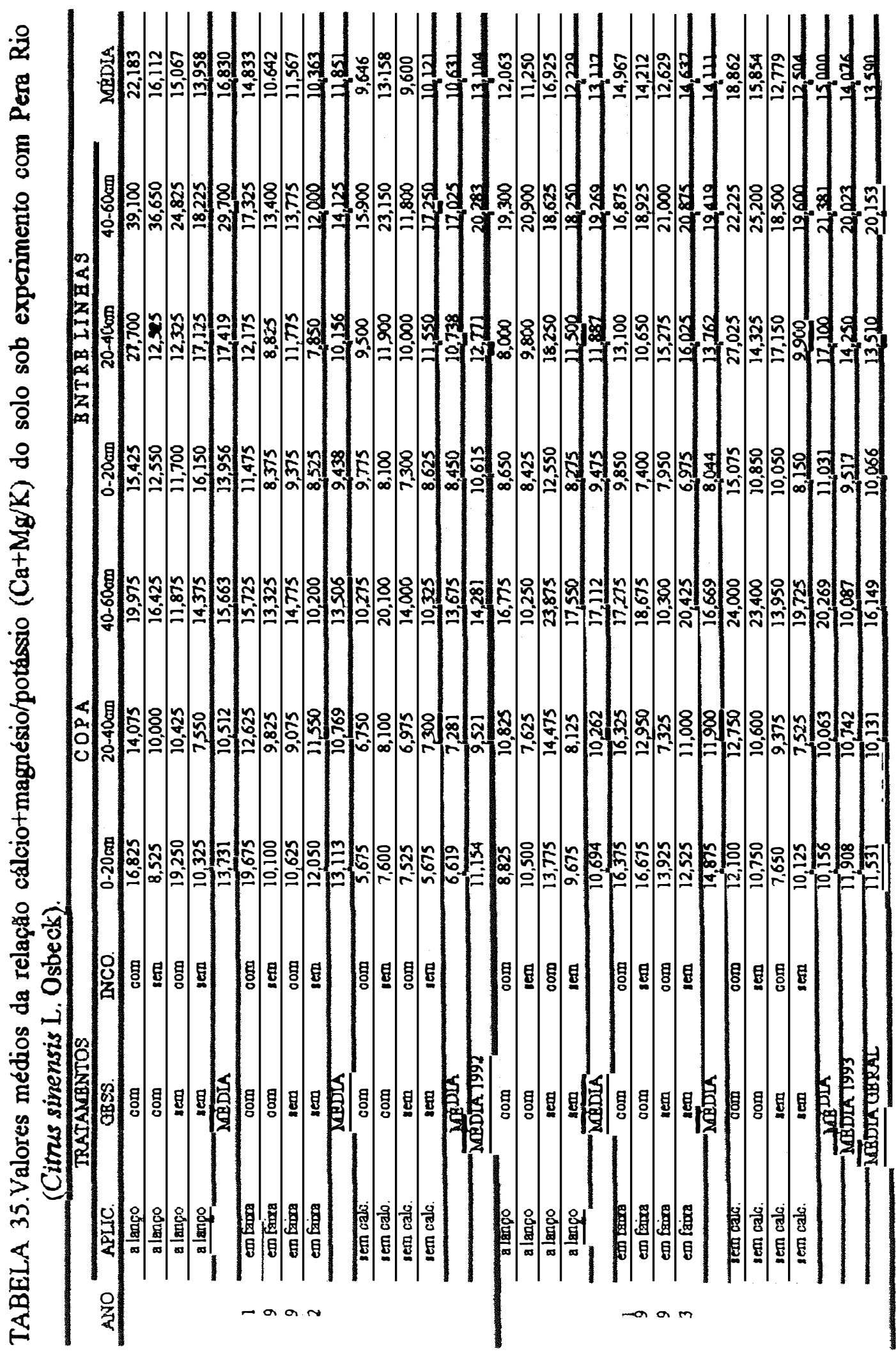




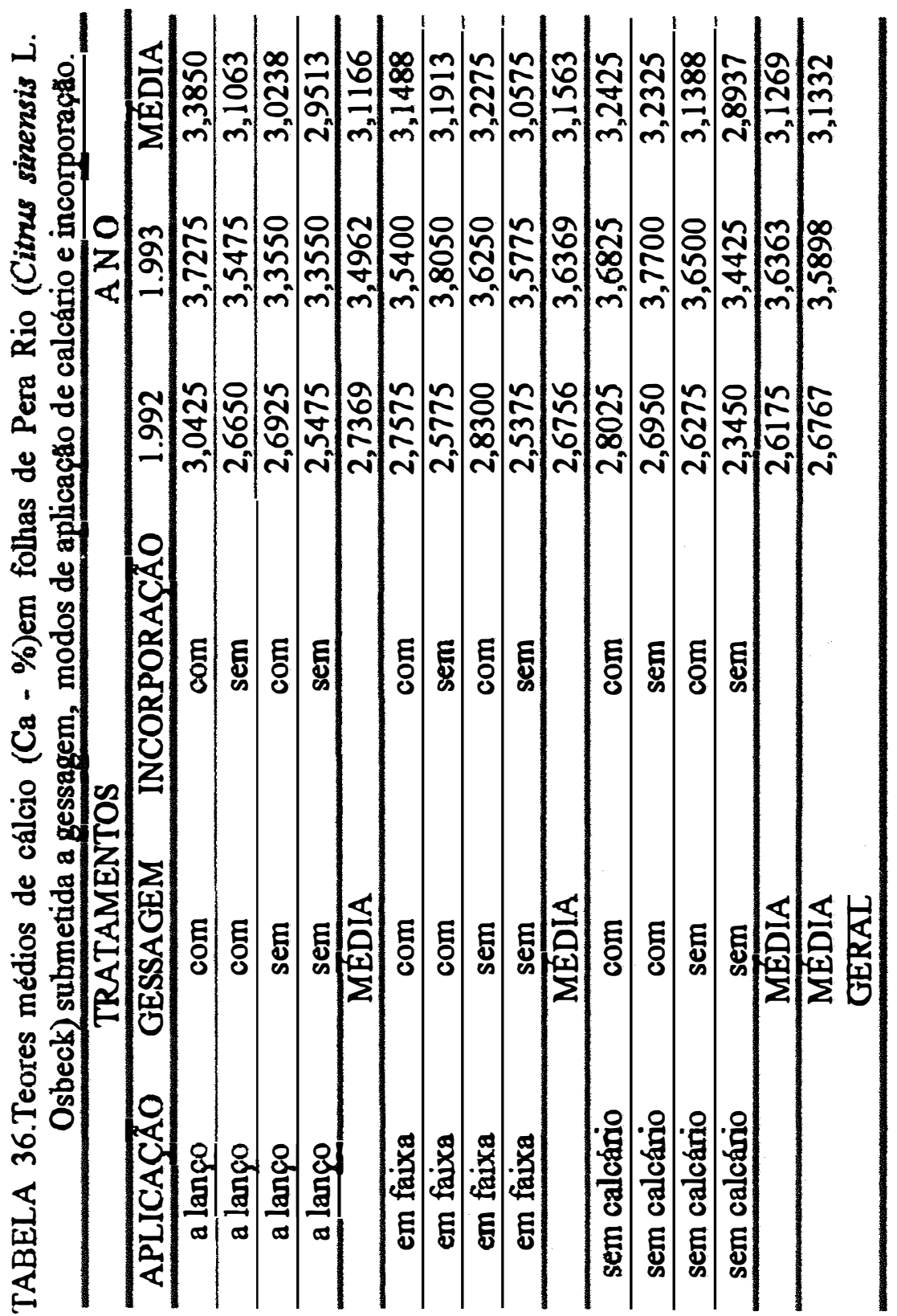




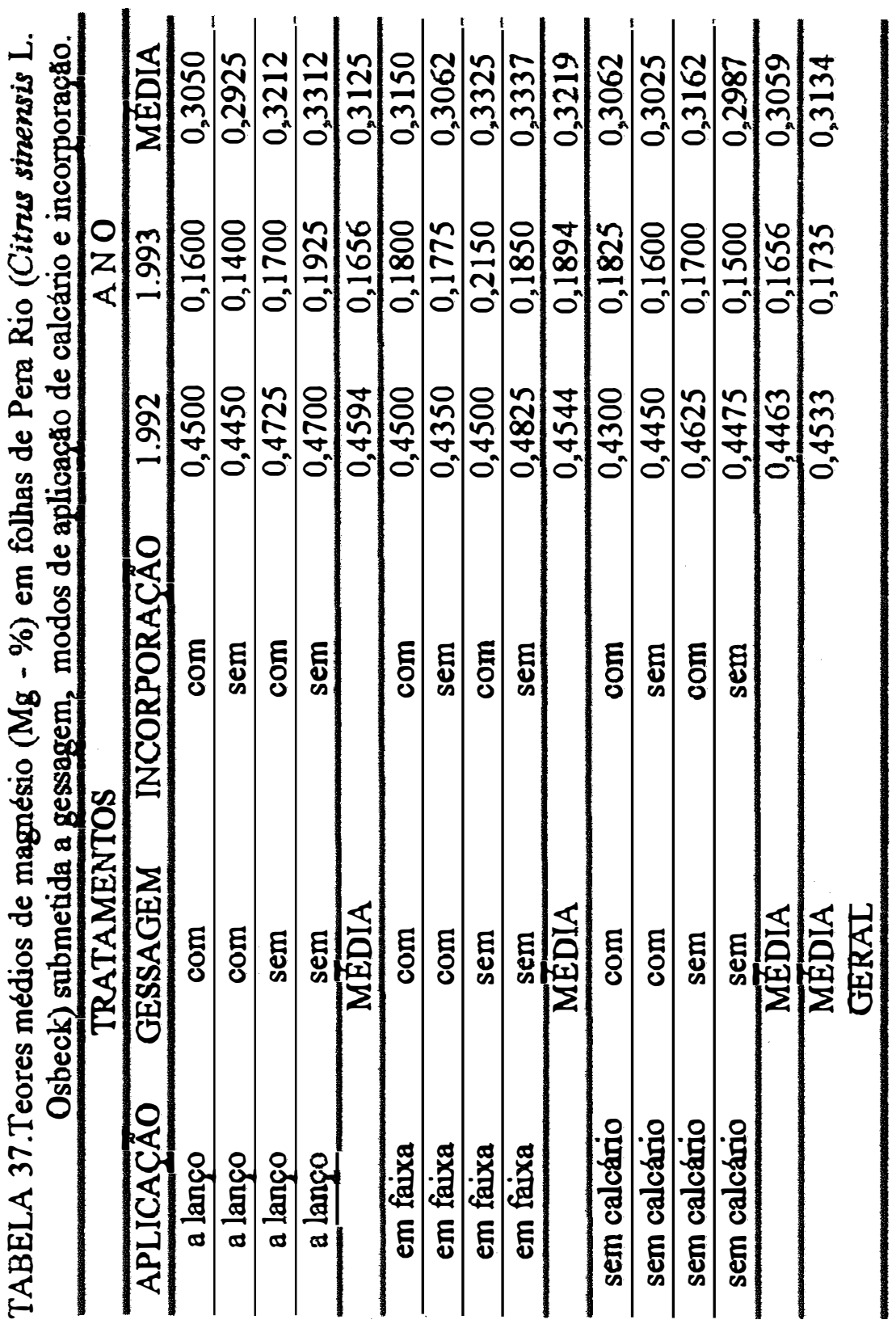




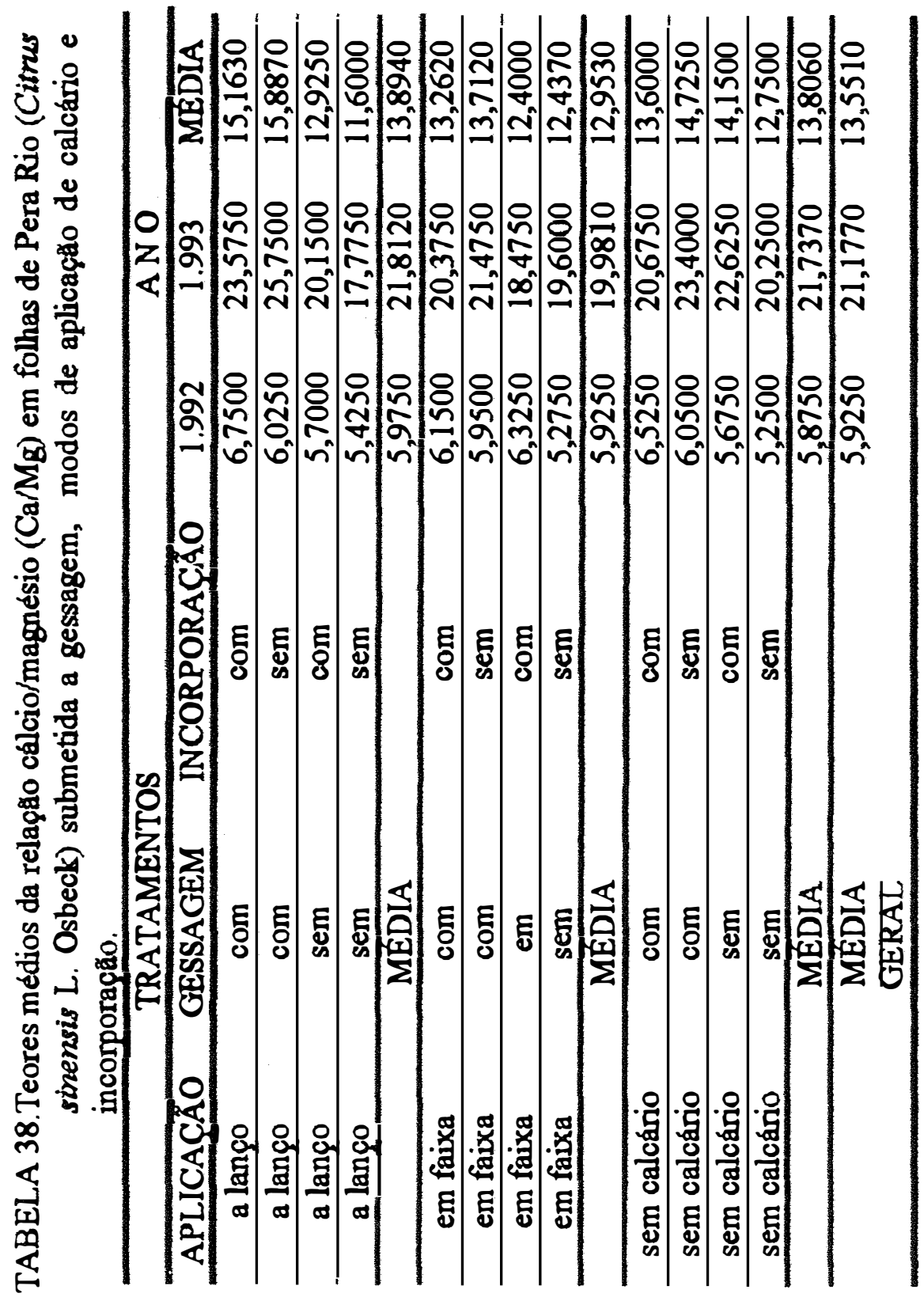




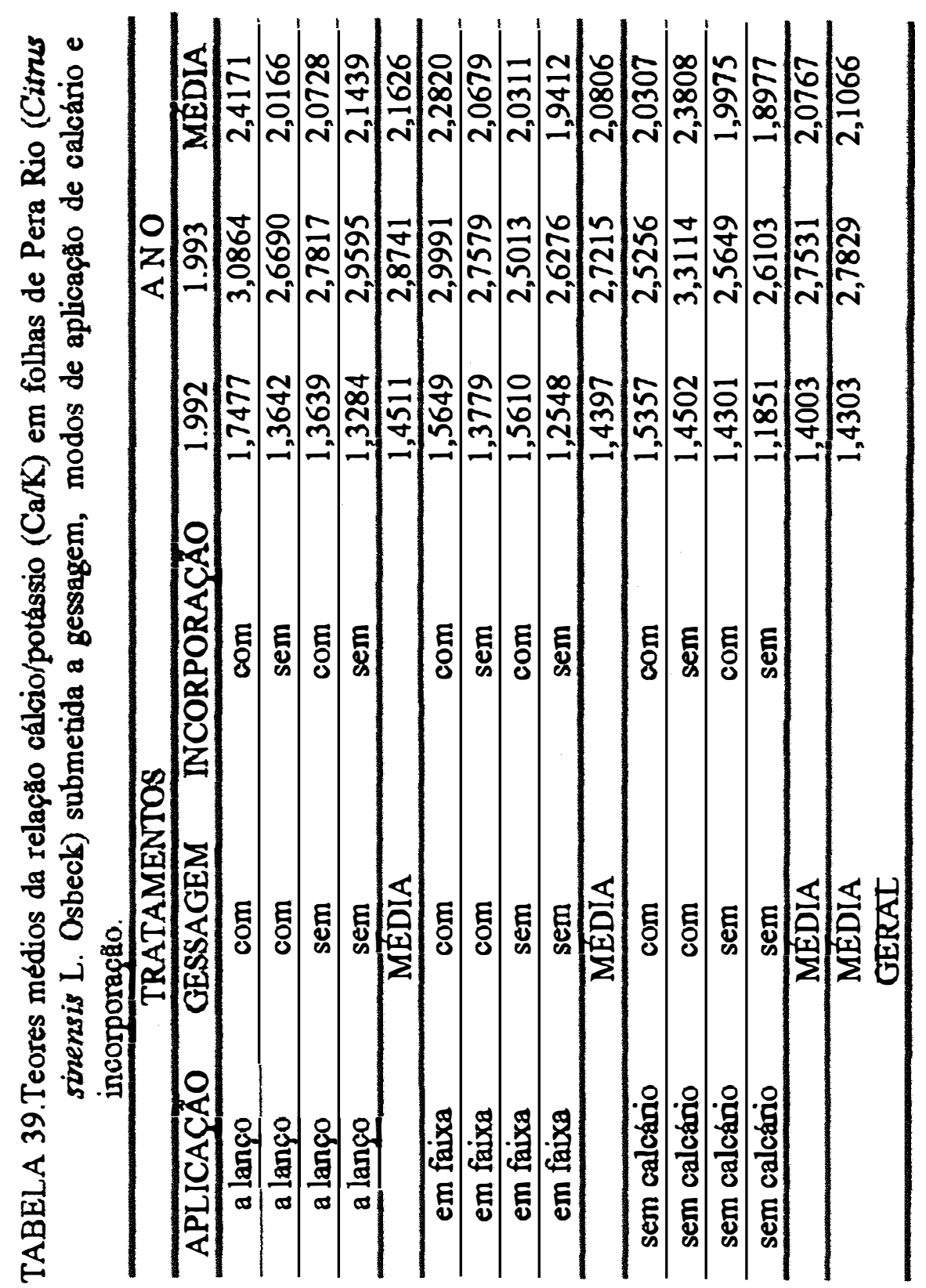


provavelmente à elevação do $\mathrm{Ca}$ formecido pelo gesso. Tal condição afetou também a relação $\mathrm{Ca}+\mathrm{Mg} / \mathrm{K}$ (Tabela 40 e Quadro 30), aumentando-a, devido às reduçðes de $\mathrm{K}$ (Tabela 41 e Quadro 31) e aos acréscimos no Ca. Os efeitos observados para a gessagem são concordantes com os obtidos por AMARAL (1989) e PARO (1991), inclusive a não constatação de efeitos para os teores foliares de $\mathrm{N}$ e P (Tabelas 42 e 43 e Quadros 32 e 33). Embora não significativo $(P>0,05)$, notou-se tendências de acréscimos nos valores de S (Tabela 44 e Quadro 34) quando se empregou a gessagem, concondando com os dados de VECCHI (1993)

A incorporação por sua vez, interferiu nos teores foliares de $\mathrm{Ca}$, na $1^{a}$ época, obtendo-se maiores valores, o que pode ser devido ao maior teor de $\mathrm{Ca}$ no solo $(0-20 \mathrm{~cm})$ proporcionado pela incorporação na mesma época, enquanto que houve reduçăo, na folha, para o $\mathrm{K}$ e $\mathrm{Mg}$ na condição incorporada, aumentando as relaçð̃es $\mathrm{Ca} / \mathrm{K}$ e $\mathrm{Ca} \mathrm{Mg}$. Tal comportamento, pode ser explicado pelo antagonismo existente entre $\mathrm{Ca} \mathrm{e} \mathrm{K}$, que é mais acentuado, e entre Ca e Mg, conforme comentário de KAMPFER (1.963), sendo também constatado por QUAGGIO (1991) para o Ca e K. Devido a diminuição dos teores de Mg e $\mathrm{K}$ provocada pelos efeitos da gessagem e incorporação, respectivamente, observa-se (Tabela 45 e Quadro 35) que os valores médios da relação $\mathrm{Mg} / \mathrm{K}$ não se alteraram $(\mathrm{P}>0,05)$.

Com relação aos niveis dos macronutrientes nas folhas, que dão um indicativo do estado nutricional da planta, usando a tabela de interpretação do GRUPO PAULISTA PARA ADUBAÇÃO E CALAGEM DOS CITROS (1994), em termos de média geral, nota-se que o Ca é considerado baixo na $1^{a}$ época, porém adequado na $2^{a}$, enquanto que para o Mg o comportamento foi ao contrário, podendo ser reflexo da redução dos teores devido à acidificação aliado a redução provocada pelo gesso. Embora tenha ocorrido redução nos niveis de $\mathrm{K}$ nas folhas, entre as épocas de amostragem, pode ser considerado 


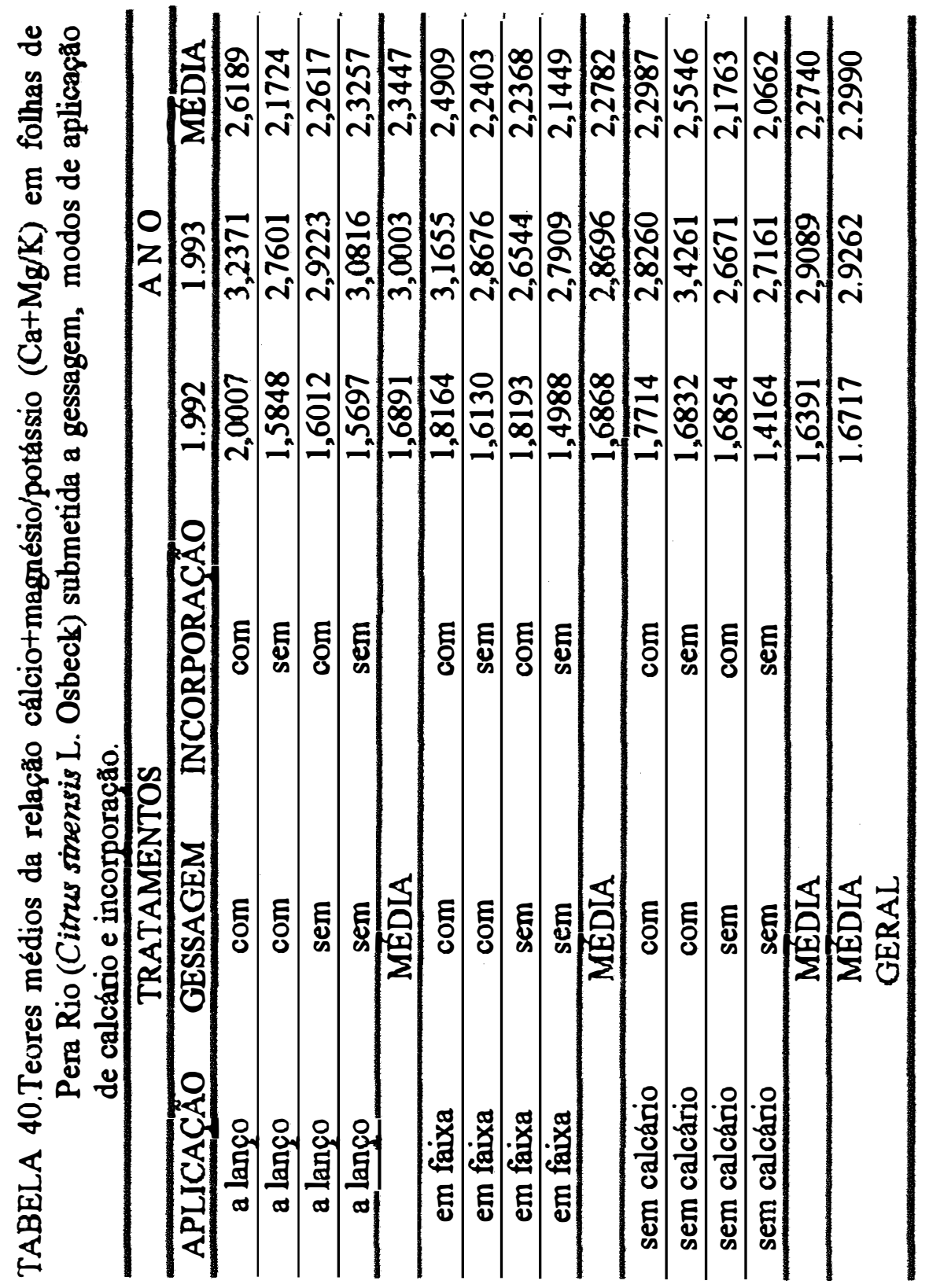




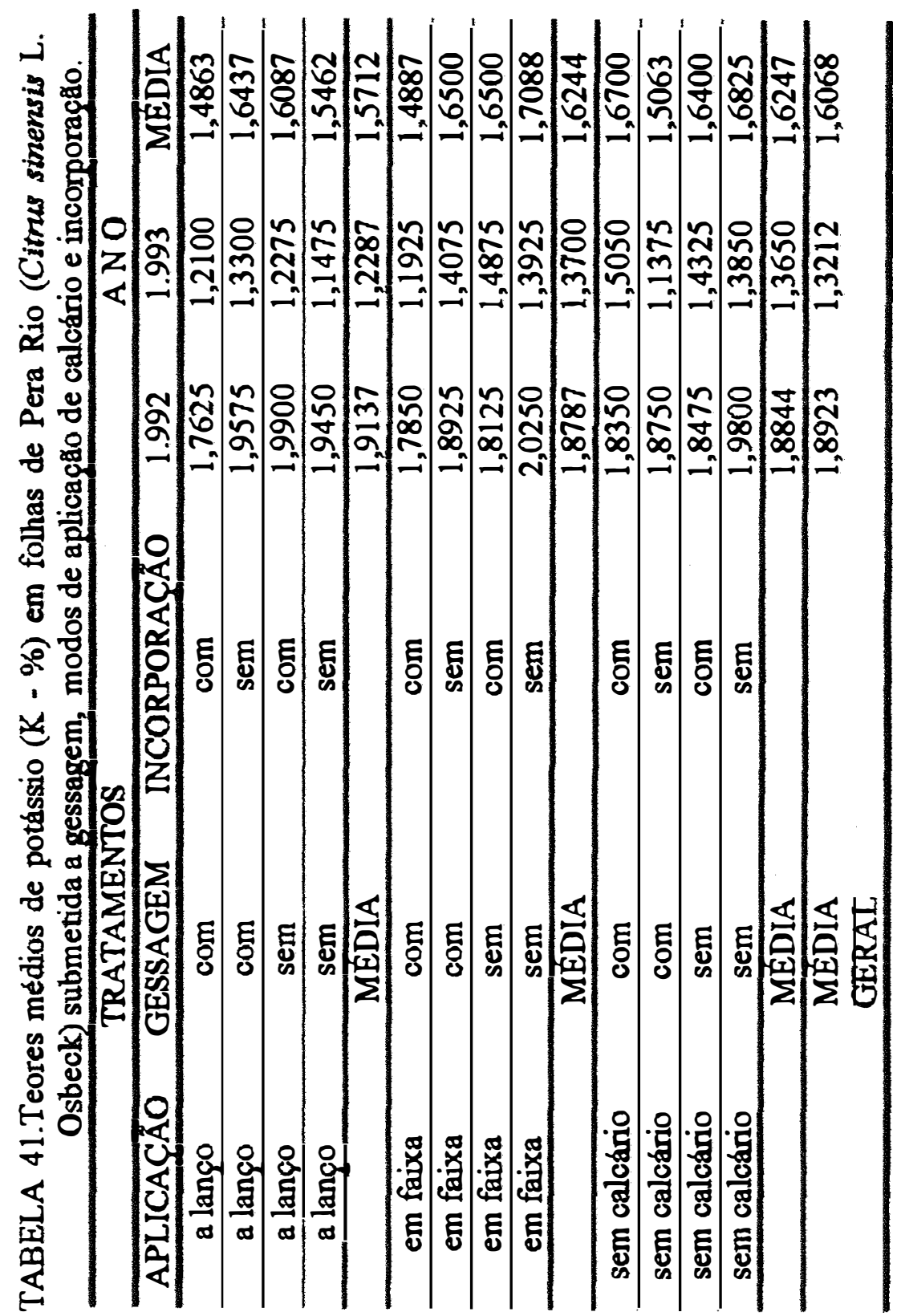




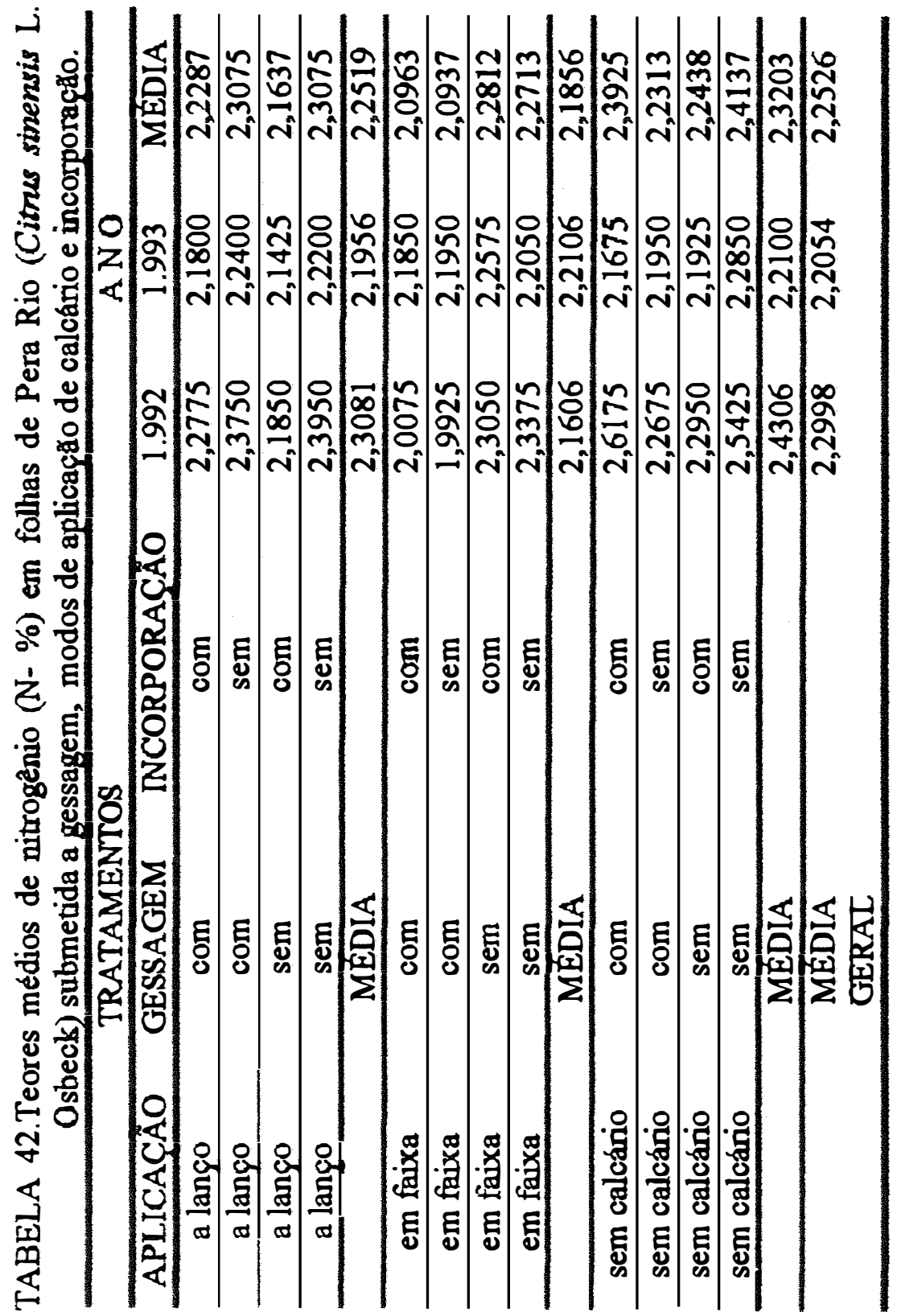




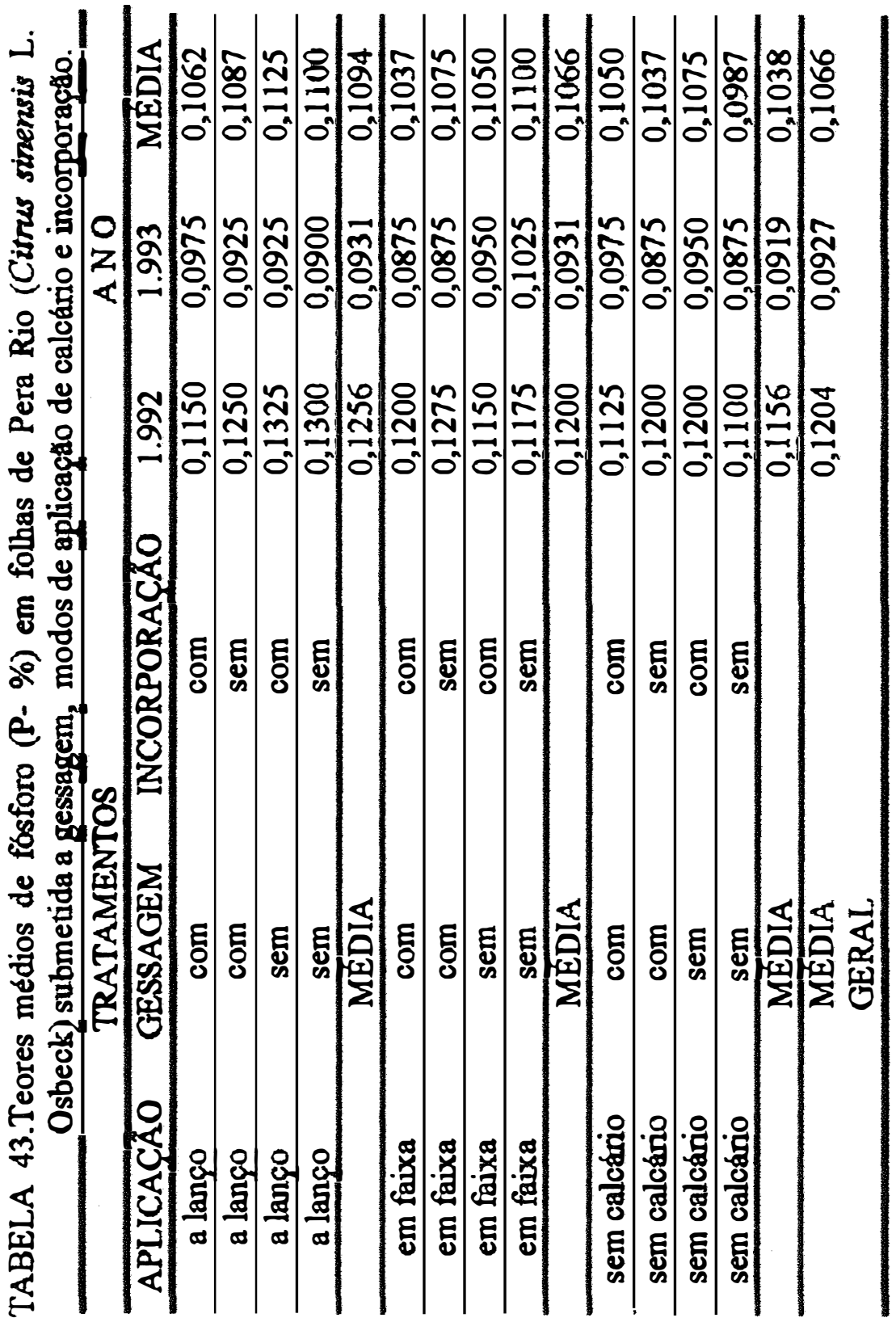




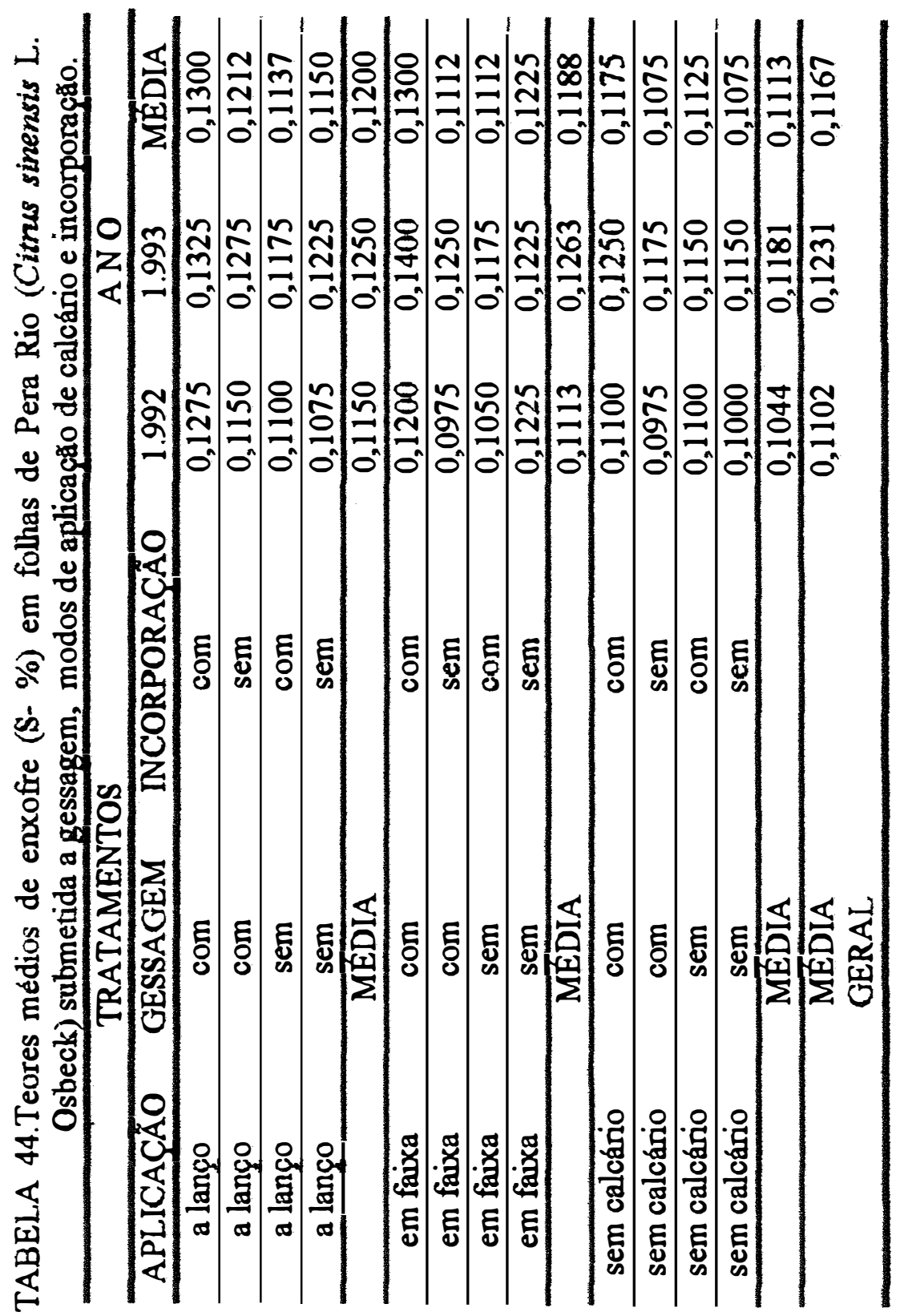




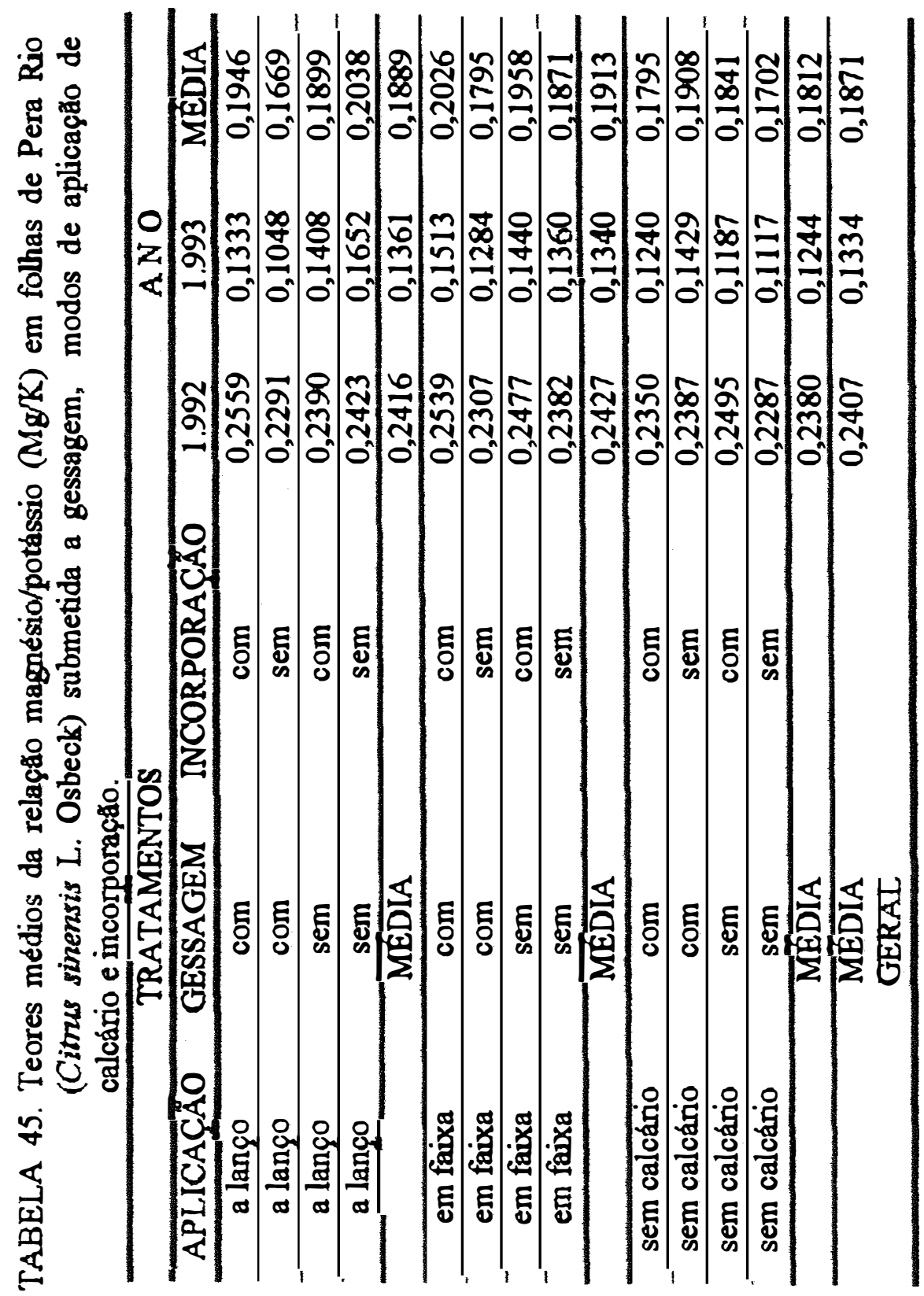


adequado em ambas. Os niveis de $\mathrm{S}$ estão baixos nas duas épocas, e o $\mathrm{P}$ e $\mathrm{N}$ encontramse nos limites inferiones da classe adequada. 


\section{CONCLUSŐES}

Considerando-se as condições nas quais se desenvolveu este estudo, os resultados permitem a elaboração das seguintes conclusões:

- o modo de aplicação do calcário em faixas propiciou melhores resultados quantitativos para o perfil transversal de aplicação, atingindo a dosagem esperada na faixa, sem deixar de distribuir no meio da entrelinha, possibilitando aplicar $80 \%$ ou $4 / 5$ da quantidade necessária de calcário, proporcionando uma recuçăo de $20 \%$ de produto;

- a segregação no peffil transversal de aplicação foi maior para o modo a lanço, gerando um PRNT médio de 59,9\%, enquanto que para o em faixa foi de $71,6 \%$, implicando em distintos potencias de reação para o calcário entre modos;

- os modos de aplicação provocaram efeitos significativos sobre os atributos qúmicos do solo relacionados à calagem, de forma a elevar os teores de $\mathrm{Ca}$ e $\mathrm{Mg}$, com maiores valores na posição da copa para o modo em faixa, e menores na entrelinha, com reflexos na V\% e CTC, levando a reduções no Al e na saturacão por Al, sem no entanto provocar modificações no estado nutricional da laranjeira Pera do Rio; 
- independente dos modos de aplicação, a calagem promoveu acréscimos nos teores de Ca e Mg do solo, elevando a V\%, sem no entanto atingir o valor esperado, aumentando também a CTC, além de promover maior retenção de K;

- a gessagem elevou os teores de $\mathrm{Ca}$ e $\mathrm{S}_{-} \mathrm{SO}_{4}$ e reduziu o $\mathrm{Al}$ e a saturação por $\mathrm{Al}$ no solo, promovendo um gradiente crescente em profundidade para o $\mathrm{S}^{-\mathrm{SO}_{4}}$, refletindo na composição mineral das folbas da laranjeira, elevando o $\mathrm{Ca}$ e reduzindo o $\mathrm{Mg}$, com alteraçðes nas relaçð̄es $\mathrm{Ca} / \mathrm{Mg}$ e $\mathrm{Ca} / \mathrm{K}$ que aumentaram;

- a incorporação refletiu na camada superficial do solo $(0-20 \mathrm{~cm})$, elevando os teores de $\mathrm{Ca}$ e Mg e diminuindo o Al e m na primeira época, implicando no estado nutricional da Pera Rio, no sentido de elevar os teores de $\mathrm{Ca}$, com aumento nas relaçðes $\mathrm{Ca} / \mathrm{K}$ e $\mathrm{Ca} / \mathrm{Mg}$;

- os modos de aplicação de calcário e a gessagem não promoveram alteraç̃es significativas na produtividade e nas caracteristicas tecnológicas dos frutos da laranjeira Pera do Rio, embora tenha se encontrado 8,0 tha de diferença entre as médias da $3^{a}$ safra, entre o tratamento com calagem em faixa, com gesso e sem incorporação e a testemunha absoluta;

- a incorporação nå alterou a produtividade, mas provocou reflexos negativos nos aspectos fisicos e qudmicos dos frutos na primeira época. 


\section{REFERÊNCIAS BIBLIOGRAFICAS}

ALCARDE, J.C. Corretivos da acidez dos solos: caracteristicas de qualidade. In: SEMINÁRIO SOBRE CORRETIVOS AGRÍCOLAS. Piracicaba, 1985. Trabalhos apresentados. Campinas, Fundação Cargill, 1985. p.97-119

AMARAL, M.M. Efeitos da aplicação de calcário dolomítico calcinado, gesso e misturas calcário/gesso na cultura de citros. Jaboticabal, 1989.67p. (Graduação- Faculdade de Ciências Agránias e Veterinánias/UNESP)

ANDERSON, C.A. Fruit yields, tree size, and mineral nutrition relation-ship in valencia orange rees affected by liming. J. plant Nutrition, New York, 10(9-16): 1907 $-16,1987$

ANGHINONI, I. Modo de aplicação de corretivo da acidez do solo para culturas anuais e perenes. In: RAIJ, B. van; BATAGLIA, O. C.; SILVA, N. M. coord. Acidez e calagem no Brasil. Campinas, Soc. Bras. de Ciência do Solo, 1983. p. 97-108. 
BATAGLIA, O.C.; FURLANI, A.M.C.; TELXEIRA, J.P.F.; FURLANI, P.R.; GALLO

J.R. Métodos de análise química de plantas. Campinas, Instituto Agronômico, 1983. 48p. (Boletim Técnico, 78).

BORKERT, C..M.; PAVAN, M.A.; LANTMANN, A.F. Consideracðes sobre o uso do gesso na agricultura (1). Piracicaba, POTAFOS, 1987. 3p. (Informaçoes Agronômicas 40)

BRASIL. Portaria n ${ }^{\circ}$ 03, de 12 de junho de 1986. Secretania Nacional de Defesa Agropecuária , Ministério da Agricultura, Brasilia, 1986.

BUCKMANN, H.O.H. \& BRADY, N.C. Natureza e propriedades dos solos. $4^{2}$ ed. Rio de Janeiro, Editora Freitas Bastos, 1976. 594p.

CANDELON, P. Máquinas para abonados. In: Las máquinas agricolas. Madnid Mundi-Prensa, 1971.pt.2, cap. 3, .p. 151-86

CARVALHO, S.A. Métodos de aplicação do superfosfato simples e do calcário dolomitico no limoeiro "cravo" em sementeira. Lavras, 1987. 124p. (Mestrado-Escola Superior de Agricultura de Lavras) 
CASARIN, V. Materiais corretivos aplicados num Latossolo vermelho escuro com cultura de citros. Piracicaba, 1994. 61p. (Mestrado-Escola Superior de Agricultura "Luiz de Queiroz"(USP)

CERQUEIRA LUZ, P.H Maquinas para aplicação de calcário. Rio Claro, Boletim Técnico EMBRACAL, 1, 1989. 51p.

CERQUEIRA LUZ, P.H \& TOURINO, M.C.C. Ensaio demonstração de faixa de deposição de corretivos no solo. In: SMMPÓSIO SOBRE APLICAÇÃO DE CALCÁRIO NA AGRICULTURA, Ipanema, 1986. Trabalhos apresentados. Campinas, Fundacão Cargill, 1986. p. 57-65.

CERQUEIRA LUZ, P.H; STOLF, R.; FURLANI, V.L. Aplicadores a lanço de corretivos para a cultura da cana-de-açúcar (S. officinarum). In: CONGRESSO NACIONAL DA STAB, 3, São Paulo, 1984. Anais. São Paulo, STAB. 1984 p. 125-34

CERQUEIRA LUZ, P.H.; VITTI, G.C.; ALMEIDA, M.C. Avaliação da distribuição de calcário a lanço e em faixa em pomar cítrico. Laranja, Cordeirópolis, 14(2):63548, 1993.

CHAVES, J.C.D.; PAVAN, M.A.; MTYAZAWA, M. Redução da acidez subsuperficial em coluna de solo. Pesquisa Agropecuária Brasileira, Brasilia, 23: 469-76, 1988 
CIPOLLI, J. R. Efeitos da aplicação de calcário calcinado, gesso e misturas calcáriogesso na cultura de citros. Jaboticabal, 1986. 49p. (Graduação- Faculdade de Ciências Agránas e VeterinAnias/UNESP)

COELHO, J.L.D.; MOLIN, J.P.; GADANHA, C.D. Avaliação do desempenho operacional de mecanismos dosadores-distribuidores na aplicação do fosfogesso. In: SEMINÁRIO SOBRE O USO DO GESSO NA AGRICULTURA, 2. Uberaba, 1992. Uberaba, IBRAFOS, 1992. p.83-103

DALMEYER, A.U. As máquinas utilizadas na distribuição e incorporação de calcário. In: SIMPÓSIO SOBRE APLICAÇÃO DE CALCARIO NA AGRICULTURA. IPanema, 1986. Trabalhos apresentados. Campinas, Fundação Cargill, 1986. p. 2339

DECHEN, A.R. Defíciência de cálcio e magnèsio nos solos e nas plantas. In: RAIJ, B. van; BATAGLIA, O.C.; SILVA, N.M. coord. Acidez e calagem no Brasil. Campinas, Soc. Bras. de Ciência do Solo, 1983. p. 87-95.

DEMATTE, J.L. \& VITTL, G.C. Alguns aspectos relacionados ao manejo de solos para os citros. In: SIMPÓSIO INTERNACIONAL DE CITROS: FISIOLOGIA, 2 , Bebedouro, 1992. Campinas, Fundação Cargill, 1992. p. 67-99 
DE NEGRI, J.D. Práticas cuturais para aumento da produrividade dos citros. In: SIMPÓSIO DE CITRICULTURA, 3, Jaboticabal, 1988. Anais. Jaboticabal, FCAV/ FUNEP,1988. p. 205-19

DI GIORGI, F.; IDE, B.Y.; DIB,K.; TRIBONI, HR.; MARCHI, R.J.; WAGNER, R.L. Qualidade da laranja para industrializacăo. Laranja, Cordeiropolis, 14(1):97-118 1993.

FONTANA, C. \& DALLMEYER, A.U. Desempenho de distribuidores centridores de discos JAN. Santa Maria, UFSM, 1985. 65p. (Relatório Técnico)

GARCIA FERNANDEZ, J. \& GARCIA DEL CAZ, R. Distribuidoras de abonos. In: . Máquinas agrícolas. Barcelona, Marcombo, 1972.pt.2, p. 164-71

GONZALES-ERICO, E.; KAMPRATH, E.J.; NADERMAN, G.C.; SOARES, W.V. Effect of depth of lime incarporation on the growth of com on an oxisol of Central Brazil. Soil Sci. Soc. Am. J., Madison, 43: 1155-8, 1979

GRUPO PAULISTA DE ADUBAÇÃO E CALAGEM PARA CITROS. Recomendações de adubação e calagem para citros no Estado de São Paulo. 1.ed. Cordeirópolis, $1988,13 p$. 
GRUPO PAULISTA DE ADUBAÇÃO E CALAGEM PARA CITROS. Recomendaç̃̃es de adubação e calagem para citros no Estado de São Paulo. 2.ed. Laranja, Cordeirópolis, 11(3): 1-14, 1990.

GRUPO PAULISTA DE ADUBAÇÃO E CALAGEM PARA CITROS. Recomendacão de adubação e calagem para citros no Estado de São Paulo. 3. ed. Laranja, Cordeirobpolis, 1994. 27p. Edição especial

KAMPFER, M. Nuevos conocimientos sobre lafertilizacion de citricos. Boletim verde, Hannover, (1): 1-104, 1963.

KEPNER, R.A.; BAINER, R.; BARGER, E.L. Applying fertilizers and granular pesticides. In: _. Principles of farm machinery. 2nd. ed. Westpost, AVI, 1972. chap. 12, p. $248-68$

LOPES, A.S.A Calagem em solos sob cerrados. In: RAIJ, B. van, coord. Acidez e calagem no Brasil. Campinas, Soc. Bras. Ciência do Solo, 1983. p.49-61

LOPES, A.S. Calagem e gesso agricola. Lavras, ESAL, 1986. 58p. (Trabalho apresentado no Encontro Técnico sobre Gesso Agricola, Belo Horizonte, 1986)

MALAVOLTA, E. ABC da adubação. São Paulo, Ceres, 1979. 255p. 
MALAVOLTA E. Reação do solo e crescimento das plantas. In: SEMINÁRIO SOBRE CORRETIVOS AGRICOLAS, Piracicaba, 1985T rabalhos apresentados. Campinas, Fundação Cargill, 1985. p.3-64.

MALAVOLTA, E.; HAAG, H.P.; MELLO, F.A.F.; BRASIL SOBRINHO, M.O.C. Nutrição mineral e adubação de plantas cultivadas. São Paulo, Pioneira, 1974. 752p.

MAZ7A, J. A. Efeitos do calcário e do gesso aplicados no plantio e em soqueira de canade-açúcar (Sacchanem spp), nos atributos quimicos do solo e na produtividade da cultura. Piracicaba, 1993. 141p. (Doutorado- Escola Superior de Agricultura "Luiz de Queiroz"/USP)

MIALHE, L. G. Caracteristicas das máquinas distribuidoras de calcário de fabricação nacional. In: SIMPÓSIO SOBRE APLICAÇÃO DE CALCÁRIO NA AGRICULTURA. Ipanema, 1986. Trabalhos apresentados. Campinas, Fundação Cargill, 1986 p. $41-56$

MENDES, L.D.T. A maturação dos frutos citricos. São Paulo, Departamento de fomento da produção vegetal. Seção de Fruticultura, 1976. 9p. (Circular). 
MOREIRA, C. S. Estudo da distribuição do sistema radicular da laranjeira 'Pera'(Citrus sinensis, L. Osbeck) com diferentes manejos do solo. Piracicaba, 1983. 97p. (Livre Docência-Escola Superior de Agricultura "Luiz de Queiroz"/USP)

MOREIRA, C. S. Manejo do solo em pomar citrico. Laranja, Cordeiropolis, 2(9):423 $-35,1988$.

MORELLI, J.L.; NELLI, E.J.; DEMATTE, J.L.; DALBEN, A.E. Efeito do gesso e calcário nas propriedades químicas de solos arenosos álicos e na produção da canade-açúcar. STAB, Piracicaba, 6(2), 24-31, 1987.

PARO, M. Efeitos da aplicação de aclcánio calcinado dolomitico, gesso e mistura calcário/gesso na cultura de citros. Jaboticabal, 1991. 64P. (Graduação- Faculdade de Ciências Agránias e Vetennárias (UNESP)

POPP, T. \& ULLRICH, K. H. La importancia de la calidad del fertilizante para la aplicacion con fertilizadoras. BASF Reportes Agricolas, Limburgeshof, (2): 3-13, 1985

PORTELLA, J.A.; FAGANELLO, A.; RAD, J.I.B.; BAUMGARDT, A. BAUMGARDT J. Avaliação de pênđulos utilizados em distribuidores penculares de fertilizantes e sementes. In: CONGRESSO BRASILEIRO DE ENGENHARIA AGRICOLA, 22, Theus, 1993 Anais. Théus, SBEA, 1993. p.1935-46 
QUAGGIO, J. A. Respostas das culturas à calagem. In: SEMINÁRIO SOBRE CORRETIVOS AGRICOLAS, Piracicaba, 1985. Trabalhos apresentados. Campinas, Fundação Cargill, 1985, p. 123-57.

QUAGGIO, J. A. Respostas da laranjeira valência (Citnus sinensis L. Osbeck) sobre limoeiro cravo (Citrus limonia L. Osbeck) d calagem e ao equilibrio de bases num Latossolo vermelho escuro de textura argilosa. Piracicaba, 1991. 107p. (DoutoradoEscola Superior de Agricultura "Luiz de Queiroz"/USP)

RAIJ, B. van. Avaliação da fertilidade do solo. Piracicaba, POTAFOS, 1983. 142p.

RAIJ, B. van. Gesso agricola na melhoria do ambiente radicular no subsolo. São Paulo, ANDA, 1988. 88p.

RAIJ. B. van. Fertilidade do solo e adubaçăo. São Paulo, Ceres/POTAFOS, 1991. $343 p$.

RAIJ, B. van. \& QUAGGIO, J.A. Métodos de análise de solo para fins de fertilidade. Campinas, Instituto Agronômico, 1983. 31p. (Boletim Técnico, 81).

RAIJ, B. van \& ZULLO,M.A.T. Métodos de análise do solo. Campinas, Instituto Agronômico, 1977. 17p. (Circular). 
RITCHEY, K.D.; SOUZA, D.M.G.; SILVA, J.E. Strategies for increasing calcium in low-CEC subsoils. In: ANNUAL MEETING OF THE AMERICAN SOCIETY OF AGRONOMY, 75, Washington, 1983. Agronomy abstracts. Washington, Am. Soc. Agron., 1983. p.202

RITCHEY, K.D.; SOUZA, D.M. G.; LOBATO, E.; CORREA, O. Calcium leaching to increase rooting depth in Brazilian savannah Oxisol. Agron. J. Madison, 72:40-4, 1980.

SALVO FILHO, A. Manejo do solo em citricultura. In: MENIEN, J.O.M. Curso Intensivo de citricultura. Piracicaba, AEC/CEPES/ESALQ, 1991. p. 69-80

SILVEIRA, G. M. Problemas de mecanização na citricultura: qualidade das máquinas. Laranja, Cordeiropolis, 11(1):263-82, 1990

SOUTO, R. F. Métodos de aplicação e doses do superfosfato simples no limoeiro (Citrus limonia L. Osbeck cv. Cravo) em viveiro. Lavras, 1993. 75p. (Mestrado- Escola Superior de Agricultura de Lavras)

SOUZA, M. Efeito do P, K, Ca no crescimento da parte aérea da laranjeira "Pera Rio" (Citrus sinensis L. Osbeck) em Latossolo vermelho escuro fase cerrado. Piracicaba, 1976. 132p. (Doutorado-Escola Superior de Agricultura "Luiz de Queiroz") 
SOUZA, D. M. G. \& RTCHEY, K.D. Uso do gesso no solo. In: SEMINARIO SOBRE O USO DO FOSFOGESSO NA AGRICULTURA, 1, Brasilia, 1985. Anais Brasilia EMBRAPA-DDT, 1986. p. 119-44

STOLF. R.; CERQUEIRA LUZ, P. H.; CASAGRANDE, J. C. Metodologia de incorporação profunda de corretivos de solo. Álcool \& Açácar, São Paulo, 8(44): p.24-9 1988.

SUZUKI, A. Doses e modos de aplicação de calcário em pomar de macieira em Latossolo húmico distrófico do Estado de Santa Catanina. Viçosa , 1989. 75p. (Mestrado-Universidade Federal de Viçosa)

THORNTHWAITE, C. W. \& MATHER, J. R. The water balance. Centerton, Drexel Institute of Tecahnology, 1955. 104p. ( Publications in Climatotogy, v. 8, $\mathrm{n}^{\circ}$ ).

VECCHI, E.R. Efeito do gesso e de diferentes corretivos de acidez, em caracteristicas quimicas do solo, produção e estado nutricional dos citros. Jaboticabal, 1993. 75p. (Graduação - Faculdade de Ciências Agránias e Veterinánias/UNESP).

VIEGAS, F.C.P. A industrialização dos produtos citricos. In: RODRIGUEZ,O.; VIEGGAS F.C.P.; POMPEU JR, J.; AMARO, A.A. Citricultura Brasileira. 2ed. Campinas Fundação Cargill, 1991. v.2, p. 898-922 
VIEIRA, D.A. Efeito residual do gesso e de diferentes corretivos de acidez, em caracteństicas quimicas do solo, produção e estado nutricional da laranjeira 'Hamlin' Jaboticabal, 1994. 63p. (Gractuaçđo- Faculdade de Ciências Agránias e Veteninánias/) UNESP).

VITTL G. C. Avaliação e interpretação do enxofre no solo e na planta. Jaboticabal, FUNEP, 1989. 37p.

VITTL, G.C. \& DONADIO, L.C. Correção do solo e micronutrientes. In: SIMPOSIO DE CITRICULTURA, 3, Jaboticabal, 1988. Anais. Jaboticabal, FCAV/FUNEP, 1988. p. $163-83$.

VITTL G.C. \& MALAVOLTA, E. Fosfogesso - uso agricola. In: SEMINARIO SOBRE CORRETIVOS AGRTCOLAS, Piracicaba, 1985. Trabalhos apresentados, Campinas, Fundacão Cangill, 1985.p. 161-201.

ZIMMERMAN, M. Distribuidoras de fertilizantes: las centrifugas o por gravead. Agricultura de Las Américas, Kansas City, 18(12): 14-7, 1969. 


\section{APÊNDICE}


QUADRO 5. Análise da variância dos efeitos de modos de aplicação de calcário, gesso e incorporação sobre a produçăo de frutos (kg/ha) da laranjeira Pera do Rio (Citrus sinensis L. Osbeck).

\begin{tabular}{|c|c|c|}
\hline CAUSAS DA VARIAÇÂO & G.L. & Q.M \\
\hline BLOCO & 3 & 131159083.4815 \\
\hline APLICAÇÃO (A) & 2 & 44856439.0903 \\
\hline GESSO $(G)$ & 1 & 8897294.6944 \\
\hline INCC $\quad$ ÃO (I) & 1 & 2533933.3611 \\
\hline$A \times G$ & 2 & 5385118.3819 \\
\hline $\mathrm{A} \times \mathrm{I}$ & 2 & 45679846.9653 \\
\hline GxI & 1 & 23438508.4444 \\
\hline$A \times G \times I$ & 2 & 2590378.5903 \\
\hline RESIDUO (a) & 33 & 47187159.5623 \\
\hline SAFRA (S) & 2 & $7159410488.8611^{* *}$ \\
\hline SxA & 4 & 31394115.2153 \\
\hline $\mathrm{S} \times \mathrm{G}$ & 2 & 11237028.6944 \\
\hline $\mathrm{S} \times \mathrm{I}$ & 2 & 4403358.6944 \\
\hline $\mathrm{S} \times \mathrm{A} \times \mathrm{G}$ & 4 & 11918878.3819 \\
\hline $\mathrm{S} \times \mathrm{A} \times \mathrm{I}$ & 4 & 8573114.8611 \\
\hline$S \times G \times I$ & 2 & 13406623.8611 \\
\hline SxAxGXI & 4 & 16966708.9444 \\
\hline RESIDUO (b) & 72 & 59459910.7153 \\
\hline TOTAL & 143 & \\
\hline${ }^{*}(\mathrm{P}<0.05) \quad * *(\mathrm{P}<0.01)$ & $\mathrm{CV}(\mathrm{a})=20,5 \%$ & $\mathrm{CV}(\mathrm{b})=39,9 \%$ \\
\hline
\end{tabular}


QUADRO 6. Analise da variância dos efeitos de modos de aplicação de calcário, gesso e incorporaçåo sobre o peso/fruto (g) da laranjeira Pera do Rio (Citrus sinensis L. Osbeck).

\begin{tabular}{|c|c|c|}
\hline CAUSAS DA VARIAÇÃ & 3 & 57.2477 \\
\hline BLOCO & $\overline{2}$ & 26.8958 \\
\hline APLICAÇÃO (A) & 1 & 173.3611 \\
\hline GESSO (G) & 1 & 237.6736 \\
\hline INCC $\quad$ ÂO (I) & 2 & 298.5903 \\
\hline $\mathrm{A} \times \mathrm{G}$ & 2 & 453.5903 \\
\hline $\mathrm{A} \times \mathrm{I}$ & 1 & 25.0000 \\
\hline Gx I & 2 & 114.4375 \\
\hline$A \times G \times I$ & 33 & 264.8777 \\
\hline RESIDUO (a) & 2 & $52795.7031^{* *}$ \\
\hline SAFRA (S) & 4 & 132.0521 \\
\hline $\mathrm{S} \times \mathrm{A}$ & 2 & 10.8872 \\
\hline$S \times G$ & 2 & 352.1267 \\
\hline $\mathrm{SxI}$ & 4 & 323.2257 \\
\hline$S \times A \times G$ & 4 & 88.1215 \\
\hline SxAxI & 2 & 228.2552 \\
\hline SxGXI & 4 & $358.8646^{*}$ \\
\hline SxAxGXI & 72 & 143.7384 \\
\hline RESIDUO (b) & 143 & \\
\hline \multicolumn{3}{|l|}{ TOTAL } \\
\hline$(\mathrm{P}<0.05) \quad * *(\mathrm{P}<0.01)$ & $\mathrm{CV}(\mathrm{a})=4,4 \%$ & $\mathrm{CV}(\mathrm{b})=5,7 \%$ \\
\hline
\end{tabular}


QUADRO 7. Análise da variância dos efeitos de modos de aplicação de calcário, gesso e incorporação sobre o suco extraído (\%) da laranjeira Pera do Rio (Citrus sinensis L. Osbeck).

\begin{tabular}{|c|c|c|}
\hline CAUSAS DA VARIAÇAO & G.L. & Q.M \\
\hline $\mathrm{BLO} \overline{\mathrm{CO}}$ & 3 & 43.5664 \\
\hline APLICAÇÃO (A) & 2 & 0.1801 \\
\hline GESSO (G) & 1 & 35.3034 \\
\hline INCC ÇÄO (I) & 1 & 0.1167 \\
\hline$A \times G$ & 2 & 30.7188 \\
\hline $\mathrm{A} \times \mathrm{I}$ & 2 & 6.5880 \\
\hline GxI & 1 & 0.0756 \\
\hline$A \times G \times I$ & 2 & 20.1890 \\
\hline RESIDUO (a) & 33 & 15.6611 \\
\hline SAFRA (S) & 2 & $291.5780^{* *}$ \\
\hline S X A & 4 & 11.0903 \\
\hline$S \times G$ & 2 & 0.6888 \\
\hline $\mathrm{S} \times \mathrm{I}$ & 2 & 30.2992 \\
\hline$S \times A \times G$ & 4 & 4.8524 \\
\hline S X A X I & 4 & 5.6167 \\
\hline SxGXI & 2 & 5.6965 \\
\hline SxAXGXI & 4 & 3.6560 \\
\hline RESIDUO (b) & 72 & 19.2257 \\
\hline TOTAL & 143 & \\
\hline$*(\mathrm{P}<0.05) \quad * *(\mathrm{P}<0.01)$ & $\mathrm{CV}(\mathrm{a})=7,5 \%$ & $\mathrm{CV}(\mathrm{b})=8,7 \%$ \\
\hline
\end{tabular}


QUADRO 8. Análise da variância dos efeitos de modos de aplicação de calcário, gesso e incorporação sobre o comprimento do fruto $(\mathrm{mm})$ da laranjeira Pera do Rio (Citrus sinensis L. Osbeck).

\begin{tabular}{|c|c|c|}
\hline CAUSAS DA VARIAÇÃO & G.L. & Q.M \\
\hline $\mathrm{BLOCO}$ & 3 & 1.0995 \\
\hline APLICAÇÃO (A) & 2 & 1.8611 \\
\hline GESSO (G) & $\bar{l}$ & 0.1736 \\
\hline INCORPORAÇÃO (I) & 1 & 11.6736 \\
\hline$A \times G$ & 2 & 0.7778 \\
\hline A x I & 2 & 6.0278 \\
\hline GxI & 1 & 0.3403 \\
\hline$A \times G \times I$ & 2 & 7.5278 \\
\hline RESIDUO (a) & 33 & 5.9177 \\
\hline SAFRA (S) & 2 & $1042.3819^{* *}$ \\
\hline $\mathrm{S} \times \mathrm{A}$ & 4 & 5.8507 \\
\hline$S \times G$ & 2 & 6.1319 \\
\hline SxI & 2 & 8.0486 \\
\hline$S \times A \times G$ & 4 & 7.8299 \\
\hline SxAxI & 4 & 7.7465 \\
\hline$S \times G \times I$ & 2 & $15.8819^{*}$ \\
\hline SxAxGXI & 4 & 4.9757 \\
\hline RESIDUO (b) & 72 & 3.4745 \\
\hline TOTAL & 143 & \\
\hline$*(\mathrm{P}<0.05) \quad * *(\mathrm{P}<0.01)$ & $C V(a)=1,8 \%$ & $C V(b)=2,4 \%$ \\
\hline
\end{tabular}


QUADRO 9. Análise da variância dos efeitos de modos de aplicação de calcário, gesso e incorporaçāo sobre o diâmetro do futo (mm) da laranjeira Pera do Rio (Citrus sinensis L. Osbeck).

\begin{tabular}{|c|c|c|}
\hline CAUSAS DA VARIAÇÄO & G.L. & Q.M. \\
\hline $\mathrm{BLOCO}$ & 3 & 1.0463 \\
\hline APLICAÇĀO (A) & 2 & 0.1736 \\
\hline GESSO (G) & 1 & 5.4444 \\
\hline INCC $\quad \overline{A O}(\mathrm{I})$ & 1 & 1.0000 \\
\hline $\mathrm{AxG}$ & 2 & 3.5486 \\
\hline $\mathrm{A} \times \mathrm{I}$ & 2 & 15.8958 \\
\hline GxI & 1 & 0.0278 \\
\hline$A \times G \times I$ & 2 & 1.3819 \\
\hline RESIDUO (a) & 33 & 5.0614 \\
\hline SAFRA (S) & 2 & $642.2986^{* *}$ \\
\hline $\mathrm{S} \times \mathrm{A}$ & 4 & 3.2986 \\
\hline$S \times G$ & 2 & 0.4236 \\
\hline S XI & 2 & 7.2708 \\
\hline$S \times A \times G$ & 4 & 5.9653 \\
\hline SxAXI & 4 & 19792 \\
\hline SxGXI & 2 & 3.0069 \\
\hline S XAXGXI & 4 & 4.7986 \\
\hline RESIDUO (b) & 72 & 3.0810 \\
\hline TOTAL & 143 & \\
\hline$* *(\mathrm{P}<0.01)$ & $\mathrm{CV}(\mathrm{a})=1,8 \%$ & $\mathrm{CV}(\mathrm{b})=2,4 \%$ \\
\hline
\end{tabular}


QUADRO 10.Análise da variância dos efeitos de modos de aplicaçăo de calcário, gesso e incorporação sobre o Brix (\%) da laranjeira Pera do Rio (Citnus sinensis L. Osbeck).

\begin{tabular}{|c|c|c|}
\hline CAUSAS DA VARIAÇA & G.L. & Q.M. \\
\hline BLOCO & 3 & 1.2801 \\
\hline APLICAÇÃO (A) & 2 & 0.5503 \\
\hline GESSO (G) & 1 & 0.2101 \\
\hline INCC ÇÃO (I) & 1 & 0.2584 \\
\hline $\mathrm{A} \times \mathrm{G}$ & 2 & 0.0253 \\
\hline $\mathrm{A} \times \mathrm{I}$ & 2 & 0.0219 \\
\hline GxI & 1 & 0.1167 \\
\hline$A \times G \times I$ & 2 & 0.6419 \\
\hline RESIDUO (a) & $\overline{33}$ & 0.6066 \\
\hline SAFRA (S) & 2 & $33.8551^{* *}$ \\
\hline SxA & 4 & 0.3657 \\
\hline$S \times G$ & 2 & 0.0197 \\
\hline SxI & 2 & 0.6892 \\
\hline$S \times A \times G$ & 4 & 0.4461 \\
\hline $\mathrm{S} \times \mathrm{A} \times \mathrm{I}$ & 4 & 0.2015 \\
\hline S X GXI & 2 & 0.4721 \\
\hline SxAxGXI & 4 & 0.0474 \\
\hline RESIDUO (b) & $\overline{72}$ & 0.4120 \\
\hline TOTAL & 143 & \\
\hline$*(\mathrm{P}<0.05) \quad$ ** $(\mathrm{P}<0.01)$ & $\mathrm{CV}(\mathrm{a})=5,0 \%$ & $C V(b)=7,1 \%$ \\
\hline
\end{tabular}


QUADRO 11.Análise da vaniância dos efeitos de modos de aplicação de calcário, gesso e incorporação sobre a acidez da laranjeira Pera do Rio (Citrus sinensis L. Osbeck).

\begin{tabular}{|c|c|c|}
\hline CAUSAS DA VARIAÇAO & G.L. & Q.M \\
\hline BLOCO & 3 & 0.0096 \\
\hline APLICAÇĀO (A) & 2 & 0.0050 \\
\hline GESSO (G) & $\overline{1}$ & 0.0001 \\
\hline INCORPORAÇÅO (I) & 1 & 0.0116 \\
\hline$A \times G$ & 2 & 0.0040 \\
\hline A x I & 2 & 0.0007 \\
\hline GxI & 1 & 0.0008 \\
\hline$A \times G \times I$ & 2 & 0.0006 \\
\hline RESIDUO (a) & 33 & 0.0056 \\
\hline SAFRA $(\mathbf{S})$ & 2 & $0.2660^{* *}$ \\
\hline $\mathrm{S} \times \mathrm{A}$ & 4 & 0.0035 \\
\hline$S \times G$ & 2 & 0.0023 \\
\hline SxI & 2 & 0.0014 \\
\hline$S \times A \times G$ & 4 & 0.0099 \\
\hline S XAxI & 4 & 0.0046 \\
\hline S x G X I & 2 & 0.0031 \\
\hline SxAxGXI & 4 & 0.0016 \\
\hline RESIDUO (b) & 72 & 0.0042 \\
\hline TOTAL & 143 & \\
\hline${ }^{* *}(\mathrm{P}<0.01)$ & $\mathrm{CV}(\mathrm{a})=6,1 \%$ & $\mathrm{CV}(\mathrm{b})=9,1 \%$ \\
\hline
\end{tabular}


QUADRO 12.Análise da variância dos efeitos de modos de aplicação de calcário, gesso e incorporação sobre a ratio (Brix/acidez) da laranjeira Pera do Rio (Citrus sinensis L. Osbeck).

\begin{tabular}{|c|c|c|}
\hline CAUSAS DA VARIACAO & G.L. & Q.M \\
\hline BLOCO & 3 & 4.6528 \\
\hline APLICAÇĀO (A) & 2 & $5.0641^{*}$ \\
\hline GESSO (G) & 1 & 0.0007 \\
\hline INCC $\quad$ ÃO (I) & 1 & 2.7917 \\
\hline$A \times G$ & 2 & 0.4538 \\
\hline $\mathrm{A} \times \mathrm{I}$ & 2 & 0.0958 \\
\hline GXI & 1 & 1.0017 \\
\hline$A \times G \times I$ & 2 & 0.9331 \\
\hline RESIDUO (a) & 33 & 1.1633 \\
\hline SAFRA (S) & 2 & $69.3417^{* *}$ \\
\hline $\mathrm{S} \times \mathrm{A}$ & 4 & 0.1106 \\
\hline$S \times G$ & 2 & 0.9441 \\
\hline SxI & 2 & $4.4700^{*}$ \\
\hline$S \times A \times G$ & 4 & 1.4775 \\
\hline SxAxI & 4 & 1.1959 \\
\hline SxGXI & 2 & 0.2115 \\
\hline SxAxGXI & 4 & 0.7945 \\
\hline RESDUO (b) & $\overline{72}$ & 1.1267 \\
\hline TOTAL & 143 & \\
\hline${ }^{* *}(\mathrm{P}<0.01)$ & $\mathrm{CV}(\mathrm{a})=4,9 \%$ & $\mathrm{CV}(\mathrm{b})=8,4 \%$ \\
\hline
\end{tabular}


QUADRO 13.Análise da variância dos efeitos de modos de aplicação de calcário, gesso e incomparacto sobre os teores de cálcio (Ca) no solo em pomar de Pera Rio (Citrus sinensis L. Osbeck).

\begin{tabular}{|c|c|c|c|}
\hline \multirow[t]{2}{*}{ CAUSAS DA VARIAÇÃ } & \multirow[t]{2}{*}{ G.L. } & \multicolumn{2}{|c|}{ Q.M } \\
\hline & & 1 至 EPOCA & 2a É EPOCA \\
\hline BLOCO & 3 & 0,0425 & 0,2393 \\
\hline APLICAÇÃO (A) & 2 & $5,8394^{* *}$ & 0,2712 \\
\hline GESSO (G) & 1 & $0,8559^{*}$ & 1,7735 \\
\hline$A \times G$ & 2 & $1,4532^{* *}$ & 0,3772 \\
\hline INCORPORAÇÃO (I) & 1 & $3,4892^{* *}$ & 1,5022 \\
\hline $\mathrm{A} \times \mathrm{I}$ & 2 & 0,5894 & 0,3135 \\
\hline GxI & 1 & 0,0184 & $2,5312^{*}$ \\
\hline $\mathrm{G} \times \mathrm{AxI}$ & 2 & $1,8282^{* *}$ & 0,0350 \\
\hline RESWUO (a) & 33 & 0,2283 & 0,5108 \\
\hline LOCAL (L) & 1 & $6,6917^{* *}$ & 0,9339 \\
\hline $\mathrm{L} \times \mathrm{A}$ & 2 & $2,7096^{* *}$ & 0,6601 \\
\hline $\mathrm{L} \times \mathrm{G}$ & 1 & 0,0528 & 0,2568 \\
\hline $\mathrm{L} \times \mathrm{I}$ & 1 & 0,6903 & $1,2800^{*}$ \\
\hline $\mathrm{L} \times \mathrm{A} \times \mathrm{G}$ & 2 & 0,3945 & 0,0301 \\
\hline $\mathrm{L} \times \mathrm{A} \times \mathrm{I}$ & 2 & 0,0970 & 0,4879 \\
\hline LxGxI & 1 & 0,2167 & 0,0312 \\
\hline RESIDUO (b) & 38 & 0,2593 & 0,2728 \\
\hline PROFUNDIDADE (P) & 2 & $10,2069 * *$ & $9,8676^{* *}$ \\
\hline$\overline{\mathrm{P} \times \mathrm{A}}$ & 4 & $0,4002^{*}$ & 0,5815 \\
\hline $\mathrm{P} \times \mathrm{G}$ & 2 & 0,0098 & 0,0829 \\
\hline $\mathrm{P} \times \mathrm{I}$ & 2 & $0,8252^{* *}$ & 0,0298 \\
\hline $\mathrm{P} \times \mathrm{L}$ & 2 & 0,3459 & 0,6754 \\
\hline PxLxA & 4 & $0,3950^{*}$ & $0,6303^{*}$ \\
\hline$P \times L \times G$ & 2 & 0,1528 & 0,1931 \\
\hline PxLxI & 2 & 0,1407 & 0,1945 \\
\hline RESWUO (c) & 172 & 0,1540 & 0,2532 \\
\hline \multirow[t]{4}{*}{ TOTAL } & 287 & & \\
\hline & & a) $=29,9$ & $C V \%(a)=44,8$ \\
\hline & & b) $=31,9$ & $C V \%(b)=32,7$ \\
\hline & & c) $=24,6$ & $C V \%(c)=31,5$ \\
\hline$(\mathrm{P}<0,05) \quad * *(\mathrm{P}<0,01)$ & & & \\
\hline
\end{tabular}


QUADRO 14.Análise da variância dos efeitos de modos de aplicação de calcário, gesso e incorporação sobre os teores de magnésio $(\mathrm{Mg})$ no solo em pomar de Pera Rio (Citrus sinensis L. Osbeck).

\begin{tabular}{|c|c|c|c|}
\hline \multirow{2}{*}{ CAUSAS DA VARIAÇÄO } & \multirow[t]{2}{*}{ G.L. } & \multicolumn{2}{|c|}{ Q.M. } \\
\hline & & 1a ÉPOCA & 2a EPOCA \\
\hline BLOCO & 3 & 0,0457 & $0,4311^{*}$ \\
\hline APLICAÇÃO (A) & 2 & $2,1162^{* *}$ & $0,7168^{*}$ \\
\hline GESSO (G) & 1 & 0,0000 & 0,0834 \\
\hline$A \times G$ & 2 & $0,3601^{*}$ & $0,7039^{*}$ \\
\hline INCORPORAÇÃO (I) & 1 & $0,5959^{*}$ & 0,3267 \\
\hline $\mathrm{A} \times \mathrm{I}$ & 2 & 0,1593 & 0,0476 \\
\hline Gx I & 1 & 0,1128 & 0,1850 \\
\hline GXAxI & 2 & $0,5262^{*}$ & 0,0039 \\
\hline RESDUO (a) & 33 & 0,1045 & 0,1399 \\
\hline LOCAL (L) & 1 & $2,5500^{* *}$ & 0,0475 \\
\hline $\mathrm{L} \times \mathrm{A}$ & 2 & $1,0868^{* *}$ & $0,6143^{* *}$ \\
\hline $\mathrm{L} \times \mathrm{G}$ & 1 & 0,0334 & 0,1128 \\
\hline $\mathrm{L} \times \mathrm{I}$ & 1 & 0,0100 & 0,2750 \\
\hline$L \times A \times G$ & 2 & 0,0651 & 0,0029 \\
\hline $\mathrm{L} \times \mathrm{A} \times \mathrm{I}$ & 2 & 0,0251 & 0,1168 \\
\hline L.x Gx I & 1 & 0,0009 & 0,2628 \\
\hline RESDUO (b) & 38 & 0,1292 & 0,1157 \\
\hline PROFUNDIDADE (P) & 2 & $3,4201^{* *}$ & $1,1313^{* *}$ \\
\hline $\mathrm{P} \times \mathrm{A}$ & 4 & $0,3726^{* *}$ & $0,2248^{*}$ \\
\hline $\mathrm{P} \times \mathrm{G}$ & 2 & 0,0367 & 0,1598 \\
\hline $\mathrm{PxI}$ & 2 & $0,6615^{* *}$ & 0,0286 \\
\hline $\mathrm{P} \times \mathrm{L}$ & 2 & 0,0357 & $1,6669^{* *}$ \\
\hline $\mathrm{P} \times \mathrm{L} \times \mathrm{A}$ & 4 & $0,5752^{* *}$ & 0,1316 \\
\hline$P \times L \times G$ & 2 & 0,1900 & 0,0595 \\
\hline PxLxI & 2 & 0,0194 & 0,0125 \\
\hline RESDUO (c) & 172 & 0,0912 & 0,0807 \\
\hline \multirow[t]{4}{*}{ TOTAL } & 287 & & \\
\hline & & $C V \%(a)=34,9$ & $C V \%(a)=40,4$ \\
\hline & & $\mathrm{CV} \%(\mathrm{~b})=38,8$ & $\mathrm{CV} \%(b)=36,7$ \\
\hline & & $\overline{C V} \%(c)=32,6$ & $\mathrm{CV} \%(\mathrm{c})=30,7$ \\
\hline$*(\mathrm{P}<0,05) \quad * *(\mathrm{P}<0,01)$ & & & \\
\hline
\end{tabular}


QUADRO 15.Análise da variância dos efeitos de modos de aplicação de calcánio, gesso e incorporação sobre o valor do $\mathrm{pH}\left(\mathrm{CaCl}_{2}\right)$ no solo em pomar de Pera Rio (Citrus sinensis L. Osbeck).

\begin{tabular}{|c|c|c|c|}
\hline \multirow[t]{2}{*}{ CAUSAS DA VARIAÇÂO } & \multirow[t]{2}{*}{ G.L. } & \multicolumn{2}{|c|}{ Q.M. } \\
\hline & & 1ㅡ ÉPOCA & $2 \underline{a}$ EPOCA \\
\hline BLOCO & 3 & 0,3333 & $0,9409^{*}$ \\
\hline APLICAÇÃO (A) & 2 & $1,0635^{* *}$ & 0,2323 \\
\hline GESSO $(\mathrm{G})$ & 1 & 0,0642 & 0,0200 \\
\hline $\mathrm{A} \times \mathrm{G}$ & 2 & 0,1768 & 0,0357 \\
\hline INCORPORAÇÃO (I) & 1 & $1,0153^{* *}$ & 0,2005 \\
\hline $\mathrm{A} \times \mathrm{I}$ & 2 & 0,3050 & 0,0713 \\
\hline $\mathrm{G} \times \mathrm{I}$ & 1 & 0,0834 & 0,2335 \\
\hline $\mathrm{G} \times \mathrm{A} \times \mathrm{I}$ & 2 & $0,6793^{* *}$ & 0,0177 \\
\hline RESDUO (a) & 33 & 0,1214 & 0,2113 \\
\hline LOCAL (L) & 1 & 0,0425 & $2,4200^{* *}$ \\
\hline $\mathrm{L} \times \mathrm{A}$ & 2 & $1,0101^{* *}$ & 0,1319 \\
\hline $\mathrm{L} \times \mathrm{G}$ & 1 & 0,0253 & 0,3068 \\
\hline $\mathrm{L} \times \mathrm{I}$ & 1 & 0,2628 & 0,6235 \\
\hline $\mathrm{L} \times \mathrm{A} \times \mathrm{G}$ & 2 & 0,0787 & 0,0611 \\
\hline $\mathrm{L} \times \mathrm{A} \times \mathrm{I}$ & 2 & 0,0117 & 0,1839 \\
\hline $\mathrm{L} \times \mathrm{G} \times \mathrm{I}$ & 1 & 0,1559 & 0,0200 \\
\hline RESIDUO (b) & 38 & 0,0951 & 0,1848 \\
\hline PROFUNDIDADE (P) & 2 & $10,2326^{* *}$ & $6,8648^{* *}$ \\
\hline $\mathrm{P} \times \mathrm{A}$ & 4 & $0,3389^{* *}$ & $0,2746^{*}$ \\
\hline $\mathrm{P} \times \mathrm{G}$ & 2 & 0,0085 & 0,1145 \\
\hline $\mathrm{P} \times \mathrm{I}$ & 2 & $0,2112^{* *}$ & 0,0731 \\
\hline $\mathrm{P} \times \mathrm{L}$ & 2 & $0,6026^{* *}$ & $1,5003^{* *}$ \\
\hline $\mathrm{P} \times \mathrm{L} \times \mathrm{A}$ & 4 & $0,1407^{* *}$ & 0,1867 \\
\hline $\mathrm{P} \times \mathrm{L} \times \mathrm{G}$ & 2 & 0,0754 & 0,0139 \\
\hline $\mathrm{P} \times \mathrm{L} \times \mathrm{I}$ & 2 & 0,0079 & 0,0600 \\
\hline RESIDUO (c) & 172 & 0,0390 & 0,1063 \\
\hline \multirow[t]{4}{*}{ TOTAL } & 287 & & \\
\hline & & $\mathrm{CV} \%(\mathrm{a})=8,2$ & $C V \%(a)=10,8$ \\
\hline & & $\mathrm{CV} \%(\mathrm{~b})=7,2$ & $C V \%(b)=10,1$ \\
\hline & & $\mathrm{CV} \%(\mathrm{c})=4,6$ & $\mathrm{CV} \%(\mathrm{c})=7,6$ \\
\hline$(\mathrm{P}<0,05) \quad * *(\mathrm{P}<0,01)$ & & & \\
\hline
\end{tabular}


QUADRO 16.Análise da variância dos efeitos de modos de aplicação de calcário, gesso e incorporação sobre a relação $\mathrm{Ca} M g$ no solo em pomar de Pera Rio (Citrus sinensis L. Osbeck).

\begin{tabular}{|c|c|c|c|}
\hline \multirow[t]{2}{*}{ CAUSAS DA VARIAÇ.ÃO } & \multirow[t]{2}{*}{ G.L. } & \multicolumn{2}{|c|}{ Q.M. } \\
\hline & & 1a ÉPOCA & 2a EPOCA \\
\hline BLOCO & 3 & 0,0451 & $4,3384^{*}$ \\
\hline APLICAÇÃO (A) & 2 & $1,8382^{\star *}$ & $3,7893^{*}$ \\
\hline GESSO (G) & 1 & $1,0755^{*}$ & 3,3153 \\
\hline $\mathrm{A} \times \mathrm{G}$ & 2 & $3,2989^{* *}$ & 1,3362 \\
\hline NCORPORAÇÃ̃O (I) & 1 & 0,2112 & 0,6328 \\
\hline $\mathrm{A} \times \mathrm{I}$ & 2 & 0,0013 & 0,0800 \\
\hline $\mathrm{G} \times \mathrm{I}$ & 1 & 0,2812 & 0,2059 \\
\hline$G \times A \times I$ & 2 & 0,1207 & 0,0068 \\
\hline RESWUO (a) & 33 & 0,1660 & 1,0687 \\
\hline LOCAL (L) & 1 & 0,0235 & $7,0000^{*}$ \\
\hline $\mathrm{L} \times \mathrm{A}$ & 2 & 0,0023 & 0,9926 \\
\hline $\mathrm{L} \times \mathrm{G}$ & 1 & 0,0035 & 1,4878 \\
\hline $\mathrm{L} \times \mathrm{I}$ & 1 & $1,3339^{* *}$ & 0,0100 \\
\hline $\mathrm{L} \times \mathrm{A} \times \mathrm{G}$ & 2 & $0,5217^{*}$ & 0,1279 \\
\hline $\mathrm{L} \times \mathrm{A} \times \mathrm{I}$ & 2 & 0,0475 & 1,6701 \\
\hline $\mathrm{L} \times \mathrm{G} \times \mathrm{I}$ & 1 & 0,2450 & $5,5278^{*}$ \\
\hline RESWUO (b) & 38 & 0,1061 & 0,9615 \\
\hline PROFUNDIDADE (P) & 2 & $1,4262^{* *}$ & $11,6263^{* *}$ \\
\hline $\mathrm{P} \times \mathrm{A}$ & 4 & $0,3429^{*}$ & 0,4289 \\
\hline$P \times G$ & 2 & 0,0705 & 2,5445 \\
\hline $\mathrm{P} \times \mathrm{I}$ & 2 & 0,3017 & 0,6763 \\
\hline $\mathrm{P} \times \mathrm{L}$ & 2 & $1,5226^{* *}$ & $21,7337^{* *}$ \\
\hline $\mathrm{P} \times \mathrm{L} \times \mathrm{A}$ & 4 & $0,4087^{* \star}$ & 0,4537 \\
\hline $\mathrm{P} \times \mathrm{L} \times \mathrm{G}$ & 2 & 0,1009 & 1,8476 \\
\hline $\mathrm{P} \times \mathrm{L} \times \mathrm{I}$ & 2 & 0,0018 & 0,2117 \\
\hline RESDUO (c) & 172 & 0,1060 & 0,8825 \\
\hline \multirow[t]{4}{*}{ TOTAL } & 287 & & \\
\hline & & $C V \%(a)=22,1$ & $C V \%(a)=56,0$ \\
\hline & & $C V \%(b)=17,7$ & $\mathrm{CV} \%(\mathrm{~b})=53,2$ \\
\hline & & $C V \%(c)=17,7$ & $C V \%(c)=50,9$ \\
\hline$*(\mathrm{P}<0,05) \quad * *(\mathrm{P}<0,01)$ & & & \\
\hline
\end{tabular}


QUADRO 17.Análise da variância dos efeitos de modos de aplicação de calcário, gesso e incorporação sobre o indice de saturação por bases (V\%) no solo em pomar de Pera Rio (Citrus sinensis L. Osbeck).

\begin{tabular}{|c|c|c|c|}
\hline \multirow[t]{2}{*}{ CAUSAS DA VARIAÇÃO } & \multirow[t]{2}{*}{ G.L. } & \multicolumn{2}{|c|}{ Q.M. } \\
\hline & & $1 \underline{a}$ ÉPOCA & 2 a ÉPOCA \\
\hline BLOCO & 3 & 404,4676 & $657,6794^{*}$ \\
\hline APLICAÇÃO $(\mathrm{A})$ & 2 & $1239,07^{* *}$ & 130,8368 \\
\hline$\overline{\mathrm{GESSO}}(\mathrm{G})$ & 1 & 42,0139 & $1805,0035^{* *}$ \\
\hline$A \times G$ & 2 & 226,4826 & $1299,5868^{* *}$ \\
\hline INCORPORAÇÄO (I) & 1 & $968,0000^{*}$ & 403,7535 \\
\hline $\mathrm{A} \times \mathrm{I}$ & 2 & 196,4479 & 102,9201 \\
\hline GxI & 1 & 24,5000 & 157,5312 \\
\hline$G \times A \times I$ & 2 & $1035,2187^{* *}$ & 33,4479 \\
\hline RESIDUO (a) & 33 & 142,5610 & 224,3435 \\
\hline LOCAL (L) & 1 & 378,1250 & 348,9201 \\
\hline $\mathrm{L} \times \mathrm{A}$ & 2 & $720,0104^{* *}$ & 48,3576 \\
\hline$\overline{L \times G}$ & 1 & 0,0139 & 286,0035 \\
\hline L x I & 1 & 107,5555 & 598,0035 \\
\hline $\mathrm{L} \times \mathrm{A} \times \mathrm{G}$ & 2 & 166,0035 & 22,8159 \\
\hline $\mathrm{L} \times \mathrm{A} \times \mathrm{I}$ & 2 & 68,8159 & 65,0659 \\
\hline $\mathrm{L} \times \mathrm{G} \times \mathrm{I}$ & 1 & 50,0000 & 175,7812 \\
\hline RESIDUO (b) & 38 & 124,2099 & 154,8679 \\
\hline PROFUNDIDADE (P) & 2 & $6610,6667^{* *}$ & $4340,3159^{* *}$ \\
\hline $\mathrm{P} \times \mathrm{A}$ & 4 & $180,8177^{* *}$ & $239,2326^{*}$ \\
\hline $\mathrm{P} \times \mathrm{G}$ & 2 & 49,1805 & 6,8159 \\
\hline $\mathrm{P} \times \mathrm{I}$ & 2 & $217,1250^{*}$ & 178,3576 \\
\hline $\mathrm{PxL}$ & 2 & $331,7917^{* *}$ & $1070,0451^{* *}$ \\
\hline $\mathrm{P} \times \mathrm{L} \times \mathrm{A}$ & 4 & 77,7239 & 104,6076 \\
\hline$P \times L \times G$ & 2 & 50,8472 & 14,0035 \\
\hline $\mathrm{P} \times \mathrm{L} \times \mathrm{I}$ & 2 & 8,0139 & 32,3368 \\
\hline RESIDUO (c) & 172 & 45,7863 & 86,4393 \\
\hline \multirow[t]{4}{*}{ TOTAL } & 287 & & \\
\hline & & $\mathrm{CV} \%(\mathrm{a})=25,9$ & CV\% $(a)=32,5$ \\
\hline & & $\mathrm{CV} \%(b)=24,2$ & $\mathrm{CV} \%(\mathrm{~b})=27,0$ \\
\hline & & $\mathrm{CV} \%(\mathrm{c})=14,7$ & $C V \%(c)=20,2$ \\
\hline$*(\mathrm{P}<0,05) \quad * *(\mathrm{P}<0,01)$ & & & \\
\hline
\end{tabular}


QUADRO 18.Análise da variância dos efeitos de modos de aplicação de calcário, gesso e incorporação sobre os teores de aluminio (Al) no solo em pomar de Pera Rio (Citrus sinensis L. Osbeck).

\begin{tabular}{|c|c|c|c|}
\hline \multirow[t]{2}{*}{ CAUSAS DA VARIAÇÃ̆O } & \multirow[t]{2}{*}{ G.L. } & \multicolumn{2}{|c|}{ Q.M. } \\
\hline & & 1 a EिPCA & 2a EPOCA \\
\hline BLOCO & 3 & $0.2604^{*}$ & 0.4965 \\
\hline APLICAÇÃO (A) & 2 & 0.1760 & 0.8239 \\
\hline GESSO (G) & 1 & 0.0501 & $1.8850^{*}$ \\
\hline$A \times G$ & 2 & $0.3860^{*}$ & 1.0396 \\
\hline INCORPORAÇÃO (I) & 1 & $0.8668^{* *}$ & 0.8128 \\
\hline $\mathrm{A} \times \mathrm{I}$ & 2 & $0.2772^{*}$ & 0.1069 \\
\hline GxI & 1 & $0.3334^{*}$ & 0.4278 \\
\hline GxA $\mathrm{A} I$ & 2 & $0.9622^{* *}$ & 0.5563 \\
\hline RESIDUO (a) & 33 & 0.0795 & 0.4333 \\
\hline LOCAL (L) & 1 & 0.2335 & $2.1184^{* *}$ \\
\hline $\mathrm{L} \times \mathrm{A}$ & 2 & $0.3044^{*}$ & 0.0429 \\
\hline $\mathrm{LxG}$ & 1 & 0.0013 & 0.0028 \\
\hline L x I & 1 & 0.1513 & 0.0001 \\
\hline$L \times A \times G$ & 2 & 0.1163 & 0.0376 \\
\hline $\mathrm{L} \times \mathrm{A} \times \mathrm{I}$ & 2 & 0.0417 & 0.1461 \\
\hline $\mathrm{L} \times \mathrm{G} \times \mathrm{I}$ & 1 & 0.0235 & 0.2167 \\
\hline RESDUO (b) & 38 & 0.0784 & 0.1441 \\
\hline PROFUNDIDADE (P) & 2 & $8.3382^{* *}$ & $7.0431^{* *}$ \\
\hline $\mathrm{P} \times \mathrm{A}$ & 4 & $0.3032^{* *}$ & 0.1827 \\
\hline $\mathrm{P} \times \mathrm{G}$ & 2 & 0.0089 & 0.1739 \\
\hline $\mathrm{P} \times \mathrm{I}$ & 2 & 0.0869 & $0.4263^{*}$ \\
\hline $\mathrm{P} \times \mathrm{L}$ & 2 & $0.5007^{* *}$ & $1.4492 * *$ \\
\hline $\mathrm{P} \times \mathrm{L} \times \mathrm{A}$ & 4 & $0.1884^{* *}$ & 0.1715 \\
\hline$P \times L \times G$ & 2 & 0.0126 & 0.0703 \\
\hline P x L x I & 2 & 0.0051 & 0.0254 \\
\hline RESIDUO (c) & 172 & 0.0395 & 0.1203 \\
\hline \multirow[t]{4}{*}{ TOTAL } & 287 & & \\
\hline & & $C V \%(a)=42,45$ & $\mathrm{CV} \%(\mathbf{a})=99,12$ \\
\hline & & $\mathrm{CV} \%(\mathrm{~b})=42,16$ & $\mathrm{CV} \%(b)=57,17$ \\
\hline & & $C V \%(c)=29,93$ & $C V \%(c)=52,23$ \\
\hline$*(\mathrm{P}<0,05) \quad * *(\mathrm{P}<0,01)$ & & & \\
\hline
\end{tabular}


QUADRO 19.Análise da variâncía dos efeitos de modos de aplicação de calcário, gesso e incorporação sobre a saturação por aluminio (m) no solo em pomar de Pera Rio (Citrus sinensis L. Osbeck).

\begin{tabular}{|c|c|c|c|}
\hline \multirow[t]{2}{*}{ CAUSAS DA VARIAÇÄO } & \multirow[t]{2}{*}{ G.L. } & \multicolumn{2}{|c|}{ Q.M. } \\
\hline & & 1ㅁ É EOCA & 2a É EPOCA \\
\hline$\overline{\mathrm{BLOCO}}$ & 3 & 220.3518 & 368.7719 \\
\hline APLICAÇÃO (A) & 2 & 210.1354 & 259.5034 \\
\hline GESSO (G) & 1 & 227.5555 & $2053.3368^{*}$ \\
\hline$A \times G$ & 2 & $304.2326^{*}$ & 878.2118 \\
\hline INCORPORAÇÃO (I) & 1 & $960.6805^{* *}$ & 1046.5312 \\
\hline $\mathrm{A} \times \mathrm{I}$ & 2 & $315.3159^{*}$ & 76.0729 \\
\hline GxI & 1 & 82.3472 & 498.7534 \\
\hline GxA $\mathrm{A} I$ & 2 & $1040.3159^{* *}$ & 428.7534 \\
\hline RESIDUO (a) & 33 & 91.5210 & 425.3275 \\
\hline LOCAL (L) & 1 & 4.5000 & $1046.5312^{*}$ \\
\hline $\mathrm{L} \times \mathrm{A}$ & 2 & $574.3854^{* *}$ & 41.7604 \\
\hline $\mathrm{LxG}$ & 1 & 16.0555 & 113.7534 \\
\hline $\mathrm{L} \times \mathrm{I}$ & 1 & 115.0139 & 188.5034 \\
\hline $\mathrm{L} \times \mathrm{A} \times \mathrm{G}$ & 2 & 68.2326 & 37.9409 \\
\hline $\mathrm{L} \times \mathrm{A} \times \mathrm{I}$ & 2 & 8.9826 & 179.1076 \\
\hline $\mathrm{L} \times \mathrm{G} \times \mathrm{I}$ & 1 & 74.0138 & 215.2812 \\
\hline RESIDUO (b) & 38 & 75.6372 & 172.8371 \\
\hline PROFUNDIDADE (P) & 2 & $8692.1979^{* *}$ & $5233.1805^{* *}$ \\
\hline $\mathrm{P} \times \mathrm{A}$ & 4 & 130.1771 & $261.4982^{*}$ \\
\hline$P \times G$ & 2 & 54.2951 & 112.5138 \\
\hline $\mathrm{P} \times \mathrm{I}$ & 2 & 131.5659 & $332.0416^{*}$ \\
\hline $\mathrm{P} \times \mathrm{L}$ & 2 & $713.0104^{* *}$ & $1977.1666^{* *}$ \\
\hline $\mathrm{P} \times \mathrm{L} \times \mathrm{A}$ & 4 & $173.7083^{* *}$ & 167.5677 \\
\hline$P \times L \times G$ & 2 & 4.6493 & 11.4305 \\
\hline $\mathrm{P} \times \mathrm{L} \times \mathrm{I}$ & 2 & 0.3784 & 3.5972 \\
\hline RESIDUO (c) & 172 & 44.1914 & 107.6039 \\
\hline \multirow[t]{4}{*}{ TOTAL } & 287 & & \\
\hline & & $C V \%(a)=46,91$ & CV\%(a)=101,13 \\
\hline & & $C V \%(b)=42,65$ & $C V \%(b)=64,46$ \\
\hline & & $\mathrm{CV} \%(\mathrm{c})=32,59$ & $C V \%(c)=50,86$ \\
\hline${ }^{*}(\mathrm{P}<0,05) \quad * *(\mathrm{P}<0,01)$ & & & \\
\hline
\end{tabular}


QUADRO 20.Análise da variância dos efeitos de modos de aplicação de calcário, gesso e incorporação sobre os valores da capacidade de troca catiônica (CTC) no solo em pomar de Pera Rio (Citrus sinensis L. Osbeck).

\begin{tabular}{|c|c|c|c|}
\hline \multirow{2}{*}{ CAUSAS DA VARIAÇÃO } & \multirow[t]{2}{*}{ G.L. } & \multicolumn{2}{|c|}{ Q.M. } \\
\hline & & 1aㅡ ÉPOCA & 2aㅡ EPOCA \\
\hline BLOCO & 3 & $13.5281^{* *}$ & $10.0910^{* *}$ \\
\hline APLICAÇ.ÃO (A) & 2 & $20.0552^{* *}$ & $20.8879^{* *}$ \\
\hline GESSO (G) & 1 & 2.2578 & 3.4672 \\
\hline $\mathrm{A} \times \mathrm{G}$ & 2 & 3.0438 & $13.8106^{* *}$ \\
\hline INCORPORAÇÃO (I) & 1 & 3.6225 & 0.0312 \\
\hline $\mathrm{A} \times \mathrm{I}$ & 2 & 0.0898 & $5.8107^{*}$ \\
\hline $\mathrm{G} \times \mathrm{I}$ & 1 & 0.0008 & $7.8012^{*}$ \\
\hline$G \times A \times I$ & 2 & 0.3077 & 0.8909 \\
\hline RESDUO (a) & 33 & 1.2586 & 1.5924 \\
\hline LOCAL (L) & 1 & $46.9642^{* *}$ & $36.8368^{* *}$ \\
\hline $\mathrm{L} \times \mathrm{A}$ & 2 & 2.4960 & $4.6962^{* *}$ \\
\hline$L \times G$ & 1 & 1.2933 & 0.0868 \\
\hline $\mathrm{L} \times \mathrm{I}$ & 1 & 0.1750 & $4.8050^{*}$ \\
\hline$L \times A \times G$ & 2 & 0.6885 & 0.2135 \\
\hline $\mathrm{L} \times \mathrm{A} \times \mathrm{I}$ & 2 & 1.3973 & 0.3982 \\
\hline $\mathrm{L} \times \mathrm{G} \times \mathrm{I}$ & 1 & 3.9903 & 0.0450 \\
\hline RESDUO (b) & 38 & 1.2293 & 0.8621 \\
\hline PROFUNDIDADE (P) & 2 & $29.5126^{* *}$ & $42.6010^{* *}$ \\
\hline $\mathrm{P} \times \mathrm{A}$ & 4 & 2.8260 & $2.2650^{*}$ \\
\hline$P \times G$ & 2 & 1.6737 & 1.3596 \\
\hline $\mathrm{P} \times I$ & 2 & 2.7518 & 1.4557 \\
\hline $\mathrm{P} \times \mathrm{L}$ & 2 & 1.4418 & 2.4383 \\
\hline $\mathrm{P} \times \mathrm{L} \times \mathrm{A}$ & 4 & 2.7508 & 1.4787 \\
\hline$P \times L \times G$ & 2 & 0.9172 & 0.0264 \\
\hline $\mathrm{P} \times \mathrm{L} \times \mathrm{I}$ & 2 & 0.7334 & 0.6076 \\
\hline RESWUO (c) & 172 & 1.3803 & 0.8289 \\
\hline \multirow[t]{4}{*}{ TOTAL } & 287 & & \\
\hline & & $C V \%(a)=18,59$ & $C V \%(a)=20,91$ \\
\hline & & $C V \%(b)=18,37$ & $\mathrm{CV} \%(\mathrm{~b})=15,38$ \\
\hline & & $C V \%(c)=19,47$ & $\mathrm{CV} \%(\mathrm{c})=15,08$ \\
\hline$*(\mathrm{P}<0,05) \quad * *(\mathrm{P}<0,01)$ & & & \\
\hline
\end{tabular}


QUADRO 21.Análise da variância dos efeitos de modos de aplicação de calcário, gesso e incorporação sobre os teores de sulfato $\left(\mathrm{S}^{\left.-\mathrm{SO}_{4}\right)}\right.$ no solo em pomar de Pera Rio (Citrus sinensis L. Osbeck).

\begin{tabular}{|c|c|c|}
\hline CAUSAS DA VARIAÇÄ & G.L. & Q.M. \\
\hline & & 1ㅡㅡ EPOCA \\
\hline BLOCO & 3 & $1386.3340^{*}$ \\
\hline APLICAÇÃO (A) & 1 & 725.1862 \\
\hline GESSO $(\mathrm{G})$ & 2 & $3851.2013^{* *}$ \\
\hline$A \times G$ & 2 & 1305.7442 \\
\hline INCORPORAÇÃO (I) & 1 & $5148.0804^{* *}$ \\
\hline $\mathrm{A} \times \mathrm{I}$ & 2 & 488.4050 \\
\hline GxI & 1 & $2430.9040^{*}$ \\
\hline $\mathrm{G} \times \mathrm{A} \times \mathrm{I}$ & 2 & 1137.2313 \\
\hline RESIDUO (a) & 33 & 464.3634 \\
\hline LOCAL (L) & 1 & $54542.9897^{* *}$ \\
\hline $\mathrm{L} \times \mathrm{A}$ & 2 & 758.5951 \\
\hline $\mathrm{L} \times \mathrm{G}$ & 1 & $3548.3292^{*}$ \\
\hline L x I & 1 & $2794.4042^{*}$ \\
\hline $\mathrm{L} \times \mathrm{A} \times \mathrm{G}$ & 2 & 444.5827 \\
\hline $\mathrm{L} \times \mathrm{A} \times \mathrm{I}$ & 2 & 257.0425 \\
\hline $\mathrm{L} \times \mathrm{G} \times \mathrm{I}$ & 1 & 1096.6025 \\
\hline RESIDUO (b) & 38 & 610.6947 \\
\hline PROFUNDIDADE (P) & 2 & $13559.4889^{* *}$ \\
\hline $\mathrm{P} \times \mathrm{A}$ & 4 & 332.6357 \\
\hline $\mathrm{P} \times \mathrm{G}$ & 2 & 243.8157 \\
\hline P x I & 2 & 196.1231 \\
\hline $\mathrm{P} \times \mathrm{L}$ & 2 & $1741.8417^{* *}$ \\
\hline $\mathrm{P} \times \mathrm{L} \times \mathrm{A}$ & 4 & 253.8933 \\
\hline$P \times L \times G$ & 2 & 391.0977 \\
\hline $\mathrm{P} \times \mathrm{L} \times \mathrm{I}$ & 2 & 406.4397 \\
\hline RESIDUO (c) & 172 & 357.3003 \\
\hline \multirow[t]{4}{*}{ TOTAL } & 287 & \\
\hline & & $C V \%(a)=60,29$ \\
\hline & & $\mathrm{CV} \%(\mathrm{~b})=69,14$ \\
\hline & & $C V \%(c)=52,87$ \\
\hline${ }^{*}(\mathrm{P}<0,05) \quad * *(\mathrm{P}<0.01)$ & & \\
\hline
\end{tabular}


QUADRO 22..Análise da variância dos efeitos de modos de aplicação de calcário, gesso e incorporação sobre os teores de potássio $(\mathrm{K})$ no solo em pomar de Pera Rio (Citrus sinensis L. Osbeck).

\begin{tabular}{|c|c|c|c|}
\hline \multirow[t]{2}{*}{ CAUSAS DA VARIAÇÃO } & \multirow[t]{2}{*}{ G.L. } & \multicolumn{2}{|c|}{ Q.M. } \\
\hline & & 1a ÉPOCA & 2a EPPOCA \\
\hline BLOCO & 3 & $0,0566^{* *}$ & $0,1592^{* *}$ \\
\hline APLICAÇÃO (A) & 2 & $0,0267^{*}$ & $0,0381^{*}$ \\
\hline GESSO (G) & 1 & 0,0197 & 0,0004 \\
\hline$A \times G$ & 2 & 0,0082 & 0,0225 \\
\hline INCORPORAÇĂO (I) & 1 & 0,0005 & 0,0012 \\
\hline $\mathrm{A} \times \mathrm{I}$ & 2 & $0,0342^{*}$ & 0,0033 \\
\hline GxI & 1 & 0,0060 & 0,0159 \\
\hline $\mathrm{G} \times \mathrm{A} \times \mathrm{I}$ & 2 & 0,0124 & 0,0065 \\
\hline RESDUO (a) & 33 & 0,0075 & 0,0112 \\
\hline LOCAL (L) & 1 & $0,3990^{* *}$ & $0,0450^{*}$ \\
\hline $\mathrm{L} \times \mathrm{A}$ & 2 & 0,0052 & 0,0008 \\
\hline $\mathrm{L} \times \mathrm{G}$ & 1 & 0,0004 & 0,0103 \\
\hline $\mathrm{L} \times \mathrm{I}$ & 1 & 0,0031 & 0,0026 \\
\hline$L \times A \times G$ & 2 & 0,0001 & 0,0112 \\
\hline $\mathrm{L} \times \mathrm{A} \times \mathrm{I}$ & 2 & 0,0134 & 0,0044 \\
\hline $\mathrm{L} \times \mathrm{G} \times \mathrm{I}$ & 1 & 0,0084 & 0,0096 \\
\hline RESDUO (b) & 38 & 0,0060 & 0,0071 \\
\hline PROFUNDIDADE (P) & 2 & $0,5616^{* *}$ & $0,3335^{* *}$ \\
\hline $\mathrm{P} \times \mathrm{A}$ & 4 & $0,0172^{* *}$ & $0,0084^{*}$ \\
\hline $\mathrm{P} \times \mathrm{G}$ & 2 & 0,0014 & $0,0119^{*}$ \\
\hline $\mathrm{P} \times \mathrm{I}$ & 2 & 0,0086 & 0,0048 \\
\hline $\mathrm{P} \times \mathrm{L}$ & 2 & $0,0243^{* *}$ & $0,1320^{* *}$ \\
\hline $\mathrm{P} \times \mathrm{L} \times \mathrm{A}$ & 4 & $0,0106^{*}$ & 0,0062 \\
\hline $\mathrm{P} \times \mathrm{L} \times \mathrm{G}$ & 2 & 0,0001 & $0,0090^{*}$ \\
\hline PxLxI & 2 & 0,0048 & 0,0022 \\
\hline RESDUO (c) & 172 & 0,0035 & 0,0028 \\
\hline \multirow[t]{4}{*}{ TOTAL } & 287 & & \\
\hline & & CV\%(a) $=39,0$ & CV\%(a) $=47,7$ \\
\hline & & $\mathrm{CV} \%(\mathrm{~b})=34,9$ & $\mathrm{CV} \%(\mathrm{~b})=38,0$ \\
\hline & & $C V \%(c)=26,7$ & $\mathrm{CV} \%(\mathrm{c})=23,8$ \\
\hline${ }^{*}(\mathrm{P}<0,05) \quad * *(\mathrm{P}<0,01)$ & & & \\
\hline
\end{tabular}


QUADRO 23..Análise da variância dos efeitos de molos de aplicação de calcário, gesso e incorporação sobre a relação $\mathrm{Ca} / \mathrm{K}$ no solo em pomar de Pera Rio (Citrus sinensis L. Osbeck).

\begin{tabular}{|c|c|c|c|}
\hline \multirow[t]{2}{*}{ CAUSAS DA VARIAÇÃO } & \multirow[t]{2}{*}{ G.L. } & \multicolumn{2}{|c|}{ Q.M. } \\
\hline & & 1a EPOCA & 2a EPOCA \\
\hline $\mathrm{BLOCO}$ & 3 & 24,9350 & $269,5793^{* *}$ \\
\hline APLICAÇÃO (A) & 2 & $508,9184^{* *}$ & 41,1505 \\
\hline GESSO $(\mathrm{G})$ & 1 & $271,2509^{* *}$ & 44,3368 \\
\hline $\mathrm{A \times G}$ & 2 & $79,9709^{*}$ & 102,3172 \\
\hline INCORPORAÇÃO(I) & 1 & 65,6467 & 62,7200 \\
\hline $\mathrm{A} \times \mathrm{I}$ & 2 & $91,2442^{* *}$ & 25,0879 \\
\hline $\mathrm{G} \times \mathrm{I}$ & 1 & 17,0625 & 0,0035 \\
\hline $\mathrm{G} \times \mathrm{A} \times \mathrm{I}$ & 2 & 34,7792 & 36,4126 \\
\hline RESIDUO (a) & $\overline{33}$ & 16,1815 & 41,9784 \\
\hline$\overline{\mathrm{LOCAL}(\mathrm{L})}$ & 1 & $291,0078^{* *}$ & 33,3472 \\
\hline $\mathrm{L} \times \mathrm{A}$ & 2 & $153,9819^{* *}$ & 32,4851 \\
\hline $\mathrm{L} \times \mathrm{G}$ & 1 & 22,9503 & 11,4401 \\
\hline $\mathrm{L} \times \mathrm{I}$ & 1 & 26,1003 & 10,4272 \\
\hline$L \times A \times G$ & 2 & 40,3332 & 48,0235 \\
\hline $\mathrm{L} \times \mathrm{A} \times \mathrm{I}$ & 2 & 5,1632 & 32,8668 \\
\hline$L \times G \times I$ & 1 & 0,2278 & 39,7535 \\
\hline RESDUO (b) & 38 & 12,5913 & 17,2548 \\
\hline PROFUNDIDADE (P) & 2 & $609,3773^{* *}$ & $709,3788^{* *}$ \\
\hline $\mathrm{P} \times \mathrm{A}$ & 4 & $56,1458^{* *}$ & 13,0992 \\
\hline$P \times G$ & 2 & $101,7146^{* *}$ & 3,4484 \\
\hline $\mathrm{P} \times \mathrm{I}$ & 2 & 13,0389 & 39,0001 \\
\hline $\mathrm{P \times L}$ & 2 & $194,5788^{* *}$ & $173,8429^{* *}$ \\
\hline$P \times L \times A$ & 4 & $52,1804^{* *}$ & 28,2896 \\
\hline $\mathrm{P} \times \mathrm{L} \times \mathrm{G}$ & 2 & 16,0319 & 23,1988 \\
\hline $\mathrm{P} \times \mathrm{L} \times \mathrm{I}$ & 2 & 11,6201 & 4,6415 \\
\hline RESDUO (c) & 172 & 9,6289 & 15,1192 \\
\hline \multirow[t]{4}{*}{ TOTAL } & 287 & & \\
\hline & & $C V \%(a)=46,6$ & $C V \%(a)=75,0$ \\
\hline & & $C V \%(b)=41,1$ & $\mathrm{CV} \%(b)=48,1$ \\
\hline & & $\mathrm{CV} \%(\mathrm{c})=35,9$ & CV\%(c) $=45,0$ \\
\hline$*(\mathrm{P}<0,05) \quad * *(\mathrm{P}<0,01)$ & & & \\
\hline
\end{tabular}


QUADRO 24..Análise da variância dos efeitos de modos de aplicação de calcário, gesso e incorporação sobre a relação $\mathrm{Mg} / \mathrm{K}$ no solo em pomar de Pera Rio (Citrus sinensis L. Osbeck).

\begin{tabular}{|c|c|c|c|}
\hline \multirow[t]{2}{*}{ CAUSAS DA VARIAÇÃO } & \multirow[t]{2}{*}{ G.L. } & \multicolumn{2}{|c|}{ Q.M. } \\
\hline & & 1 a ÉPOCA & 2a ÉPOCA \\
\hline BLOCO & 3 & 9,3083 & $54,9659^{* *}$ \\
\hline APLICAÇÃO (A) & 2 & $96,7635^{* *}$ & 8,2454 \\
\hline GESSO (G) & 1 & $31,6012^{*}$ & 5,5834 \\
\hline$A \times G$ & 2 & 1,4337 & $76,8556^{* *}$ \\
\hline INCORPORAÇÃO (I) & 1 & 12,5835 & 7,7684 \\
\hline $\mathrm{A} \times \mathrm{I}$ & 2 & $25,7051^{*}$ & 7,4027 \\
\hline GxI & 1 & 13,5200 & 8,2350 \\
\hline GxAxI & 2 & 13,7029 & 7,7817 \\
\hline RESDUO (a) & 33 & 4,9368 & 10,5764 \\
\hline $\operatorname{LOCAL}(\mathrm{L})$ & 1 & $38,8668^{* *}$ & 12,2925 \\
\hline $\mathrm{L} \times \mathrm{A}$ & 2 & $30,7268^{* *}$ & $18,3889^{*}$ \\
\hline $\mathrm{L} \times \mathrm{G}$ & 1 & 0,6422 & 1,1125 \\
\hline $\mathrm{L} \times \mathrm{I}$ & 1 & 0,0555 & 2,2934 \\
\hline$L \times A \times G$ & 2 & 0,7851 & 10,6388 \\
\hline $\mathrm{L} \times \mathrm{A} \times \mathrm{I}$ & 2 & 3,0568 & 13,3667 \\
\hline $\mathrm{L} \times \mathrm{G} \times \mathrm{I}$ & 1 & 2,7612 & 0,1750 \\
\hline RESIDUO (b) & 38 & 3,3109 & 5,3391 \\
\hline PROFUNDDADE (P) & 2 & $122,5294^{* *}$ & $251,2171^{\text {** }}$ \\
\hline $\mathrm{P} \times \mathrm{A}$ & 4 & $20,4404^{* *}$ & 4,9939 \\
\hline $\mathrm{P \times G}$ & 2 & $19,3326^{* *}$ & 1,2961 \\
\hline $\mathrm{P} \times I$ & 2 & 4,8659 & $20,7742^{*}$ \\
\hline $\mathrm{P} \times \mathrm{L}$ & 2 & $11,1127^{*}$ & 12,7096 \\
\hline PxLxA & 4 & 5,3577 & 8,9004 \\
\hline$P \times L \times G$ & 2 & 3,0486 & 3,4698 \\
\hline PxL x I & 2 & 2,8146 & 1,3659 \\
\hline RESDUO (c) & 172 & 2,4516 & 5,1821 \\
\hline \multirow[t]{4}{*}{ TOTAL } & 287 & & \\
\hline & & $C V \%(a)=45,1$ & $\mathrm{CV} \%(\mathrm{a})=66,1$ \\
\hline & & $\mathrm{CV} \%(\mathrm{~b})=37,0$ & $\mathrm{CV} \%(\mathrm{~b})=47,0$ \\
\hline & & $\mathrm{CV} \%(\mathrm{c})=31,8$ & $\mathrm{CV} \%(\mathrm{c})=46,3$ \\
\hline$(\mathrm{P}<0,05) \quad * *(\mathrm{P}<0,01)$ & & & \\
\hline
\end{tabular}


QUADRO 25..Análise da variância dos efeitos de modos de aplicação de calcário, gesso e incorporação sobre a relação $\mathrm{Ca}+\mathrm{Mg} / \mathrm{K}$ no solo em pomar de Pera Rio (Citrus sinensis L. Osbeck).

\begin{tabular}{|c|c|c|c|}
\hline CAUSAS DA VARIAÇÃO & G.L. & \multicolumn{2}{|c|}{ Q.M. } \\
\hline & & 1 a ÉPOCA & 2a ÉPOCA \\
\hline BLOCO & 3 & 73,6334 & $531,1479^{* *}$ \\
\hline APLICAÇÃO (A) & 2 & $1035,3132^{* *}$ & 85,2169 \\
\hline GESSO $(\mathrm{G})$ & 1 & $505,6200^{* *}$ & 60,5917 \\
\hline$A \times G$ & 2 & $71, \overline{2747}$ & $350,0156^{*}$ \\
\hline$\overline{\text { INCORPORAÇÃO (I) }}$ & 1 & 145,9201 & 113,6278 \\
\hline $\mathrm{A} \times \mathrm{I}$ & 2 & $217,8096^{* *}$ & 71,2709 \\
\hline GxI & 1 & 49,1701 & 5,2003 \\
\hline $\mathrm{G} \times \mathrm{A} \times \mathrm{I}$ & 2 & 102,9198 & 87,9482 \\
\hline RESIDUO (a) & 33 & 39,9838 & 86,3701 \\
\hline LOCAL (L) & $T$ & $607,2612^{* *}$ & 78,0209 \\
\hline $\mathrm{L} \times \mathrm{A}$ & 2 & $411,2788^{* *}$ & 84,9094 \\
\hline $\mathrm{L} \times \mathrm{G}$ & 1 & 56,7112 & 17,3559 \\
\hline LxI & 1 & 11,3605 & 25,9800 \\
\hline$L \times A \times G$ & 2 & 58,7541 & 100,0225 \\
\hline $\mathrm{L} \times \mathrm{A} \times \mathrm{I}$ & 2 & 4,9136 & 75,3396 \\
\hline LxGxI & 1 & 34,4450 & 26,9500 \\
\hline RESDUO (b) & 38 & 29,2224 & 36,9064 \\
\hline PROFUNDIDADE (P) & 2 & $1258,5251^{* *}$ & $1836,0545^{* *}$ \\
\hline $\mathrm{P} \times \mathrm{A}$ & 4 & $106,4705^{* *}$ & 30,7900 \\
\hline $\mathrm{P} \times \mathrm{G}$ & 2 & $170,7488^{* *}$ & 1,4034 \\
\hline $\mathrm{P} \times \mathrm{I}$ & 2 & 24,8146 & $108,2928^{*}$ \\
\hline $\mathrm{P} \times \mathrm{L}$ & 2 & $258,9132 * *$ & $225,6317^{* *}$ \\
\hline$P \times L \times A$ & 4 & $84,2558^{* *}$ & 61,2291 \\
\hline$P \times L \times G$ & 2 & 35,2107 & 20,1609 \\
\hline$\overline{P x} L \times I$ & 2 & 42,2589 & 14,1213 \\
\hline RESIDUO (c) & $\overline{172}$ & 22,3866 & 32,1256 \\
\hline TOTAL & $\overline{287}$ & & \\
\hline & & $C V \%(a)=46,5$ & $C V \%(a)=68.4$ \\
\hline & & $\overline{C V \%(b)}=39,8$ & $\overline{C V} \%(b)=44,7$ \\
\hline & & $\overline{C V \%(c)}=34,8$ & $\mathrm{CV} \%(\mathrm{c})=41,7$ \\
\hline$*(\mathrm{P}<0,05) \quad * *(\mathrm{P}<0,01)$ & & & \\
\hline
\end{tabular}


QUADRO 26..Análise da variância dos efeitos de modos de aplicação de calcário, gesso e incorporação sobre os teores foliares de cálcio (Ca) em pomar de Pera Rio (Citrus sinensis L. Osbeck).

\begin{tabular}{|c|c|c|c|}
\hline \multirow[t]{2}{*}{ CAUSAS DA VARIAÇÃO } & \multirow[t]{2}{*}{ G.L. } & \multicolumn{2}{|c|}{ Q.M. } \\
\hline & & 1a ÉPOCA & 2a EPOCA \\
\hline BLOCO & 3 & 0.0058 & $1.2396^{* *}$ \\
\hline APLICAÇÃO (A) & 2 & 0.0570 & 0.1050 \\
\hline GESSO $(\mathrm{G})$ & 1 & $0.3072^{*}$ & 0.3798 \\
\hline INCORPORAÇÃO (I) & 1 & $0.6394^{\neq *}$ & 0.0023 \\
\hline $\mathrm{A} \times \mathrm{G}$ & 2 & 0.0940 & 0.0446 \\
\hline $\mathrm{A} \times \mathrm{I}$ & 2 & 0.0045 & 0.0459 \\
\hline GxI & 1 & 0.0010 & 0.0609 \\
\hline$A \times G \times I$ & 2 & 0.0482 & 0.0781 \\
\hline RESIDUO & 33 & 0.0810 & 0.2048 \\
\hline TOTAL & 47 & & \\
\hline C.V.\% & & 10,63 & 3,59 \\
\hline$*(\mathrm{P}<0,05) \quad * *(\mathrm{P}<0,01)$ & & & \\
\hline
\end{tabular}

QUADRO 27..Análise da variância dos efeitos de modos de aplicação de calcário, gesso e incorporação sobre os teores foliares de magnésio (Mg) em pomar de Pera Rio (Citrus sinensis L. Osbeck).

\begin{tabular}{|c|c|c|c|}
\hline \multirow[t]{2}{*}{ CAUSAS DA VARIAÇĀO } & \multirow[t]{2}{*}{ G.L. } & \multicolumn{2}{|c|}{ Q.M. } \\
\hline & & 1토OCA & 2a EPOCA \\
\hline BLOCO & 3 & 0.0001 & 0.0035 \\
\hline APLICAÇÃO (A) & 2 & 0.0007 & 0.0030 \\
\hline GESSO (G) & 1 & $0.0056^{* *}$ & 0.0023 \\
\hline INCORPORAÇÄO (I) & 1 & 0.0000 & 0.0017 \\
\hline $\mathrm{AxG}$ & 2 & 0.0001 & 0.0019 \\
\hline$A \times I$ & 2 & 0.0002 & 0.0005 \\
\hline $\mathrm{G} \times \mathrm{I}$ & 1 & 0.0001 & 0.0001 \\
\hline$A \times G \times I$ & 2 & 0.0015 & 0.0012 \\
\hline RESIDUO & 33 & 0.0007 & 0.0016 \\
\hline TOTAL & 47 & & \\
\hline C.V. $\%$ & & 5,69 & 22,99 \\
\hline${ }^{*}(\mathrm{P}<0,05) \quad{ }^{* *}(\mathrm{P}<0,01)$ & & & \\
\hline
\end{tabular}


QUADRO 28..Análise da variância dos efeitos de modos de aplicação de calcário, gesso e incorporação sobre a relação calcio/magnésio $(\mathrm{Ca} / \mathrm{Mg})$ em folhas de Pera Rio (Citrus sinensis L. Osbeck).

\begin{tabular}{|c|c|c|c|}
\hline \multirow[t]{2}{*}{ CAUSAS DA VARIAÇÄO } & \multirow[t]{2}{*}{ G.L. } & \multicolumn{2}{|c|}{ Q.M. } \\
\hline & & 1ㅡ EPOCA & 2a EPOCA \\
\hline $\mathrm{BLOCO}$ & 3 & 0.0461 & $58.7219^{* *}$ \\
\hline APLICACC $\bar{A} \overline{O(A)}$ & 2 & 0.0400 & 17.1827 \\
\hline GESSO (G) & 1 & $4.8133^{* *}$ & $89.3802^{*}$ \\
\hline INCORPORAÇÃO(I) & 1 & $3.3075^{*}$ & 1.8802 \\
\hline $\mathrm{A} \times \mathrm{G}$ & 2 & 0.4408 & 28.1352 \\
\hline $\mathrm{A} \times \mathrm{I}$ & 2 & 0.0325 & 1.61645 \\
\hline GxI & 1 & 0.0408 & 30.8802 \\
\hline$A \times G \times I$ & 2 & 0.4433 & 7.9164 \\
\hline RESIDUO & 33 & 0.4678 & 12.9520 \\
\hline TOTAL & 47 & & \\
\hline C.V.\% & & 11,54 & 16,99 \\
\hline${ }^{*}(\mathrm{P}<0,05) \quad * *(\mathrm{P}<0,01)$ & & & \\
\hline
\end{tabular}

QUADRO 29..Análise da variância dos efeitos de modos de aplicação de calcário, gesso e incorporação sobre a relação calcio/potássio $(\mathrm{Ca} / \mathrm{K}) \mathrm{em}$ folhas de Pera Rio (Citrus sinensis L. Osbeck).

\begin{tabular}{|c|c|c|c|}
\hline \multirow[t]{2}{*}{ CAUSAS DA VARIAÇÃO } & \multirow[t]{2}{*}{ G.L. } & \multicolumn{2}{|c|}{ Q.M. } \\
\hline & & 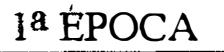 & 2a EPOCA \\
\hline$\overline{B L O C O}$ & 3 & 0.0016 & 0.5728 \\
\hline APLICAÇÃO (A) & 2 & 0.0113 & 0.1039 \\
\hline GESSO (G) & 1 & $0.2805^{*}$ & 0.5670 \\
\hline INCORPORACCAO (I) & 1 & $0.5147 * *$ & 0.0757 \\
\hline $\mathrm{A} \times \mathrm{G}$ & 2 & 0.0245 & 0.1328 \\
\hline AxI & 2 & 0.0066 & 0.3428 \\
\hline GxI & 1 & 0.0016 & 0.0164 \\
\hline$A \times G \times I$ & 2 & 0.0795 & 0.5105 \\
\hline RESIDUO & 33 & 0.0577 & 0.2197 \\
\hline TOTAL & 47 & & \\
\hline C.V.\% & & 16,80 & 16,84 \\
\hline$*(\mathrm{P}<0,05) \quad * *(\mathrm{P}<0,01)$ & & & \\
\hline
\end{tabular}


QUADRO 30..Análise da variância dos efeitos de modos de aplicação de calcário, gesso e incorporação sobre a relação cálciotmagnésio/potássio $(\mathrm{Ca}+\mathrm{Mg} / \mathrm{K})$ em folhas de Pera Rio (Citrus sinensis L. Osbeck).

\begin{tabular}{|c|c|c|c|}
\hline \multirow[t]{2}{*}{ CAUSAS DA VARIAÇÃO } & \multirow[t]{2}{*}{ G.L. } & \multicolumn{2}{|c|}{ Q.M. } \\
\hline & & la EPOCA & 2a EPOCA \\
\hline BLOCO & 3 & 0.0015 & 0.5491 \\
\hline APLICAÇÃO (A) & 2 & 0.0127 & 0.0719 \\
\hline GESSO (G) & 1 & $0.2573^{*}$ & 0.7008 \\
\hline INCORPORAÇÃO (I) & 1 & $0.5884^{* *}$ & 0.0096 \\
\hline $\mathrm{A} \times \mathrm{G}$ & 2 & 0.0257 & 0.1998 \\
\hline $\mathrm{A} \times \mathrm{I}$ & 2 & 0.0069 & 0.2693 \\
\hline Gx I & 1 & 0.0025 & 0.0900 \\
\hline$A \times G \times I$ & 2 & 0.0958 & 0.4037 \\
\hline RESIDUO & 33 & 0.0659 & 0.2446 \\
\hline TOTAL & $\overline{47}$ & & \\
\hline C.V.\% & & 15,37 & 16,90 \\
\hline$* *(\mathrm{P}<0,01)$ & & & \\
\hline
\end{tabular}

QUADRO 31..Análise da variància dos efeitos de modos de aplicação de calcário, gesso e incorporação sobre os teores foliares de potássio $(\mathrm{K}) \mathrm{em}$ pomar de Pera Rio (Citrus sinensis L. Osbeck).

\begin{tabular}{|c|c|c|c|}
\hline \multirow[t]{2}{*}{ CAUSAS DA VARIAÇÄO } & \multirow[t]{2}{*}{ G.L. } & \multicolumn{2}{|c|}{ Q.M. } \\
\hline & & 1a EPOCA & 2을ㅇ \\
\hline BLOCO & 3 & 0.0117 & 0.0245 \\
\hline APLICAÇÃO(A) & 2 & 0.0056 & 0.1028 \\
\hline GESSO $(\mathrm{G})$ & 1 & 0.0808 & 0.0280 \\
\hline INCORPORAÇÃO (I) & 1 & $0.1376^{*}$ & 0.0217 \\
\hline $\mathrm{AxG}$ & 2 & 0.0024 & 0.0541 \\
\hline $\mathrm{A} \times \mathrm{I}$ & 2 & 0.0085 & 0.0833 \\
\hline GxI & 1 & 0.0006 & 0.0120 \\
\hline$A \times G \times I$ & 2 & 0.0383 & 0.1132 \\
\hline RESIDUO & 33 & 0.0246 & \\
\hline TOTAL & 47 & & \\
\hline C.V.\% & & 8,29 & 16,50 \\
\hline${ }^{*}(\mathrm{P}<0,05) \quad * *(\mathrm{P}<0,01)$ & & & \\
\hline
\end{tabular}


QUADRO 32..Análise da variância dos efeitos de modos de aplicação de calcário, gesso e incorporação sobre os teores foliares de nitrogênio $(\mathbb{N})$ em pomar de Pera Rio (Citnus sinensis L. Osbeck).

\begin{tabular}{|c|c|c|c|}
\hline \multirow[t]{2}{*}{ CAUSAS DA VARIAÇÃO } & \multirow[t]{2}{*}{ G.L. } & \multicolumn{2}{|c|}{ Q.M. } \\
\hline & & la ÉPOCA & 2a É EPOCA \\
\hline BLOCO & 3 & 0.115941 & $0.0645^{* *}$ \\
\hline APLICAÇÃO (A) & 2 & 0.292433 & 0.0011 \\
\hline GESSO (G) & 1 & 0.091002 & 0.0065 \\
\hline INCORPORAÇÃO (I) & 1 & 0.016502 & 0.0154 \\
\hline$A \times G$ & 2 & 0.164658 & 0.0084 \\
\hline $\mathrm{A} \times \mathrm{I}$ & 2 & 0.044433 & 0.0098 \\
\hline Gx I & 1 & 0.191269 & 0.0001 \\
\hline$A \times G \times I$ & 2 & 0.090325 & 0.0041 \\
\hline RESWUO & 33 & 0.131103 & 0.0078 \\
\hline TOTAL & 47 & & \\
\hline C.V.\% & & 3,99 & 15,74 \\
\hline$* *(\mathrm{P}<0,01)$ & & & \\
\hline
\end{tabular}

QUADRO 33..Análise da variância dos efeitos de modos de aplicação de calcário, gesso e incorporação sobre os teores foliares de fósforo $(\mathrm{P}) \mathrm{em}$ pomar de Pera Rio (Citrus sinensis L. Osbeck).

\begin{tabular}{|c|c|c|c|}
\hline \multirow[t]{2}{*}{ CAUSAS DA VARIAÇẢO } & \multirow[t]{2}{*}{ G.L. } & \multicolumn{2}{|c|}{ Q.M. } \\
\hline & & 1a É EPOCA & 2 a EPOCA \\
\hline BLOCO & 3 & 0.0001 & $0.0004^{* *}$ \\
\hline APLICAÇÃO (A) & 2 & 0.0004 & 0.0001 \\
\hline GESSO $(\mathrm{G})$ & 1 & 0.0001 & 0.0001 \\
\hline INCORPORAÇÃO(I) & 1 & 0.0001 & 0.0001 \\
\hline $\mathrm{A} \times \mathrm{G}$ & 2 & 0.0004 & 0.0002 \\
\hline $\mathrm{A} \times \mathrm{I}$ & 2 & 0.0001 & 0.0001 \\
\hline$G \times I$ & 1 & 0.0004 & 0.0001 \\
\hline$A \times G \times I$ & 2 & 0.0001 & 0.0001 \\
\hline RESIDUO & 33 & 0.0003 & 0.0001 \\
\hline TOTAL & 47 & & \\
\hline C.V.\% & & 15,50 & 9,97 \\
\hline$* *(\mathrm{P}<0,01)$ & & & \\
\hline
\end{tabular}


QUADRO 34..Análise da variância dos efeitos de modos de aplicação de calcário, gesso e incorporação sobre os teores foliares de enxofre (S) em pomar de Pera Rio (Citrus sinensis L. Osbeck).

\begin{tabular}{|c|c|c|c|}
\hline \multirow[t]{2}{*}{ CAUSAS DA VARIAÇÄO } & \multirow[t]{2}{*}{ G.L. } & \multicolumn{2}{|c|}{ Q.M. } \\
\hline & & 19 EPOCA & 2a EPOCA \\
\hline BLOCO & 3 & $0.0035^{* *}$ & 0.0009 \\
\hline APLICAÇÅO(A) & 2 & 0.0004 & 0.0003 \\
\hline GESSO (G) & 1 & 0.0000 & 0.0011 \\
\hline INCORPORAÇÁO (1) & 1 & 0.0006 & 0.0001 \\
\hline$A \times G$ & 2 & 0.0003 & 0.0001 \\
\hline $\mathrm{A} \times \mathrm{I}$ & 2 & 0.0001 & 0.0001 \\
\hline $\mathrm{GxI}$ & 1 & 0.0010 & 0.0005 \\
\hline$A \times G \times I$ & 2 & 0.0004 & 0.0001 \\
\hline RESIDUO & 33 & 0.0003 & 0.0003 \\
\hline TOTAL & 47 & & \\
\hline C.V.\% & & 16,55 & 15,27 \\
\hline${ }^{* *}(\mathrm{P}<0,01)$ & & & \\
\hline
\end{tabular}

QUADRO 35..Análise da variância dos efeitos de modos de aplicação de calcário, gesso e incorporação sobre a relação magnésio/potássio $(\mathrm{Mg} / \mathrm{K}) \mathrm{em}$ folhas de Pera Rio (Citrus sinensis L. Osbeck).

\begin{tabular}{|c|c|c|c|}
\hline \multirow[t]{2}{*}{ CAUSAS DA VARIAÇÃO } & \multirow[t]{2}{*}{ G.L. } & \multicolumn{2}{|c|}{ Q.M. } \\
\hline & & 1 EPOCA & 2 EPOCA \\
\hline BLOCO & 3 & 0.0002 & 0.0012 \\
\hline APLICAÇÅO(A) & 2 & 0.0001 & 0.0010 \\
\hline GESSO (G) & 1 & 0.0001 & 0.0003 \\
\hline INCORPORAÇAOO (I) & 1 & 0.0018 & 0.0002 \\
\hline$A \times G$ & 2 & 0.0001 & 0.0028 \\
\hline $\mathrm{A} \times \mathrm{I}$ & 2 & 0.0001 & 0.0005 \\
\hline GxI & 1 & 0.0001 & 0.0006 \\
\hline$A \times G \times I$ & 2 & 0.0008 & 0.0015 \\
\hline RESIDUO & 33 & 0.0005 & 0.0010 \\
\hline TOTAL & 47 & & \\
\hline C.V.\% & & 9,36 & 23,23 \\
\hline${ }^{*}(\mathrm{P}<0,05) \quad * *(\mathrm{P}<0,01)$ & & & \\
\hline
\end{tabular}

